\title{
CAUSES AND CONSEQUENCES OF SOIL BACTERIAL RARITY
}

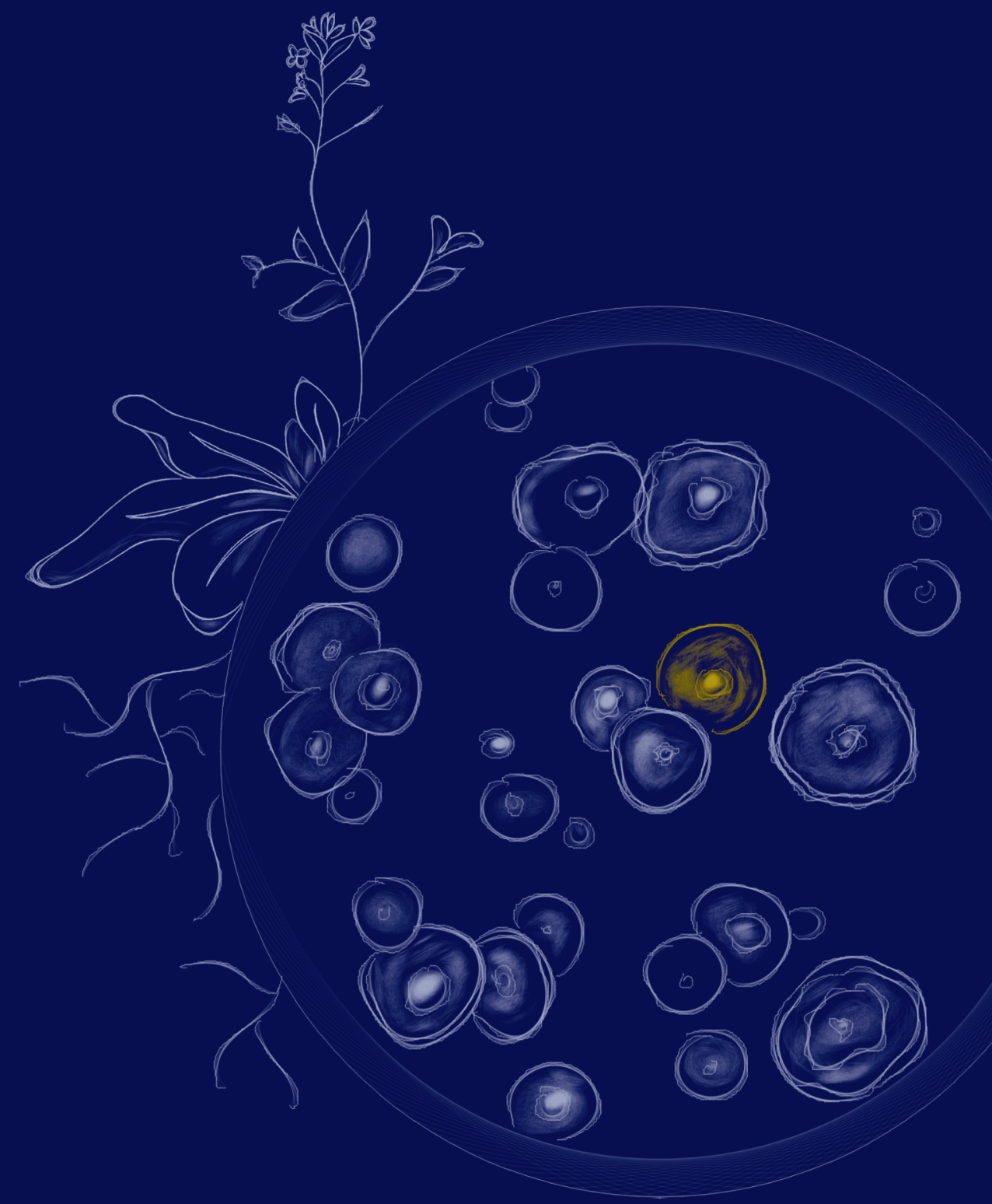

VIOLA KURM 



\section{Causes and consequences of soil bacterial rarity}




\section{Thesis committee}

\section{Promotor}

Prof. Dr W.H. van der Putten

Special Professor Functional Biodiversity

Wageningen University \& Research

\section{Co-Promotor}

Dr W.H.G. Hol

Scientist

Netherlands Institute of Ecology, Wageningen

\section{Other members}

Prof. Dr A.H.J. Bisseling, Wageningen University \& Research

Prof. Dr E.T. Kiers, VU Amsterdam

Prof. Dr H. Smidt, Wageningen University \& Research

Dr A.J. Veraart, Radboud University Nijmegen

This research was conducted under the auspices of the C.T. de Wit Graduate School for Production Ecology \& Resource Conservation (PE\&RC) 


\title{
Causes and consequences of soil bacterial rarity
}

\author{
Viola Kurm
}

\section{Thesis}

submitted in fulfilment of the requirements for the degree of doctor at Wageningen University

by the authority of the Rector Magnificus, Prof. Dr A.P.J. Mol, in the presence of the Thesis Committee appointed by the Academic Board to be defended in public on Tuesday 22 May 2018 at 4 p.m. in the Aula. 
Viola Kurm

Causes and consequences of soil bacterial rarity,

206 pages.

PhD thesis, Wageningen University, Wageningen, the Netherlands (2018)

With references, with summaries in English, Dutch and German.

ISBN: 978-94-6343-249-8

DO: https://doi.org/10.18174/440534 
You can't just boss bacteria around like that," said the younger Mrs. Hempstock. "They don't like it." "Stuff and silliness," said the old lady. "You leave wigglers alone and they'll be carrying on like anything. Show them who's boss and they can't do enough for you. You've tasted my cheese.."

- Neil Gaiman, The Ocean at the End of the Lane 



\section{Content}

$\begin{array}{llr}\text { Chapter } 1 & \text { Introduction } & \mathbf{8}\end{array}$

Chapter 2 Underrepresentation of rare soil bacterial species in a cultivation approach using flow cell sorting and oligotrophic cultivation media

Chapter 3 Low abundant soil bacteria can be metabolically versatile 55 and fast growing

Chapter 4 Causes of bacterial rarity: importance of competition and 83 predation for species abundance

Chapter 5 Soil microbial species loss affects plant biomass and survival of an introduced bacterial strain, but not inducible plant defences

Chapter 6 General discussion

References

Summary 188

Samenvatting

Zusammenfassung

Acknowledgements

About the author

List of publications

Graduate school training and courses 
Chapter 1

\section{Introduction}




\section{Biodiversity and rare species in macroorganism- and microorganism communities}

There is a stunning diversity of species on earth, although estimates of the exact numbers

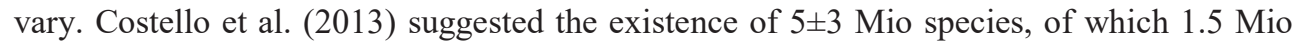
have been described at this time. This number excludes bacteria, which are the most diverse group by far. One reason for the high proportion of undescribed species is that in most communities only a small number of species is common, i.e. abundant, whereas most species are rare, i.e. low abundant (Magurran and Henderson 2003, McGill et al. 2007, Chase 2013). According to the mass-ratio-hypothesis, dominant species should control communities and ecosystem processes (Grime 1998). Rare species, on the other hand, are expected to have a low contribution and their loss would have no or little consequence for ecosystem functioning (Chase 2013). However, there is increasing evidence that low abundant species can support ecosystem functions in several ways and often have over-proportional roles in their communities (Jousset et al. 2017). Still, there are considerable gaps in our knowledge about rare species. In particular, we know little about the causes of species rarity and the mechanisms by which rare species affect ecosystem functions. Advancement in this field of study is critical in the light of the vulnerability of rare species and global decrease of diversity.

Microbial communities are well suited to study the causes and consequences of species rarity. They are highly diverse with an estimated $10^{4}-10^{6}$ species $^{1}$ per gram soil in most habitats, surpassing the estimations for every other single group of organisms by far (Bent and Forney 2008). What is true for other organisms is even more so for bacteria: only a small number of species is present in high and easily detectable abundances, whereas the majority is uncommon, belonging to the so-called rare biosphere (Sogin et al. 2006). Improved molecular and cultivation techniques are becoming available to detect and study microbial communities, enabling us to study also low abundant species (Hill et al. 2000, Alain and Querellou 2009, Hirsch et al. 2010). In addition, studies on microorganisms may be conducted at very small scales using small sample sizes and high-throughput arrays. However, research on microorganisms still involves inherent difficulties because of their minuscule size and highly skewed abundance distribution. Thus, it is not surprising that concepts on species abundance have been based on macroorganisms and that these are the main source for predictions about the behaviour of microbial communities (Prosser et al. 2007). However, testing these concepts with microorganisms are required in order to show if microbes behave similar to macroorganisms, and if insights from microbial studies can be applied to macroorganisms in return.

\footnotetext{
${ }^{1}$ It must be noted that there is no common definition of the term species with respect to bacteria. Here, I will use species instead of taxon or OTU (operational taxonomic unit).
} 


\section{The definition of rare species}

Rare species in general

There is no universal definition of rare species, because abundance is a continuum without a natural threshold that separates rare from abundant species. Furthermore, the abundance of one species can only be defined relative to the abundance of other species (Flather and Sieg 2007). Perhaps the most exhaustive definition of rarity is provided by Rabinowitz (1981), who distinguishes three attributes of species to characterize their rarity or dominance: geographic range, habitat specificity and local population size. A species can be considered rare if its distribution is restricted to a narrow geographic range, but also if it occurs only in specific habitats. Finally a species can be rare, even if it is widely distributed, if it has a low local population size. Rabinowitz (1981) combines these three attributes in an eight-celled block, of which seven blocks define a rare species (Table 1). Thus, she provides examples that a species can be considered rare if it is geographically wide spread, but locally low abundant, but also if it occupies a narrow range of habitats, albeit occurring there at high densities. Although all these seven definitions of rarity are equally valid, I will use being rare as a synonym for a low local abundance since this thesis focuses on this specific aspect of rarity (Table 1). Moreover, for microorganisms, only little is known about their habitat ranges and geographic distribution. 
Table 1: Seven different forms of rarity. Only species in the upper left corner are dominant. In this thesis rare species are defined as those with a low local abundance (gray cells). Adapted from Rabinowitz (1981).

\begin{tabular}{|c|c|c|c|c|}
\hline Geographic & Large & & Small & \\
\hline $\begin{array}{l}\text { Habitat } \\
\text { specificity }\end{array}$ & Broad & Narrow & Broad & Narrow \\
\hline $\begin{array}{l}\text { Local } \\
\text { population } \\
\text { size }\end{array}$ & & & & \\
\hline $\begin{array}{l}\text { Large, } \\
\text { dominant } \\
\text { somewhere }\end{array}$ & $\begin{array}{l}\text { Locally } \\
\text { abundant over } \\
\text { a large range } \\
\text { in several } \\
\text { habitats }\end{array}$ & $\begin{array}{l}\text { Locally } \\
\text { abundant over } \\
\text { a large range } \\
\text { in a specific } \\
\text { habitat }\end{array}$ & $\begin{array}{l}\text { Locally abundant } \\
\text { in several } \\
\text { habitats but } \\
\text { restricted } \\
\text { geographically }\end{array}$ & $\begin{array}{l}\text { Locally abundant } \\
\text { in a specific } \\
\text { habitat but } \\
\text { restricted } \\
\text { geographically }\end{array}$ \\
\hline $\begin{array}{l}\text { Small, non- } \\
\text { dominant }\end{array}$ & $\begin{array}{l}\text { Constantly } \\
\text { sparse over a } \\
\text { large range in } \\
\text { several } \\
\text { habitats }\end{array}$ & $\begin{array}{l}\text { Constantly } \\
\text { sparse in a } \\
\text { specific } \\
\text { habitat but } \\
\text { over a large } \\
\text { range }\end{array}$ & $\begin{array}{l}\text { Constantly sparse } \\
\text { and } \\
\text { geographically } \\
\text { restricted in } \\
\text { several habitats }\end{array}$ & $\begin{array}{l}\text { Constantly sparse } \\
\text { and } \\
\text { geographically } \\
\text { restricted in a } \\
\text { specific habitat }\end{array}$ \\
\hline
\end{tabular}

\section{Rare bacterial species}

The framework proposed by Rabinowitz (1981), which has been derived from studies on macroorganisms, can also be applied to microorganisms, but even if we consider only local abundance there is by no means a common definition of what is a rare bacterial species. In fact, there is even no common agreement on the definition of a bacterial species. Before sequencing became widely applicable bacteria were grouped into species on the basis of DNA-DNA hybridization. Bacteria showing $70 \%$ or greater hybridization were considered to belong to the same species (Stackebrandt and Goebel 1994). After introduction of the sequence of the small subunit ribosomal RNA (16S rRNA) gene as a basis for bacterial phylogeny, single species groups were found to actually comprise several genera and species. Since then, 16S rRNA sequencing has become the most commonly used technique for bacterial identification (Staley 2006). Typically, sequences are grouped into operational 
taxonomic units (OTUs) at a threshold of 97\% sequence similarity and these OTUs are assumed to represent a species (Tindall et al. 2010). However, studies have shown that bacteria belonging to the same OTU can behave ecologically very differently (Koeppel and $\mathrm{Wu} 2013$ ), so that sequence similarities of $>98.5 \%$ have been proposed to distinguish species (Kim et al. 2014). Nevertheless, in this thesis I will refer to bacterial OTUs defined at a sequence similarity of $97 \%$ as a species, because it is still the standard that most studies adhere to.

Currently, the relative quantification of species in bacterial communities is largely based on datasets created by high-throughput sequencing of the 16S rRNA gene currently generating several million reads per sample (Buermans and den Dunnen 2014). Rare species have often been defined by arbitrarily applying an upper abundance threshold on these datasets. Commonly species are defined as rare if they constitute less than $1 \%$ of the community (defined as the proportion of $16 \mathrm{~S}$ reads) (Nacke et al. 2011, Skopina et al. 2016). However, also other thresholds have been used, such as $0.1 \%$ or even $0.01 \%$ (Fuhrman 2009, Hausmann et al. 2016, Suriya et al. 2017). Further variation arises from the differences in sequencing techniques and sequencing depths used in the different studies. In addition, it has been demonstrated frequently that current sequencing technology suffers from a number of biases, such as bias in DNA extraction, primer bias during PCR, and differences in 16S rRNA copies between species. These sources of bias might lead to either under- or overestimation of bacterial diversity and the abundance of particular bacterial taxa (Kunin et al. 2010, DeAngelis and Firestone 2012, Gonzalez et al. 2012, Kembel et al. 2012). These technical shortcomings and the application of arbitrary thresholds show that the definition of rare bacterial species is at best disputable. Until significant methodological and conceptional improvements have been made these restriction should be kept in mind when presenting and discussing the research on rare bacteria.

\section{Rare species are everywhere}

One reason why we should not disregard the rare species is that they represent the largest part of all species on earth. The most common way to depict species in relation to their abundances is the species abundance distribution (SAD) (Chisholm 2007, Rajkumar et al. 2010). A frequently used plot for SADs is the Whittaker plot or rank abundance plot, in which the species abundance, often displayed as $\log _{10}$, is plotted against the species rank (species ordered from most abundant to last abundant) or vice versa (Whittaker 1965). SADs from widely different communities have in common that they often show a high number of rare species (McGill et al. 2007) (for a schematic depiction see Fig.1). Many different models have been proposed to describe the form of SADs. The model found to fit a majority of data is the log-normal distribution by Preston (1948), although this is often criticized since 
abundance distributions often appears truncated at the rare end. Another often observed pattern is the abundance-occupancy relationship: species that are locally abundant tend to be widely distributed, while species that are locally rare tend to have a narrow distribution (Gaston et al. 2000). Widely distributed and locally abundant species are often called core species, whereas the narrowly distributed and locally rare species have been called satellite or occasional species (Hanski and Gyllenberg 1993, Magurran and Henderson 2003). Explanations for this bimodal distribution include generalist-specialist differences and enhanced colonization by locally common species (Hanski and Gyllenberg 1997).

Bacterial communities have an especially long "tail" of rare species when depicted in a rank abundance plot, yet the underlying abundance distribution is less well investigated than for macroorganisms (Lynch and Neufeld 2015). However, Galand et al. (2009) showed for bacterial communities in the Arctic Ocean SAD patterns that were similar to ones observed for macroorganisms, with log-normal and log-series distributions for dominant and rare taxa, respectively. This is in accordance with Pedrós-Alió (2006), who suggested that the coresatellite species concept might also be valid for bacterial species. The core-satellite hypothesis by Hanski and Gyllenberg (1993) also predicts that some species can switch from the abundant core state to the rare satellite state and vice versa. This has been observed frequently for bacteria. Up to $28 \%$ of all low abundant taxa in bacterial communities have been found to become abundant at one point in time and to disproportionally contribute to temporal changes in community composition (Shade et al. 2014). Such changes in abundance might be one important mechanism by which rare bacterial species can influence and stabilize ecosystem functions. Still, a large fraction of the rare biosphere stays constantly rare and yet there are strong indications that this fraction, too, can play an important role in ecosystems. 


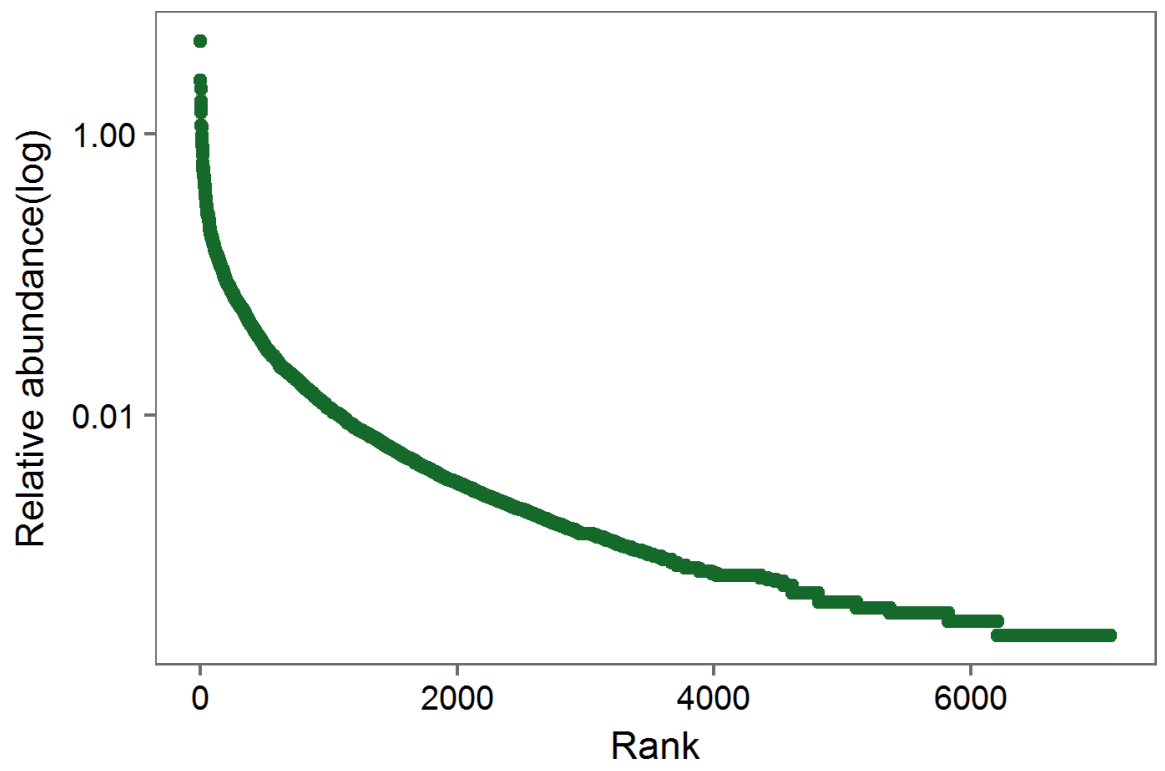

Fig. 1: Schematic rank abundance plot with relative abundance on a log scale plotted against species rank.

\section{Rare species influence ecosystem functioning}

The benefit of species diversity is subject to wide and intensive debate. However, it is often neglected that species diversity means mostly rare as rare species represent the majority of all species in a community. However, rare species have often been thought to be functionally redundant to more abundant species. Indeed, some studies do not indicate an effect of reducing rare species on ecosystem functioning (Smith and Knapp 2003, Solan et al. 2004). These studies have usually been carried out under stable conditions within short periods of time (Duffy 2009). They do not take into account that rare species can contribute to the resistance and resilience of communities and consequently ecosystem functions (Shade et al. 2012b). Environmental changes or disturbances might lead to a decline of abundant species supporting important ecosystem functions. A vast pool of rare species increases the probability that another species with similar functional traits but less sensitivity to the disturbance will be present. Such a species might become abundant under the changing conditions and continue to support the respective functions (Loreau et al. 2001). This redundancy in functional effect traits and diversity in response traits is considered a key mechanism for ecosystem stability, according to the ecosystem insurance hypothesis (Yachi and Loreau 1999, Hooper et al. 2005). The fluctuations in species abundances over space and 
time support this assumption. Especially in a time when human activity leads to both longterm global changes and sudden local alterations of ecosystems, the continued provisioning of essential ecosystem services relies on the functional redundancy of a highly diverse species community.

Not all rare species possess redundant functions. In fact, rare species can be even less redundant in their functional traits than abundant species (Soliveres et al. 2016). A variety of communities, such as of alpine plants, tropical forests, and coral reef fish contain low abundant species that possess distinct trait combinations or carry out unique functions (Chase 2013, Mouillot et al. 2013). Thus, a large number of rare species does not only increase the functional resistance of a community, but also the probability of containing species with particularly important and unique traits (sampling effect) and the functional complementarity (complementarity effect) of a community (see definition by Hooper et al. (2005)). Species that possess unique traits may even be so called keystone species, defined as species with a much larger effect on ecosystem processes than would be predicted from their abundance (Power et al. 1996, Hooper et al. 2005, Mouillot et al. 2013). Examples for low abundant keystone species are predators, such as starfish and sea otters whose presence or absence may lead to very different communities (Paine 1969, Estes and Palmisano 1974). The functional complementarity of species, on the other hand, can lead to enhanced ecosystem productivity through differences in resource use (Tilman et al. 1996, Hector et al. 1999). In addition, this complementarity in niche space has been evoked as one mechanism by which diverse communities can resist the invasion by foreign species (Lyons and Schwartz 2001). Current research indicates that these effects of biodiversity can be ascribed largely to the action of rare species.

\section{Rare species are vulnerable}

Some species may be rare due to unfavourable conditions, while for other species rarity can be seen as a natural state and they have traits that allow them to persist at low abundances. Still, rare species are extremely vulnerable to disturbances. Threats, such as overexploitation, habitat loss, invasion by exotic species, climate change or man-made and natural calamities will naturally be more disastrous for rare species than for abundant ones and can drive them to their extinction (Mouillot et al. 2013). There is evidence from macroorganisms that species with a low local density and a restricted habitat are more likely to go extinct (Pimm et al. 1988, Cardillo et al. 2008). Loss of these species is predicted to lead to the loss of unique functions and therefore disproportionally impact our ecosystems (Mouillot et al. 2013, Leitão et al. 2016). Importantly, these studies have been conducted on known species, but it is assumed that many species, and especially increasingly rare ones, are not even described yet. Including these unknown species, it is predicted, for example for plant species, that $30 \%$ are currently under the risk of extinction (Pimm et al. 2014). The huge diversity of 
microorganism and the even larger number we assume have never been found, does not even allow an estimation of the extinction threat for bacterial species (Veresoglou et al. 2015). Therefore, it is crucial to assess what makes a (microbial) species rare and which functions it has in an ecosystem as a first step to maintain ecosystem functionality in a changing world.

\section{Functions of rare bacteria}

In many aspects, functions of rare bacterial species are similar to those of rare macroorganisms. It has been suggested that the high number of species in microbial communities compared to communities of macroorganisms would lead to an even higher functional redundancy, so that a reduction of microbial species would not matter for ecosystem functioning (Franklin and Mills 2006, Wertz et al. 2006). However, just as for macroorganisms, this redundancy is essential for ecosystem stability as species with differing sensitivities to environmental conditions can support ecosystem functions upon environmental changes (Lemanceau et al. 2015). In support of this concept, studies repeatedly found a high number of taxa that fluctuate in abundance in space and time, the so called conditionally rare taxa (Shade et al. 2014). In addition, rare bacteria are often highly active and show the ability to grow rapidly, which might enable them to respond quickly to environmental change (Aanderud et al. 2015). These taxa can become abundant in reaction to changes in conditions or absence of competitors, and compensate for the decline of abundant species. Low-Décarie et al. (2015) even found the resistance of a community to a herbicide to be dependent on the increase of initially rare taxa.

In addition to functionally redundant species, the rare bacterial biosphere also contains species that carry out specific non-redundant functions and can be seen as keystone species. For example, the rare bacterial taxon Desulfospirosinus sp. has been found to be an important sulfate-reducer in peatlands in spite of occurring at the relative abundance of only $0.006 \%$ (Pester et al. 2010). Complementarity plays a role in many functions carried out by microbial communities. For instance, in grassland communities a positive effect of the presence of rare species on several ecosystem functions, such as organic $\mathrm{C}$ mineralisation and chitin and cellulose degradation, has been reported (Peter et al. 2011, Juarez et al. 2013). Rare bacterial species have also shown the ability to influence more abundant species and thereby their environment, for example in a bioreactor experiment by Rafrafi et al. (2013). Microorganisms may engage in elaborate networks of communication via metabolic compounds by which they can substantially alter each other's physiology (Dunn and Handelsman 2002, Schmidt et al. 2015). The influence of rare species on the environment via abundant species has so far mostly been demonstrated for bacterial communities. 
Nevertheless, it seems conceivable that similar mechanisms exist in communities of macroorganisms.

\section{The functions of rare soil bacterial species}

The soil microbiome hosts an incredibly high number of microbial species, which are essential for many ecosystem processes and crucial for life on earth. For example, $90 \%$ of all decomposition processes are mediated by microorganisms. Rare microbial species loss has already been found to lead to a decrease in general decomposition (Salonius 1981). This is supposed to be due to rare microbial species possessing distinct functions allowing them to break down specific recalcitrant compounds contributing to a more efficient resource use by the community (Baumann et al. 2013). However, inconsistent results exist with respect to the role of rare bacteria in general decomposition processes. Griffiths et al. (2001a) found no relationship between the reduction of rare soil bacterial species and decomposition. The same investigators demonstrated that less diverse communities were more sensitive to disturbance treatments. This indicates that there is a high functional redundancy in soil microbial communities with respect to traits involved in general decomposition, but also that this redundancy is important for resistance to disturbance (Griffiths et al. 2001b). In contrast to functional redundancy in general decomposition, several specific biogeochemical processes, such as denitrification and the degradation of pollutants have been found to be restricted to a narrow set of often rare species (Philippot et al. 2013b, Delgado-Baquerizo et al. 2016) (Fig. 2).

Rare soil bacterial species can also play a role in the suppression of soil-borne diseases (Fig. 2). One mechanism is the increase of resistance to invasions. A soil microbial community containing rare species has been found to reduce the survival of an invading Escherichia coli strain compared to a community deficient in rare species (Van Elsas et al. 2007). The addition of further resources to the community, however, increased invader survival, demonstrating that complementarity in resource use is likely to be responsible for invasion resistance (Mallon et al. 2015). In addition to indirect suppression of potential invading pathogens through resource competition, rare species can be involved directly in pathogen suppression through the production of volatile organic compounds (VOCs). VOCs are one important way of communication among microorganisms and different species and even species combinations have been found to produce their own specific blend of compounds (Tyc et al. 2015). The presence of rare bacterial species may alter the volatile profile of the microbial community and thereby affect the growth of a fungal pathogen (Hol et al. 2015b). Still, it is not known if this effect is due to compounds produced directly by the rare species or their interaction with dominant members of the microbial community. Volatile compounds can also affect plant growth (Ryu et al. 2003) (Fig. 2). However, the effect of volatiles produced by bacterial communities in the presence or absence of rare species on plants has not been tested yet. 


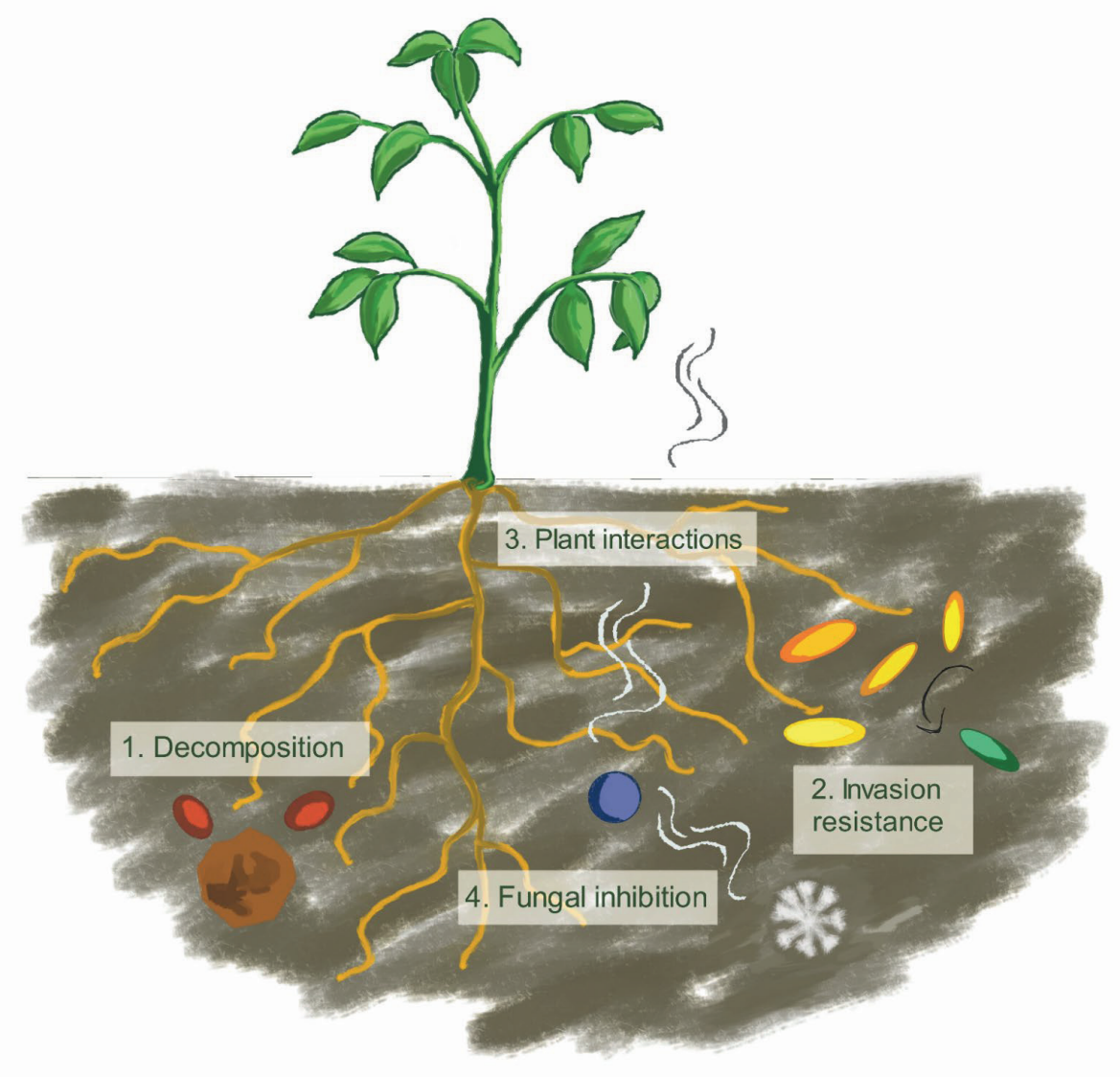

Fig. 2: Examples for the various functions of rare soil bacteria; 1. Decomposition and mineralization, 2. Resistance against pathogen invasion, 3. Interactions with plants (e.g. induction of resistance) through volatiles or other metabolites, 4. Inhibition of fungal pathogens, e.g. via volatiles 


\section{Rare bacteria in above-belowground interactions}

Rare soil bacteria can influence their community through interactions with other species and their interactions with plants are of specific interest. The following paragraph will briefly introduce current knowledge on the general interactions between plants and soil microorganisms. Thereafter, the potential role of rare species in above-belowground interactions will be outlined.

Soil bacteria can interact intimately with plants. This interaction flows both ways as different plant species and even accessions are known to cultivate their own rhizosphere microbiome by releasing a distinctive blend of root exudates (Bakker et al. 2013). In return, rhizosphere bacteria significantly affect plant growth and performance. On the one hand, this is mediated through mineralization processes, which make nutrients available for the plant, and stimulation of plant nutrient uptake (Rodríguez and Fraga 1999). On the other hand, soil bacteria also affect plants directly by producing signalling compounds such as flavonoids, sesquiterpenes and phytohormones (Bloemberg and Lugtenberg 2001, Philippot et al. 2013a). Specific bacterial species that have positive effects on plant growth are named plant-growth promoting rhizobacteria (PGPR). PGPR can also be involved in direct and indirect pathogen suppression in the soil via competition for resources or direct antagonistic interactions (Haas and Defago 2005). In addition, some PGPR can protect plants from aboveground enemies by systemically priming plant defences. An infection of aboveground plant parts with pathogens or herbivores subsequently induces a stronger and faster defence response in the plant than would be observed without priming. This enhanced defence response through interactions with PGPR is called induced systemic resistance (ISR) (Berendsen et al. 2012). Soil bacterial pathogens can also induce a primed state in the plant, which increases systemic resistance to later infections. This mechanism is called systemic acquired resistance (SAR) (Van Loon 2007). ISR and SAR are mediated by different signalling pathways in the plant, which can also overlap and interact with each other resulting in a fine-tuning of defences against different pests (Feys and Parker 2000).

Rare soil bacteria might play an important role in above-belowground interactions, as they can influence plant growth and health. While it has not been tested yet if bacteria can affect plants when rare, it has been shown that species that are rare in the bulk soil can increase in abundance in the plant rhizosphere or endosphere (Edwards et al. 2015, Nuccio et al. 2016). Rare soil bacteria might be involved in inducing plant resistance against insect herbivores. A reduction of rare soil bacterial species has been demonstrated to lead to increased performance of aphid herbivores and at the same time reduce the glucosinolate content in Brussel sprouts (Hol et al. 2010). This indicates that the presence of rare bacteria increased plant resistance against aphids compared to a soil bacterial community reduced in rare species. The effect of rare soil bacteria on plant defence might have been due to hostspecificity of plant-bacteria interactions (Wintermans et al. 2016). A more diverse 
community containing rare species has a higher probability of including a strain or species that can induce resistance in the respective plant cultivar. Alternatively, changes in composition of the dominant species as a consequence of rare species reduction could have influenced plant defences. In addition, it is still unknown whether plant resistance in the presence of rare species is induced by similar mechanisms as by PGPR strains. Overall, contemporary studies indicate that low abundant bacterial species in the soil are involved in protecting plants from pathogens and insects by various mechanisms, such as resistance to pathogen invasion, the production of inhibiting compounds and by eliciting systemic resistance in the plant (Hol et al. 2010, Hol et al. 2015b, Mallon et al. 2015).

The awareness is increasing that the use of chemical pesticides and other anthropogenic influences in the long term can lead to a decline in soil diversity and in the ecosystem services that we depend on (Altieri 1999). Therefore, investigating the mechanisms behind abovebelowground interactions for plant protection against pathogens is gaining importance steadily. Only if we increase our understanding of the role of microbial communities in supporting plant growth as well as other ecosystem functions, we can take steps to improve these functions in a sustainable way by managing the belowground community.

\section{Causes for species rarity}

In contrast to the functions of rare species, much less is known about the causes of species rarity. Nevertheless, there are many possible explanations for the coexistence of such a large number of low abundant species. They can be divided into neutral and niche models. In addition, elements from both niche and neutral models have been combined to explain the presence of a high number of rare species in communities (Chesson 2000, Ai et al. 2013). These models, however, rarely have been used to explain why species are rare or abundant. Briefly: according to neutral models rarity might arise from limited dispersal or recent colonization of a new habitat, whereas according to the niche hypothesis rare species utilize scarce resources and dominant species either use common resources or are very generalistic in their resource use (Mi et al. 2012). I will not go into detail about the differences between the respective models since comparing them was not part of my research.

Although species rarity might arise from stochastic processes, there is no doubt that species can differ in their niche preferences. Thus, it is not surprising that species traits in interactions with biotic and abiotic factors have been found to play an important role in driving species abundance (Jousset et al. 2017). Slow growth and reproduction are examples of traits that might cause rarity of species. At the same time, slow growth is often correlated with resistance to stress and environmental disturbances allowing rare species to persist in the community (Jousset et al. 2017). In addition, competition for limiting resources strongly 
affects species abundance by so-called bottom-up (resource-based) effects. In his resource ratio-model of competition Tilman et al. (1982) stated that the species that can reduce a limiting resource to the lowest level $\mathrm{R}^{*}$ will outcompete the other species. A low $\mathrm{R}^{*}$, and therefore a competitive advantage under resource limited conditions, has also been found to be correlated with a slow growth rate indicating a trade-off between competitiveness under resource limitation and the ability for fast growth (Harpole and Tilman 2006). If only bottomup effects play a role, the abundance of a species should depend on its competitive ability, growth rate and on resource availability. In nutrient-rich environments, fast growing species are supposed to be competitively superior and thus become abundant, whereas, according to this theory, in nutrient-poor environments slow growing species that are able to tolerate nutrient-poor conditions should increase in abundance due to a higher resource use efficiency (Harpole and Tilman 2006).

Under field conditions the abundance of a species is not only controlled by competition for limiting resources, but also by predation from higher trophic levels (so-called top-down effects). The relative importance of predation and competition is supposed to be dependent on resource availability. Predictions can be made with respect to the abundance of a species in the presence of competitors and predators at different resource concentrations based on frequently invoked plant ecological concepts. One is Tilman's R* theory as outlined above, the other is a trade-off between the ability for fast growth and resistance to herbivory as investment in fast growth can prevent species to invest in defence mechanisms (Herms and Mattson 1992, Endara and Coley 2011).

Consider a community of two species (Fig. 3). One is able to reduce a given resource to the lowest level, but at the same time slow growing and well defended against herbivory, since the cost of tissue loss is high. The other is fast growing, but less well defended against herbivory. As outlined above, in an environment without or with little predation the slow grower should be the better competitor at low resource availabilities, whereas the fast grower should be the better competitor at high resource availabilities (Harpole and Tilman 2006). In the presence of herbivores we can expect a different outcome. In an environment with low resource availability the slow growing species should still be the dominant competitor since it should also be most resistant to herbivory. However, in an environment with high resource availability herbivory can reduce the fast growing species, as it is presumed that it is less well defenced, and therefore lead to an advantage for the slow growing species. Hence herbivory should play a minor role for community composition at low, but a major role at high resource availabilities. Still, the reality will be more complicated. Plant species will compete for more than one resource with different affinities for each of them. Moreover, plants can have different types of defence mechanisms, both constitutive and inducible, which differ in their fitness cost. In communities plants will have to compete with multiple other species with different defence mechanisms and likely be subjected to multiple herbivores with different 
feeding preferences and degree of specificity. In addition, other (abiotic) factors, such as $\mathrm{pH}$ or temperature will play a role.
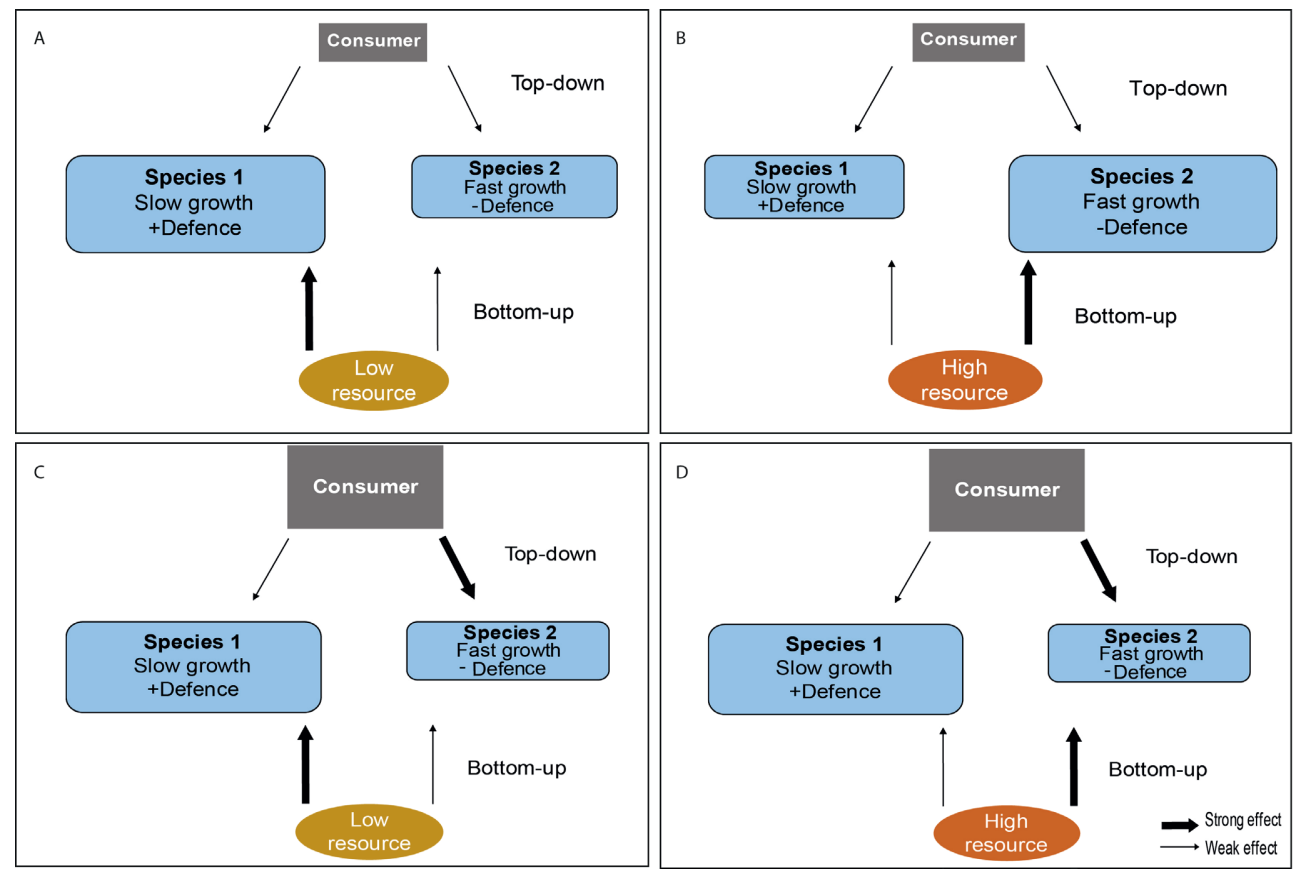

Fig. 3: Effects of resource availability (bottom-up) and consumption (top-down) on the abundances of species with different life-history traits. A) Low resource availability and weak or no herbivory, B) high resource availability and weak or no herbivory, C) low resource availability and herbivory, D) high resource availability and herbivory. The size of species boxes represent high or low abundance; the size of consumer boxes represent herbivory pressure, or no or weak herbivory.

\section{Causes of rarity in bacteria}

Niche and neutral processes for community assembly and species coexistence, such as have been explored for plants, are also expected to operate in the case of assembly of bacterial communities. However, studies attempting to quantify the relative importance of niche differences and environmental variation vs. dispersal and stochastic events find variable results (Östman et al. 2010, Jeraldo et al. 2012). Still, niche processes have been demonstrated often to be the dominant mechanism indicating significant ecological differences between species (Powell et al. 2015, Liao et al. 2017). In support of the niche theory, Koch (2001) proposed the oligotrophic-copiotrophic concept for bacteria. This concept incorporates both species life-history traits and resource availability. Copiotrophic 
species are fast growing under nutrient rich conditions, whereas oligotrophic species are slow growing, but exhibit a higher nutrient affinity and are therefore able to persist under nutrient poor conditions. Copiotrophs are assumed to be able to cope with a wide range of changing conditions, while oligotrophs are supposed to be more specialized (Christie-Oleza et al. 2012). Studies on microbial communities could indeed distinguish species by those traits and the traits were found to be partially phylogenetically conserved (Fierer et al. 2007). Nevertheless, it should be kept in mind that only few species can be classified as "real" copiotrophs or oligotrophs, and that the concept describes a continuum of species traits rather than strict categories.

According to the oligotrophic-copiotrophic concept the competitive ability of bacterial species should be dependent on species life-history traits in combination with nutrient availability. In nutrient-rich environments copiotrophic species can be expected to have a competitive advantage, whereas in nutrient-poor environments oligotrophic species are supposed to be the better competitors for limited nutrients (Hu et al. 1999). Interestingly, bacteria are known not only to engage in competition for nutrients without direct interaction (so-called exploitative competition), but also in direct antagonistic interaction (so-called interference competition) (Hibbing et al. 2010). In interference competition different bacterial species or populations inhibit or even kill each other through the production and excretion of antimicrobial compounds. The soil bacterial taxon Pseudomonas sp., for instance, is known to produce an arsenal of different antibiotics, such as hydrogen cyanide (HCN), 2,4-diacetylphloroglucinol (DAPG), pyrrolnitrin and pyoluteorin, which make this taxon suitable as a biocontrol agent against soil-borne diseases (Raaijmakers et al. 2002). However, antibiotics production includes a fitness cost, which could outweigh the competitive advantage of toxin production if resources are limited (Hibbing et al. 2010). In addition, some bacterial species have developed strategies to protect themselves against contest competition. They can either be resistant against certain antibiotics, or disrupt signalling networks required for antibiotic production (Hibbing et al. 2010). However, it is still unclear how interference competition and exploitative competition independently or together shape species abundance in bacterial communities.

In spite of the important contribution of competition in structuring ecological communities, it is unlikely that competition alone will account for the high diversity of species (Chesson and Kuang 2008). The maintenance of a high diversity has been partially ascribed to predation (Corno et al. 2008). Bacterial predators are mainly protists, such as flagellates, ciliates and amoebae, but also nematodes, enchytraeids and even other bacteria (Ekelund and Rønn 1994, Jousset 2012). Additionally, viruses can be a significant source of mortality (Fuhrman and Noble 1995). Similar to theory on plant communities the relative impact of predation on the abundance of a bacterial species and on community composition can be expected to be dependent on species traits and nutrient availability. The theory of the 
oligotrophic-copiotrophic continuum assumes slow growing oligotrophic species to be more successful under low nutrient condition and fast growing copiotrophic species to be dominant under high nutrient conditions (Fierer et al. 2007). In addition, the "Kill the Winner" (KtW) hypothesis states that fast growing species are preferentially consumed and lysed by predators and viruses (Våge et al. 2014). This preferential consumption is supposed to be due to both probability of encounter, but also to a lower predation resistance of fast growing species, comparable to the trade-off between growth and resistance in plants (Herms and Mattson 1992, Bouvier and Del Giorgio 2007). Consequentially, the presence of predators could change the outcome of competitive interactions substantially, dependent on nutrient availability.

According to the oligotrophic-copiotrophic concept and the KtW hypothesis, competition between species should be the dominant factor shaping microbial communities at low nutrient concentrations as slow growing oligotrophic species have an advantage. At higher nutrient concentrations, however, predators can be expected to have a larger effect on community composition as they preferentially reduce the fast growing species, which would otherwise dominate the community (Bohannan and Lenski 2000b). In addition, bacteria are able to express different forms of facultative grazing resistance in the presence of predators, such as cell aggregation or a bulky morphology (Jürgens and Matz 2002), which are comparable to induced defences in plants. Grazing resistance forms are more prevalent at conditions of high nutrient availability, presumably because of the costs of resistance that will be relatively lower (Corno and Jürgens 2006). This cost of resistance adds to the higher impact of predation on bacterial communities under high nutrient concentrations compared to low nutrient concentrations. The interplay of resource availability, competition, and predation on overall community composition and diversity has been studied especially for aquatic systems (Corno et al. 2008, Hiltunen and Laakso 2013). Nevertheless, very few if any studies have experimentally tested if competitiveness and resistance to predation are correlated with lifehistory traits such as growth rate and if these factors in turn are related to species rarity or abundance in the field. Especially soil bacterial communities have been poorly studied with respect to possible causes of species rarity.

\section{Methodological aspects for the research of rare bacterial species}

While communities of macroorganisms can be relatively easily investigated in observational studies and experiments in the laboratory, greenhouse or field, the study of microorganisms is often technically more complicated. This is especially true for rare microorganisms, their functional traits and response to changes in environmental conditions as they are even more difficult to detect. 
Fortunately, improvements in molecular methods provide us with increasingly precise ways to characterized microbial communities. Sequencing of the small subunit or 16S rRNA gene is still the most commonly applied method to characterize microbial community composition and phylogeny. High-throughput sequencing techniques, such as Illumina MiSeq or Ion Torrent can generate up to 25 Mio reads per run, but even more sophisticated methods become more and more widely available. However, these techniques still have severe limitations with respect to the study of rare microbial species. First, there are many sources of bias and error during all steps of DNA extraction, library preparation, sequencing and data analysis that can cause the number of sequence reads to differ from the actual species abundance (Schloss et al. 2011). Gonzalez et al. (2012) have shown that these biases can lead to an underrepresentation of rare species. At the same time, the opposite can occur, i.e. sequencing errors can lead to artefacts that are undistinguishable from true rare species (Caporaso et al. 2011). Second, relatively short sequence reads rarely provide enough resolution to classify them below family- or genus- levels. Third, insufficient coverage might prevent the detection of rare species. However, while developments in sequencing techniques and bioinformatical tools for sequence analysis improve our ability to detect rare species, metagenome sequencing does not provide information about species functions. Sequencing of the meta-transcriptome or meta-proteome of microbial communities does provide this information, but has similar shortcomings as metagenome-sequencing (Tsementzi et al. 2014, McCarthy et al. 2015). Moreover, difficulties arise in assigning the expression of specific genes or proteins to individual species in complex communities. Comparison of short RNAtags to pre-existing databases will only identify already known organisms. Since rare bacterial species, due to their low abundance, are likely to be underrepresented in these databases, there is a high probability of them not being detected (Urich et al. 2008).

Since molecular methods are still limited by biases, it is clear that we still require cultivationbased approaches to experimentally test the functional traits of specific bacterial species. However, also cultivation poses severe challenges to the study of microbes. It is assumed that only between $0.1 \%$ and $10 \%$ of all bacterial species can cultivated, which is termed the great plate count anomaly (Staley and Konopka 1985). Various factors can lead to this "uncultivability" of bacterial species, such as high nutrient contents in common cultivation media, the requirement of specific carbon substrates and electron-donors, the dependence on metabolites from other species, or competition in cultivation media (Alain and Querellou 2009). However, new developments in culturing systems have led to the successful isolation of many additional species. Diffusion cells that can be directly incubated in the environment or cell encapsulation in gel droplets are only two examples of the numerous systems that have been developed (Zengler et al. 2002, Nichols et al. 2010). Nevertheless, even with simple plating techniques and standard media novel species could be cultivated, indicating that increased cultivation effort might already be sufficient to expand the number of isolated species (Janssen et al. 2002, Joseph et al. 2003). Importantly, cultivability is not restricted to 
abundant species. The same techniques also capture many rare species (Buerger et al. 2012, Shade et al. 2012a). Still, only few cultivation studies make the effort to assess the abundance of isolated bacterial species in the field.

Studying the abundance of bacterial isolates in the field can be valuable for several reasons. First, it would allow researchers to assess if the set of isolates that is used in subsequent studies accurately represents the abundance distribution of the ingenious community or if it is biased towards either rare or abundant species. This knowledge might be especially valuable in studies on community assembly. Second, low abundant species could be specifically tested for their functional traits and/or their reaction to different abiotic and biotic conditions. These tests might give us further indications about the causes of species rarity and the mechanisms behind ecosystem insurance through abundance fluctuations.

\section{Objectives of this thesis and thesis outline}

To advance knowledge on rare species in general and rare bacteria in particular, in my thesis I will study, which factors are the major predictors of bacterial species abundance in the environment. Moreover, I investigate the effects of rare bacterial species in ecosystems through their interactions with other microbes and plants. I compare the results from experiments with soil bacteria with concepts from research on macroorganisms.

Theories on causes of species rarity in macroorganisms are mostly based on observations in natural communities, assessing population size, habitat range, body size, fertility dispersal and many other measures. However, such measures are not available for most bacteria. Current sequencing techniques can show us at an increasing resolution which species are present, but cannot yet indicate their respective traits that might contribute to rarity or abundance. Moreover, sequencing results are snapshots of a particular point in time and do not allow to draw conclusions about species dynamics. To determine the individual lifehistory traits of bacterial species and observe their interactions cultivation techniques are still irreplaceable. However, the number of species that can be cultivated is severely limited and low abundant taxa are assumed to be especially recalcitrant to isolation. In Chapter 2 of my thesis I describe a simple cultivation approach for the isolation soil bacterial species. By comparing the sequences of those isolates to a sequencing database from the same soil I determine species abundances in the field.

The isolates from Chapter 2 I used in the following studies on the causes of species rarity. Ample ecological theory exists about factors that structure communities, like niche and neutral processes, species life-history traits and biotic and abiotic interactions, but it has seldom if ever been tested if rare species share a certain set of traits, how these factors interact 
or if some are more important than others. In Chapter 3 I investigate the role of species traits as a cause of rarity. I focus on growth rate and substrate utilization. Slow growing species and species that utilize a narrow set of resources have been assumed more likely to be rare in the field. In bacteria these traits might be correlated since according to the oligotrophiccopiotrophic concept (Koch 2001) species that are oligotrophic are supposed to be slow growing and more specialized on certain substrates, whereas copiotrophic species are typically fast growing generalists (Christie-Oleza et al. 2012). I hypothesized that bacterial species that are rare in the environment are on average slower growing and more specialized in their resource use. In addition, I test the hypothesis that growth rate is positively correlated with the number of substrates a species can use.

In the field, species typically do not live in isolation, but in complex communities. Therefore, in Chapter 4 I investigate the role of the presence of competitors and predators in interaction with species traits and environmental nutrient status for species abundance. Competition and species traits have been suggested to structure communities together with predation and resource availability (Bohannan and Lenski 2000b, Winter et al. 2010). However, it has not yet been tested what the relative roles of predators and competitors at different nutrient concentrations are in shaping individual species abundances and how they interact with species traits. I investigate the importance of these factors for species abundance at the example of bacterial communities, employing a collection of well-characterized bacterial isolates. In a high-throughput assay I subject artificial bacterial communities to different nutrient concentrations in combination with different predators. I test whether potential species growth rate or field abundance (as measured in Chapter 3) can predict species competitiveness in interaction with nutrient availability. Moreover, I test whether competitively superior species are more susceptible to predation by protists and if this susceptibility differs between species that are rare or abundant in the field.

In the final experimental chapter of my thesis I investigate a potential function of low abundant species. Rare species have been implicated to be the drivers of many ecosystem functions. For bacteria, these have been, for example, particular mineralization processes or invasion resistance. Although soil bacteria are also known to be intimately engaged in interactions with plant roots, only few studies address the effect of rare bacterial species on plants. Understanding these effects can be essential since rare soil bacteria have been suggested to be involved in plant-insect interaction (Hol et al. 2010). Therefore, their loss can have consequences of a magnitude far beyond their abundance. A reduction of rare soil bacteria species has been found to increase plant susceptibility to aphid feeding (Hol et al. 2010). However, the mechanism behind this interaction remains unclear. In Chapter 5 I test the hypothesis that rare soil bacteria are involved in the induction of systemic resistance in plants and thereby increase plant performance in the presence of insect herbivores. For this I reduce rare microbial species in a natural community by serial dilution. As an additional 
treatment I add a Pseudomonas strain, known to induce systemic resistance, to all dilutions. A wild-type Arabidopsis thaliana accession, obtained from the same site, is grown subsequently in soil inoculated with the different dilutions. The plants are infested with the aphid Myzus persicae and plant defence gene expression, biomass and aphid performance are assessed.

In Chapter 6 I provide a discussion of the results of this thesis. I explicitly compare my findings on rare bacteria to current concepts and studies on rare species from other kingdoms. 


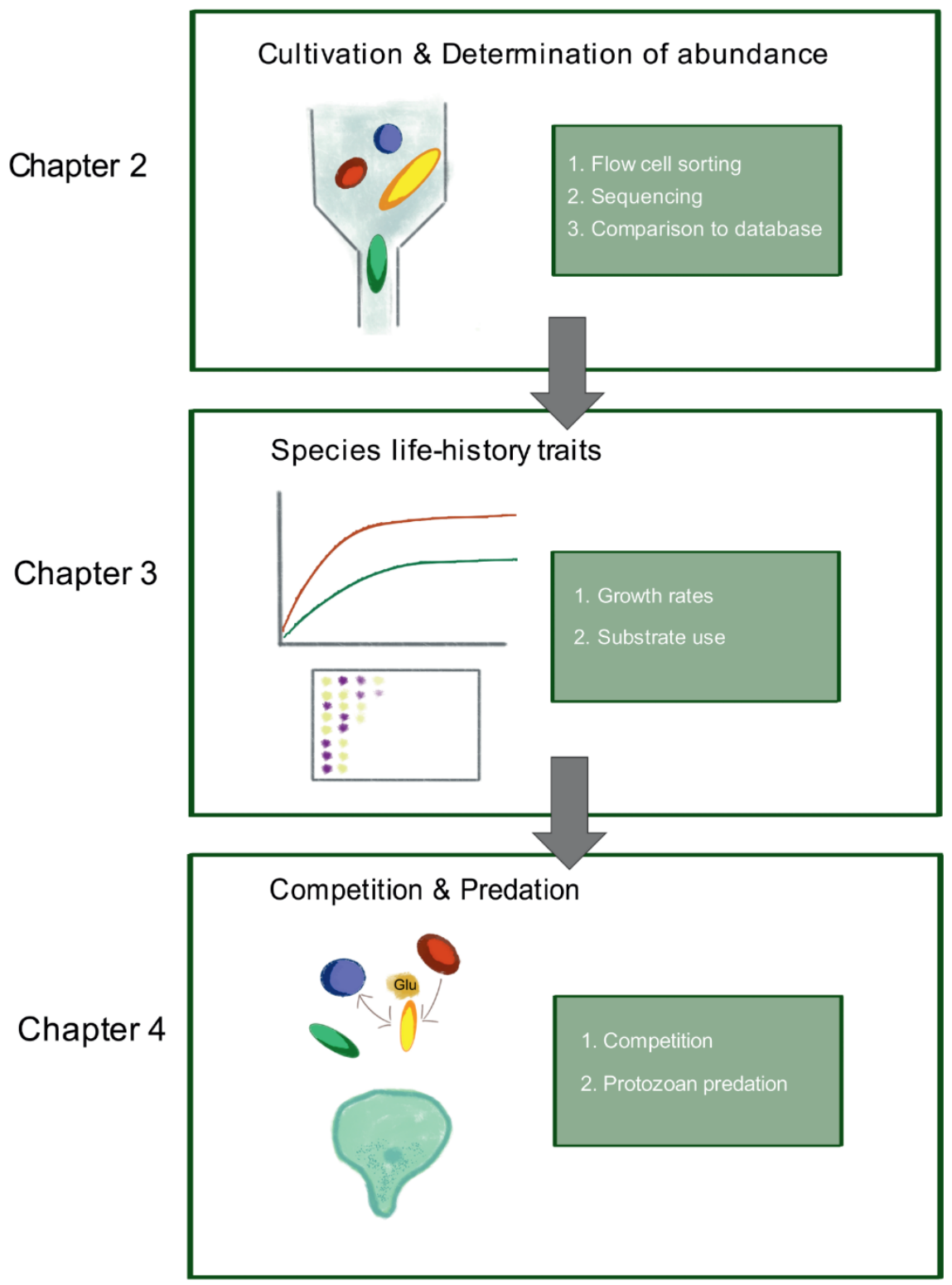




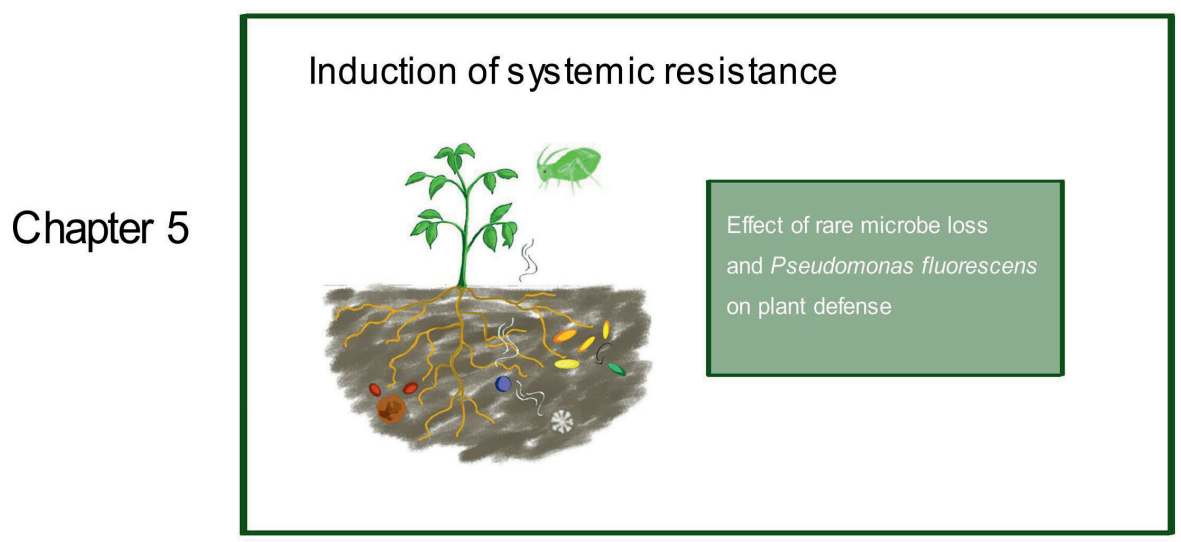

Figure 4: Overview of the chapters of this thesis. Consecutive workflow for investigating the causes of bacterial rarity from bacterial isolation in Chapter 2 to testing competition and predation in Chapter 4; in addition, test of a potential function of rare microbes in Chapter 5. 


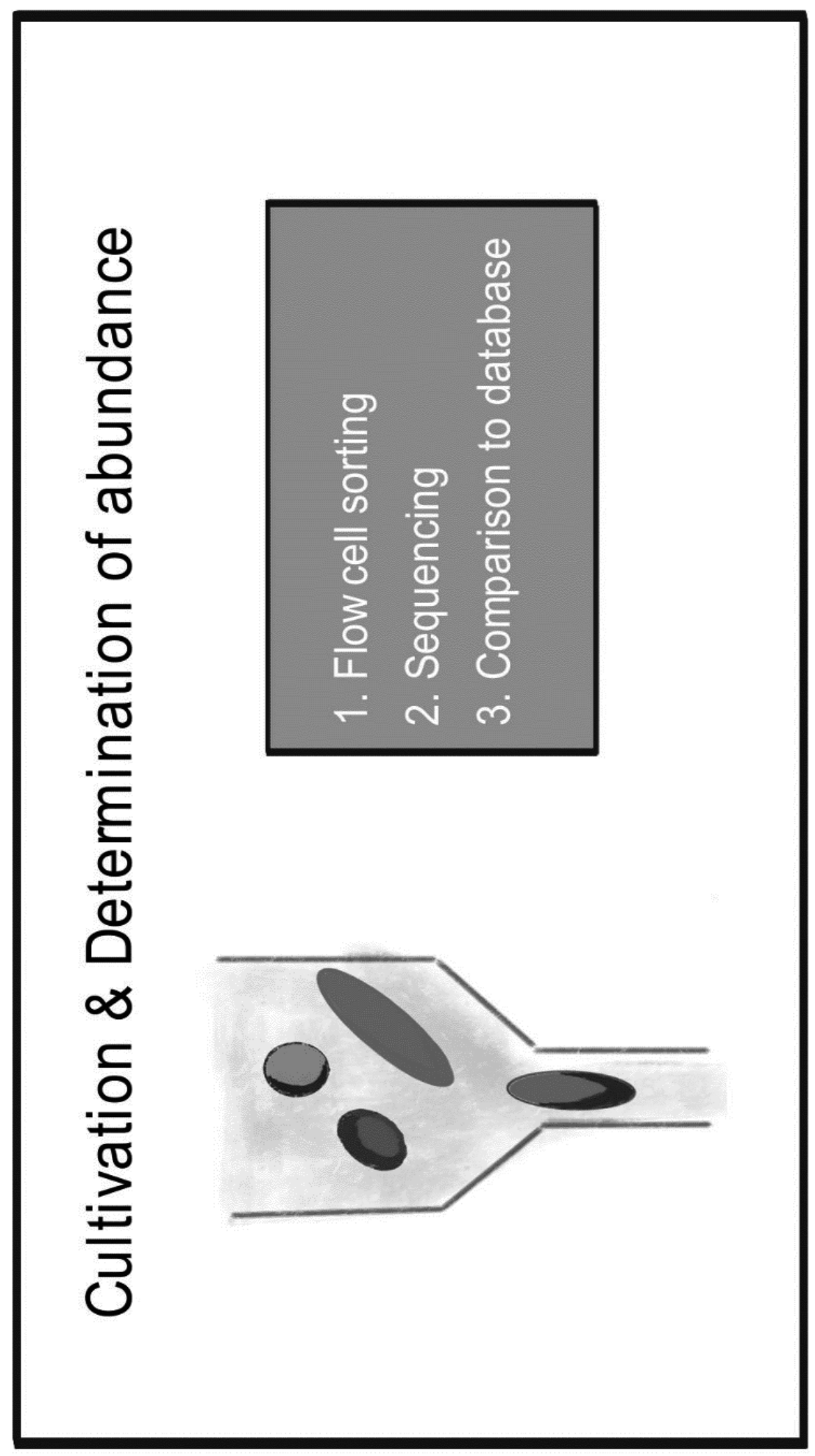




\section{Chapter 2}

\section{Underrepresentation of rare soil bacterial species in a cultivation approach using flow cell sorting and oligotrophic cultivation media}

Viola Kurm, Wim H. van der Putten \& W.H. Gera Hol 


\begin{abstract}
In order to study the cultivability and traits of rare soil bacterial species we conducted a cultivation study using flow cell sorting, and grew bacteria on different oligotrophic media under prolonged incubation times. We assessed the abundance of the isolates in the field by comparing them to a 454-sequencing dataset from the same soil. The proportion of isolates with a low field abundance $(<0.01 \%$ relative abundance) was significantly lower than expected based on the abundance distribution of the whole field community. Especially for the class Actinobacteria, fewer rare isolates were retrieved than expected from their abundance distribution in the field. This biased outcome despite increased efforts to target rare bacteria indicates that rare bacterial species will be underrepresented in many cultivation-based approaches and hence studies using these isolates will be biased towards species that are abundant. Rare and abundant isolates had similar incubation times. However, Alpha- and Gammaproteobacteria required on average longer incubation times than other classes. In contrast to former studies using similar methods, we did not obtain hitherto unknown species. In conclusion, our results suggest that cultivation studies should aim at assessing the field abundance of isolates in order to test how well they represent the field community.
\end{abstract}

\title{
Introduction
}

The invention and improvement of high-throughput sequencing techniques has led to the discovery of a large proportion of previously undetected rare species in bacterial communities. These new techniques allowed thousands of sequence reads per sample, which today has advanced to several millions (Bartram et al. 2011). Although this discovery can be considered as one of the milestones in microbial research, sequencing can merely show which species are present at a specific time point. It provides useful information about the potential functions of a particular species or a community, however, these still have to be tested in experimental bioassays in order to verify actual functioning. Besides functioning, little is known about the causes of bacterial rarity. Metagenomics and metatranscriptomics can be used to identify possible species traits that might lead to a permanent or temporal low abundance, such as a slow growth rate, the sensitivity to environmental conditions, competition or predation (Corno and Jürgens 2008, Morrissey et al. 2016), but also these potential traits will have to be verified by studying individual species in isolation. However, it has been suggested for long that only a very small minority of all bacterial species may be cultivated; this has been named 'the great plate count anomaly' (Staley and Konopka 1985). Moreover, these species might not represent the actual community composition in situ (Dunbar et al. 1999, McCaig et al. 2001).

In addition, it is still poorly investigated how many rare species are captured by cultivation. The only studies that we are aware of, which looked at rare species specifically, report contrasting results (Shade et al. 2012a, VanInsberghe et al. 2013). Thus, after centuries of 
cultivation efforts we still hardly know to what extent the subset of species captured by culturing is actually a good representation of the abundance distribution in the field. Only with such a baseline of current cultivation success we will be able to enhance the proportion of rare species in cultivation. However, cultivation-independent studies give valuable information about some attributes of rare species that can be used to increase cultivation success. Portillo et al. (2013) showed by separating bacterial communities in different size classes that low abundant species were mostly found in the small-size fraction of $<0.8 \mu \mathrm{m}$. Therefore, the selection of small cells might increase the proportion of cultured rare species. In addition, it has been suggested that rare species might be low abundant in the community due to a poor competitive ability compared to species that are more abundant.

The separation of single cells could favour the growth of rare species as it prevents direct competition. Cell separation may be achieved by several means, for example with isolation chips with miniature diffusion chambers or gel encapsulation in microdroplets (Zengler et al. 2002, Nichols et al. 2010). In addition, a prolonged incubation time might increase the proportion of rare species since they have often been assumed to be slow growing, leading to a low abundance, or to be part of a dormant seed-bank (Aanderud et al. 2015). However, in a follow-up study on bacterial isolates we did not find a difference in growth rate between rare or abundant species (Kurm et al. 2017). Therefore, it seems less likely that a longer incubation time would lead to capturing more rare species.

In contrast to the investigation of rare species, many studies have focused on the cultivation of novel (i.e. yet uncultivated) species or genera. The use of oligotrophic cultivation media has led to the successful cultivation of formerly uncultured species. Oligotrophic media are assumed to mimic environmental conditions more closely and many species have been found to grow exclusively at low nutrient concentrations (Hamaki et al. 2005). Examples of media for the isolation of soil bacteria are dilute tryptone soy broth or dilute nutrient broth (DNB) that allow for the growth of many different taxa (McCaig et al. 2001, Janssen et al. 2002). Different gelling agents, such as gellan gum, instead of agar, have been proven effective as well (Janssen et al. 2002). Attempts to mimic soil conditions have also led to the development of soil extract media, which yielded strains that could not grow on conventional media before (Smirnov and Brown 2004, Hamaki et al. 2005). Unfortunately, there is very little information on cultivation success on different media in relation to the abundance of an isolated species in the environment.

The cultivation of novel species might also be aided by the selection of small cells similar to the cultivation of rare species. Portillo et al. (2013) did not only find more rare taxa in the smaller size fractions of microbial communities, but also many uncultivated species, although they did not correlate these two measures with each other. Moreover, Davis et al. (2005) found that a decrease in inoculum size in common plating increased the number of novel species and genera. They suggest that a decreased density on the plate alleviated competition 
by spatial separation of cells. As such, the principle is similar to other, more complicated, cell separation techniques. However, a decreased inoculum size requires dilution, which is known to remove mostly rare species. In addition, a prolonged incubation time has been shown in several studies to lead to the cultivation of rarely isolated or novel species (Sait et al. 2002, Davis et al. 2005), although Buerger et al. (2012) did not find more novel species at later time points in incubation. In summary, there are indications that some methods that select for novel species, such as inoculum dilution or prolonged incubation time, are not suitable for the isolation of low abundant species. Cell separation by other means and the selection for small cells, however, might serve for both purposes, while there is not much known about the suitability of different isolation media for rare species.

In the present study, we focused on the cultivation of bacterial species that are low abundant in soil, in order to enable further tests of their traits experimentally, e.g. as Kurm et al. (2017). For this purpose, we employed several measures. First, we used flow cell sorting for cell separation and the selection of small cells. Second, we used different oligotrophic growth media, which have been recommended for the cultivation of soil bacteria (Sait et al. 2002, Joseph et al. 2003). Finally, we incubated the inoculated media for up to 5 months. We identified the isolated strains by Sanger-sequencing and assessed their abundance by comparing their sequences to a 454-sequencing database of samples originating from the same soil. We expected that cell sorting and the selection of small cells would lead to a high percentage of species that are low abundant in soil among the isolates because of their smaller cell sizes and decreased competition. In addition, we expected that this approach would also lead to the cultivation of novel genera or species. Further, we expected more novel taxa to appear later during the incubation than commonly isolated taxa, but incubation time should not affect the isolation of rare species.

\section{Material and Methods}

\section{Isolation of bacteria}

In May and June 2014, soil samples for bacterial cultivation were taken from a long-term biodiversity experim ent, nam ed CLUE, near Ede (Gelderland, the Netherlands, $52^{\circ} 04^{\prime} \mathrm{N}$ $05^{\circ} 45^{\prime} \mathrm{E}$ ) at a depth of $0-20 \mathrm{~cm}$. Bacteria were isolated by a flow sorting in combination with different media. The following cultivation media were used: 0.1 strength tryptone soy agar (0.1TSA; 3 g. $1^{-1}$ tryptone soy broth, 15 g..$^{-1}$ bacto agar), 0.01 strength TSA (0.01TSA; 0.3 g. $.1^{-1}$ tryptone soy broth, 15 g. $1^{-1}$ bacto agar), dilute nutrient broth agar (DNB; $0.03 \mathrm{~g} . \mathrm{l}^{-1}$ meat extract, 0.05 g. $1^{-1}$ peptone, 8 g. $1^{-1}$ gellan gum, $1.26 \mathrm{mmol} \mathrm{CaCl}$ ), water yeast agar (WYA; 5 g. $1^{-1} \mathrm{NaCl}, 0.05$ g..$^{-1}$ yeast extract, 20 g..$^{-1}$ bacto agar) and soil agar with and without the addition of nutrients (SA+ and SA- respectively, see Kurm et al. (2017)). Five 96-well plates were prepared from each medium. One day prior to cell sorting $5.4 \mathrm{~g}$ of sieved soil were 
added to $130 \mathrm{ml}$ phosphate buffer and shaken for $1.5 \mathrm{~h}$ at $120 \mathrm{rpm}$. Sonication was performed 2x 1 min to detach bacterial cells from soil particles. After shaking again for $0.5 \mathrm{~h}$ the soil solution was passed through a $45 \mu \mathrm{m}$ sieve. $130 \mathrm{ml}$ of phosphate without added soil was used as a control. The soil solution and the control were stained with SYBR green stain (SigmaAldrich, St. Louis, Missouri, USA). Using a flow cytometer (MoFlo Legacy Cell Sorter; Beckm an Coulter, Miam i, Florida, USA) cells of an approxim ate size of $0.5 \mu \mathrm{m}$ were sorted into single wells of the 96-well plates. The plates were inspected every other day for visible bacterial growth for 5 months. This study was conducted before our follow-up study showed that there is no difference between rare and abundant taxa with respect to growth rates (Kurm et al. 2017). Therefore, rare species were still expected to require longer incubation times. We define cultivation success as the number of isolates that could be retrieved relative to the number of wells that were inoculated.

\section{Identification of bacterial cultures}

The 16S rRNA was amplified with colony PCR using cell material picked from agar plates, suspended in SDS-lysis buffer and lysed for $5 \mathrm{~min}$ at $95^{\circ} \mathrm{C}$. DNA from isolates recalcitrant to this method was extracted using the ZR fungal/bacterial DNA MiniPrep kit (Zymo Research, Irvine, U.S.A.), the Power soil DNA isolation kit (MO BIO laboratories, Carlsbad, U.S.A.) or the QIAm p DNA Mini kit (Qiagen, Venlo, The Netherlands) and $1 \mu$ L DNA was used as a template in the PCR. 16S rDNA fragments were amplified using the primers $\mathrm{pA}$ (5'-AGAGTTTGATCCTGGCTCAG-3') and 1492r (5'-GRTACCTTGTTACGACTT-3') and sequenced by Sanger sequencing by Macrogen (Amsterdam, The Netherlands) or Baseclear (Leiden, The Netherlands) using the primer $515 \mathrm{f}$ (5' GTGCCAGCMGCCGCGGTAA-3'). After sequence quality trim $m$ ing using the program Phred (Green and Ewing 2002), sequences were blasted against the greengenes and SILVA database using the SINA alignment service for phylogenetic identification (Pruesse et al. 2012). The sequences were deposited in Genbank under the accession numbers KX503324KX503369.

\section{Estimation of relative abundance in field soil}

For estimation of abundance in field soil the isolate sequences were blasted against an OTU reference table using NCBI blastn (NCBI, Bethesda, Maryland, USA). The OTU reference table had been generated from a 454-sequencing database containing sequences from seven soil replicates that were collected from the same site as the isolates. The isolate sequences were matched to an OTU with a percentage identity cut-off of $97 \%$. The mean relative abundance of the OTU match in the sequencing database was taken as the relative abundance of the isolate in soil. In addition, we will in the following define rare OTUs as those occurring at a relative abundance $<0.01 \%$ and abundant OTUs as those occurring $>0.01 \%$ in the sequencing database. 
For a detailed description of isolation of soil bacteria, identification of isolates, and estimation of relative abundance in the environment see Kurm et al. (2017). The present study contains a subset of the isolates used in Kurm et al. (2017) as additional isolates were obtained by other methods that could not be directly compared with the flow sorting.

\section{Data analysis}

All statistical analyses were performed in R studio with R version 3.2.3. (R Core Team 2016). Abundance distributions between the field soil and unique isolated OTUs were compared with a Kolmogorov Smirnov-test. The abundance distributions of the different phylogenetic classes were tested in the same way. In addition, species abundance distribution models were fitted to the relative abundances of the OTUs in the field community and to the isolated OTUs using the radfit function from the vegan package (Oksanen et al. 2016). The Akaike Information Criterion (AIC) values of the models were compared to determine, which model fitted best. For this purpose, OTUs that were not detected in the field community, but present in the whole sequencing dataset were assigned an abundance of $1 * 10^{-7}$. The effect of different cultivation media on both the total number of isolates and the number of members of the different classes was tested with a generalized linear model using the $g \operatorname{lm}()$ function, with the distribution family specified as "poisson" $(n=5)$. The overall significance of the models were determined with the Anova() function from the car package (Fox and Weisberg 2011) and pairwise comparisons were performed with the function lsmeans() from the package lsmeans (Lenth 2016). The proportions of the five different classes found in this study was compared to their proportions in field soil (taking into account only the number of OTUs within a class, irrespective of their abundance) using a Chi-square test. The effect of cultivation medium on the square-root-transformed relative abundance in the environment averaged over the five replicates was tested with a one-way anova $(n=5)$. The relationship between incubation time (defined as the time until first visible growth on plate) and relative abundance was tested with a Spearman rank correlation test. Similarly, the relationships between average growth rate (as assessed in (Kurm et al. 2017)) and incubation time, and between relative abundance and the number of times the same OTU was isolated, were determined. Whether different classes differed in their average incubation time was assessed with a linear model, using the average incubation time for each unique OTU as the dependent variable. To detect effects of the different growth media on incubation time a linear model was used with incubation time averaged over the five replicates per medium. Accumulation curves were generated for the incubation time on the different media and differences between the curves were tested with a Kolmogorov-Smirnov test.

\section{Results}

In total 172 isolates were obtained, corresponding to a cultivation success of $6 \%$ (defined as the number of isolates retrieved relative to the number of wells that were inoculated). Of 
these isolates 113 were phylogenetically identified by sequencing and matched to an OTU from the 454-sequencing database. Based on the OTU match, the isolates could be grouped into 43 different OTUs.

\section{Relative abundance}

From the 43 isolates with unique OTUs, 30\% were abundant and 70\% were rare, based on their abundance in the field (Table 1). In the field community, across all OTUs, $95 \%$ of all OTUs were rare and 5\% were abundant. The relative abundances of the isolated OTUs differed significantly from the relative abundances of the field community (KolmogorovSmirnov test; $\mathrm{D}=0.3, \mathrm{p}<0.01)$. Moreover, the shape of the species abundance distributions differed between the field community and the isolated OTUs: a Zipf-distribution fitted best for the field com $m$ unity (param eters: $A=7430, \gamma-2.56$ ), while the best fit for the isolated OTUs was a Zipf-Mandelbrot distribution (parameters: $A=5.9 * 10^{12}, \gamma=-10.34, \beta=17.1$ ) (Fig. 1 , for all models fits see Table S1). There was no significant correlation between the number of times the same OTU was isolated and its relative abundance in the field (Spearman correlation; $\mathrm{rho}=0.15, \mathrm{p}=0.35$ ).

Cultivation success differed significantly between the media (Anova, $\mathrm{X}^{2}=33.15, \mathrm{p}<0.01$ ). Most isolates were obtained from 0.01-strength and 0.1-strength tryptone soy broth agar ( 0.01 TSA and 0.1 TSA), whereas least isolates grew on soil agar without added nutrients (SA-) and dilute nutrient broth agar (DNB) (Fig. S1, Table 1). Of the 43 unique OTUs, 60\% were specific to one medium. Most of these unique OTUs were obtained from ${ }_{0.1}$ TSA and WYA ( 8 and 7 OTUs respectively). The relative abundances of isolates growing on one medium were highly variable. There was no significant difference in average abundance of isolates between the different cultivation media (anova, $\mathrm{F}_{5,22}=1.5$, $\mathrm{p}=0.23$; Fig. 2). 
Table 1: Number of isolates from the respective cultivation medium, abundance and incubation time

\begin{tabular}{|c|c|c|c|c|c|c|c|}
\hline & $\begin{array}{l}\text { No. of } \\
\text { isolates }\end{array}$ & 0.01 TSA & 0.1 TSA & DNB & SA- & SA+ & $\begin{array}{l}\text { WY } \\
\text { A }\end{array}$ \\
\hline \multicolumn{8}{|l|}{ No. of isolates } \\
\hline Total no. of isolates & 113 & 36 & 23 & 13 & 7 & 15 & 19 \\
\hline No. of rare isolates & 76 & 22 & 14 & 10 & 5 & 11 & 14 \\
\hline $\begin{array}{r}\text { No. of abundant } \\
\text { isolates }\end{array}$ & 37 & 14 & 9 & 3 & 2 & 4 & 5 \\
\hline No. of OTUs & 43 & 18 & 17 & 10 & 7 & 9 & 11 \\
\hline No. of rare OTUs & 30 & 10 & 9 & 7 & 5 & 7 & 10 \\
\hline No. of abundant OTUs & 13 & 8 & 8 & 3 & 2 & 2 & 1 \\
\hline No. of unique OTUs & 26 & 4 & 8 & 2 & 1 & 4 & 7 \\
\hline No. of shared OTUs & 17 & 14 & 9 & 8 & 6 & 5 & 4 \\
\hline \multicolumn{8}{|l|}{ Class } \\
\hline No. Actinobacteria & 22 & 6 & 4 & 7 & 1 & 1 & 3 \\
\hline No. Bacilli & 11 & 4 & 1 & 0 & 1 & 4 & 1 \\
\hline $\begin{array}{r}\text { No. } \\
\text { Alphaproteobacteria }\end{array}$ & 28 & 10 & 5 & 1 & 2 & 2 & 8 \\
\hline $\begin{array}{r}\text { No. } \\
\text { Betaproteobacteria }\end{array}$ & 17 & 6 & 5 & 2 & 1 & 1 & 2 \\
\hline $\begin{array}{r}\text { No. } \\
\text { Gammaproteobacteria }\end{array}$ & 35 & 10 & 8 & 3 & 2 & 7 & 5 \\
\hline \multicolumn{8}{|l|}{ Incubation time } \\
\hline $\begin{array}{r}\text { Average incubation } \\
\text { time }\end{array}$ & 38.74 & 42.06 & $\begin{array}{l}19.8 \\
9\end{array}$ & 31.38 & $\begin{array}{l}60.5 \\
0\end{array}$ & $\begin{array}{l}31.8 \\
5\end{array}$ & $\begin{array}{l}55.9 \\
4\end{array}$ \\
\hline SE incubation time & 2.73 & 4.89 & 4.52 & 6.22 & $\begin{array}{l}14.6 \\
9\end{array}$ & 5.35 & 6.42 \\
\hline
\end{tabular}


$\mathbf{a}$

Field community

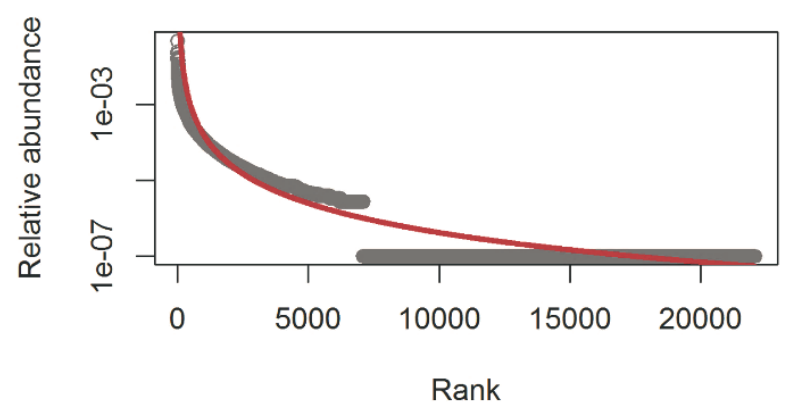

b

Isolates

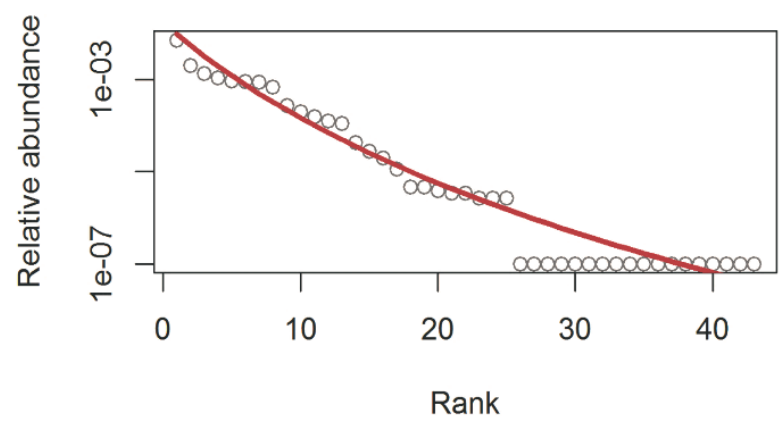

Fig. 1: Rank abundance distributions of a) all OTUs in the field community and b) isolated OTUs; grey dots represent OTUs and lines represent the fit of the best species abundance distribution model. 


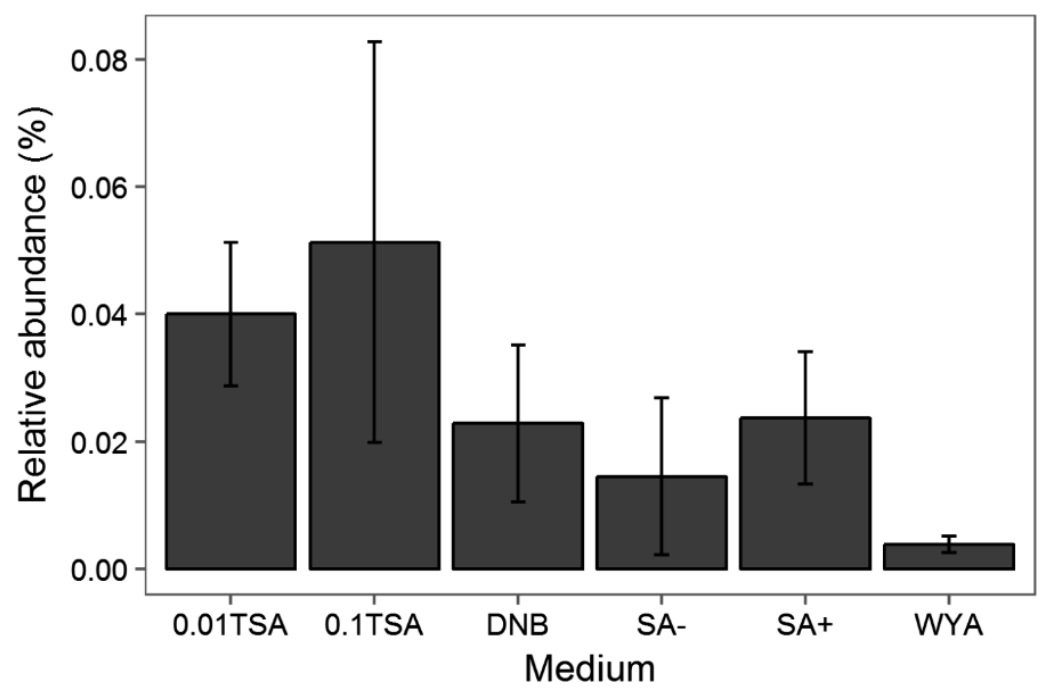

Fig. 2: Relative abundance of isolates grown on the different media averaged over the 5 replicates per medium; error bars represent the standard error $(n=5)$.

\section{Phylogeny}

All isolates matched with a similarity of $98 \%-100 \%$ sequence identity to already cultivated species. The isolates belonged to 5 different classes (Actinobacteria, Bacilli, Alphaproteobacteria, Betaproteobacteria and Gammaproteobacteria), 13 orders and 23 families (Table S2).

The proportions of the different classes among our isolates was similar to the proportions of the classes in soil (Chi-square test, $X^{2}=10_{8}, p=0.27$; Fig. 3). However, there were significant differences in the abundance distributions of the different classes between the field soil and the isolates. There were significantly more abundant and less rare species among the isolated Actinobacteria and Bacilli than would be expected, but there were no differences for the Proteobacteria (Kolmogorov-Smirnov test, Alphaproteobacteria: $\mathrm{D}=0.4, \mathrm{p}=0.11$, Betaproteobacteria: $\mathrm{D}=0.2, \mathrm{p}=0.80$, Gammaproteobacteria: $\mathrm{D}=0.2, \mathrm{p}=0.99$, Actinobacteria: $0.5, \mathrm{p}<0.01$, Bacilli: $\mathrm{D}=0.7, \mathrm{p}=0.03$, Fig. 4).

All classes were found on all media, except for Bacilli, which were not found on DNB. There were no significant differences in class occurrence between the different media (Anova, Alphaproteobacteria: $\quad \mathrm{X}^{2}: \quad 17.25, \quad \mathrm{p}<0.01$; Betaproteobacteria: $\mathrm{X}^{2}: \quad 8.85, \mathrm{p}=0.12$, Gam $\mathrm{m}$ aproteobacteria: $\mathrm{X}: 11.35, \mathrm{p}=0.05$; Actinobacteria: 9.25, $\mathrm{p}=0.10$; Bacilli: $9.95, \mathrm{p}=0.08$; Fig. S2). For Alphaproteobacteria and Gammaproteobacteria the overall occurrence was significantly different, but this effect was no longer detectable in pairwise comparisons between the media. 


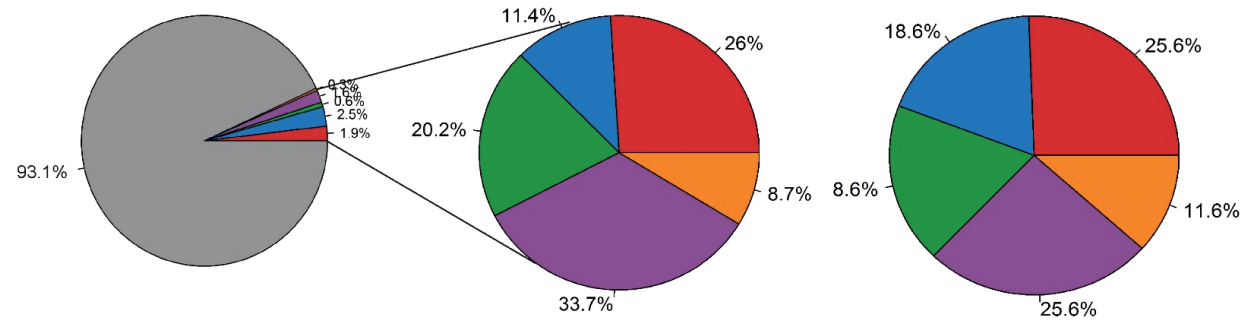

Fig. 3: Percentage of the classes Alpha-, Beta- and Gammaproteobacteria, Actinobacteria and Bacilli in the field community including all other 80 classes and the 5 isolated classes only in the field community as well as in the set of isolated OTUs $(n=43)$.

Field community

Isolates

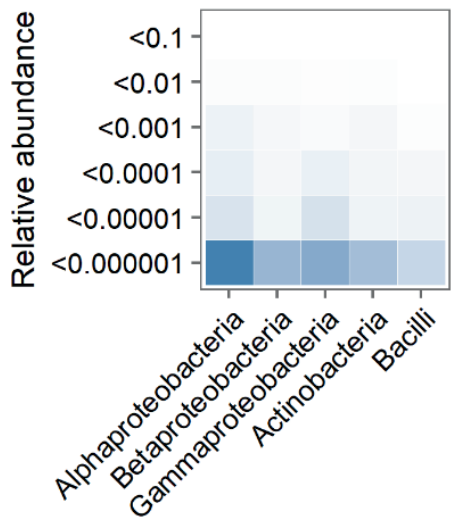

Class

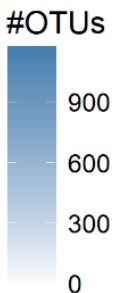

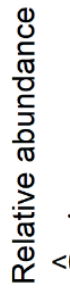

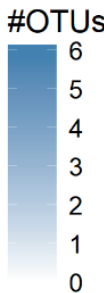

Fig. 4: Frequency of OTUs belonging to the five classes at different relative abundances in the field community and in the isolate collection retrieved by flow cytometry. 


\section{Incubation time}

The first growth event was observed 3 days after inoculation, the last after 133 days. On average isolates grew after $39( \pm 29)$ days (Table 1). OTUs that were isolated several times were obtained at the beginning, as well as at the end of the experiment. Isolates that were only retrieved once in this experiment were found at the beginning, but also after approximately 3 months of incubation.

There was no significant correlation between relative abundance and incubation time (defined as the time until first visible growth on plate) (Spearman correlation, rho $=-0.01$, $\mathrm{p}=0.91$ ). However, there were significant differences between the various phylogenetic classes in their average incubation time (Anova, $\mathrm{F}_{4,36}=5.14, \mathrm{p}<0.01$ ). Actinobacteria and Betaproteobacteria on average were observed earlier than Gammaproteobacteria and Alphaproteobacteria (Fig. 5).

The growth medium did not significantly influence the incubation time (Anova, $\mathrm{F}_{5,22}=1.93$, $\mathrm{p}=0.13$ ). The first growth event was observed after 3 days on $\mathrm{SA}+$ medium and the last after 133 days on SA- and ${ }_{0.01}$ TSA, but on each medium growth events were widely distributed over time leading to no significant differences. However, the pattern of cumulative growth events over time differed between the media. Whereas on ${ }_{0.1}$ TSA growth occurred mostly at the beginning over a short time period and levelled off after approximately 20 days, other media such as 0.01 TSA and WYA showed a second series of growth events after approximately 50 days (Fig. S3). Accumulation curves differed significantly between ${ }_{0.1}$ TSA and ${ }_{0.01}$ TSA, WYA, DNB and SA- (Table S3). Most of the growth events occurred within 3 months of incubation. Thereafter, only very few new growth events were observed. 


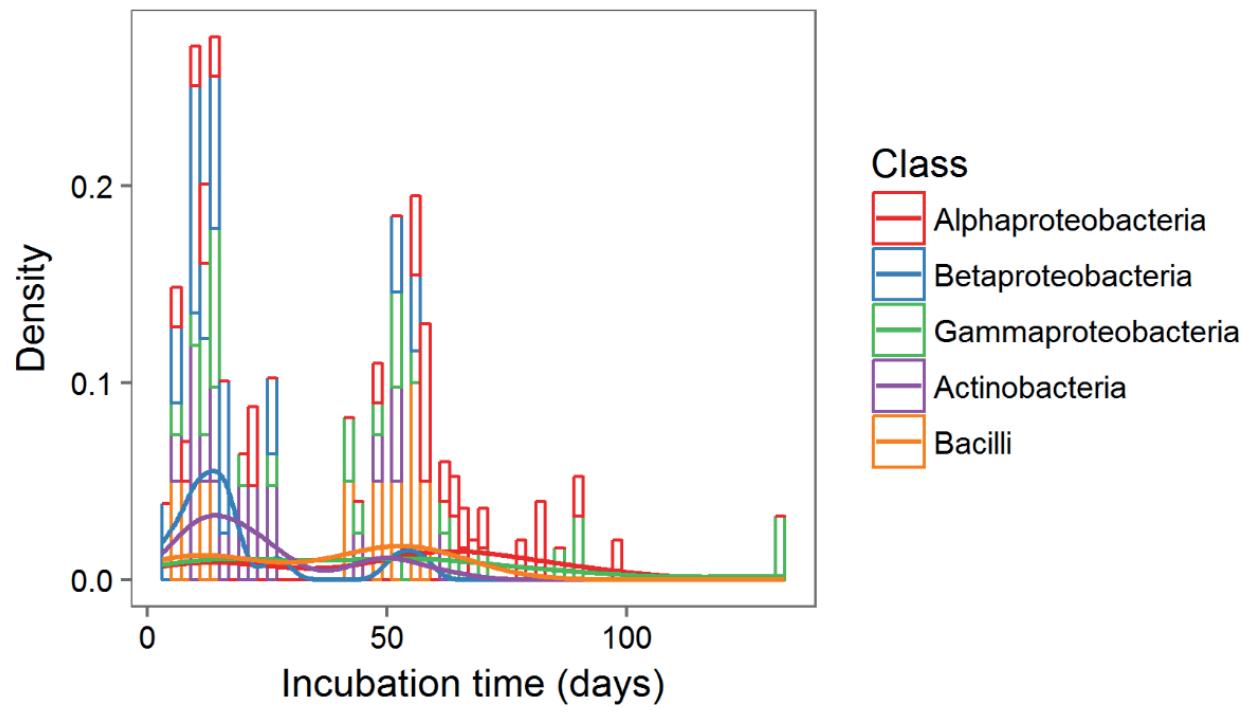

Fig. 5: Density plot of number of isolates showing visible growth along incubation time; lines represent densities of the different classes.

\section{Discussion}

Soil bacterial communities consist of a vast majority of rare species. While the cultivation approach presented in this study captured more rare than abundant bacterial OTUs (in the following called species), the proportion of rare species was significantly lower than the actual proportion in soil. This was confirmed by differences in species abundance distributions as a higher $\gamma$-parameter indicates a lower species evenness and an abundance distribution of few dominant and many rare species (Wilson 1991, Spatharis and Tsirtsis 2013). On the one hand, this can result from the naturally larger cell density of abundant species, which makes them more likely to be recovered by chance. On the other hand, species that are abundant in the field might possess traits that facilitate their growth in culture. Still, the recovery of a high proportion of abundant species is unexpected since we selected for rare species by sorting small cells with a diameter of $\sim \quad 0.5 \mu \mathrm{m}$ and preventing interspecific competition. A low competitive ability has been suggested to be a main cause of species rarity (Hibbing et al. 2010). Excluding competition did not lead to an adequate representation of rare species among the isolates. Therefore, competition was likely not the main restriction for their cultivation. Still, our findings indicate that rare soil bacterial species are likely to be underrepresented in many contemporary cultivation attempts since we employed common cultivation techniques, while also selecting for rare species using methods suggested by former studies (Hibbing et al. 2010, Portillo et al. 2013). 
As rare species were not restricted by competition, the choice of cultivation media might have favoured the growth of more abundant species. Although the media used in this study differed in composition, most of them contained easily degradable substrate and commonly support the growth of a variety of saprotrophic species. It has been suggested that rare species might be adapted to specific niches or scarce substrates accounting for their low abundance (Flather and Sieg 2007). Alternatively, rare species might require chemical compounds produced by other species either as signalling compounds or as a nutrient source (Kaeberlein et al. 2002). These species consequentially could not be cultured with common media and in isolation. Soil agar should have provided substrates that are naturally present in soil and similar media have been reported to lead to the cultivation of a diverse array of species. However, autoclaving can lead to significant changes in the structure of soil organic carbon and especially increase the amount of easily degradable carbohydrates (Berns et al. 2008). In contrast to species abundance, the media differed in the number of cultured species. TSA medium of 0.01 - strength showed the highest cultivation success indicating that this lowstrength medium can be even more efficient for bacterial cultivation than the frequently used 0.1-strength TSA (McCaig et al. 2001). This might be because of the lower nutrient concentrations that more closely resemble oligotrophic conditions in soil.

In contrast to our expectations, we did not find novel (i.e. previously uncultured) taxa in our set of isolates. All of them were highly similar to sequences of cultured isolates in the NCBI Genbank. Davis et al. (2005) reported an increase in novel isolates with increased inoculum dilution and suggested that a decrease in competition might have led to the growth of yet uncultured species. Our results do not support this assumption because flow sorting effectively excluded interspecific competition on the cultivation medium. In addition to novel species, several widespread soil taxa were missing from our isolates, such as members of the phyla Acidobacteria, Verrucomicrobia and Gemmatimonadetes, which can be prominent in soils (Janssen 2006, DeBruyn et al. 2011). In several studies, using similar media as were employed here, such as ${ }_{0.1}$ TSA and DNB, members of these phyla were isolated, as well as novel orders and families (Sait et al. 2002, Joseph et al. 2003). Low abundance cannot explain their absence from our culture collection, as several of these taxa have been found to be highly abundant in soil (Janssen 2006, Bergmann et al. 2011). Verrucomicrobia, for example, occurred at an average abundance of $0.17 \%$ in the sampled soil, based on the sequencing data. Moreover, selecting for small cells should have favoured the cultivation of these taxa as they have been reported to belong to a size range of $<0.8 \mu \mathrm{m}$ (Portillo et al. 2013). It is possible that the flow sorting approach and prior treatment of the soil samples discriminated against these taxa, for example due to sensitivity of some taxa to sonication (Foladori et al. 2007). Alternatively, isolates that were cultured but that could not be identified by Sanger sequencing, either due to being recalcitrant to DNA extraction or subsequent PCR, might contain additional bacterial taxa. It has been shown that primers that were formerly thought 
to be universal for the bacterial 16S rRNA gene, discriminate against Verrucomicrobia, including the 1492r-primer (Bergmann et al. 2011) that was used in our study.

While many bacterial taxa were not present among our isolates, the proportions of the classes Alpha-, Beta- and Gammaproteobacteria as well as Actinobacteria and Bacilli were remarkably similar to their proportions in soil. In addition, there were no differences between cultivation media with respect to the recovery of the different classes. Together these results indicate that the flow cell sorting, the used media, and subsequent molecular identification did not discriminate against these classes. Many studies on the cultivation of soil bacteria reported these five classes as among the most frequently isolated (Ellis et al. 2003, Davis et al. 2005, Nunes da Rocha et al. 2009). They contain a high diversity of families, orders and genera with many members that are adapted to saprotrophic growth. Nevertheless, we found differences between the relative abundance distribution of the isolates in the field and the overall relative abundance of these classes. Isolates belonging to the Actinobacteria and Bacilli were on average more abundant in soil than would be expected. This was especially pronounced for the Actinobacteria, although they were among the most commonly isolated classes in this experiment and hence a higher number of rare species would be expected by chance. Studies concentrating on enhancing the cultivation success of Actinobacteria have suggested that members of this class are slow growing and sensitive to competition (Srinivasan et al. 1991). However, this cannot explain the underrepresentation of rare Actinobacteria in the present study, as our approach excluded competition and provided long incubation times.

According to our expectations, rare species did not require longer incubation times than abundant species. This is in support of findings that rare species can be fast growing and highly active in the environment (Baldrian et al. 2012, Kurm et al. 2017). However, we did not find evidence that novel species would emerge on plates after longer incubation times as has been reported by Davis et al. (2005). Still, there were differences between classes with respect to incubation time as Alpha-and Gammaproteobacteria required longer incubation times than Actinobacteria and Betaproteobacteria. These differences between classes suggest that growth in culture might not be completely random, but partly dependent on bacterial phylogeny. Mitsui et al. (1997) found that Alphaproteobacteria needed longer incubation times than other taxa and suggested slow growth and an oligotrophic life-style as the underlying mechanism. For the Gammaproteobacteria, however, we can only speculate about the possible causes of such temporal dynamics. First, members of this class might have been disproportionally inactive in the soil due to unfavourable condition at the time of sample collection. Second, the isolated species might have been less efficient in adjusting to changes in environmental conditions, such as transfer to an artificial medium. Differences in cultivation media are unlikely to affect the incubation times of the different classes since none showed preferential growth on one medium. We also did not detect differences in 
incubation time between the media. The differences between taxa with respect to incubation time indicates an increase in phylogenetic diversity with progressing incubation time. Interestingly, in spite of the lack of overall differences in incubation time between the media the patterns of cumulative growth differed between the media emphasizing the merit of a prolonged incubation time for at least some cultivation media.

In conclusion, we show that rare soil bacterial species were underrepresented in an isolate collection even when selecting for small cells and alleviating competition. This suggests that also other collections might be skewed towards the more abundant species. Hence, insights originating from the study of isolated species so far might be based on the more abundant species, which could behave differently from the rare ones. Many steps still have to be taken to comprehensively study the cultivability of rare species as the present study represents only one of many available techniques. We propose that the use of a wider variety of substrates for cultivation, including recalcitrant compounds, as well as co-cultivation techniques with other species should be tested for their suitability for the cultivation of low abundant species. Extended incubation time, however, might not be necessary.

\section{Acknowledgements}

We thank Suzanne Naus-Wiezer for her invaluable help in the operation of the flow cytometer. Moreover, we are grateful to Wietse de Boer for advice on bacterial cultivation techniques. 


\section{Supplementary Information}

Table S1: Model fits and parameter estimates of the broken-stick, the niche-preemption, the log-normal, the Zipf and the Zipf-Mandelbrot model for species abundance distributions in the field community and for unique isolated OTUs; the broken-stick model is the Nullmodel; the models were fitted using the function radfit from the vegan package in $\mathrm{R}$ (Oksanen et al. 2016); the Zipf-Mandelbrot and log-normal models did not converge for the field community and the log-normal model did not converge for the isolated OTUs; param eter 2 represents the $\gamma$ parameter of Zipf and Zipf-Mandelbrot models and parameter 3 represents the $\beta$-parameter of Zipf and Zipf-Mandelbrot models.

\begin{tabular}{|r|l|l|l|l|l|}
\hline Model & $\begin{array}{l}\text { Parameter } \\
\mathbf{1}\end{array}$ & $\begin{array}{l}\text { Parameter } \\
\mathbf{2}\end{array}$ & $\begin{array}{l}\text { Parameter } \\
\mathbf{3}\end{array}$ & Deviance & AIC \\
\hline Broken-stick & & & & 138352 & -519288 \\
\hline Niche preemption & 0.00046 & & & 61959 & -544667 \\
\hline Zipf & 7430.4 & -2.56 & & 14314 & -583699 \\
\hline & & & & & \\
\hline Biche preemption & 0.25 & & & 279.7 & -822 \\
\hline Zipf & 510.9 & -4.87 & & 46.2 & -923 \\
\hline Zipf-Mandelbrot & $5.9 * 10^{12}$ & -10.34 & 17.06 & 55.8 & -912 \\
\hline
\end{tabular}


Table S2: Unique OTUs, phylogenetic affiliation and relative abundance in the field soil

\begin{tabular}{|c|c|c|c|c|c|c|c|}
\hline $\begin{array}{r}\text { OTU } \\
\text { numbe } \\
r\end{array}$ & Phylum & Class & Order & Family & Genus & Species & $\begin{array}{l}\text { Relative } \\
\text { abundance } \\
(\%)\end{array}$ \\
\hline $\begin{array}{r}\text { Otu000 } \\
004\end{array}$ & $\begin{array}{l}\text { Actinob } \\
\text { acteria }\end{array}$ & $\begin{array}{l}\text { Actinobacte } \\
\text { ria }\end{array}$ & $\begin{array}{l}\text { Actinomy } \\
\text { cetales }\end{array}$ & $\begin{array}{l}\text { Micrococca } \\
\text { ceae }\end{array}$ & $\begin{array}{l}\text { Arthrobac } \\
\text { ter }\end{array}$ & $\begin{array}{l}\text { psychrola } \\
\text { ctophilus }\end{array}$ & 0.70986 \\
\hline $\begin{array}{r}\text { Otu000 } \\
009\end{array}$ & $\begin{array}{l}\text { Proteob } \\
\text { acteria }\end{array}$ & $\begin{array}{l}\text { Gammaprot } \\
\text { eobacteria }\end{array}$ & $\begin{array}{l}\text { Pseudomo } \\
\text { nadales }\end{array}$ & $\begin{array}{l}\text { Pseudomon } \\
\text { adaceae }\end{array}$ & \multicolumn{2}{|c|}{ Pseudomonas } & 0.08773 \\
\hline $\begin{array}{r}\text { Otu000 } \\
019\end{array}$ & $\begin{array}{l}\text { Proteob } \\
\text { acteria }\end{array}$ & $\begin{array}{l}\text { Betaproteob } \\
\text { acteria }\end{array}$ & $\begin{array}{l}\text { Burkholde } \\
\text { riales }\end{array}$ & $\begin{array}{l}\text { Oxalobacte } \\
\text { raceae }\end{array}$ & \multicolumn{2}{|c|}{ Janthinobacterium } & 0.20133 \\
\hline $\begin{array}{r}\text { Otu000 } \\
043\end{array}$ & $\begin{array}{l}\text { Proteob } \\
\text { acteria }\end{array}$ & $\begin{array}{l}\text { Betaproteob } \\
\text { acteria }\end{array}$ & $\begin{array}{l}\text { Burkholde } \\
\text { riales }\end{array}$ & $\begin{array}{l}\text { Comamona } \\
\text { daceae }\end{array}$ & & & 0.13353 \\
\hline $\begin{array}{r}\text { Otu000 } \\
103\end{array}$ & $\begin{array}{l}\text { Actinob } \\
\text { acteria }\end{array}$ & $\begin{array}{l}\text { Actinobacte } \\
\text { ria }\end{array}$ & $\begin{array}{l}\text { Actinomy } \\
\text { cetales }\end{array}$ & $\begin{array}{l}\text { Microbacte } \\
\text { riaceae }\end{array}$ & \multicolumn{2}{|c|}{ Microbacterium } & 0.09286 \\
\hline $\begin{array}{r}\text { Otu000 } \\
146 \\
\end{array}$ & $\begin{array}{l}\text { Proteob } \\
\text { acteria }\end{array}$ & $\begin{array}{l}\text { Alphaproteo } \\
\text { bacteria }\end{array}$ & $\begin{array}{l}\text { Caulobact } \\
\text { erales }\end{array}$ & $\begin{array}{l}\text { Caulobacte } \\
\text { raceae }\end{array}$ & \multicolumn{2}{|c|}{ Phenylobacterium } & 0.08986 \\
\hline $\begin{array}{r}\text { Otu000 } \\
168 \\
\end{array}$ & $\begin{array}{l}\text { Actinob } \\
\text { acteria }\end{array}$ & $\begin{array}{l}\text { Actinobacte } \\
\text { ria }\end{array}$ & $\begin{array}{l}\text { Kineospor } \\
\text { iales }\end{array}$ & $\begin{array}{l}\text { Kineospori } \\
\text { aceae }\end{array}$ & \multicolumn{2}{|c|}{ Quadrisphaera } & 0.10911 \\
\hline $\begin{array}{r}\text { Otu000 } \\
182\end{array}$ & $\begin{array}{l}\text { Firmicu } \\
\text { tes }\end{array}$ & Bacilli & Bacillales & Bacillaceae & Bacillus & flexus & 0.01102 \\
\hline $\begin{array}{r}\text { Otu000 } \\
201\end{array}$ & $\begin{array}{l}\text { Actinob } \\
\text { acteria }\end{array}$ & $\begin{array}{l}\text { Actinobacte } \\
\text { ria }\end{array}$ & $\begin{array}{l}\text { Actinomy } \\
\text { cetales }\end{array}$ & $\begin{array}{l}\text { Intrasporan } \\
\text { giaceae }\end{array}$ & \multicolumn{2}{|c|}{ Terracoccus } & 0.06953 \\
\hline $\begin{array}{r}\text { Otu000 } \\
323\end{array}$ & $\begin{array}{l}\text { Actinob } \\
\text { acteria }\end{array}$ & $\begin{array}{l}\text { Actinobacte } \\
\text { ria }\end{array}$ & $\begin{array}{l}\text { Actinomy } \\
\text { cetales }\end{array}$ & $\begin{array}{l}\text { Nocardioid } \\
\text { aceae }\end{array}$ & \multicolumn{2}{|c|}{ Aeromicrobium } & 0.02741 \\
\hline $\begin{array}{r}\text { Otu000 } \\
410\end{array}$ & $\begin{array}{l}\text { Proteob } \\
\text { acteria }\end{array}$ & $\begin{array}{l}\text { Alphaproteo } \\
\text { bacteria }\end{array}$ & $\begin{array}{l}\text { Rhizobiale } \\
\text { s }\end{array}$ & $\begin{array}{l}\text { Bradyrhizo } \\
\text { biaceae }\end{array}$ & \multicolumn{2}{|c|}{ Rhodopseudomonas } & 0.01974 \\
\hline $\begin{array}{r}\text { Otu000 } \\
486\end{array}$ & $\begin{array}{l}\text { Proteob } \\
\text { acteria }\end{array}$ & $\begin{array}{l}\text { Alphaproteo } \\
\text { bacteria }\end{array}$ & $\begin{array}{l}\text { Rhizobiale } \\
\text { s }\end{array}$ & $\begin{array}{l}\text { Phyllobacte } \\
\text { riaceae }\end{array}$ & \multicolumn{2}{|c|}{ Mesorhizobium } & 0.01251 \\
\hline $\begin{array}{r}\text { Otu000 } \\
660\end{array}$ & $\begin{array}{l}\text { Firmicu } \\
\text { tes }\end{array}$ & Bacilli & Bacillales & $\begin{array}{l}\text { Paenibacill } \\
\text { aceae }\end{array}$ & $\begin{array}{l}\text { Paenibaci } \\
\text { llus }\end{array}$ & $\begin{array}{l}\text { amylolytic } \\
\text { us }\end{array}$ & 0.01559 \\
\hline $\begin{array}{r}\text { Otu001 } \\
096 \\
\end{array}$ & $\begin{array}{l}\text { Actinob } \\
\text { acteria }\end{array}$ & $\begin{array}{l}\text { Actinobacte } \\
\text { ria }\end{array}$ & $\begin{array}{l}\text { Propioniba } \\
\text { cteriales }\end{array}$ & $\begin{array}{l}\text { Nocardioid } \\
\text { aceae }\end{array}$ & \multicolumn{2}{|c|}{ Nocardioides } & 0.00283 \\
\hline $\begin{array}{r}\text { Otu001 } \\
144\end{array}$ & $\begin{array}{l}\text { Proteob } \\
\text { acteria }\end{array}$ & $\begin{array}{l}\text { Gammaprot } \\
\text { eobacteria }\end{array}$ & $\begin{array}{l}\text { Pseudomo } \\
\text { nadales }\end{array}$ & $\begin{array}{l}\text { Pseudomon } \\
\text { adaceae }\end{array}$ & $\begin{array}{l}\text { Pseudomo } \\
\text { nas }\end{array}$ & viridiflava & 0.00000 \\
\hline $\begin{array}{r}\text { Otu001 } \\
370\end{array}$ & $\begin{array}{l}\text { Actinob } \\
\text { acteria }\end{array}$ & $\begin{array}{l}\text { Actinobacte } \\
\text { ria }\end{array}$ & $\begin{array}{l}\text { Actinomy } \\
\text { cetales }\end{array}$ & $\begin{array}{l}\text { Nocardioid } \\
\text { aceae }\end{array}$ & & & 0.00116 \\
\hline $\begin{array}{r}\text { Otu001 } \\
629\end{array}$ & $\begin{array}{l}\text { Firmicu } \\
\text { tes }\end{array}$ & Bacilli & Bacillales & $\begin{array}{l}\text { Staphyloco } \\
\text { ccaceae }\end{array}$ & \multicolumn{2}{|c|}{ Staphylococcus } & 0.00434 \\
\hline $\begin{array}{r}\text { Otu002 } \\
092 \\
\end{array}$ & $\begin{array}{l}\text { Proteob } \\
\text { acteria }\end{array}$ & $\begin{array}{l}\text { Gammaprot } \\
\text { eobacteria }\end{array}$ & $\begin{array}{l}\text { Enterobact } \\
\text { eriales }\end{array}$ & $\begin{array}{l}\text { Enterobact } \\
\text { eriaceae }\end{array}$ & Pantoea & & 0.00034 \\
\hline $\begin{array}{r}\text { Otu002 } \\
494\end{array}$ & $\begin{array}{l}\text { Proteob } \\
\text { acteria }\end{array}$ & $\begin{array}{l}\text { Alphaproteo } \\
\text { bacteria }\end{array}$ & $\begin{array}{l}\text { Sphingom } \\
\text { onadales }\end{array}$ & $\begin{array}{l}\text { Sphingomo } \\
\text { nadaceae }\end{array}$ & \multicolumn{2}{|c|}{ Sphingomonas } & 0.00027 \\
\hline $\begin{array}{r}\text { Otu003 } \\
445\end{array}$ & $\begin{array}{l}\text { Proteob } \\
\text { acteria }\end{array}$ & $\begin{array}{l}\text { Alphaproteo } \\
\text { bacteria }\end{array}$ & $\begin{array}{l}\text { Rhizobiale } \\
\text { s }\end{array}$ & $\begin{array}{l}\text { Methyloba } \\
\text { cteriaceae }\end{array}$ & \multicolumn{2}{|c|}{ Methylobacterium } & 0.00027 \\
\hline $\begin{array}{r}\text { Otu004 } \\
780\end{array}$ & $\begin{array}{l}\text { Firmicu } \\
\text { tes }\end{array}$ & Bacilli & $\begin{array}{l}\text { Lactobacil } \\
\text { lales }\end{array}$ & $\begin{array}{l}\text { Carnobacte } \\
\text { riaceae }\end{array}$ & \multicolumn{2}{|c|}{ Carnobacterium } & 0.00047 \\
\hline $\begin{array}{r}\text { Otu004 } \\
967\end{array}$ & $\begin{array}{l}\text { Proteob } \\
\text { acteria }\end{array}$ & $\begin{array}{l}\text { Betaproteob } \\
\text { acteria }\end{array}$ & $\begin{array}{l}\text { Burkholde } \\
\text { riales }\end{array}$ & $\begin{array}{l}\text { Oxalobacte } \\
\text { raceae }\end{array}$ & \multicolumn{2}{|c|}{ Janthinobacterium } & 0.00000 \\
\hline $\begin{array}{r}\text { Otu005 } \\
079\end{array}$ & $\begin{array}{l}\text { Firmicu } \\
\text { tes }\end{array}$ & Bacilli & Bacillales & $\begin{array}{l}\text { Staphyloco } \\
\text { ccaceae }\end{array}$ & \multicolumn{2}{|c|}{ Staphylococcus } & 0.00027 \\
\hline $\begin{array}{r}\text { Otu005 } \\
151\end{array}$ & $\begin{array}{l}\text { Proteob } \\
\text { acteria }\end{array}$ & $\begin{array}{l}\text { Alphaproteo } \\
\text { bacteria }\end{array}$ & $\begin{array}{l}\text { Rhizobiale } \\
\text { s }\end{array}$ & $\begin{array}{l}\text { Xanthobact } \\
\text { eraceae }\end{array}$ & \multicolumn{2}{|c|}{ Ancylobacter } & 0.00197 \\
\hline $\begin{array}{r}\text { Otu005 } \\
676\end{array}$ & $\begin{array}{l}\text { Proteob } \\
\text { acteria }\end{array}$ & $\begin{array}{l}\text { Alphaproteo } \\
\text { bacteria }\end{array}$ & $\begin{array}{l}\text { Sphingom } \\
\text { onadales }\end{array}$ & $\begin{array}{l}\text { Sphingomo } \\
\text { nadaceae }\end{array}$ & $\begin{array}{l}\text { Sphingom } \\
\text { onas }\end{array}$ & echinoides & 0.00000 \\
\hline $\begin{array}{r}\text { Otu005 } \\
905\end{array}$ & $\begin{array}{l}\text { Proteob } \\
\text { acteria }\end{array}$ & $\begin{array}{l}\text { Alphaproteo } \\
\text { bacteria }\end{array}$ & $\begin{array}{l}\text { Rhizobiale } \\
\text { s }\end{array}$ & $\begin{array}{l}\text { Bradyrhizo } \\
\text { biaceae }\end{array}$ & \multicolumn{2}{|c|}{ Bradyrhizobium } & 0.00034 \\
\hline
\end{tabular}




\begin{tabular}{|c|c|c|c|c|c|c|c|}
\hline $\begin{array}{r}\text { Otu007 } \\
241\end{array}$ & $\begin{array}{l}\text { Proteob } \\
\text { acteria }\end{array}$ & $\begin{array}{l}\text { Alphaproteo } \\
\text { bacteria }\end{array}$ & $\begin{array}{l}\text { Sphingom } \\
\text { onadales }\end{array}$ & $\begin{array}{l}\text { Sphingomo } \\
\text { nadaceae }\end{array}$ & \multicolumn{2}{|c|}{ Sphingomonas } & 0.00000 \\
\hline $\begin{array}{r}\text { Otu007 } \\
669 \\
\end{array}$ & $\begin{array}{l}\text { Proteob } \\
\text { acteria }\end{array}$ & $\begin{array}{l}\text { Gammaprot } \\
\text { eobacteria }\end{array}$ & $\begin{array}{l}\text { Pseudomo } \\
\text { nadales }\end{array}$ & $\begin{array}{l}\text { Pseudomon } \\
\text { adaceae }\end{array}$ & \multicolumn{2}{|c|}{ Pseudomonas } & 0.00000 \\
\hline $\begin{array}{r}\text { Otu008 } \\
022\end{array}$ & $\begin{array}{l}\text { Proteob } \\
\text { acteria }\end{array}$ & $\begin{array}{l}\text { Alphaproteo } \\
\text { bacteria }\end{array}$ & $\begin{array}{l}\text { Rhizobiale } \\
\text { s }\end{array}$ & $\begin{array}{l}\text { Bradyrhizo } \\
\text { biaceae }\end{array}$ & \multicolumn{2}{|c|}{ Bradyrhizobium } & 0.00000 \\
\hline $\begin{array}{r}\text { Otu008 } \\
409\end{array}$ & $\begin{array}{l}\text { Proteob } \\
\text { acteria }\end{array}$ & $\begin{array}{l}\text { Betaproteob } \\
\text { acteria }\end{array}$ & $\begin{array}{l}\text { Burkholde } \\
\text { riales }\end{array}$ & $\begin{array}{l}\text { Burkholder } \\
\text { iaceae }\end{array}$ & \multicolumn{2}{|c|}{ Burkholderia } & 0.00000 \\
\hline $\begin{array}{r}\text { Otu009 } \\
814\end{array}$ & $\begin{array}{l}\text { Proteob } \\
\text { acteria }\end{array}$ & $\begin{array}{l}\text { Gammaprot } \\
\text { eobacteria }\end{array}$ & $\begin{array}{l}\text { Pseudomo } \\
\text { nadales }\end{array}$ & $\begin{array}{l}\text { Pseudomon } \\
\text { adaceae }\end{array}$ & \multicolumn{2}{|c|}{ Pseudomonas } & 0.00000 \\
\hline $\begin{array}{r}\text { Otu010 } \\
816\end{array}$ & $\begin{array}{l}\text { Proteob } \\
\text { acteria }\end{array}$ & $\begin{array}{l}\text { Betaproteob } \\
\text { acteria }\end{array}$ & $\begin{array}{l}\text { Burkholde } \\
\text { riales }\end{array}$ & $\begin{array}{l}\text { Oxalobacte } \\
\text { raceae }\end{array}$ & & & 0.00000 \\
\hline $\begin{array}{r}\text { Otu012 } \\
375\end{array}$ & $\begin{array}{l}\text { Proteob } \\
\text { acteria }\end{array}$ & $\begin{array}{l}\text { Alphaproteo } \\
\text { bacteria }\end{array}$ & $\begin{array}{l}\text { Rhizobiale } \\
\text { s }\end{array}$ & $\begin{array}{l}\text { Phyllobacte } \\
\text { riaceae }\end{array}$ & \multicolumn{2}{|c|}{ Mesorhizobium } & 0.00000 \\
\hline $\begin{array}{r}\text { Otu014 } \\
999\end{array}$ & $\begin{array}{l}\text { Proteob } \\
\text { acteria }\end{array}$ & $\begin{array}{l}\text { Betaproteob } \\
\text { acteria }\end{array}$ & $\begin{array}{l}\text { Burkholde } \\
\text { riales }\end{array}$ & $\begin{array}{l}\text { Comamona } \\
\text { daceae }\end{array}$ & & viridiflava & 0.00000 \\
\hline $\begin{array}{r}\text { Otu015 } \\
064\end{array}$ & $\begin{array}{l}\text { Proteob } \\
\text { acteria }\end{array}$ & $\begin{array}{l}\text { Gammaprot } \\
\text { eobacteria }\end{array}$ & $\begin{array}{l}\text { Pseudomo } \\
\text { nadales }\end{array}$ & $\begin{array}{l}\text { Pseudomon } \\
\text { adaceae }\end{array}$ & \multicolumn{2}{|c|}{ Pseudomonas } & 0.00000 \\
\hline $\begin{array}{r}\text { Otu015 } \\
154\end{array}$ & $\begin{array}{l}\text { Proteob } \\
\text { acteria }\end{array}$ & $\begin{array}{l}\text { Betaproteob } \\
\text { acteria }\end{array}$ & $\begin{array}{l}\text { Burkholde } \\
\text { riales }\end{array}$ & $\begin{array}{l}\text { Oxalobacte } \\
\text { raceae }\end{array}$ & $\begin{array}{l}\text { Janthinob } \\
\text { acterium }\end{array}$ & veronii & 0.00000 \\
\hline $\begin{array}{r}\text { Otu015 } \\
590\end{array}$ & $\begin{array}{l}\text { Proteob } \\
\text { acteria }\end{array}$ & $\begin{array}{l}\text { Gammaprot } \\
\text { eobacteria }\end{array}$ & $\begin{array}{l}\text { Pseudomo } \\
\text { nadales }\end{array}$ & $\begin{array}{l}\text { Pseudomon } \\
\text { adaceae }\end{array}$ & \multicolumn{2}{|c|}{ Pseudomonas } & 0.00000 \\
\hline $\begin{array}{r}\text { Otu016 } \\
359\end{array}$ & $\begin{array}{l}\text { Actinob } \\
\text { acteria }\end{array}$ & $\begin{array}{l}\text { Actinobacte } \\
\text { ria }\end{array}$ & $\begin{array}{l}\text { Propioniba } \\
\text { cteriales }\end{array}$ & $\begin{array}{l}\text { Propioniba } \\
\text { cteriaceae }\end{array}$ & \multicolumn{2}{|c|}{ Microlunatus } & 0.00000 \\
\hline $\begin{array}{r}\text { Otu016 } \\
709\end{array}$ & $\begin{array}{l}\text { Actinob } \\
\text { acteria }\end{array}$ & $\begin{array}{l}\text { Actinobacte } \\
\text { ria }\end{array}$ & $\begin{array}{l}\text { Actinomy } \\
\text { cetales }\end{array}$ & $\begin{array}{l}\text { Microbacte } \\
\text { riaceae }\end{array}$ & Cryocola & & 0.00000 \\
\hline $\begin{array}{r}\text { Otu017 } \\
060\end{array}$ & $\begin{array}{l}\text { Actinob } \\
\text { acteria }\end{array}$ & $\begin{array}{l}\text { Actinobacte } \\
\text { ria }\end{array}$ & $\begin{array}{l}\text { Corynebac } \\
\text { teriales }\end{array}$ & $\begin{array}{l}\text { Nocardiace } \\
\text { ae }\end{array}$ & \multicolumn{2}{|c|}{ Rhodococcus } & 0.00039 \\
\hline $\begin{array}{r}\text { Otu017 } \\
699 \\
\end{array}$ & $\begin{array}{l}\text { Proteob } \\
\text { acteria }\end{array}$ & $\begin{array}{l}\text { Betaproteob } \\
\text { acteria }\end{array}$ & $\begin{array}{l}\text { Burkholde } \\
\text { riales }\end{array}$ & $\begin{array}{l}\text { Oxalobacte } \\
\text { raceae }\end{array}$ & \multicolumn{2}{|c|}{ Janthinobacterium } & 0.00047 \\
\hline $\begin{array}{r}\text { Otu018 } \\
048 \\
\end{array}$ & $\begin{array}{l}\text { Actinob } \\
\text { acteria }\end{array}$ & $\begin{array}{l}\text { Actinobacte } \\
\text { ria }\end{array}$ & $\begin{array}{l}\text { Actinomy } \\
\text { cetales }\end{array}$ & $\begin{array}{l}\text { Microbacte } \\
\text { riaceae }\end{array}$ & \multicolumn{2}{|c|}{ Microbacterium } & 0.00000 \\
\hline $\begin{array}{r}\text { Otu021 } \\
922\end{array}$ & $\begin{array}{l}\text { Proteob } \\
\text { acteria }\end{array}$ & $\begin{array}{l}\text { Gammaprot } \\
\text { eobacteria }\end{array}$ & $\begin{array}{l}\text { Xanthomo } \\
\text { nadales }\end{array}$ & $\begin{array}{l}\text { Xanthomon } \\
\text { adaceae }\end{array}$ & \multicolumn{2}{|c|}{ Pseudoxanthomonas } & 0.00000 \\
\hline
\end{tabular}


Table S3: Results of pairwise Kolmogorov-Smirnov tests between the accumulation curves of growth events on the different media

\begin{tabular}{|c|c|c|c|c|c|c|}
\hline Medium & 0.01 TSA & 0.1 TSA & DNB & SA- & $\mathbf{S A}+$ & WYA \\
\hline 0.01 TSA & & $\begin{array}{l}\mathrm{D}=0.46 \\
\mathrm{p}=0.02 *\end{array}$ & $\begin{array}{l}\mathrm{D}=0.34 \\
\mathrm{p}=0.23\end{array}$ & $\begin{array}{l}\mathrm{D}=0.42 \\
\mathrm{p}=0.34\end{array}$ & $\begin{array}{l}D=0.26 \\
p=0.58\end{array}$ & $\begin{array}{l}\mathrm{D}=0.25 \\
\mathrm{p}=0.50\end{array}$ \\
\hline 0.1 TSA & & & $\begin{array}{l}\mathrm{D}=0.64 \\
\mathrm{p}<0.01 *\end{array}$ & $\begin{array}{l}\mathrm{D}=0.84 \\
\mathrm{p}<0.01 *\end{array}$ & $\begin{array}{l}\mathrm{D}=0.46 \\
\mathrm{p}=0.08\end{array}$ & $\begin{array}{l}\mathrm{D}=0.62 \\
\mathrm{p}<0.01 *\end{array}$ \\
\hline DNB & & & & $\begin{array}{l}D=0.62 \\
p=0.09\end{array}$ & $\begin{array}{l}D=0.23 \\
p=0.89\end{array}$ & $\begin{array}{l}\mathrm{D}=0.49 \\
\mathrm{p}=0.05\end{array}$ \\
\hline SA- & & & & & $\begin{array}{l}D=0.46 \\
p=0.35\end{array}$ & $\begin{array}{l}D=0.22 \\
p=0.98\end{array}$ \\
\hline SA+ & & & & & & $\begin{array}{l}\mathrm{D}=0.47 \\
\mathrm{p}=0.07\end{array}$ \\
\hline
\end{tabular}

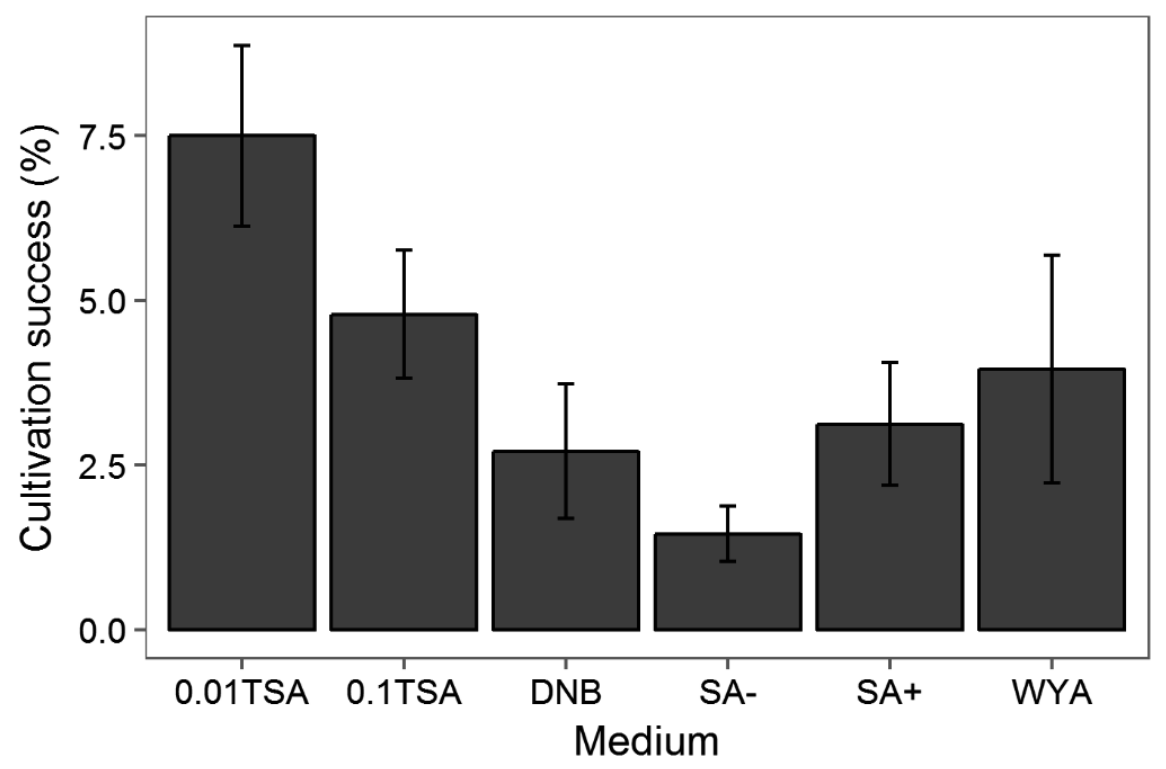

Fig. S1: Cultivation success (number of isolates relative to all 96 wells inoculated) on the different media; error bars represent the standard error $(n=5)$. 


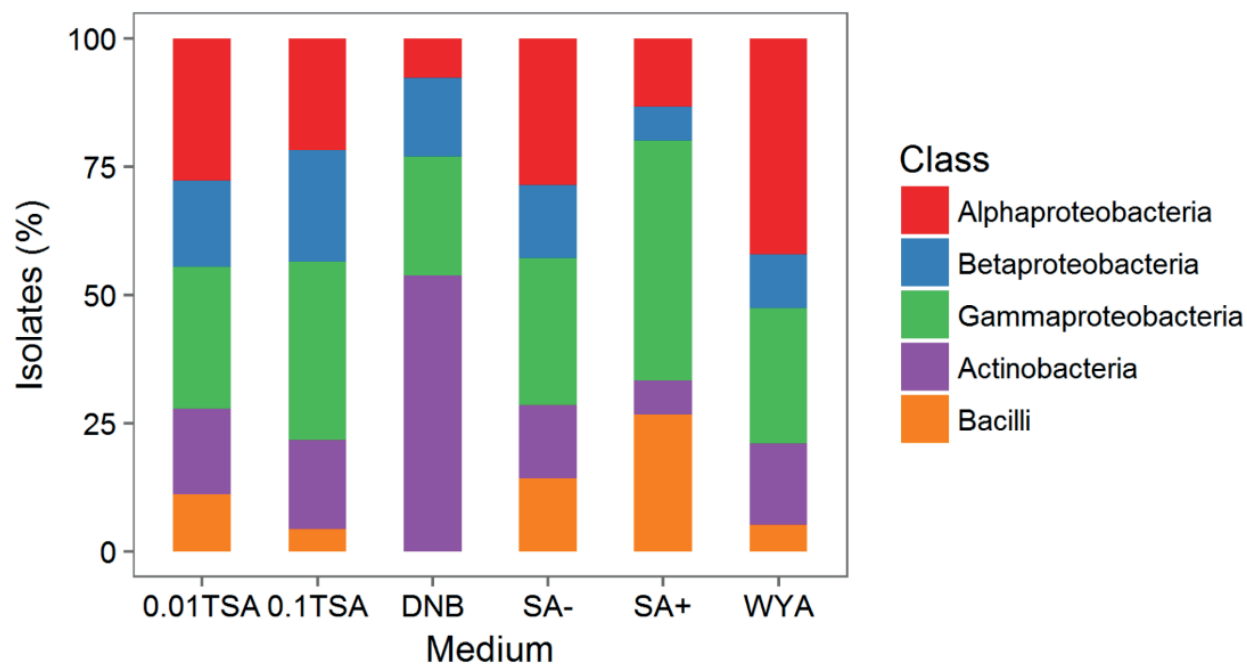

Fig. S2: Proportion of isolates belonging to the five different classes retrieved from the different media.

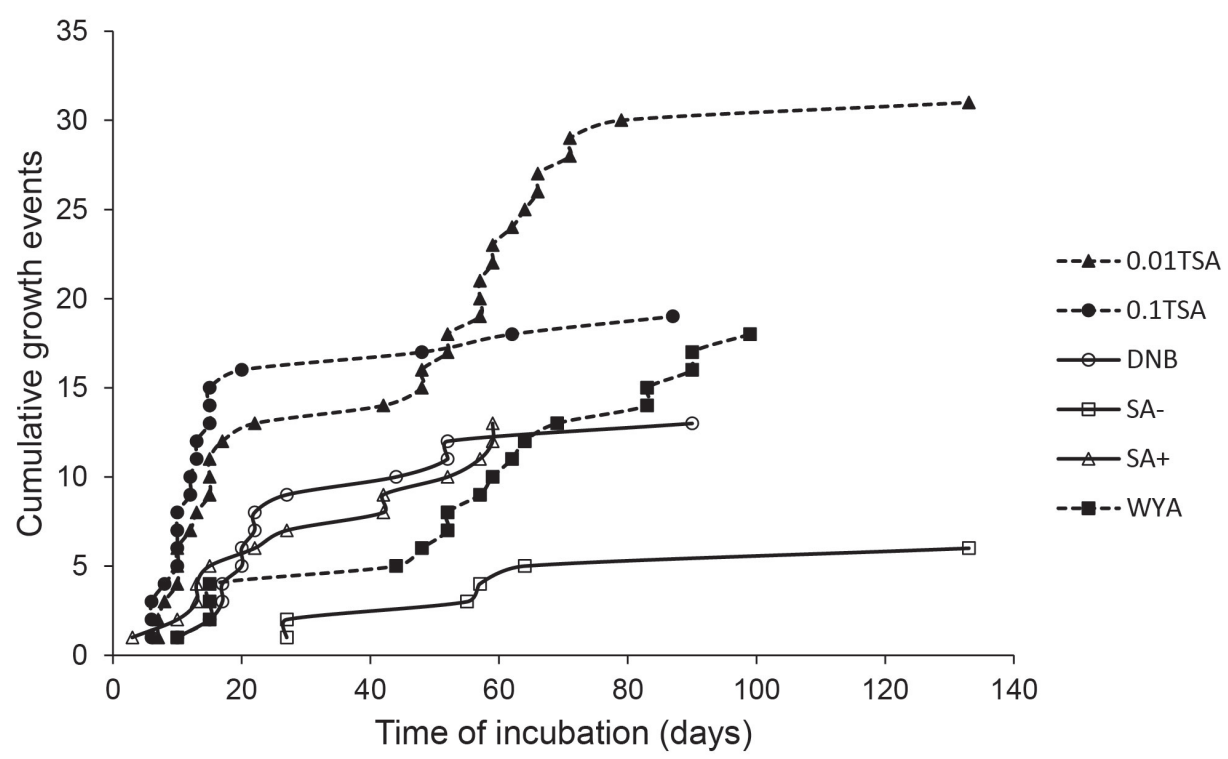

Fig. S3: Cumulative growth events over time on the different media; each symbol represents one growth-event. 


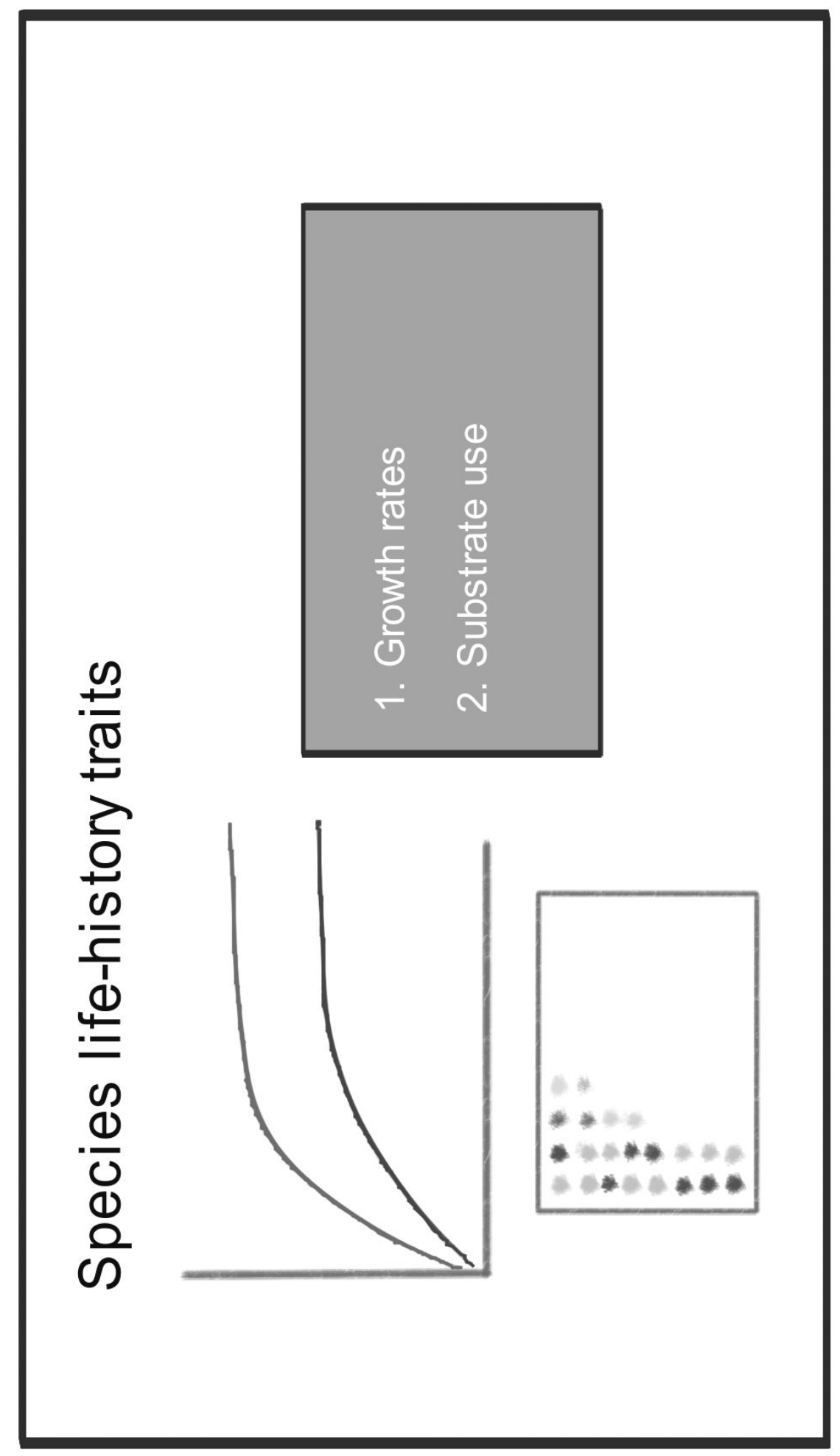




\section{Chapter 3}

\section{Low abundant soil bacteria can be metabolically versatile and fast growing}

Viola Kurm, Wim H. van der Putten, Wietse de Boer, Suzanne Naus-Wiezer \& W.H. Gera Hol

Ecology (2017), 98:555-564 


\begin{abstract}
The abundance of species is assumed to depend on their life history traits, such as growth rate and resource specialization. However, this assumption has not been tested for bacteria. Here we investigate how abundance of soil bacteria relates to slow growth and substrate specialization (oligotrophy) versus fast growth and substrate generalization (copiotrophy). We collected 47 saprotrophic soil bacterial isolates of differing abundances and measured their growth rate and the ability to use a variety of single carbon sources. Opposite to our expectation, there was no relationship between abundance in soil and the measured growth rate or substrate utilization profile (SUP). However, isolates with lower growth rates used fewer substrates than faster growing ones supporting the assumption that growth rate may relate to substrate specialization. Interestingly, growth rate and SUP were correlated with phylogeny, rather than with abundance in soil. Most markedly, Gammaproteobacteria on average grew significantly faster and were able to use more substrates than other bacterial classes, whereas Alphaproteobacteria were growing relatively slowly and used fewer substrates. This finding suggests that growth and substrate utilization are phylogenetically deeply conserved.

We conclude that growth rate and substrate utilization of soil bacteria are not general determinants of their abundance. Future studies on explaining bacterial abundance need to determine how other factors, such as competition, predation and abiotic factors may contribute to rarity or abundance in soil bacteria.
\end{abstract}

\title{
Introduction
}

Many communities contain a few abundant species, while most other species are low abundant, or even rare (Magurran and Henderson 2003), so that a general question in ecology is what causes rarity and abundance. However, this question has not yet been extensively addressed with respect to soil bacteria. Recent developments in sequencing technology reveal enormous numbers of belowground bacterial species with approximately $10^{4}-10^{6}$ different species, based on numbers of OTUs (operational taxonomic units), in one single gram of soil (Bent and Forney 2008). As a consequence of this high diversity the species abundance distribution of microorganisms in soil is even more skewed than of most other species in their habitat, resulting in a long tail of many low abundant species. Some of these species detected by sequencing might be inactive or relic DNA (Carini et al. 2016), but many were found to be actively contributing to community dynamics in space and time (Shade et al. 2014). This has been named the 'rare biosphere' (Sogin et al. 2006). Although there are many studies that provide indications on the functions of rare bacterial species, the causes of their low abundance are poorly investigated.

Species abundance can be driven by a variety of factors. The most fundamental are the local abiotic conditions and the biotic interactions that a species experiences. These act in concert with a species' inherent traits, for example growth rate or substrate utilization, the ability to 
tolerate abiotic conditions, and habitat range, which can be regarded as measures for niche breadth. Moreover, these factors can act interdependently to shape species abundance (Van der Putten et al. 2010). Here we study which inherent traits can potentially determine the abundance, and especially rarity, of bacterial taxa in soil. Rarity can be defined as either a restriction in habitat and geographic range (i.e. occurrence at few sites) or local abundance (i.e. species density at one site) (Rabinowitz 1981). In our study, we consider rarity as a synonym for a low local abundance.

Studies on macroscopic organisms suggest that rarity of species is often associated with low growth rate and/or low fecundity; this relationship has been found for plants (Murray et al. 2002), as well as for vertebrates such as mice and darter fish (Kunin and Gaston 2012). Also for bacteria it has been suggested that rare taxa are slow growing with small cell sizes, which enables escape from predation and viral lysis (Pedrós-Alió 2006). This reflects a life-history strategy of permanent rarity that has indeed been demonstrated for some taxa (Lynch and Neufeld 2015). However, there is also a high number of so-called conditionally rare taxa that can be either rare or abundant at different points in time and space, largely dependent on changes in abiotic conditions (Shade et al. 2014). In addition, bacterial species have been found that are actively growing, but still are rare, possibly due to disproportional competition or predation (Hugoni et al. 2013).

Also niche breadth is suggested to be positively correlated to both range size and local abundance, which we study here (Slatyer et al. 2013). In other words, regionally and locally rare species are supposed to be more likely to be specialists, albeit that highly specialized species can still be locally abundant if suitable conditions are met. Niche breadth for saprotrophic microorganisms has been commonly assessed by measuring the species' substrate utilization profile (SUP), differentiating between substrate specialists with a narrow SUP and generalists that have a wide SUP (Wei et al. 2015). Also for bacteria, generalist species may attain higher abundances, whereas specialists may be more rare (Wilson and Lindow 1994). A narrower range of substrate utilization and high overlap of SUP with other bacterial species are also possible causes of low abundance, since it can lead to increased competition (Wei et al. 2015). On the other hand, studies on decomposition have shown that at least some low abundant bacterial taxa are highly specialized in their substrate use (Pester et al. 2010) and have little niche overlap with more abundant species as their loss leads to a decrease in some aspects of decomposition (Peter et al. 2011, Philippot et al. 2013b).

Growth rate and substrate utilization are two important traits in the oligotrophic-copiotrophic concept (Koch 2001). According to this concept, copiotrophic bacteria exhibit high growth rates under nutrient-rich conditions, whereas oligotrophic bacteria have lower growth rates, but are able to sustain growth under nutrient-poor conditions. Thus, oligotrophs may be at disadvantage under nutrient-rich conditions, but are able to outcompete copiotrophs when 
the environment is nutrient-poor. In addition, copiotrophs are assumed to be able to adapt to a wide range of habitats and niches marking them as generalists (Koch 2001). Based on this, oligotrophic species are expected to be more specialized. This is further supported by the finding that oligotrophic species often have smaller genomes than copiotrophs (ChristieOleza et al. 2012). Moreover, fast growing copiotrophic bacteria have been proposed to contain more copies of the $16 \mathrm{~S}$ rRNA gene enabling them to more rapidly respond to enhanced resource availability (Roller et al. 2016). The exhibition of oligotrophic and copiotrophic traits could influence the abundance of bacteria in the natural environment and these traits might be conserved in certain classes or phyla (Fierer et al. 2007).

Oligotrophic bacteria are supposed to be slow growing and more specialized in their substrate use (Semenov 1991). Similarly, it is often assumed that low growth rates can lead to bacterial rarity (Pedrós-Alió 2006). However, it has not yet been tested to what extent restricted substrate use and slow growth determine bacterial abundance in soil. Here we investigate the relationship between two intrinsic species traits, growth rate and substrate utilization, and abundance of saprotrophic bacteria in soil to elucidate potential factors shaping microbial communities. We tested three hypotheses: 1) rare bacterial species have on average lower growth rates than abundant species, 2) rare bacterial species utilize fewer carbon-sources than abundant bacterial species, and 3) bacterial species with a lower growth rate are also utilizing fewer carbon-sources than fast growing species.

In order to test the three hypotheses, we isolated 47 saprotrophic (i.e. organotrophic and heterotrophic) bacterial strains from soil in an old field in The Netherlands and determined relative abundance in soil by blasting the isolate sequences against an OTU reference database generated from a pyrosequencing approach using the same soil. Growth rates were determined experimentally and all strains were exposed to 31 different substrates in order to test relationships between relative abundance, growth rate, the number of carbon-sources used, and the substrate utilization profile.

\section{Methods}

\section{Isolation of bacteria}

Soil samples for bacterial cultivation were taken from a long-term diversity experiment on ex-arable land near Ede (Gelderland, the Netherlands, $52^{\circ} 04^{\prime} \mathrm{N} 05^{\circ} 45^{\prime} \mathrm{E}$ ), in which the development of a variety of abiotic and biotic measurements is being followed since abandonment from agriculture in 1995 (Van der Putten et al. 2000). This site was selected because of the high amount of information available on the soil characteristics (Olsen $\mathrm{P}=90 \pm 3$ mg. $\mathrm{kg}^{-1}, \%$ orgC $=4.2 \pm 0.3, \mathrm{C}: \mathrm{N}=16.8 \pm 0.1$, Min-N=10.6 $\pm 0.8 \mathrm{mg} \cdot \mathrm{kg}^{-1}, \mathrm{pH}=6.2 \pm 0.1$ ) (van de Voorde et al. 2012). Bacteria were isolated by both flow sorting with a flow cytometer (MoFlo Legacy Cell Sorter; Beckman Coulter, Miami, FL, U.S.A) and dilution plating. Flow sorting was done to increase the chance of isolating rare taxa as those have been found to be 
overrepresented among the smaller cell size fractions (Portillo et al. 2013). Different approaches and media were chosen to enhance the chances of cultivating a broader range of bacterial species. Several oligotrophic media were used that have been shown to enable the cultivation of many previously uncultured microorganisms (Janssen et al. 2002, Joseph et al. 2003). For the flow sorting approach, the media used were tryptone soy agar at $1 / 10$ and a 1/100 dilution, water yeast agar, dilute nutrient broth solidified with gellan gum, and soil agar with or without addition of nutrients (for composition of media see Appendix: Table S1). The media were used to prepare 96-well agar plates and wetted with phosphate buffer before flow sorting. One day prior to flow sorting $5.4 \mathrm{~g}$ of sieved soil were added to $130 \mathrm{ml}$ phosphate

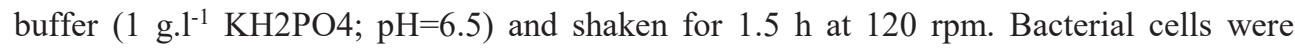
obtained from soil particles with sonication ( $2 \mathrm{x} 1 \mathrm{~min}$ ) followed by shaking for $0.5 \mathrm{~h}$ and passing the soil solution through a $45 \mu \mathrm{m}$ sieve. In addition, $130 \mathrm{ml}$ of phosphate buffer without soil added was subjected to the same treatment as a control. The soil solution and the control were stained with SYBR green stain (Sigma-Aldrich) at a concentration of 1:100 and stored at $4^{\circ} \mathrm{C}$ in the dark until flow sorting. Due to the high cell density in the soil samples they were diluted 1:10 with the phosphate buffer to a concentration suitable for counting.

The SYBR green stained particles in the samples were excited with a $488 \mathrm{~nm}$ laser beam. Fluorescence was measured at $580 \mathrm{~nm}$ and $530 \mathrm{~nm}$ as emitted by the SYBR green stain. Particles with low intensity fluorescence and a size of approxim ately $0.5 \mu \mathrm{m}$ were selected and sorted into single wells of the 96-well plates, each containing one of 6 different media with 5 plates per medium. The plates were incubated at $20^{\circ} \mathrm{C}$ and checked regularly for visible bacterial growth.

For dilution plating VL55 medium was used with the addition of $0.2 \mathrm{M}$ xylan instead of glucose (Appendix: Table S1). This composition has been found to be suitable for the isolation of a wide range of different soil bacterial taxa (Sait et al. 2002). In addition, soil agar was prepared according to the protocol for the soil extract with salts (SES) medium described by Smirnov and Brown (2004) (Appendix: Table S1). One gram fresh weight of sieved soil was dispersed in $100 \mathrm{ml}$ phosphate buffer and shaken for $1.5 \mathrm{~h}$. Sonication $(2 \mathrm{x} 1$ min) was followed by shaking for $0.5 \mathrm{~h}$. The soil solution was passed through a $45 \mu \mathrm{m}$ sieve. This $10^{-2}$ dilution was serially diluted in phosphate buffer up to $10^{-7}$. The $10^{-2}$ and $10^{-7}$ dilution were used to inoculate two plates each from both the VL55 and SES medium. One plate was inoculated with $100 \mu \mathrm{l}$ of inoculum, the other by dipping the inoculation loop into the soil solution using the streak plate method. One plate of each medium was inoculated with 200 $\mu l$ of the $10^{-7}$ dilution only using the spread plate method. The plates were checked for colony formation every other day. Colonies visible by eye were purified by subcultivation on the respective medium.

All cultures were repeatedly subcultivated on 1/10 diluted tryptone soy agar prior to the subsequent experiments. 


\section{Identification of bacterial cultures}

Colony-PCR was performed for amplification of the 16S rRNA gene. Colonies of pure isolates were picked from plates using sterile toothpicks and suspended in $25 \mu 1$ SDS-lysis buffer (1.21 g. $1^{-1}$ Tris, 0.372 g. $1^{-1}$ EDTA, 0.5\% SDS). The cells were lysed in a PCR thermocycler at $95^{\circ} \mathrm{C}$ for $5 \mathrm{~min}$ and $1 \mu \mathrm{l}$ of the suspension was used as a template for PCR. From those isolates recalcitrant to this method, DNA was extracted using either the ZR fungal/bacterial DNA MiniPrep kit (Zymo Research, Irvine, U.S.A.), the Power soil DNA isolation kit (MO BIO laboratories, Carlsbad, U.S.A.) or the QIAmp DNA Mini kit (Qiagen, Venlo, The Netherlands) and $1 \mu \mathrm{l}$ DNA was used as a template in the PCR. 16S rDNA fragments were amplified using the primers pA (5'-AGAGTTTGATCCTGGCTCAG-3') and 1492r (5'-GRTACCTTGTTACGACTT-3'). Reaction mixes of $25 \mu$ l were prepared containing $2.5 \mathrm{x}$ PCR buffer, $200 \mu \mathrm{M}$ of each deoxynucleoside triphosphate, $0.6 \mu \mathrm{M}$ of each primer and $0.04 \mu \mathrm{M}$ FastStart High Fidelity Polymerase (Roche, Basel, Switzerland). Amplification was carried out in a PCR C100 Touch Thermocycler (Bio-Rad Laboratories, Hercules, U.S.A.) using the following schedule: initial 2 min of denaturation at $94^{\circ} \mathrm{C}$ followed by 35 cycles of denaturation at $94^{\circ} \mathrm{C}$ for $30 \mathrm{~s}$, annealing at $55^{\circ} \mathrm{C}$ for $1 \mathrm{~min}$ and extension at $72^{\circ} \mathrm{C}$ for $45 \mathrm{~s}$. PCR products were sent for Sanger sequencing by Macrogen (Amsterdam, The Netherlands) or Baseclear (Leiden, The Netherlands) using the primer $515 \mathrm{f}$ (5'-GTGCCAGCMGCCGCGGTAA-3').

Sequence quality trimming was done on $\mathrm{ABI}$ format chromatograms using the program Phred (Green and Ewing 2002) with a phred quality value P of 0.00317 as trim cut-off. The trimmed sequences were blasted against the greengenes and the SILVA database using the SINA alignment service for phylogenetic affiliation (Pruesse et al. 2012). Sequences were deposited in Genbank under the accession numbers KX503324-KX503369 with the exception of VK47, which had an insufficient sequence-length.

\section{Estimation of relative abundance in field soil}

In order to estimate the relative abundance of the isolated strains in the field, their partial $16 \mathrm{~S}$ rRNA gene sequences were compared to a sequence database containing 267189 sequences from 7 soil replicate samples. The replicates originate from the same soil used for bacterial cultivation. Samples were collected in February 2013 at $10 \mathrm{~cm}$ depth at a minimum distance of $30 \mathrm{~cm}$. Sequences were obtained by pyrosequencing and grouped into 7086 reference OTUs at a $97 \%$ identity cut-off by de novo clustering (Kurm 2016). The de novo clustering method has the advantage that it is independent of a reference database and therefore does not discriminate against less well described lineages (Westcott and Schloss 2015). DNA extraction, sequencing and bioinformatics were done as described earlier (Hol et al. 2015a). We are aware of the semi-quantitative nature of pyrosequencing data, but it has been shown that proportional abundances can be approximated which allows separation into rare or abundant taxa (Pilloni et al. 2012). 
The trimmed Sanger sequences were blasted against the OTU reference table generated from the respective database using NCBI blastn. The strains were matched to the OTU with percentage identity above a cut-off of $97 \%$. The strain was subsequently matched to the closest related OTU. The mean relative abundance of sequences grouped into the respective reference OTU was consequentially taken as the relative abundance of the strain in soil. Several OTUs were not detected in the 7 pyrosequencing replicates used for comparison in this study, but were detected in other samples from the respective study, in which different disturbance treatments were applied to the soil indicating that they were present but under detection level in the undisturbed soil. Therefore, their relative abundance is designated as 0 . Two strains, VK8 and VK14, could not be reliably assigned to an OTU and therefore were excluded from the data analysis on relative abundance.

\section{Growth rate measurement}

Precultures of isolates were prepared in liquid ${ }_{0.1}$ TSB ( 3 g. $^{-1}$ tryptone soy broth) on 96-well microplates (Greiner flat-bottom) and incubated for $48 \mathrm{~h}$ at $25^{\circ} \mathrm{C}$ on a flatbed shaker in order to achieve a similar growth stage for all isolates. For the final culture the precultures were inoculated at a concentration of 1:10 into both fresh ${ }_{0.1}$ TSB (i.e. low nutrient medium) and full strength TSB (30 g. $\mathrm{l}^{-1}$ tryptone soy broth) (i.e. high nutrient medium) on a new microplate. Plates were placed immediately in a Synergy HT microplate reader (Biotek, Winooski, U.S.A.). The optical density at $600 \mathrm{~nm}$ (OD600) was automatically recorded every 30 min over a time period of maximal $60 \mathrm{~h}$ with continuous shaking between the measurements and normalized against an uninoculated blank medium measured simultaneously on the same plate. At least 5 independent measurements were performed for each strain. For isolate VK11, VK13, VK18, VK 20, VK21 and VK 38 1-2 replicates had to be omitted from statistical analysis due to difficulties in obtaining accurate measurements. Growth models were fitted and growth rates were calculated using the function gcFit from the package grofit in R (Kahm et al. 2010).

\section{Substrate utilization profiling}

The substrate utilization profile was assessed by the same principle as in Biolog microplates (Biolog, Inc., Hayward, USA). Microplates (96-well Greiner flat-bottom) contained a freshly prepared minimal OS medium (Schnider-Keel et al. 2000) with $0.2 \%$ Iodonitrotetrazoliumchloride (INT) as a redox dye and 31 different substrates as a sole carbon source at a concentration of $10 \mathrm{mM}$ ( 6 amino acids, 7 carbohydrates, 11 carboxylic acids, 1 phenolic acid, 4 polymeres and 2 miscellaneous) (Appendix: Table S2) together with one water control, fitting 3 assays per plate. The compounds were chosen to resemble substrates present in root exudates (Campbell et al. 1997). The availability of these substrates in the soil at the site of the isolates' origin is, however, unknown. 
Precultures in liquid ${ }_{0.1}$ TSB were washed 3 times in phosphate buffer and adjusted to an OD600 of 0.5 . Subsequently, $20 \mu \mathrm{l}$ of bacterial suspension were inoculated into $130 \mu \mathrm{l}$ of m edium resulting in a total volum e of $150 \mu \mathrm{l}$ per well. Strains were inoculated in duplicate on two different plates. The experiment was repeated 3 times for each strain, resulting in an $\mathrm{n}$ of 6. Optical density at $590 \mathrm{~nm}$ was measured in a microplate reader immediately after inoculation and subsequently once per day over a time period of 7 days. In between, plates were incubated at $25^{\circ} \mathrm{C}$ on a flatbed shaker.

\section{Data analysis}

All statistical calculations were done in R version 3.2.3 (R Core Team 2016).

The mean growth rate in TSB and 0.1TSB and the difference between the two means was calculated for each strain. The relationship between relative abundance in soil and mean growth rate was tested with a Spearman rank correlation test. To test for differences in phylogeny at class level between rare and abundant isolates a one-way Anova and Tukey Posthoc test were used. To determine the substrate utilization profile on microplates the slope of color development for each compound was calculated and the color development of the respective control well was subtracted. The compound was considered to be utilized by the inoculated bacterium if the resulting value exceeded a threshold of 0.001 . In a matrix of compounds and replicates of strains tested, utilization was given the value 1 , non-utilization was given a 0 . This matrix was used subsequently to calculate the average number of carbon sources used by each strain. Spearman rank correlation tests were performed for number of carbon sources used, relative abundance, and growth rate. To detect potential patterns in the substrate utilization profiles the substrate utilization matrix was analysed by principal component analysis using the function prcomp(). Effects of relative abundance, growth rate and phylogeny of class level on the matrix were determined by permutational multivariate analysis using the function adonis() from the vegan package (Oksanen et al. 2016). A binary metric of carbon-source utilization was implemented with the function nestednodf(). Two isolates (VK13, VK20) had to be excluded from the substrate utilization analysis due to insufficient growth in precultures and sensitivity to EDTA respectively.

The number of copies of 16S rRNA genes of the isolated species were estimated by aligning their sequences to a sequence database provided by Větrovský and Baldrian (2013) containing 7,081 16S rRNA gene sequences. The average 16S rRNA gene copy number from all members of the genera they were most closely related with (provided in the same article) was calculated to achieve the best estimate of copy number for the isolated species. Correlations between rRNA gene copy number, genome size, growth rate and number of carbon sources used were performed as described above. One-way Anovas and a subsequent Tukey Posthoc tests were used to test for differences in average growth rate, relative abundance, carbon source use and rRNA gene copy numbers between classes of bacterial isolates. 


\section{Results}

Isolation of bacteria

Isolation by flow sorting and dilution plating yielded 160 isolates in total, which represented 47 different OTUs. One representative isolate per OTU was used for all further analyses. For complete phylogeny see Supplementary Material (Appendix: Table S3). All isolates belonged to the classes Actinobacteria, Bacilli, Gammaproteobacteria, Betaproteobacteria and Alphaproteobacteria. All five classes included isolates of both rare and abundant taxa (Fig. 1). There were no significant differences in mean relative abundance of isolates among classes. It was not possible to statistically compare relative abundances among families, because most families were represented by only one or two isolates.

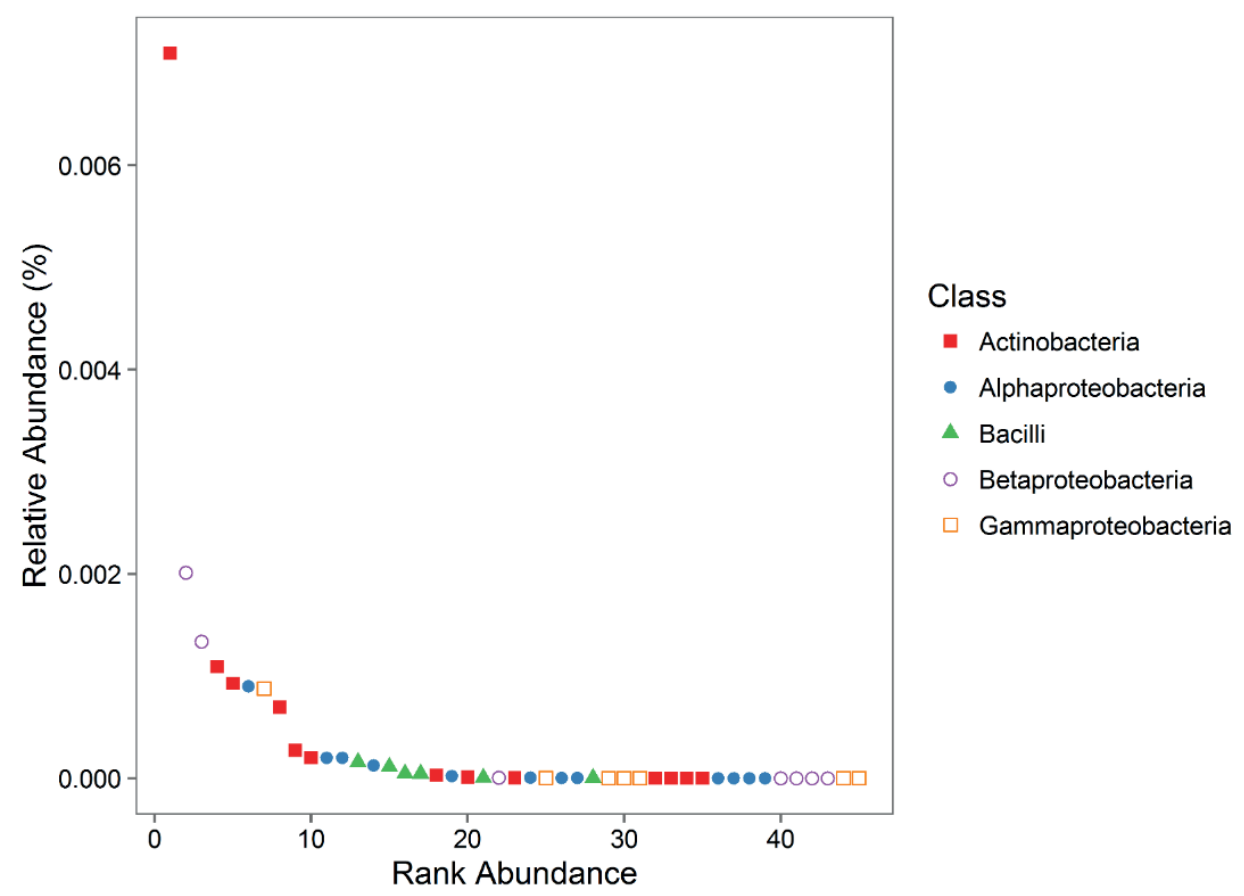

Figure 1: Relative abundance of isolates plotted against rank abundance; different colours and symbols indicate different phylogenetic classes.

\section{Relationship between growth rates and relative abundance}

Strains grew on average faster in the high nutrient medium than in the low nutrient medium ( $\mathrm{p}$-value $<0.01, \mathrm{~F} 1.0=65.5$ ). The growth rates varied considerably among strains, especially in the high nutrient medium, differing with a factor of 30 between the fastest and slowest growing isolate. Variability of measurements was highly strain-specific: several strains were highly variable, whereas others were less so (Appendix: Table S4). Over all, there was no 
significant correlation between growth rate and the relative abundance in soil, neither in low nutrient ( $\mathrm{p}$-value $=0.43$, rho=-0.12, data not shown), nor in high nutrient media ( $\mathrm{p}$-value $=$ 0.64 , rho=-0.07; Fig. 2).

Growth rates differed significantly between classes $(\mathrm{p}<0.01, \mathrm{~F} 4.0=10.1)$. In nutrient-rich medium Gammaproteobacteria had on average a 1.5x higher growth rate than Actinobacteria and an almost 4x higher growth rate than Alphaproteobacteria, whereas Bacilli had a $3 \mathrm{x}$ higher growth rate and Betaproteobacteria a $2.7 \mathrm{x}$ higher growth rate than Alphaproteobacteria (Appendix: Table S5). In the lower-nutrient medium, however, only Gammaproteobacteria were still faster growing than the other classes except for Betaproteobacteria $(\mathrm{p}<0.01, \mathrm{~F} 4.0=6.7)$. Classes with a higher growth rate in TSB also had a higher number of rRNA gene copies $(\mathrm{p}<0.01, \mathrm{~F} 4.0=10.78)$; Gammaproteobacteria had a significantly higher number of copies than Alphaproteobacteria and Betaproteobacteria, whereas Bacilli had more rRNA gene copies than members of all other classes except for the Gammproteobacteria where the difference was only marginally significant. Accordingly, there was a positive correlation between growth rates and the number of rRNA gene copies of the isolates $(\mathrm{p}<0.01$, $\mathrm{rho}=0.48$ and $\mathrm{p}=0.01$, $\mathrm{rho}=0.36$ in low and high nutrient medium respectively) (Appendix: Table $\mathrm{S} 4$ ).

As the distinct differences in growth rates between classes might have obscured a potential relationship between growth rate and relative abundance we tested for such a relationship within each class. However, also within each single class there was no correlation between relative abundance and growth rate. 


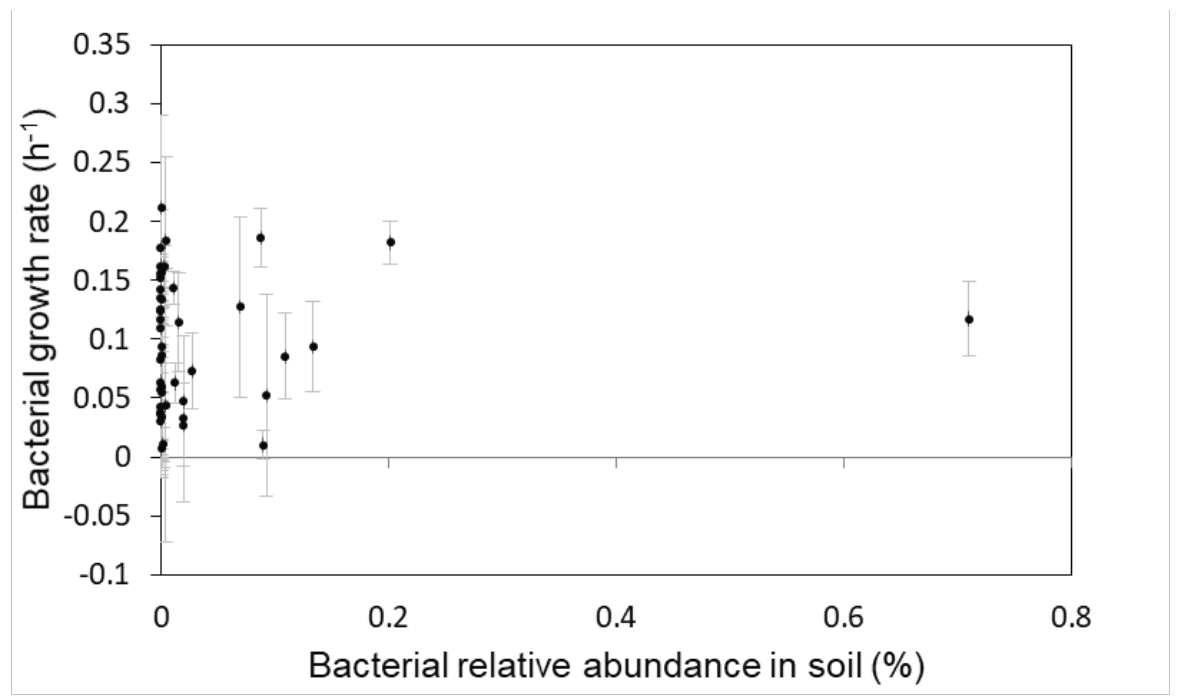

Figure 2: Average bacterial growth rates in high nutrient medium of single isolates $\left(\mathrm{OD}_{600}\right.$ change $\left.\mathrm{h}^{-1}\right)$ plotted against their relative abundances (\%) in soil ( $\left.\mathrm{n}=45\right)$; each dot represents a single isolate; the error bars indicate standard deviation. 
A

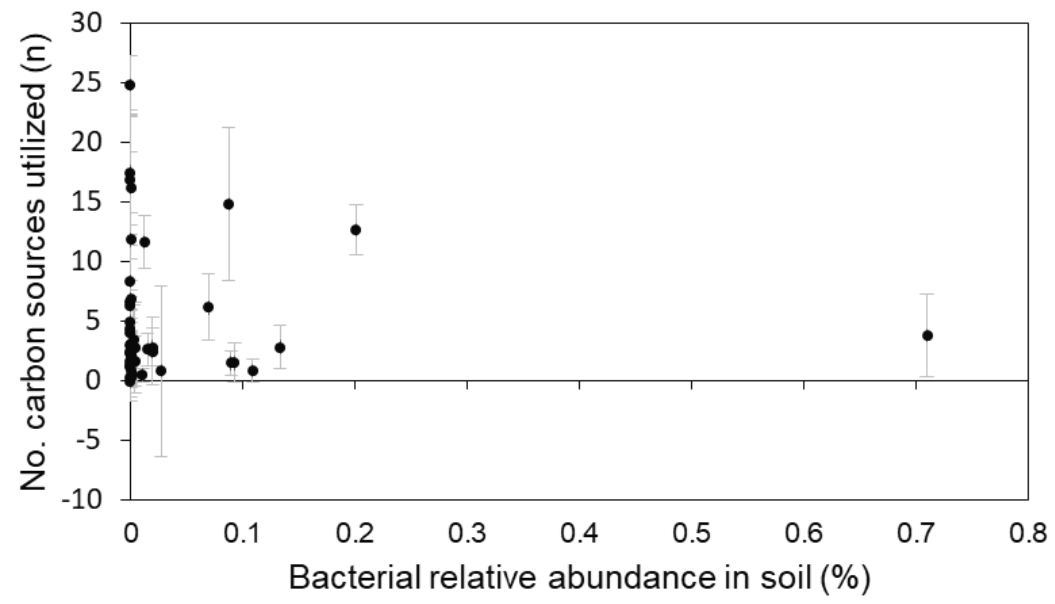

B

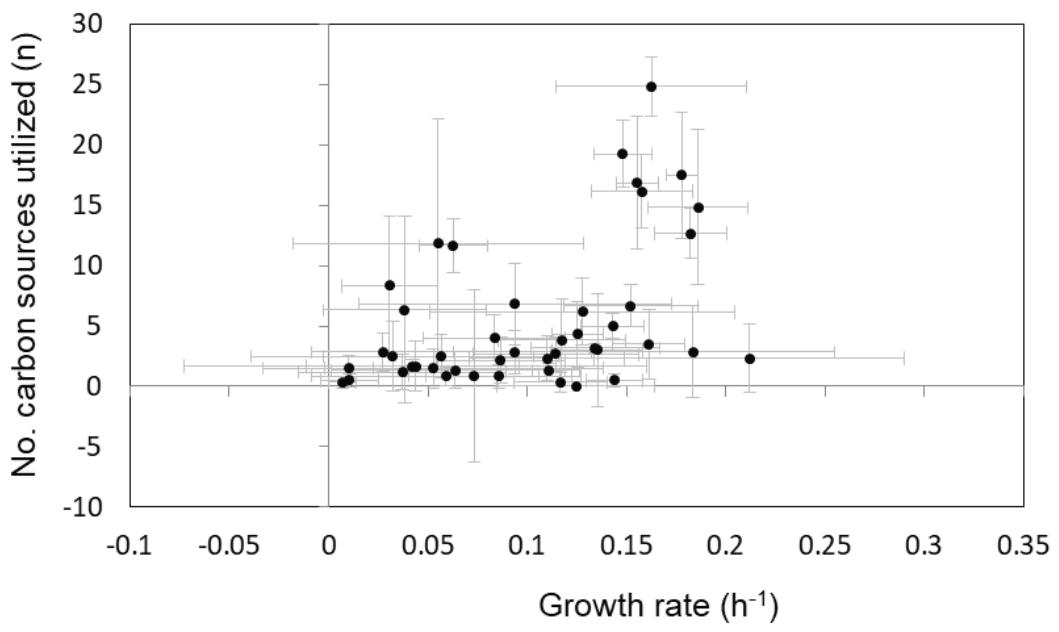

Figure 3: The average number of carbon sources utilized by bacterial isolates plotted against A) their relative abundance in soil $(\%)(n=43)$ and B) average bacterial growth rate in high nutrient medium $\left(\mathrm{h}^{-1}\right)(\mathrm{n}=45)$; dots represent single isolates; the error bars indicate standard deviation.

Substrate utilization profile (SUP)

The number of used carbon sources showed a significant positive association with growth rate in both media $(\mathrm{p}<0.01$, rho $=0.63$ and $\mathrm{p}<0.01$, rho $=0.47$ for low and high nutrient media respectively) (Fig. 3b) and with the difference between growth in low and high nutrient medium $(\mathrm{p}<0.01, \mathrm{rho}=0.43)$. Gammaproteobacteria, which were growing fastest on average, 
were able to utilize a higher number of carbon sources than strains belonging to the other classes $(p<0.01, F 4.0=8.73)$. However, we did not detect a relationship between number of carbon sources utilized and relative abundance in soil (Fig. 3a).

Along the first axis of the PCA the SUPs of the isolates separated out into two groups (Figure 4). The substrates that contributed to this separation belonged to a variety of different compound classes, i.e. carbohydrates, carboxylic acids, amino acids as well as polymeric compounds. There was a significant association between growth rate and SUP (Fmodel $=3.83, \mathrm{R}^{2}=0.08, \mathrm{p}<0.01 ; \mathrm{F}$-model $=2.37, \mathrm{R}^{2}=0.05, \mathrm{p}=0.02$ in both media respectively). SUPs of strains belonging to different classes were significantly different from each other (Fmodel: $\left.1.79, \mathrm{R}^{2}=0.16, \mathrm{p}<0.01\right)$. On the other hand, relative abundance in soil did not correlate with the SUP.

A binary matrix of utilization of every carbon source by every isolate showed that niche overlap was relatively high as every compound could be used by at least 6 isolates. Isolates that utilized only few substrates often used substrates that were also utilized by many other isolates (Appendix: Fig. S1).

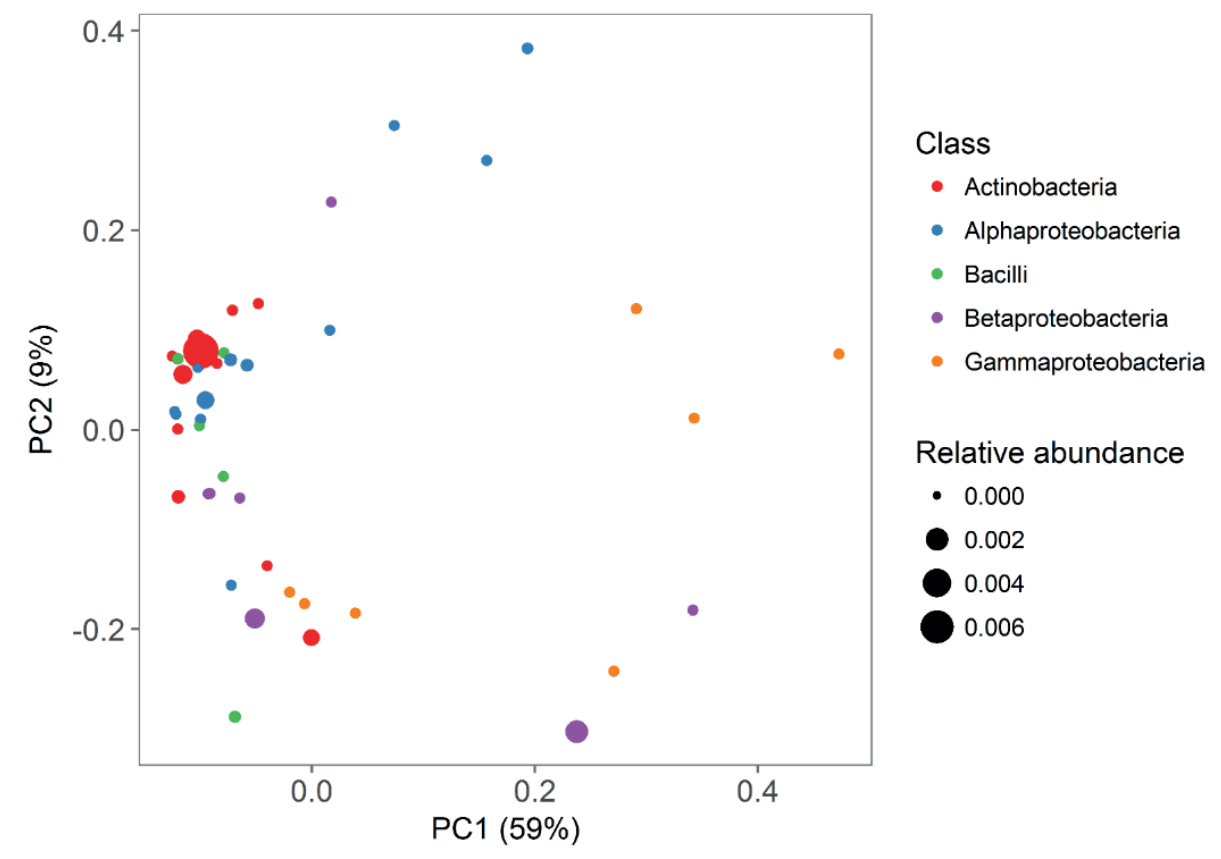

Figure 4: PCA of carbon source utilization of all bacterial strains, dots represent single isolates. Colors represent different bacterial classes; the size of the dots represents relative abundance in soil on a continuous scale; proportion of variance explained expressed as percentages on the axes. 


\section{Discussion}

The aim of this study was to elucidate if growth rate and substrate utilization can explain the abundance of saprotrophic bacteria in soil. Growth rate was positively related to the number of substrates a species could use. This indicates that the isolates were distributed along a gradient from oligotrophic to copiotrophic species. Moreover, growth rate and substrate utilization differed with species phylogeny. We did not find relative abundance in soil to be linked to slow growth or restricted substrate use that would have indicated an oligotrophic lifestyle of low abundant species. On the contrary, there was a high variation of these traits among the isolates irrespective of their abundance.

Consequentially we had to reject our first hypothesis because there was no significant difference in growth rate between rare and abundant strains. Most rare species had potential growth rates as high as or even higher than abundant species. This is supported by the observation that many rare taxa are in fact highly active (Campbell et al. 2011). Some can become abundant upon change of environmental conditions, others are permanently rare in spite of their activity (Hugoni et al. 2013). For a few of the isolated strains, however, their low abundance in soil corresponded with a low growth rate. (Pedrós-Alió 2006) suggests that these slow growing strains can persist at low abundances because they are less vulnerable to predation since they have a small cell size and are less likely to be encountered. Interestingly, differences in growth rate between classes diminished with decreased nutrient concentration. This indicates that in even more nutrient-poor environments, such as soil, species identified as slow growers in this study might attain the same as, or even higher growth rates than their counterparts with the higher in vitro growth rates.

Secondly, we tested the hypothesis that rare bacterial species are able to utilize fewer carbonsources than more abundant species. This hypothesis was rejected, because the number of substrates used was unrelated to relative abundance. Moreover, substrate utilization showed high overlap between isolates. In other words, there was an overlap in metabolic niche. This was unexpected, because organisms with a narrow niche breadth usually are less abundant than organisms with a wider niche (Tilman 2004, Wamelink et al. 2014). For example, epiphytic bacterial species that use more substrates had higher competitive advantage when co-inoculated (Wilson and Lindow 1994). A similar pattern emerges from invasion experiments; invasion success decreased when the invading strain had large niche overlap in substrate utilization with the resident community (Wei et al. 2015). Therefore, species utilizing few substrates that are also used by many other species are expected to be less abundant in their natural environment than species with a more general substrate uptake capacity. However, in the present study niche overlap could have been overestimated, because many substrates used in the SUP assay are easily degradable. 
Strains that grew faster were able to utilize a higher number of substrates. Moreover, strains that diverged more in their growth in low and high nutrient medium utilized more substrates than strains showing a less pronounced decrease in growth rate under low nutrient conditions. This is in support of our third hypothesis and the oligotrophy-copiotrophy concept as copiotrophs respond more strongly to elevated nutrient conditions and are more generalistic in their resource use. In fact, we report for the first time a direct relationship between growth rate in a defined medium and the number of substrates that bacterial isolates utilize in an in vitro SUP analysis. Prior studies, on the other hand, have shown the ability of fast growing copiotrophs to quickly respond to labile C-sources. In an in situ study a relationship between the capability for fast growth and the rapid utilization of easily available carbon-sources was shown in highly diverse communities (Goldfarb et al. 2011). Fast growing bacterial taxa respond quickly to addition of labile substrates, whereas slow growing taxa declined in relative abundance upon substrate addition. Although slow growing organisms also might utilize many labile substrates, they are supposed to be less competitive under the employed conditions. Yet, we show that slow growing bacteria are restricted in their substrate use, even when growing in monoculture. Oligotrophic species not only appear to be less competitive with regard to their response to resource availability, as indicated by Goldfarb et al. (2011), but they also lack the ability to utilize as many substrates as copiotrophs in the first place.

We found a trend for a positive relationship between rRNA gene copy number and growth rate, as has also been recently reported by Roller et al. (2016). It is assumed that a high number of rRNA gene copies can enable a fast synthesis of ribosomes and a rapid response of the bacterium to increases in nutrient concentrations (Stevenson and Schmidt 2004). To a certain degree the number of rRNA gene copies is phylogenetically conserved (Lee et al. 2009). Indeed, our results show that differences in growth rate and substrate utilization correspond to differences in phylogeny. Also the substrate utilization profile differed significantly between phylogenetic classes. For a long time, it has been assumed that even closely related bacterial taxa differ substantially in their traits (Jaspers and Overmann 2004). While it may depend on the specific traits, only recently an in situ approach using stable isotope probing showed deeply rooted phylogenetic similarities in microbial activities (Morrissey et al. 2016). In the study by Morrissey et al. (2016) growth and rate of carbon assimilation from glucose were clustered at the phylum level. Alphaproteobacteria were on average more oligotrophic, whereas Beta- and Gammaproteobacteria showed rather copiotrophic traits. This is similar to our results, where Alphaproteobacteria are mostly slow growing and use only few substrates while Gammaproteobacteria grow fast and have a generalistic substrate use. Therefore, we demonstrate that even with in vitro substrate utilization tests of single isolates differences between broad taxonomic groups can be measured. 
The lack of a relationship between relative abundance and growth rate or substrate use raises the question if the isolates and the general approach used in the present study sufficiently represent conditions in the soil. We were able to cultivate approximately $5 \%$ of the bacteria that were collected with the flow sorting approach, which is within the range of frequently reported cultivation efficiencies of bacteria collected from soil (Janssen et al. 2002, Puspita et al. 2012). A large proportion of the isolates are potentially low abundant in the environment. Still, soil hosts many more rare taxa that have not been included in our study. However, we already find considerable variation in growth rate and substrate use within our selection of isolates. The addition of more taxa would most likely have increased the variation. On the other hand, several candidate phyla have been found to contain mostly rare species (Lynch et al. 2012), which indicates that within these phyla shared traits contribute to their low abundance. Other potential limitations must be kept in mind as well, for example species-specific growth rates in other cultivation media or soil might differ from the rates recorded in the present study. Nevertheless, additional experiments with a subset of 10 of our isolates in Luria-Bertani (LB)-medium showed a high correlation between growth rates in the different media (Appendix S1: Fig. S2) indicating that our results are similar across media types. An advantage in the choice of TSB as a growth medium is that it shares no compounds with the SUP assay, so that the results from the two measurements are independent. In addition, we use relatively high nutrient concentrations to assess growth rates. Similar concentrations are likely to occur in the vicinity of plant roots, whereas bulk soil is rather nutrient poor. As mentioned above this might change the rank order of species growth rates.

Laboratory conditions are often criticized to poorly resemble the natural environment. However, isolation allows to perform measurements on individual bacterial strains that are to date not possible to perform in situ. Especially for low abundant strains isolation-based methods are irreplaceable to study traits of specific species. However, it is notoriously difficult to determine the abundance of a cultured strain in the environment due to the high diversity in soil and phylogenetic identification by short $16 \mathrm{~S}$ rRNA sequences. It has even been shown that $16 \mathrm{~S}$ rRNA is often insufficient to distinguish ecologically different strains (Jaspers and Overmann 2004). Although the relative abundance reported in our study might not represent the exact abundance in soil, it is an approximation allowing us to investigate trends in the relationship of abundance with intrinsic bacterial traits.

Over all, our results indicate that the abundance of bacterial species in soil are not solely determined by their growth rate. We also show that a narrow metabolic niche breadth and high overlap in substrate utilization among species do not necessarily lead to low relative abundance. Metabolic niche breadth is only one component of a species' total niche breadth and other dimensions of a niche, such as habitat range and environmental tolerance might be better correlated with species abundance (Slatyer et al. 2013). We showed a separation of bacterial isolates into more oligotrophic or more copiotrophic species, but these two lifestyles 
were not related to relative abundance in soil. It is likely that other factors differentially affect bacterial abundance. Apart from abiotic conditions, such as soil $\mathrm{pH}$, temperature or salinity, competitive ability and vulnerability to predation or viral lysis can affect abundance in soil (Neuenschwander et al. 2015, Kirchman 2016). A competitively inferior strain can be low abundant in spite of its ability to grow fast. Similarly, fast growing species could be strongly controlled by protozoan predators or viruses (Simek et al. 1997). As a consequence, there might be considerable temporal and spatial variation in species abundance (Caporaso et al. 2012). However, testing these possibilities requires further studies.

\section{Conclusions}

We conclude that bacterial growth rate is positively correlated to the number of carbon sources that it can use. This indicates that species are distributed along a gradient from oligotrophic to copiotrophic lifestyles. However, we did not find a relationship between relative abundance in soil and growth rate, or substrate use. On the contrary, rare bacterial species showed high variation in these traits. Therefore, we conclude that abundance in soil cannot be explained by growth rate and substrate use alone.

\section{Acknowledgements}

We thank Tianjie Yang from Utrecht University for her kind advice on assessment of bacterial substrate utilization. Moreover, we thank Rienke Ruijs, Nico Helmsing and Max Ballhausen for assistance during the setup and conduction of experiments. This is publication 6200 of NIOO-KNAW. 


\section{Supplementary Information}

Table S1: Composition of media used for bacterial isolation and cultivation success for flowsorting in percentage of isolates per number of inoculated wells.

\begin{tabular}{|c|c|c|}
\hline Name of medium & Composition & $\begin{array}{l}\text { Cultivation } \\
\text { success }(\%)\end{array}$ \\
\hline $\begin{array}{l}0.1 \text { Tryptone soy broth } \\
\text { agar (TSA) }\end{array}$ & $\begin{array}{l}3 \mathrm{~g} \mathrm{l}^{-1} \text { tryptone soy broth, } 15 \mathrm{~g} \mathrm{l}^{-1} \text { bacto } \\
\text { agar }\end{array}$ & 6.7 \\
\hline $\begin{array}{l}\text { 0.01 Tryptone soy broth } \\
\text { agar (TSA) }\end{array}$ & $\begin{array}{l}0.3 \mathrm{~g} \mathrm{l}^{-1} \text { tryptone soy broth, } 15 \mathrm{~g} \mathrm{l}^{-1} \text { bacto } \\
\text { agar }\end{array}$ & 9.1 \\
\hline Water yeast agar (WYA) & $\begin{array}{l}5 \mathrm{~g} \mathrm{l}^{-1} \mathrm{NaCl}, 0.05 \mathrm{~g} \mathrm{l}^{-1} \text { yeast extract, } 20 \mathrm{~g} \\
\mathrm{l}^{-1} \text { bacto agar }\end{array}$ & 6.5 \\
\hline $\begin{array}{l}\text { Dilute nutrient broth agar } \\
\text { (DNB) }\end{array}$ & $\begin{array}{l}0.03 \mathrm{~g} \mathrm{l}^{-1} \text { meat extract, } 0.05 \mathrm{~g} \mathrm{l}^{-1} \text { peptone, } \\
8 \mathrm{~g} \mathrm{l}^{-1} \text { gellan gum, } 1.26 \mathrm{mmol} \mathrm{CaCl}_{2}\end{array}$ & 4.2 \\
\hline Soil agar + nutrients & $\begin{array}{l}\text { Supernatant of soil suspended in phosphate } \\
\text { buffer (64 g } l^{-1} \quad \mathrm{KH}_{2} \mathrm{PO}_{4}, 36 \mathrm{~g} \mathrm{l}^{-1} \\
\left.\mathrm{Na}_{2} \mathrm{HPO}_{4}\right), 20 \mathrm{~g} \mathrm{l}^{-1} \text { bacto agar, } 0.03 \mathrm{~g} \mathrm{l}^{-1} \\
\text { meat extract, } 0.05 \mathrm{~g} \mathrm{l}^{-1} \text { peptone }\end{array}$ & 5.4 \\
\hline Soil agar - nutrients & $\begin{array}{l}\text { Supernatant of soil suspended in phosphate } \\
\text { buffer (64 } \quad \mathrm{g} \quad \mathrm{l}^{-1} \quad \mathrm{KH}_{2} \mathrm{PO}_{4}, \quad 36 \quad \mathrm{~g} \quad \mathrm{l}^{-1} \\
\left.\mathrm{Na}_{2} \mathrm{HPO}_{4}\right), 20 \mathrm{~g} \mathrm{l}^{-1} \text { bacto agar }\end{array}$ & 3.5 \\
\hline VL55+ xylan & $\begin{array}{l}\text { ATCC } ® \quad \text { medium } 2734 \text { protocol } \\
\text { (http://www.lgcstandards-atcc.org) }+0.2 \\
\text { M xylan instead of glucose }\end{array}$ & $*$ \\
\hline SES agar & $\begin{array}{l}100 \mathrm{ml} \text { supernatant of soil in tap water, } \\
0.02 \mathrm{~g} \mathrm{l}^{-1} \mathrm{KH}_{2} \mathrm{PO}_{4}, 0.02 \mathrm{~g} \mathrm{l}^{-1} \mathrm{MgSO}_{4} \mathrm{X} \\
7 \mathrm{H}_{2} \mathrm{O}, 0.02 \mathrm{~g} \mathrm{l}^{-1} \mathrm{KNO}_{3}, 15 \mathrm{~g} \mathrm{l}^{-1} \text { bacto agar }\end{array}$ & * \\
\hline
\end{tabular}

* These media were used for isolation by dilution and not in combination with flow sorting; therefore, no data on cultivation success is available 
Table S2: Sole carbon sources used for substrate use profiling; numbers behind compounds refer to Figure S1.

Carbohydrates

Mannitol (9)
N-acetylglucosamine (5)
D-cellobiose (22)
M-inositol (30)
Xylose (13)

Erythritol (24)

Lactose (29)

\section{Carboxylic acids}

Glutamic acid (11)

Pyruvic acid (8)

Lactic acid (10)

Propionic acid (31)

Gluconic acid lactone (17)

Galacturonic acid (3) Glutamine (26)

4-hydroxy benzoic acid (25)

Formic acid (14)

Succinic acid (1)

$\alpha$-ketoglutaric acid (2)

Malic acid (12)

\section{Amino acids}

\section{Glycine (15)}

Arginine (23)

Asparagine (20)

Phenylalanine (16)

Serine (18)

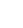


Table S3: Phylogeny of isolates used in this study.

\begin{tabular}{|c|c|c|c|c|c|c|}
\hline ID & phylum & class & order & family & genus & species \\
\hline VK1 & $\begin{array}{l}\text { Actinobact } \\
\text { eria }\end{array}$ & $\begin{array}{l}\text { Actinobact } \\
\text { eria }\end{array}$ & $\begin{array}{l}\text { Actinomyc } \\
\text { etales }\end{array}$ & $\begin{array}{l}\text { Intrasporan } \\
\text { giaceae }\end{array}$ & $\begin{array}{l}\text { Terracoccu } \\
s\end{array}$ & \\
\hline VK2 & $\begin{array}{l}\text { Actinobact } \\
\text { eria }\end{array}$ & $\begin{array}{l}\text { Actinobact } \\
\text { eria }\end{array}$ & $\begin{array}{l}\text { Corynebact } \\
\text { eriales }\end{array}$ & $\begin{array}{l}\text { Nocardiace } \\
\text { ae }\end{array}$ & $\begin{array}{l}\text { Rhodococc } \\
\text { us }\end{array}$ & \\
\hline VK3 & $\begin{array}{l}\text { Proteobact } \\
\text { eria }\end{array}$ & $\begin{array}{l}\text { Alphaprote } \\
\text { obacteria }\end{array}$ & $\begin{array}{l}\text { Rhizobiale } \\
\text { s }\end{array}$ & $\begin{array}{l}\text { Bradyrhizo } \\
\text { biaceae }\end{array}$ & $\begin{array}{l}\text { Bradyrhizo } \\
\text { bium }\end{array}$ & \\
\hline VK4 & $\begin{array}{l}\text { Proteobact } \\
\text { eria }\end{array}$ & $\begin{array}{l}\text { Betaproteo } \\
\text { bacteria }\end{array}$ & $\begin{array}{l}\text { Burkholder } \\
\text { iales }\end{array}$ & $\begin{array}{l}\text { Comamona } \\
\text { daceae }\end{array}$ & & \\
\hline VK5 & $\begin{array}{l}\text { Proteobact } \\
\text { eria }\end{array}$ & $\begin{array}{l}\text { Gammapro } \\
\text { teobacteria }\end{array}$ & $\begin{array}{l}\text { Pseudomo } \\
\text { nadales }\end{array}$ & $\begin{array}{l}\text { Pseudomo } \\
\text { nadaceae }\end{array}$ & $\begin{array}{l}\text { Pseudomo } \\
\text { nas }\end{array}$ & viridiflava \\
\hline VK6 & $\begin{array}{l}\text { Proteobact } \\
\text { eria }\end{array}$ & $\begin{array}{l}\text { Gammapro } \\
\text { teobacteria }\end{array}$ & $\begin{array}{l}\text { Pseudomo } \\
\text { nadales }\end{array}$ & $\begin{array}{l}\text { Pseudomo } \\
\text { nadaceae }\end{array}$ & $\begin{array}{l}\text { Pseudomo } \\
\text { nas }\end{array}$ & \\
\hline VK7 & $\begin{array}{l}\text { Proteobact } \\
\text { eria }\end{array}$ & $\begin{array}{l}\text { Gammapro } \\
\text { teobacteria }\end{array}$ & $\begin{array}{l}\text { Pseudomo } \\
\text { nadales }\end{array}$ & $\begin{array}{l}\text { Pseudomo } \\
\text { nadaceae }\end{array}$ & $\begin{array}{l}\text { Pseudomo } \\
\text { nas }\end{array}$ & \\
\hline VK8 & $\begin{array}{l}\text { Proteobact } \\
\text { eria }\end{array}$ & $\begin{array}{l}\text { Gammapro } \\
\text { teobacteria }\end{array}$ & $\begin{array}{l}\text { Pseudomo } \\
\text { nadales }\end{array}$ & $\begin{array}{l}\text { Pseudomo } \\
\text { nadaceae }\end{array}$ & $\begin{array}{l}\text { Pseudomo } \\
\text { nas }\end{array}$ & \\
\hline VK9 & $\begin{array}{l}\text { Proteobact } \\
\text { eria }\end{array}$ & $\begin{array}{l}\text { Gammapro } \\
\text { teobacteria }\end{array}$ & $\begin{array}{l}\text { Xanthomo } \\
\text { nadales }\end{array}$ & $\begin{array}{l}\text { Xanthomo } \\
\text { nadaceae }\end{array}$ & $\begin{array}{l}\text { Pseudoxan } \\
\text { thomonas }\end{array}$ & \\
\hline VK10 & $\begin{array}{l}\text { Actinobact } \\
\text { eria }\end{array}$ & $\begin{array}{l}\text { Actinobact } \\
\text { eria }\end{array}$ & $\begin{array}{l}\text { Actinomyc } \\
\text { etales }\end{array}$ & $\begin{array}{l}\text { Microbacte } \\
\text { riaceae }\end{array}$ & Cryocola & \\
\hline VK11 & $\begin{array}{l}\text { Actinobact } \\
\text { eria }\end{array}$ & $\begin{array}{l}\text { Actinobact } \\
\text { eria }\end{array}$ & $\begin{array}{l}\text { Actinomyc } \\
\text { etales }\end{array}$ & $\begin{array}{l}\text { Microbacte } \\
\text { riaceae }\end{array}$ & $\begin{array}{l}\text { Curtobacte } \\
\text { rium }\end{array}$ & \\
\hline VK12 & $\begin{array}{l}\text { Actinobact } \\
\text { eria }\end{array}$ & $\begin{array}{l}\text { Actinobact } \\
\text { eria }\end{array}$ & $\begin{array}{l}\text { Actinomyc } \\
\text { etales }\end{array}$ & $\begin{array}{l}\text { Microbacte } \\
\text { riaceae }\end{array}$ & $\begin{array}{l}\text { Microbacte } \\
\text { rium }\end{array}$ & \\
\hline VK13 & $\begin{array}{l}\text { Actinobact } \\
\text { eria }\end{array}$ & $\begin{array}{l}\text { Actinobact } \\
\text { eria }\end{array}$ & $\begin{array}{l}\text { Actinomyc } \\
\text { etales }\end{array}$ & $\begin{array}{l}\text { Microbacte } \\
\text { riaceae }\end{array}$ & $\begin{array}{l}\text { Microbacte } \\
\text { rium }\end{array}$ & \\
\hline VK14 & $\begin{array}{l}\text { Actinobact } \\
\text { eria }\end{array}$ & $\begin{array}{l}\text { Actinobact } \\
\text { eria }\end{array}$ & $\begin{array}{l}\text { Actinomyc } \\
\text { etales }\end{array}$ & $\begin{array}{l}\text { Micrococc } \\
\text { aceae }\end{array}$ & $\begin{array}{l}\text { Arthrobact } \\
\text { er }\end{array}$ & $\begin{array}{l}\text { psychrolac } \\
\text { tophilus }\end{array}$ \\
\hline VK15 & $\begin{array}{l}\text { Actinobact } \\
\text { eria }\end{array}$ & $\begin{array}{l}\text { Actinobact } \\
\text { eria }\end{array}$ & $\begin{array}{l}\text { Actinomyc } \\
\text { etales }\end{array}$ & $\begin{array}{l}\text { Micrococc } \\
\text { aceae }\end{array}$ & $\begin{array}{l}\text { Arthrobact } \\
\text { er }\end{array}$ & \\
\hline VK16 & $\begin{array}{l}\text { Actinobact } \\
\text { eria }\end{array}$ & $\begin{array}{l}\text { Actinobact } \\
\text { eria }\end{array}$ & $\begin{array}{l}\text { Actinomyc } \\
\text { etales }\end{array}$ & $\begin{array}{l}\text { Nocardioid } \\
\text { aceae }\end{array}$ & & \\
\hline VK17 & $\begin{array}{l}\text { Actinobact } \\
\text { eria }\end{array}$ & $\begin{array}{l}\text { Actinobact } \\
\text { eria }\end{array}$ & $\begin{array}{l}\text { Actinomyc } \\
\text { etales }\end{array}$ & $\begin{array}{l}\text { Nocardioid } \\
\text { aceae }\end{array}$ & $\begin{array}{l}\text { Aeromicro } \\
\text { bium }\end{array}$ & \\
\hline VK18 & $\begin{array}{l}\text { Actinobact } \\
\text { eria }\end{array}$ & $\begin{array}{l}\text { Actinobact } \\
\text { eria }\end{array}$ & $\begin{array}{l}\text { Actinomyc } \\
\text { etales }\end{array}$ & $\begin{array}{l}\text { Nocardioid } \\
\text { aceae }\end{array}$ & & \\
\hline VK19 & $\begin{array}{l}\text { Actinobact } \\
\text { eria }\end{array}$ & $\begin{array}{l}\text { Actinobact } \\
\text { eria }\end{array}$ & $\begin{array}{l}\text { Actinomyc } \\
\text { etales }\end{array}$ & $\begin{array}{l}\text { Propioniba } \\
\text { cteriaceae }\end{array}$ & $\begin{array}{l}\text { Microlunat } \\
\text { us }\end{array}$ & \\
\hline VK20 & $\begin{array}{l}\text { Actinobact } \\
\text { eria }\end{array}$ & $\begin{array}{l}\text { Actinobact } \\
\text { eria }\end{array}$ & $\begin{array}{l}\text { Kineospori } \\
\text { ales }\end{array}$ & $\begin{array}{l}\text { Kineospori } \\
\text { aceae }\end{array}$ & $\begin{array}{l}\text { Angustibac } \\
\text { ter }\end{array}$ & \\
\hline VK21 & $\begin{array}{l}\text { Actinobact } \\
\text { eria }\end{array}$ & $\begin{array}{l}\text { Actinobact } \\
\text { eria }\end{array}$ & $\begin{array}{l}\text { Kineospori } \\
\text { ales }\end{array}$ & $\begin{array}{l}\text { Kineospori } \\
\text { aceae }\end{array}$ & $\begin{array}{l}\text { Quadrisph } \\
\text { aera }\end{array}$ & \\
\hline VK22 & Firmicutes & Bacilli & Bacillales & Bacillaceae & Bacillus & flexus \\
\hline VK23 & Firmicutes & Bacilli & Bacillales & $\begin{array}{l}\text { Paenibacill } \\
\text { aceae }\end{array}$ & $\begin{array}{l}\text { Paenibacill } \\
\text { us }\end{array}$ & $\begin{array}{l}\text { amylolytic } \\
\text { us }\end{array}$ \\
\hline VK24 & Firmicutes & Bacilli & Bacillales & $\begin{array}{l}\text { Paenibacill } \\
\text { aceae }\end{array}$ & $\begin{array}{l}\text { Paenibacill } \\
\text { us }\end{array}$ & \\
\hline
\end{tabular}




\begin{tabular}{|c|c|c|c|c|c|c|}
\hline VK25 & Firmicutes & Bacilli & Bacillales & $\begin{array}{l}\text { Staphyloco } \\
\text { ccaceae }\end{array}$ & $\begin{array}{l}\text { Staphyloco } \\
\text { ccus }\end{array}$ & \\
\hline VK26 & Firmicutes & Bacilli & Bacillales & $\begin{array}{l}\text { Staphyloco } \\
\text { ccaceae }\end{array}$ & $\begin{array}{l}\text { Staphyloco } \\
\text { ccus }\end{array}$ & \\
\hline VK27 & Firmicutes & Bacilli & $\begin{array}{l}\text { Lactobacill } \\
\text { ales }\end{array}$ & $\begin{array}{l}\text { Carnobacte } \\
\text { riaceae }\end{array}$ & $\begin{array}{l}\text { Carnobact } \\
\text { erium }\end{array}$ & \\
\hline VK28 & $\begin{array}{l}\text { Proteobact } \\
\text { eria }\end{array}$ & $\begin{array}{l}\text { Alphaprote } \\
\text { obacteria }\end{array}$ & $\begin{array}{l}\text { Caulobacte } \\
\text { rales }\end{array}$ & $\begin{array}{l}\text { Caulobacte } \\
\text { raceae }\end{array}$ & $\begin{array}{l}\text { Phenyloba } \\
\text { cterium }\end{array}$ & \\
\hline VK29 & $\begin{array}{l}\text { Proteobact } \\
\text { eria }\end{array}$ & $\begin{array}{l}\text { Alphaprote } \\
\text { obacteria }\end{array}$ & $\begin{array}{l}\text { Rhizobiale } \\
\text { s }\end{array}$ & $\begin{array}{l}\text { Bradyrhizo } \\
\text { biaceae }\end{array}$ & $\begin{array}{l}\text { Bradyrhizo } \\
\text { bium }\end{array}$ & \\
\hline VK30 & $\begin{array}{l}\text { Proteobact } \\
\text { eria }\end{array}$ & $\begin{array}{l}\text { Alphaprote } \\
\text { obacteria }\end{array}$ & $\begin{array}{l}\text { Rhizobiale } \\
\text { s }\end{array}$ & $\begin{array}{l}\text { Bradyrhizo } \\
\text { biaceae }\end{array}$ & $\begin{array}{l}\text { Rhodopseu } \\
\text { domonas }\end{array}$ & \\
\hline VK31 & $\begin{array}{l}\text { Proteobact } \\
\text { eria }\end{array}$ & $\begin{array}{l}\text { Alphaprote } \\
\text { obacteria }\end{array}$ & $\begin{array}{l}\text { Rhizobiale } \\
\mathrm{S}\end{array}$ & $\begin{array}{l}\text { Methyloba } \\
\text { cteriaceae }\end{array}$ & $\begin{array}{l}\text { Methyloba } \\
\text { cterium }\end{array}$ & \\
\hline VK32 & $\begin{array}{l}\text { Proteobact } \\
\text { eria }\end{array}$ & $\begin{array}{l}\text { Alphaprote } \\
\text { obacteria }\end{array}$ & $\begin{array}{l}\text { Rhizobiale } \\
\text { S }\end{array}$ & $\begin{array}{l}\text { Phyllobact } \\
\text { eriaceae }\end{array}$ & & \\
\hline VK33 & $\begin{array}{l}\text { Proteobact } \\
\text { eria }\end{array}$ & $\begin{array}{l}\text { Alphaprote } \\
\text { obacteria }\end{array}$ & $\begin{array}{l}\text { Rhizobiale } \\
\text { S }\end{array}$ & $\begin{array}{l}\text { Phyllobact } \\
\text { eriaceae }\end{array}$ & & \\
\hline VK34 & $\begin{array}{l}\text { Proteobact } \\
\text { eria }\end{array}$ & $\begin{array}{l}\text { Alphaprote } \\
\text { obacteria }\end{array}$ & $\begin{array}{l}\text { Rhizobiale } \\
\mathrm{s}\end{array}$ & $\begin{array}{l}\text { Phyllobact } \\
\text { eriaceae }\end{array}$ & $\begin{array}{l}\text { Mesorhizo } \\
\text { bium }\end{array}$ & \\
\hline VK35 & $\begin{array}{l}\text { Proteobact } \\
\text { eria }\end{array}$ & $\begin{array}{l}\text { Alphaprote } \\
\text { obacteria }\end{array}$ & $\begin{array}{l}\text { Rhizobiale } \\
\text { s }\end{array}$ & $\begin{array}{l}\text { Xanthobact } \\
\text { eraceae }\end{array}$ & & \\
\hline VK36 & $\begin{array}{l}\text { Proteobact } \\
\text { eria }\end{array}$ & $\begin{array}{l}\text { Alphaprote } \\
\text { obacteria }\end{array}$ & $\begin{array}{l}\text { Sphingomo } \\
\text { nadales }\end{array}$ & $\begin{array}{l}\text { Sphingomo } \\
\text { nadaceae }\end{array}$ & $\begin{array}{l}\text { Sphingomo } \\
\text { nas }\end{array}$ & echinoides \\
\hline VK37 & $\begin{array}{l}\text { Proteobact } \\
\text { eria }\end{array}$ & $\begin{array}{l}\text { Alphaprote } \\
\text { obacteria }\end{array}$ & $\begin{array}{l}\text { Sphingomo } \\
\text { nadales }\end{array}$ & $\begin{array}{l}\text { Sphingomo } \\
\text { nadaceae }\end{array}$ & $\begin{array}{l}\text { Sphingomo } \\
\text { nas }\end{array}$ & \\
\hline VK38 & $\begin{array}{l}\text { Proteobact } \\
\text { eria }\end{array}$ & $\begin{array}{l}\text { Alphaprote } \\
\text { obacteria }\end{array}$ & $\begin{array}{l}\text { Sphingomo } \\
\text { nadales }\end{array}$ & $\begin{array}{l}\text { Sphingomo } \\
\text { nadaceae }\end{array}$ & $\begin{array}{l}\text { Sphingomo } \\
\text { nas }\end{array}$ & \\
\hline VK39 & $\begin{array}{l}\text { Proteobact } \\
\text { eria }\end{array}$ & $\begin{array}{l}\text { Betaproteo } \\
\text { bacteria }\end{array}$ & $\begin{array}{l}\text { Burkholder } \\
\text { iales }\end{array}$ & $\begin{array}{l}\text { Burkholder } \\
\text { iaceae }\end{array}$ & $\begin{array}{l}\text { Burkholder } \\
\text { ia }\end{array}$ & \\
\hline VK40 & $\begin{array}{l}\text { Proteobact } \\
\text { eria }\end{array}$ & $\begin{array}{l}\text { Betaproteo } \\
\text { bacteria }\end{array}$ & $\begin{array}{l}\text { Burkholder } \\
\text { iales }\end{array}$ & $\begin{array}{l}\text { Oxalobacte } \\
\text { raceae }\end{array}$ & $\begin{array}{l}\text { Janthinoba } \\
\text { cterium }\end{array}$ & \\
\hline VK41 & $\begin{array}{l}\text { Proteobact } \\
\text { eria }\end{array}$ & $\begin{array}{l}\text { Betaproteo } \\
\text { bacteria }\end{array}$ & $\begin{array}{l}\text { Burkholder } \\
\text { iales }\end{array}$ & $\begin{array}{l}\text { Oxalobacte } \\
\text { raceae }\end{array}$ & $\begin{array}{l}\text { Janthinoba } \\
\text { cterium }\end{array}$ & \\
\hline VK42 & $\begin{array}{l}\text { Proteobact } \\
\text { eria }\end{array}$ & $\begin{array}{l}\text { Betaproteo } \\
\text { bacteria }\end{array}$ & $\begin{array}{l}\text { Burkholder } \\
\text { iales }\end{array}$ & $\begin{array}{l}\text { Comamona } \\
\text { daceae }\end{array}$ & & \\
\hline VK43 & $\begin{array}{l}\text { Proteobact } \\
\text { eria }\end{array}$ & $\begin{array}{l}\text { Betaproteo } \\
\text { bacteria }\end{array}$ & $\begin{array}{l}\text { Burkholder } \\
\text { iales }\end{array}$ & $\begin{array}{l}\text { Oxalobacte } \\
\text { raceae }\end{array}$ & & \\
\hline VK44 & $\begin{array}{l}\text { Proteobact } \\
\text { eria }\end{array}$ & $\begin{array}{l}\text { Betaproteo } \\
\text { bacteria }\end{array}$ & $\begin{array}{l}\text { Burkholder } \\
\text { iales }\end{array}$ & $\begin{array}{l}\text { Oxalobacte } \\
\text { raceae }\end{array}$ & $\begin{array}{l}\text { Janthinoba } \\
\text { cterium }\end{array}$ & \\
\hline VK45 & $\begin{array}{l}\text { Proteobact } \\
\text { eria }\end{array}$ & $\begin{array}{l}\text { Gammapro } \\
\text { teobacteria }\end{array}$ & $\begin{array}{l}\text { Enterobact } \\
\text { eriales }\end{array}$ & $\begin{array}{l}\text { Enterobact } \\
\text { eriaceae }\end{array}$ & Pantoea & \\
\hline VK46 & $\begin{array}{l}\text { Proteobact } \\
\text { eria }\end{array}$ & $\begin{array}{l}\text { Gammapro } \\
\text { teobacteria }\end{array}$ & $\begin{array}{l}\text { Pseudomo } \\
\text { nadales }\end{array}$ & $\begin{array}{l}\text { Pseudomo } \\
\text { nadaceae }\end{array}$ & $\begin{array}{l}\text { Pseudomo } \\
\text { nas }\end{array}$ & veronii \\
\hline VK47 & $\begin{array}{l}\text { Proteobact } \\
\text { eria }\end{array}$ & $\begin{array}{l}\text { Gammapro } \\
\text { teobacteria }\end{array}$ & $\begin{array}{l}\text { Pseudomo } \\
\text { nadales }\end{array}$ & $\begin{array}{l}\text { Pseudomo } \\
\text { nadaceae }\end{array}$ & $\begin{array}{l}\text { Pseudomo } \\
\text { nas }\end{array}$ & viridiflava \\
\hline
\end{tabular}


Table S4: Average growth rate and standard deviation in high nutrient (TSB) and low nutrient medium (0.1TSB), relative abundance in soil, number of C-sources utilized and number of rRNA copies from Větrovský and Baldrian (2013) of isolates used in this study.

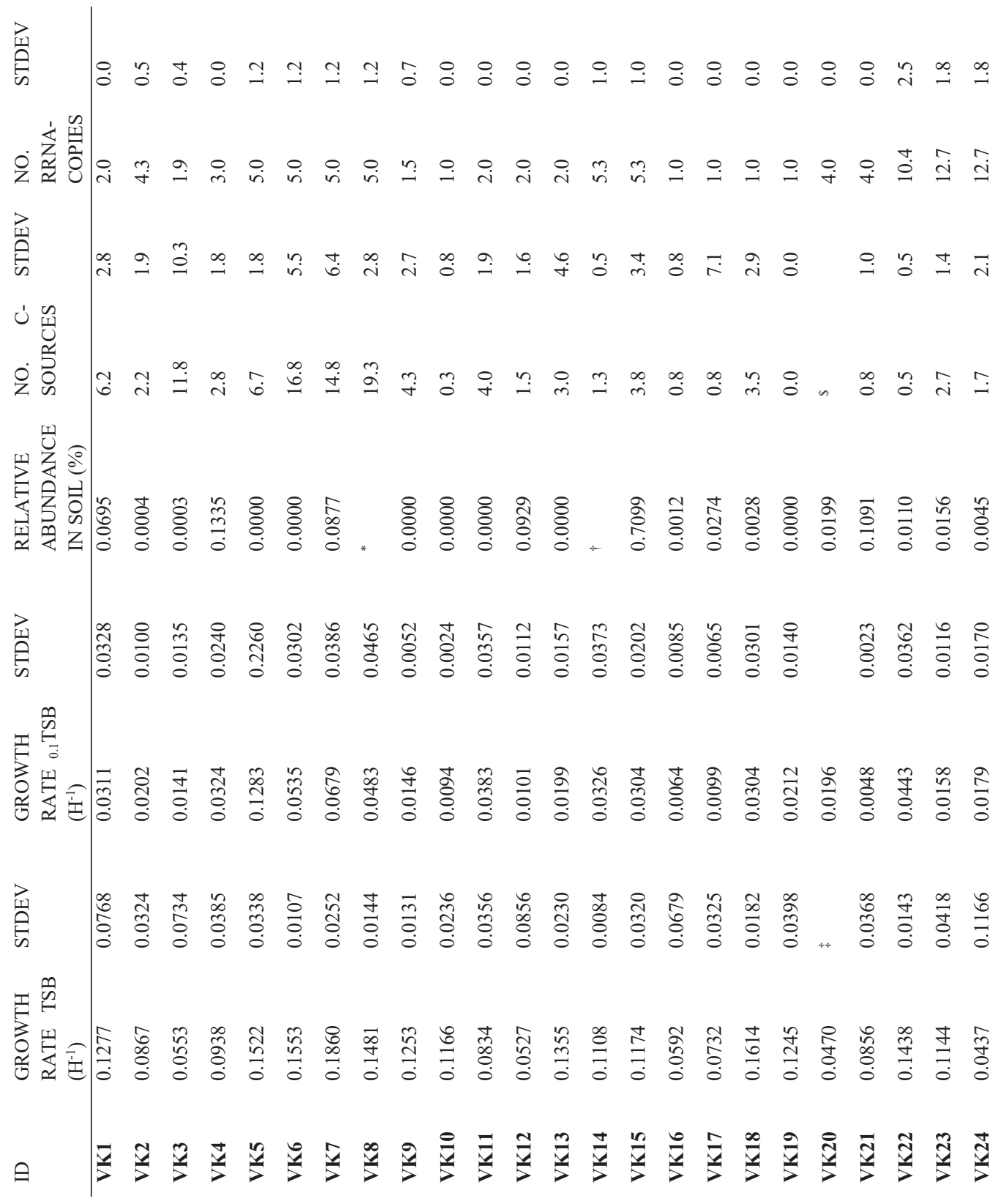




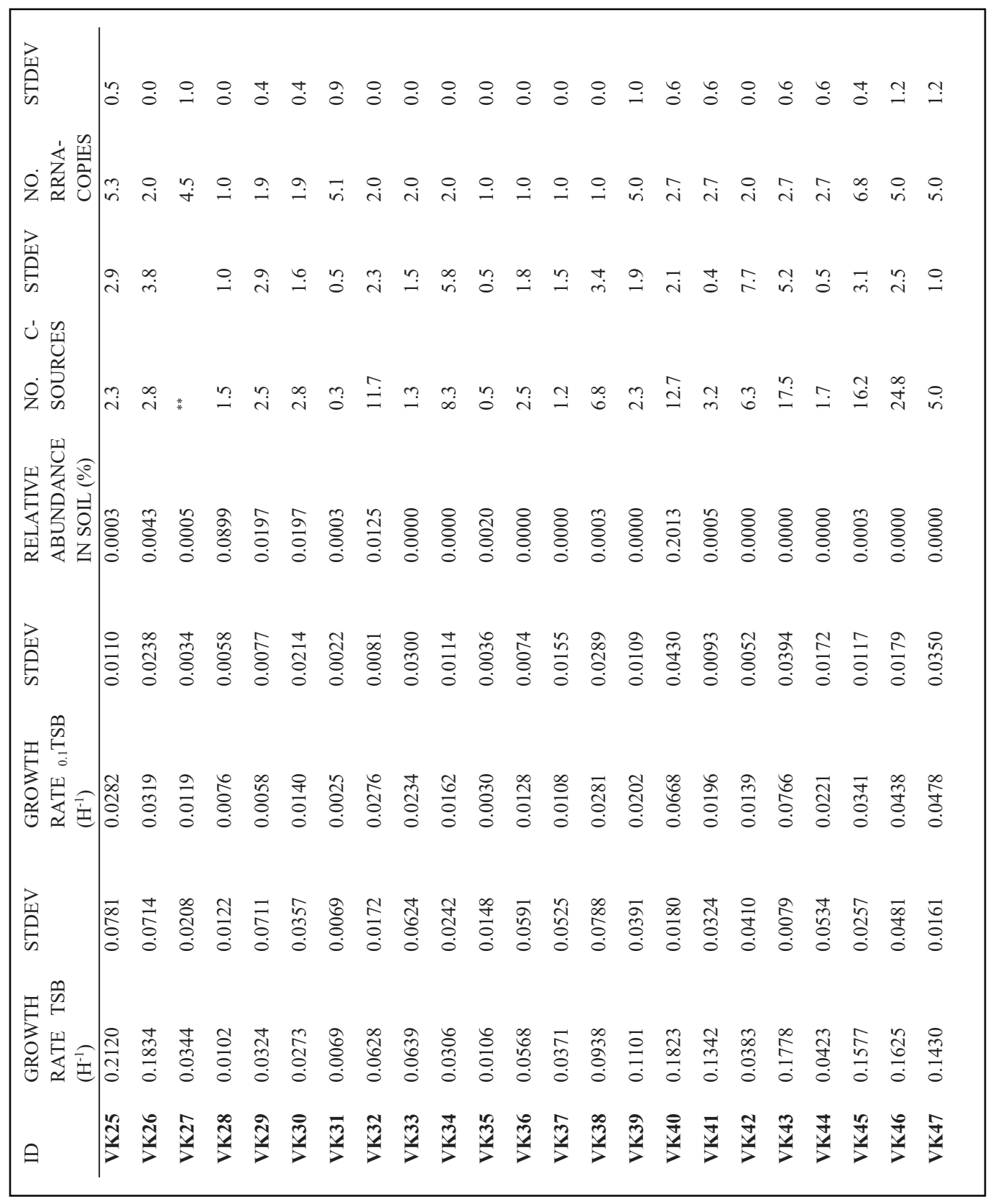

*Isolate sequence could not be reliably assigned to one OTU (see Material and methods) ${ }^{\dagger}$ Isolate sequence could not be reliably assigned to one OTU (see Material and methods) ${ }^{\ddagger}$ Growth rate measurement could not be replicated due to cell aggregate formation \$Substrate use could not be assessed due to insufficient growth in the preculture ${ }^{* *}$ Substrate use could not be assessed due to isolate sensitivity to EDTA 
Table S5: Growth rate (in TSB and $0.1 \mathrm{TSB}$ ) and rRNA copy number of the 5 distinct classes (averages with minima and maxima in brackets and standard deviation); values followed by different letters indicate significant differences based on a Tukey HSD test, $p<0,05$.

\begin{tabular}{|c|c|c|c|c|c|c|}
\hline Class & $\begin{array}{c}\text { Average } \\
\text { growth } \\
\text { rate in } \\
T S B\left(h^{-1}\right)\end{array}$ & Stdev & $\begin{array}{c}\text { Average } \\
\text { growth rate in } \\
0.1 T S B\left(h^{-1}\right)\end{array}$ & Stdev & $\begin{array}{l}\text { Average } \\
\text { rRNA copy } \\
\text { number }\end{array}$ & Stdev \\
\hline Actinobacteria & $\begin{array}{c}0.099 \mathrm{~b} \\
(0.047- \\
0.161)\end{array}$ & 0.039 & $\begin{array}{c}0.020 \mathrm{a} \\
(0.005-0.038)\end{array}$ & 0.011 & $\begin{array}{c}2.55 \mathrm{ac} \\
(1.00-5.25)\end{array}$ & 1.64 \\
\hline Bacilli & $\begin{array}{c}0.122 \mathrm{bc} \\
(0.034- \\
0.212)\end{array}$ & 0.044 & $\begin{array}{c}0.025 \mathrm{a} \\
(0.012-0.044)\end{array}$ & 0.0121 & $\begin{array}{c}7.93 \mathrm{bd} \\
(2.00-12.71)\end{array}$ & 4.60 \\
\hline $\begin{array}{r}\text { Alphaproteo- } \\
\text { bacteria }\end{array}$ & $\begin{array}{c}0.041 \mathrm{a} \\
(0.007- \\
0.094)\end{array}$ & 0.069 & $\begin{array}{c}0.014 \mathrm{a} \\
(0.003-0.028)\end{array}$ & 0.0088 & $\begin{array}{c}1.81 \mathrm{a} \\
(1.00-5.14)\end{array}$ & 1.15 \\
\hline $\begin{array}{r}\text { Betaproteo- } \\
\text { bacteria }\end{array}$ & $\begin{array}{c}0.111 \mathrm{bc} \\
(0.038- \\
0.182)\end{array}$ & 0.035 & $\begin{array}{c}0.036 \mathrm{ab} \\
(0.014-0.077)\end{array}$ & 0.0252 & $\begin{array}{c}2.95 \mathrm{a} \\
(2.00-4.96)\end{array}$ & 0.94 \\
\hline $\begin{array}{r}\text { Gammaproteo- } \\
\text { bacteria }\end{array}$ & $\begin{array}{c}0.154 \mathrm{c} \\
(0.125- \\
0.186)\end{array}$ & 0.0575 & $\begin{array}{c}0.055 b \\
(0.0 .15-0.128)\end{array}$ & 0.0335 & $\begin{array}{c}4.82 \mathrm{~cd} \\
(1.50-6.80)\end{array}$ & 1.47 \\
\hline
\end{tabular}


Figure S1: Binary matrix of bacterial isolates and carbon source use; black checkerboardunits indicate substrate utilization; carbon sources 1-31: see Appendix: Table S2; bacterial isolates VK1-VK47 see Table S3.

\section{Bacterial Isolates}

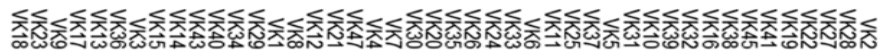

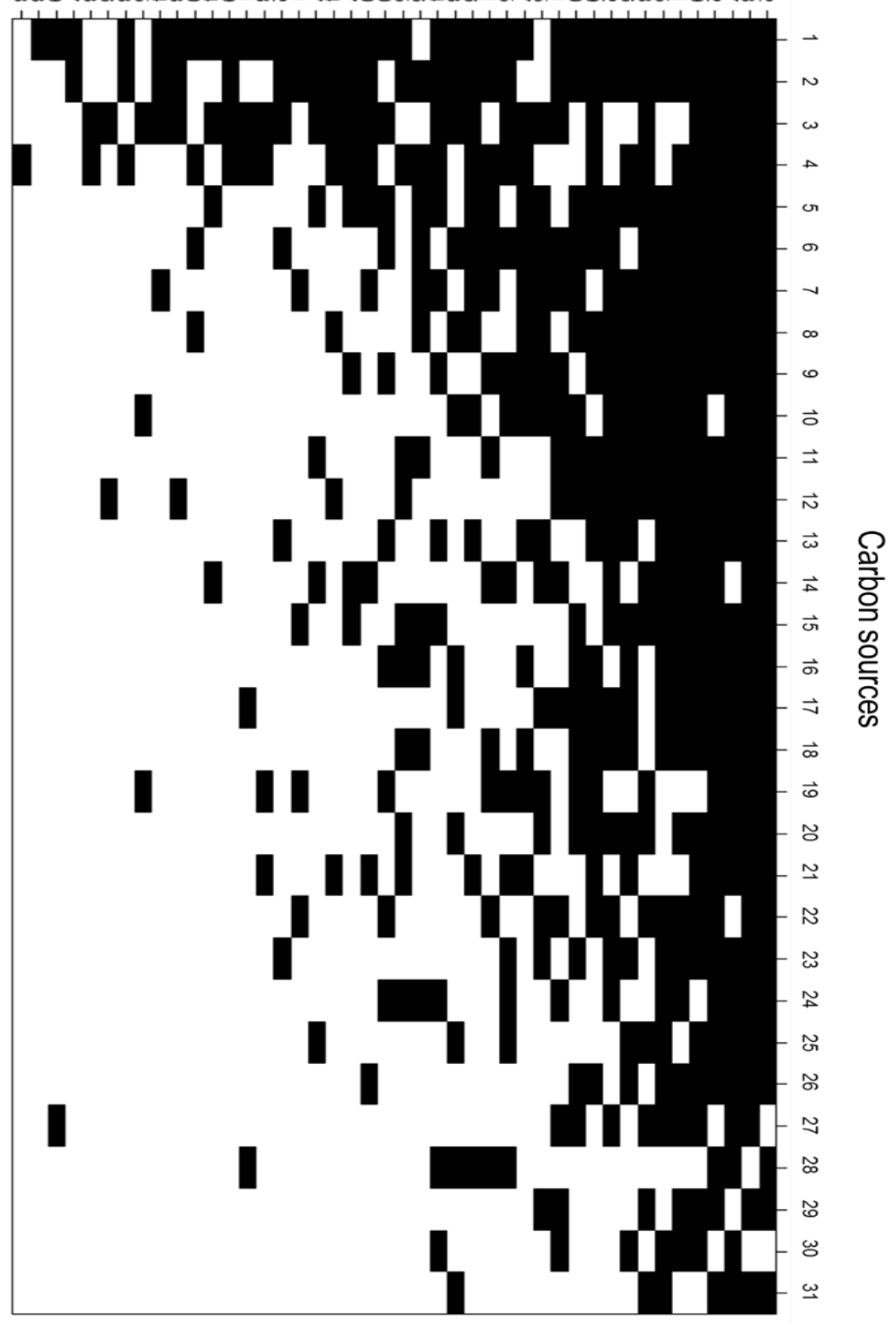


Figure S2: Average bacterial growth rate in LB-medium plotted against average growth rate in TSB-medium $\left(\mathrm{OD}_{600}\right.$ change $\left.\mathrm{h}^{-1}\right)(\mathrm{n}=10)$; error bars indicate standard deviations; results of a spearman correlation test: $r h o=0.88, p<0.01$.

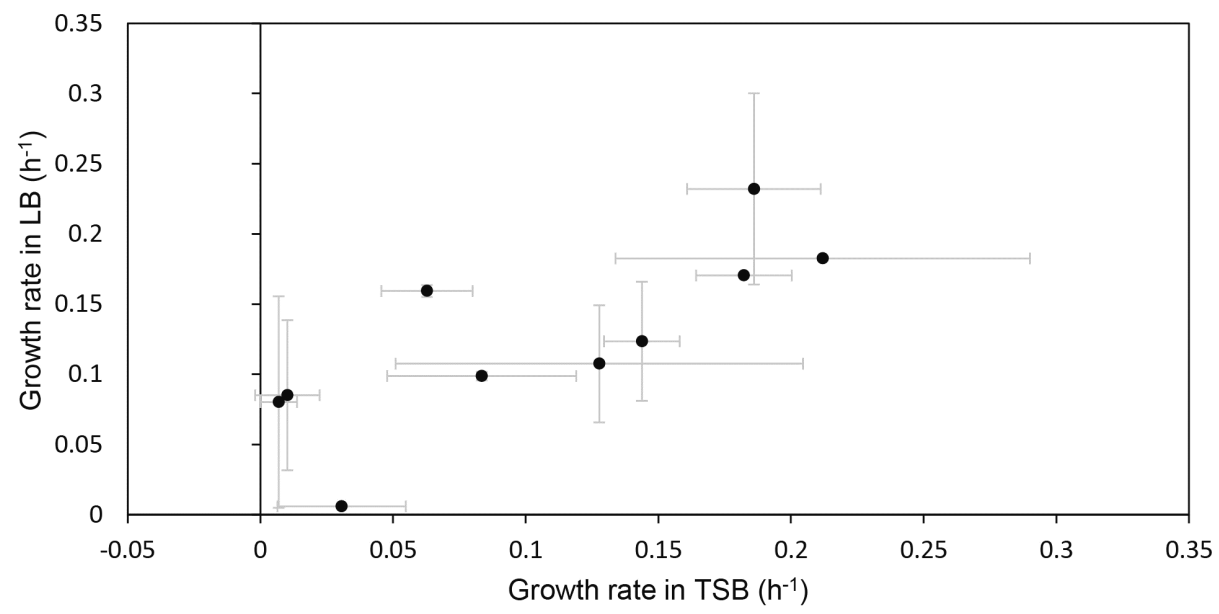




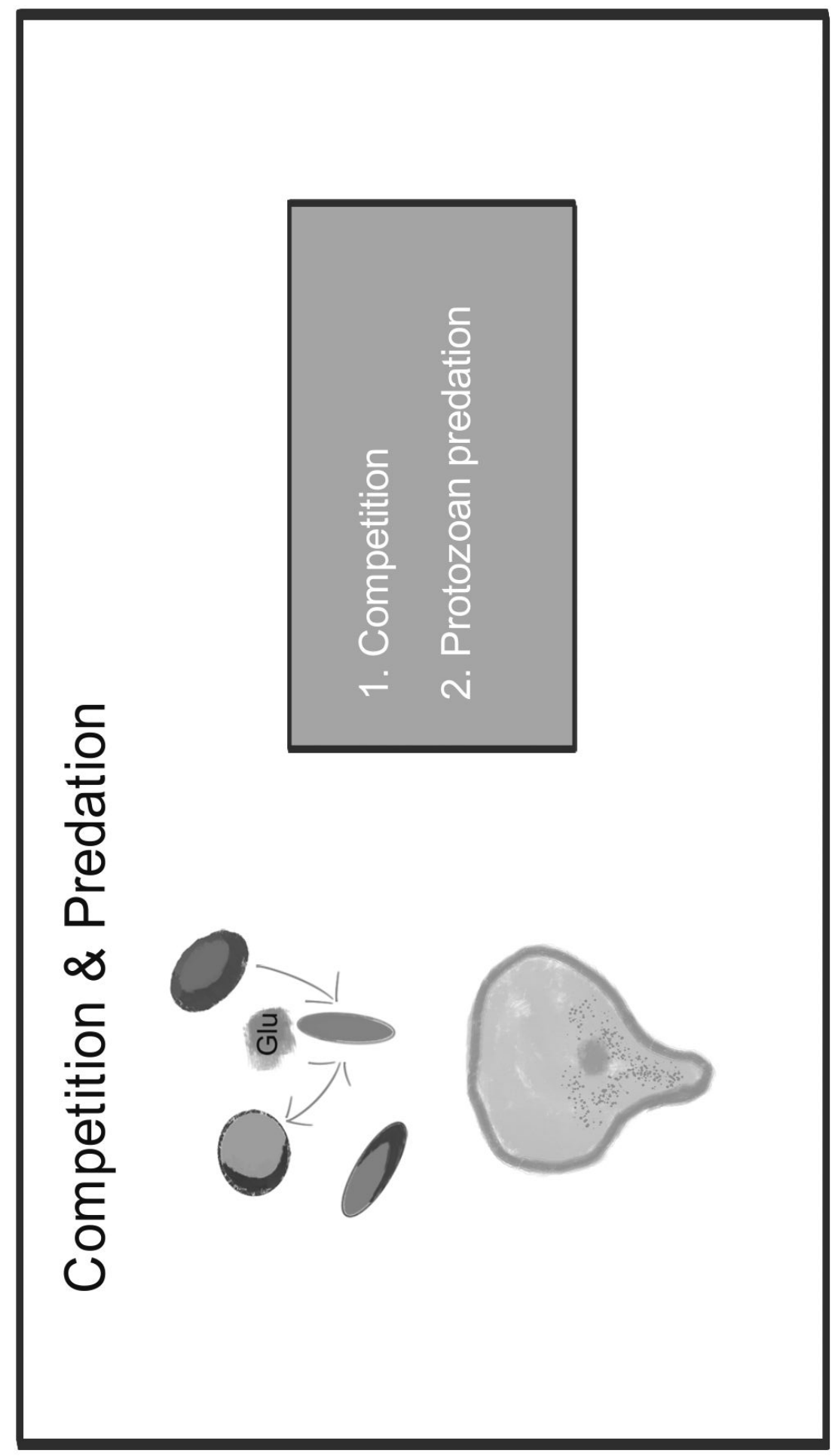




\section{Chapter 4}

\section{Importance of competition and predation as cause of bacterial rarity}

Viola Kurm, Wim H. van der Putten, Simone Weidner, Stefan Geisen, Basten Snoek, W.H. Gera Hol 


\begin{abstract}
Low abundant species make up the majority of species in most communities, but the underlying reasons are still highly debated. To get a more comprehensive understanding of bacterial rarity, we studied constructed bacterial communities consisting of species differing in potential growth rates and their abundance in field soil. We tested how competition affected species abundance in these constructed communities under four different nutrient concentrations and with or without protist predation. Moreover, we tested whether there are indications for a trade-off between competitiveness and resistance to predation. We found that some fast growing species that were rare in the field, were able to reach high abundances in the constructed communities showing that they can be highly competitive and have the ability to become abundant. However, rare species were more reduced in abundance at lower nutrient concentrations compared to high nutrient concentrations than abundant species suggesting a competitive disadvantage of rare species under low-nutrient field conditions. In addition, we found that species that were rare in the field, especially those that were more successful in the predator-free communities, were more strongly reduced by predation than abundant species. Therefore, we conclude that bacterial species rarity could be caused by a more negative trade-off between competitive ability and predation resistance.
\end{abstract}

\title{
Introduction
}

Most communities consist of only a few abundant species, whereas the majority of species is low abundant, or rare (Magurran and Henderson 2003). This pattern, which applies to organisms of any size, from macro- to microorganisms, has stimulated studies addressing the question why so many species are rare (see e.g. Buckling et al. (2000); Torsvik et al. (1996)). However, only few studies have examined the causes of species rarity. Although several studies have identified single factors that might influence species abundance, it is poorly investigated how combinations of factors influence abundance. Several single species traits have been associated with abundance, such as growth rate, niche specialization and reproductive traits (Flather and Sieg 2007). For instance, slow growing species are supposed to be less abundant than fast growing species (Murray et al. 2002). In addition, a high niche specialization has been found to correlate with low abundance (Wamelink et al. 2014). However, these traits alone are insufficient to explain species abundance in the field. It is unknown how they interact with other biotic factors, such as the presence of competitors and predators, or abiotic factors, such as nutrient availability, to shape species abundance.

Competition can substantially influence species abundance. Certain species traits, such as growth rate, have been identified as good predictors of a species' competitive ability. Fast growing species have been assumed to become abundant by quickly exploiting resources (Grime 1977, Amarasekare 2003). However, the species with the fastest maximal growth rate does not per se dominate the community (Grover 1991, Aerts 1999). Rather, the relationship between growth rate and competitive ability is dependent on nutrient availability. While 
species with fast maximal growth rates and a high fecundity (so-called r-strategists) have an advantage when resources are abundant, slow-growing species (K-strategists) can outcompete fast growing species in environments with low resource availability due to their higher individual fitness (Wilbur et al. 1974). Thus, species growth rate in concert with nutrient availability may be a good predictor of its competitive ability and of its abundance in the community.

Competition may be especially strong for bacteria because the high species diversity in bacterial communities should lead to a high redundancy in species traits and niche requirements (Hibbing et al. 2010). Many ecological concepts that have been developed for macroorganisms can be applied to the microbial world (Barberán et al. 2014) and it is not surprising that the same traits or trait combinations might predict the competitive success of macroorganisms, as well as of bacteria. For example, bacterial species may be differentiated into r- and K-strategists, which are called copiotrophs and oligotrophs, respectively. Copiotrophs show high growth rates in nutrient-rich environments, whereas oligotrophs are typically slow growing (Fierer et al. 2007). Results from in vitro as well as in situ studies suggest that slow growing species may have an advantage under low nutrient concentrations due to their higher substrate affinities (Suwa and Hattori 1984, Vergin et al. 2013). As in plant communities, nutrient availability could influence the outcome of competition when the competitors differ in nutrient affinity. However, species traits, competitive ability and nutrient status alone might not sufficiently explain abundance, as many rare species have been found to be capable of fast growth and to be highly competitive (Rabinowitz et al. 1984, Campbell et al. 2011, Baldrian et al. 2012).

In addition to competition, predation and viral lysis are also involved in determining species abundances, for example by influencing the outcome of competitive interactions. The "Kill the Winner" hypothesis, coined by Thingstad and Lignell (1997), states that the most competitive species for a resource is also most suppressed by predation. On the one hand, predation on the most competitive species might simply be the result of chance encounter (Bouvier and Del Giorgio 2007). On the other hand, species might invest more in traits increasing their competitiveness than in predator resistance or tolerance (Herms and Mattson 1992, Strauss and Agrawal 1999, Winter et al. 2010). This differential allocation of limiting resources can consequentially result in a trade-off between a species performance in a community with and without predators. In addition, the ability to acquire resources can be impaired by predator avoidance strategies (Kneitel and Chase 2004b). Therefore, if such differences result in trade-offs, in the presence of predators, species that are (partially) resistant to predation, can outgrow non-resistant species, while in the absence of predators, the non-resistant species are supposed to be dominant. 
Mechanisms of bacterial resistance to protist predation include morphological defences, such as the formation of filaments or cell aggregates, but also chemical defences, such as toxin production (Jürgens and Matz 2002). The cost of such anti-protist defences and hence the magnitude of a trade-off with bacterial competitiveness is poorly understood. It has been shown that species with rapid growth rates and a high competitive ability can be reduced to low abundances by protist predation, which indicates that predation might play an important role for species rarity (Neuenschwander et al. 2015). However, it is still unclear if this phenomenon of increased predation on fast growing species is due to a trade-off between competitiveness and predation resistance. Alternatively, chance of encounter could determine intensity of predation as assumed by studies proposing a low loss rate of rare species by predation and viral lysis due to their low abundance (Galand et al. 2009). Hence, the role of protist predation for bacterial abundances is still poorly understood.

Several studies have shown that nutrient availability can alter the relative importance of competition and predation. In nutrient-poor environments, competition among plants and in rocky shore communities was the most important factor in shaping species abundances (Proulx and Mazumder 1998, Worm et al. 2002). At high nutrient levels, however, consumers (herbivores or predators respectively) were dominant in shaping community composition. The resource availability hypothesis (Endara and Coley 2011) predicts that slow growing plant species are not only more competitive under low nutrient concentrations, but also better defended against herbivores as the cost of tissue loss is higher. Thus, slow growing plant species are expected to have an advantage under low nutrient concentrations regardless of herbivory, whereas under high nutrient concentrations herbivory can have a more severe impact on community composition by reducing the fast growing species, which would otherwise outcompete slow growing species and might even drive them to extinction. Also in the bacterial world competition and predation can be modified by nutrient availability (Bohannan and Lenski 2000b). This can be due to the high production costs of predation resistance. Since the relative cost of grazing resistance is lower under nutrient-rich conditions, grazing resistant, inedible forms of bacteria should occur more frequently under nutrient-rich conditions (Jürgens and Matz 2002, Corno and Jürgens 2008). Furthermore, high nutrient concentrations have been found to increase predator densities leading to increased predation pressure (Corno and Jürgens 2008). This increased predation pressure as well as higher prevalence of inedible prey forms could contribute to an increased importance of the trade-off between competitive ability and predation resistance under high nutrient concentrations for bacteria.

The aim of the present study is to investigate how nutrient availability can influence the abundance of species with different traits in the presence of competitors and predators. Based on the oligotrophic-copiotrophic concept we expect that fast growing species have a competitive advantage under high, but not under low nutrient conditions. Thus we tested the 
hypothesis that species with high potential growth rates will become abundant under high nutrient concentrations, whereas species with low maximal growth rates will become abundant under low nutrient concentrations (1). Still, species of equal activity and growth rate have been found to be rare or dominant respectively under the same conditions (Hamasaki et al. 2007, Baldrian et al. 2012), inferring another important factor. Therefore, we tested the hypothesis that species that are low abundant in the field will be negatively affected by predation (2a) with a more negative relationship between abundance in the predator free communities and communities with predators compared to abundant species, which is indicative of a stronger trade-off between competitiveness and predation resistance (2b). Moreover, we hypothesize that the effect of predation on species abundances will be stronger at high nutrient concentrations than at low nutrient concentrations (3a) and that nutrient concentration will influence the relationship between abundance in predator free communities and communities with predators (3b). To test these hypotheses we used bacterial isolates, which we have grouped based on field abundance and potential growth rate in vitro (Kurm et al. 2017) resulting in four species groups: rare and slow growing (RarSlo), abundant and slow growing (AbunSlo), rare and fast growing (RarFas) and abundant and fast growing (AbunFas) species. We studied their abundances in constructed communities at 4 different nutrient levels and in the presence and absence of protozoan predators.

\section{Material and methods}

\section{Bacterial isolates}

For cultivation of bacterial isolates see Supplementary Methods.

We classified the bacterial isolates into rare and abundant species, with relative abundance cut-offs of $<0.01 \%$ and $>0.01 \%$ relative abundance in the field respectively. This particular cut-off was chosen as a rather conservative value of defining rare bacterial species, and has previously been employed by Galand et al. (2009). We further classified the isolates into slow and fast growing strains based on their average growth rate in TSB. Species with a growth rate $<0.1 \mathrm{~h}^{-1}$ were considered to be slow growing, whereas species with a growth rate $>0.1 \mathrm{~h}^{-}$ 1 were considered as fast growing. This differentiation was based on the range and distribution of growth rates in our isolate collection (average growth rate: $0.098 \mathrm{~h}^{-1}$ ). Hence, the 24 species were grouped into 4 categories of 6 species each: (a) rare and slow growing (RarSlo), (b) abundant and slow growing (AbunSlo), (c) rare and fast growing (RarFas) and (d) abundant and fast growing (AbunFas) species (Table S1).

\section{Protist predators}

We used 3 protist isolates that were all member of the amoeboid genus Vanella sp. (supergroup: Amoebozoa, family: Vanellidae) isolated from grassland soil.

For cultivation of protists see Supplementary Methods. 


\section{Community design and microcosm construction}

We designed 24 bacterial communities to contain 12 species each, with 3 species from each of the 4 abundance/growth rate categories (RarSlo, AbunSlo, RarFas, and AbunFas). For each category, the 3 species were drawn from the pool of 6 species in a constrained random approach avoiding overrepresentation of particular species or species combinations (Table S2). Microcosms consisted of Nunc $1.0 \mathrm{ml}$ 96- Deep-well plates (Thermo Fisher Scientific, Waltham, Massachusetts, USA) containing $850 \mu \mathrm{l}$ of m edium (see below) and $50 \mu \mathrm{l}$ $\mathrm{MgSO}_{4}$ - buffer. We inoculated every community into each of 4 concentrations of liquid TSB $(0.1,0.01,0.001$ and $0.0001 \mathrm{TSB})$ resulting in 96 microcosms. All 24 communities at all nutrient concentrations were set up 4 times, crossed in a full-factorial design with each of the 3 protist predators and a predator-free control, resulting in 384 microcosms in total. We inoculated one additional replicate of each community in 0.1 TSB and harvested them immediately to serve as a baseline control to detect potential sequencing biases.

Communities were constructed with a pipetting robot (Freedom Evo, Tecan, Männedorf, Switzerland), which transferred $8.3 \mu$ of each bacterial m onoculture into the respective well to create the designed com m unities consisting of $50 \mu \mathrm{l}$ ixed bacterial cultureyielding a

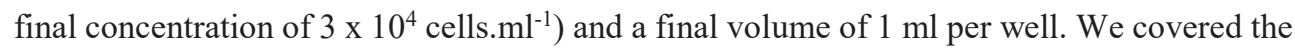
plates with sterile air-permeable sealing film and incubated them at $25^{\circ} \mathrm{C}$. Starting $24 \mathrm{~h}$ after community construction the plates were agitated gently at $100 \mathrm{rpm}$ until harvest to prevent anaerobic conditions.

The samples were stored at $-20^{\circ} \mathrm{C}$ until DNA extraction.

\section{DNA extraction and Illumina library preparation}

We extracted DNA from all microcosm communities using the QIAmp DNA Mini kit (Qiagen, Venlo, The Netherlands) with a pre-treatment with lysozyme and proteinase K according to manufacturer's instructions. Subsequently, we amplified the v4-region of the 16S rRNA gene using custom primers (Table S3). The reverse primer was barcoded with a 12 bp goaly barcode enabling multiplexing. Each sample was amplified in triplicate. All PCR reactions contained $11.75 \mu \mathrm{l}$ MQ-water $10 \mu \mathrm{l} 5$ Prim e Hot Masterm ix (Quantabio, Beverly, Massachusetts, USA), $1.25 \mu \mathrm{l}$ BSA, $0.5 \mu \mathrm{l}$ of forward and reverse prim er $(10 \mu \mathrm{M}$ final concentration) and $1.0 \mu \mathrm{l}$ genom ic DNA. The PCR conditions were as follows: an initial denaturation step of $94^{\circ} \mathrm{C}$ for $5 \mathrm{~min}, 35$ cycles of $45 \mathrm{~s}$ at $94^{\circ} \mathrm{C}, 60 \mathrm{~s}$ at $50^{\circ} \mathrm{C}$ and $90 \mathrm{~s}$ at $72^{\circ} \mathrm{C}$, followed by a final extension step for $10 \mathrm{~min}$ at $72^{\circ} \mathrm{C}$.

We purified the PCR products using Agencourt AMPure beads (Beckman Coulter, Indianapolis, Indiana, USA) using a ratio of 1:0.7 of PCR product to bead volume. The purification was carried out according to manufacturer's protocol and purified products were diluted in $30 \mu \mathrm{l} \mathrm{MQ-water.} \mathrm{We} \mathrm{then} \mathrm{measured} \mathrm{the} \mathrm{concentrations} \mathrm{of} \mathrm{the} \mathrm{purified} \mathrm{PCR}$ products with a fragment analyser (Advanced Analytical, Ankeny, Iowa, USA) using the standard sensitivity NGS fragment analysis kit (Advanced Analytical). The products were 
mixed in equal nanogram quantities and sent to BGI (Shenzhen, China) for $150 \mathrm{bp}$ pairedend sequencing. The three custom sequencing primers include two primers for reading the amplicon from each side and one for reading the barcode (for primer sequences see (Apprill et al. 2015)).

\section{Sequence analysis}

We merged paired end reads using the fastq-mergefiles option implemented in VSEARCH version 1.0.10 (Rognes et al. 2016), converted all sequences to the FASTA format and concatenated them to a single file. We clustered sequences into OTUs by de-replication with the UPARSE strategy using the UCLUST smallmem algorithm (Edgar 2010) and removed chimeric sequences with the UCHIME algorithm (Edgar et al. 2011). To match the sequences to the original 24 species we created a custom sequence database consisting of Sanger sequences from all isolates from the same region as the Illumina reads. In addition, we obtained neighbouring sequences of $97-100 \%$ identity for each isolate from the SILVAdatabase and NCBI-genbank and included those in the custom database. Subsequently we mapped all reads before the de-replication step to the custom database with the usearch_global method from VSEARCH and a sequence identity of $97 \%$. However, for the species S9 and S20 (Nocardioidaceae), S13 and S19 (Staphylococcaceae) and S16 and S23 (Pseudomonadaceae), mapping was done at a 99\% identity because of the high similarity between the isolate sequences. $89 \%$ of all sequences were successfully mapped to one of the reference sequences and we summed all sequences for each of the 24 species per sample. We removed samples that contained less than 1000 sequences from the dataset. Relative abundance of each species in each sample was calculated, followed by normalization with the 16S-copy number from the nearest neighbour sequence in the database by Větrovský and Baldrian (2013).

Most communities differed in species composition and species number from the original species design. Even the 24 communities that were frozen immediately after construction by pipetting robot showed a different composition. Species S17 was not detected at all in the entire sequencing dataset. These differences might result from sequencing bias and/or crosscontamination. While this clearly is undesired 'noise' in our dataset, the majority of the communities consisted of the intended species, so we kept all retrieved sequences in the analysis and analysed the relative abundances of the species in relation to the treatments and the species groups.

\section{Statistical analysis}

All statistical analyses were performed in R version 3.4.0 with R Studio (R Core Team 2016). A linear mixed effect model testing the effects of the 3 different predators on species abundance with nutrient concentration and community as random factors indicated no difference between the different predators except for species S18, for which the effects of 
two of the three predators on abundance different significantly ( $t$ ratio: $-3.3, p=0.01$ ). Given the similar response of all but one of the bacterial species, we averaged the relative abundance over the 3 different predators, resulting in one predation treatment.

We analysed whether relative abundance in the constructed communities was dependent on nutrient concentration, predation and species group (RarSlo, AbunSlo, RarFas and AbunFas respectively) by fitting a linear mixed model from the lme4-package with species as the random factor and obtaining the minimal model using the step() function from the lmerTest package (Bates et al. 2015). The same model was fitted for each species separately to test how many species in each group followed the main group effect. Moreover, the differences between the groups in relative abundance change with nutrient gradient were assessed by fitting linear mixed effect models for each group pair with predation and species as a random factor. We performed a similar test for differences in the slope between control and predator treatment between the groups with nutrient level and species as random factors to assess the predator effect only.

For each species, we tested the relationship between relative abundance and abundance change in the presence of predation with a Spearman correlation between relative abundance in the control (i.e. competitiveness) and change in relative abundance with predation (i.e. predation resistance). To test whether there is a relationship between competitiveness and predation resistance independent of species abundance a linear mixed model was fitted for relative abundance in the control dependent on change with predation, species group and nutrient concentration with community nested in nutrient concentration as a random factor. However, the random effects were not significant. Therefore, we fitted simple linear models for each pair of species group. In addition, a separate model was fitted to test for the effect of nutrients with nutrient concentration included as a fixed factor. Furthermore we fitted the same model for each species group and each group pair separately to determine changes within and between groups with nutrient level.

\section{Results}

All groups (RarSlo, AbunSlo, RarFas and AbunFas) were affected significantly by the treatments (Table S4). Only for one group of species there was a statistically significant interaction between the treatments, and hence the main effects are shown first, followed by the interaction effects (Fig. S1).

On average bacteria belonging to the RarSlo, AbunSlo and AbunFas group had low relative abundances of $4 \%, 2 \%$ and $3 \%$ respectively, whereas the group of RarFas bacteria dominated the communities with a relative abundance of $10 \%$. Only the RarFas group was significantly more abundant than the AbunSlo group ( $\mathrm{t}=-2.4_{19}, \mathrm{p}=0.03$ ) 


\section{Effect of nutrients}

Fast growing species increased significantly in abundance with increase in nutrient concentration ( $\mathrm{t}=3.4_{21}, \mathrm{p}<0.01$ ), whereas slow growing species did not respond significantly to nutrient concentration ( $\mathrm{t}=1.6_{21}, \mathrm{p}=0.12$; Fig. $\mathrm{S} 2$ ). However, potential species growth rate interacted significantly with species abundance resulting in differences between the four species groups. Increase of nutrient concentration significantly enhanced average relative abundance of the RarFas group $\left(\mathrm{t}=3.2_{869}, \mathrm{p}<0.01\right)$, while it significantly decreased the relative abundance of the AbunFas and AbunSlo groups (AbunFas: $\mathrm{t}=-2.7_{1001}, \mathrm{p}<0.01$, AbunSlo: $\left.\mathrm{t}=-4.3_{804}, \mathrm{p}<0.02\right)$. There was no change for the RarSlo group $\left(\mathrm{t}=-1.2_{1065}, \mathrm{p}=0.23\right.$; Fig. 1). Consequentially, the effects of an increase in nutrient concentration was significantly more positive for the RarFas group than for the other groups (Table S5).

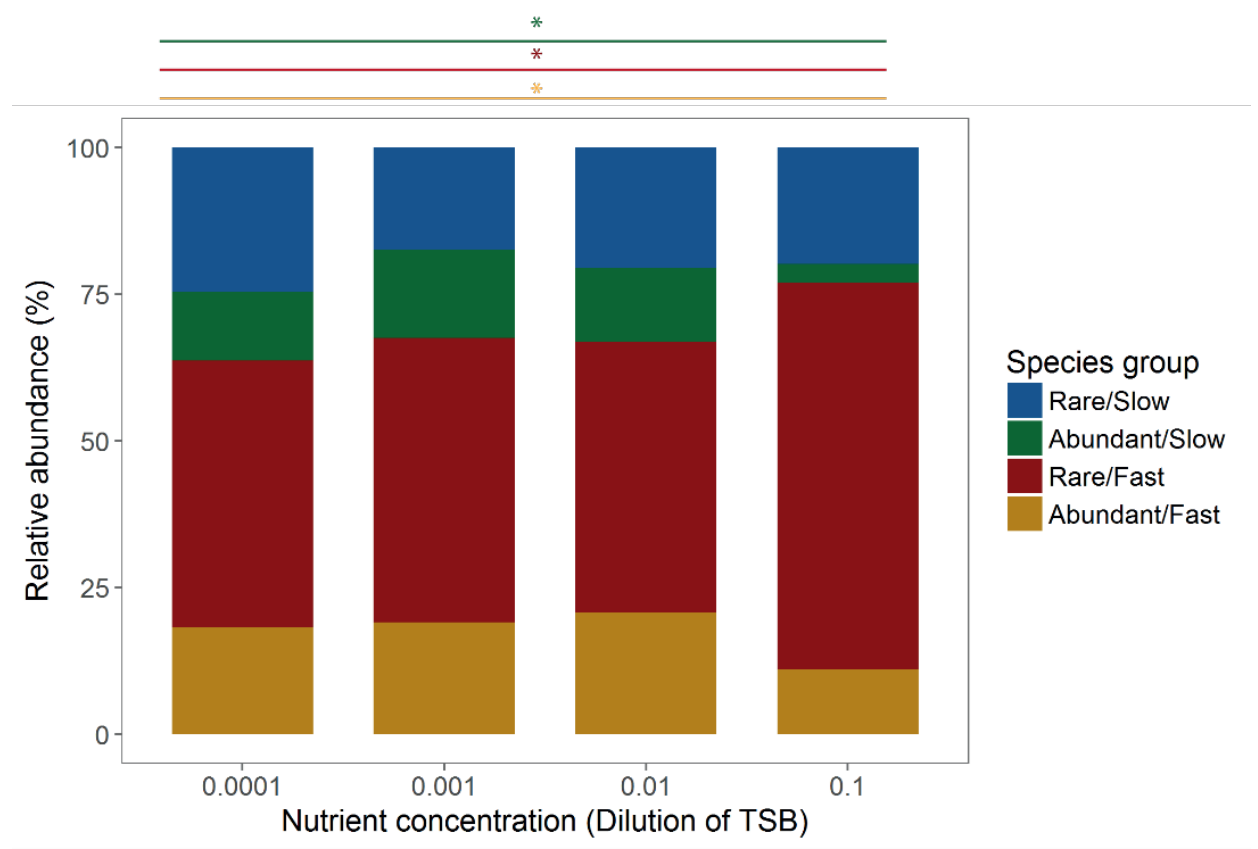

Fig. 1: Average relative abundance of the four bacterial species groups at the different nutrient concentrations; relative abundances are averaged over predation treatments and communities; significant changes in abundance with nutrient concentration are indicated with a coloured line for the relevant species groups and an *

\section{Effects of predation}

Rare species decreased with the addition of predators, but the overall effect of predation on rare species was not significant (Fig. S3).

However, predation differentially affected the four species groups. The RarFas group significantly declined with predation $\left(\mathrm{t}=-2.8_{867}, \mathrm{p}<0.01\right)$ and this decline was significantly 
stronger than for all other groups (Fig. 2). The RarSlo group significantly increased in abundance with predation $\left(\mathrm{t}=3.9_{1036}, \mathrm{p}<0.01\right)$, whereas there was not more than a trend for the AbunSlo group $\left(\mathrm{t}=1.9_{802}, \mathrm{p}=0.05\right)$. The RarSlo group showed a significantly stronger increase than the AbunFas group and a tendency for a stronger increase than the AbunSlo group (Table S5).

\section{Relationship between competitive success and predation resistance}

Most species showed a negative relationship between relative abundance in the control and loss by predation (Fig. S4, Table S6). However, species groups differed with respect to the magnitude of this response. No significant effect of community was detected when testing for frequency dependent predation effects making purely frequency dependent predation unlikely.

Averaged over all nutrient levels RarFas and RarSlo species showed a significantly negative relationship (RarFas: $\mathrm{t}=-12.0_{1,420}, \mathrm{p}<0.01$, RarSlo: $\mathrm{t}=-7.0_{1,509}, \mathrm{p}<0.01$ ), whereas it was significantly positive for AbunSlo $\left(\mathrm{t}=4.6_{1,367}, \mathrm{p}<0.01\right)$ species and there was no significant relationship for the AbunFas group ( $\mathrm{t}=-1.2_{1,479}, \mathrm{p}=0.21$; Fig. 3 ). The relationship between abundance in the control and reduction by predation differed significantly between all species groups except for AbunFas and RarSlo (Table S7, S8).

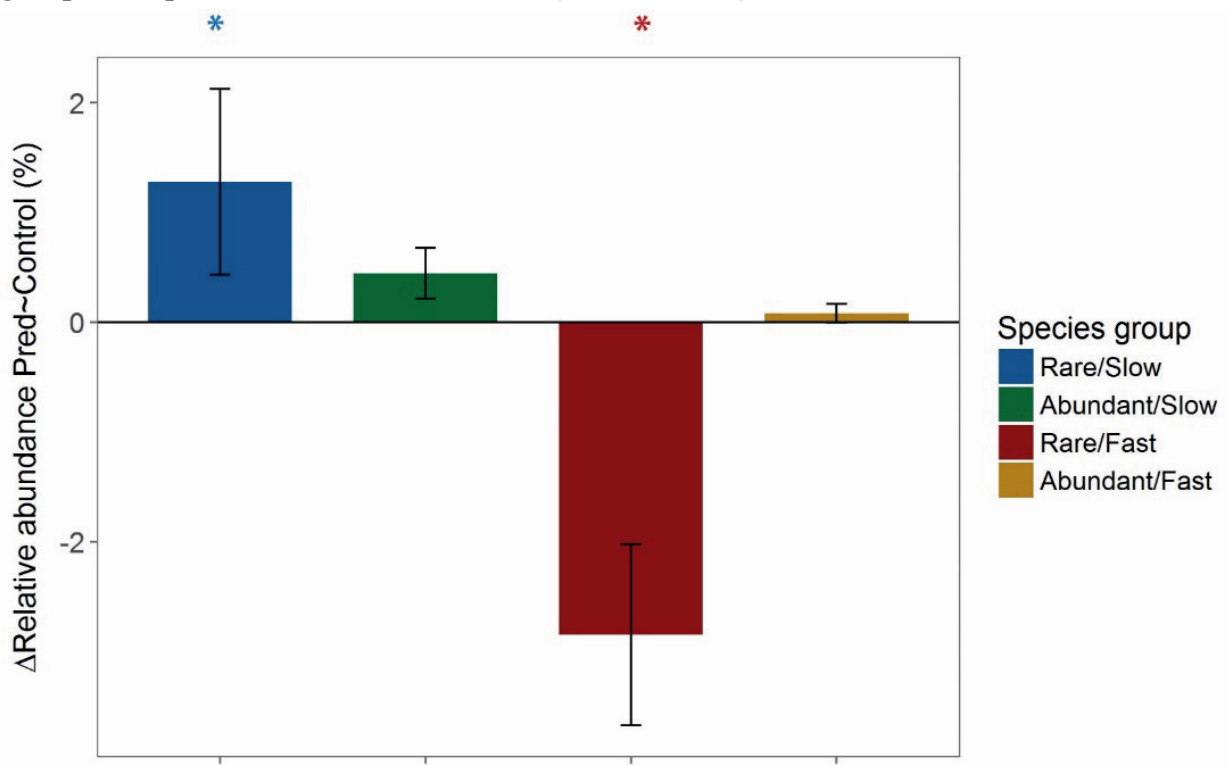

Fig. 2: Average difference in relative abundance of the four bacterial species groups between the predation-free control and the predation treatment; relative abundances are averaged over nutrient concentrations and communities; error bars represent the standard error; significant changes in relative abundance by predation are indicated by *. 


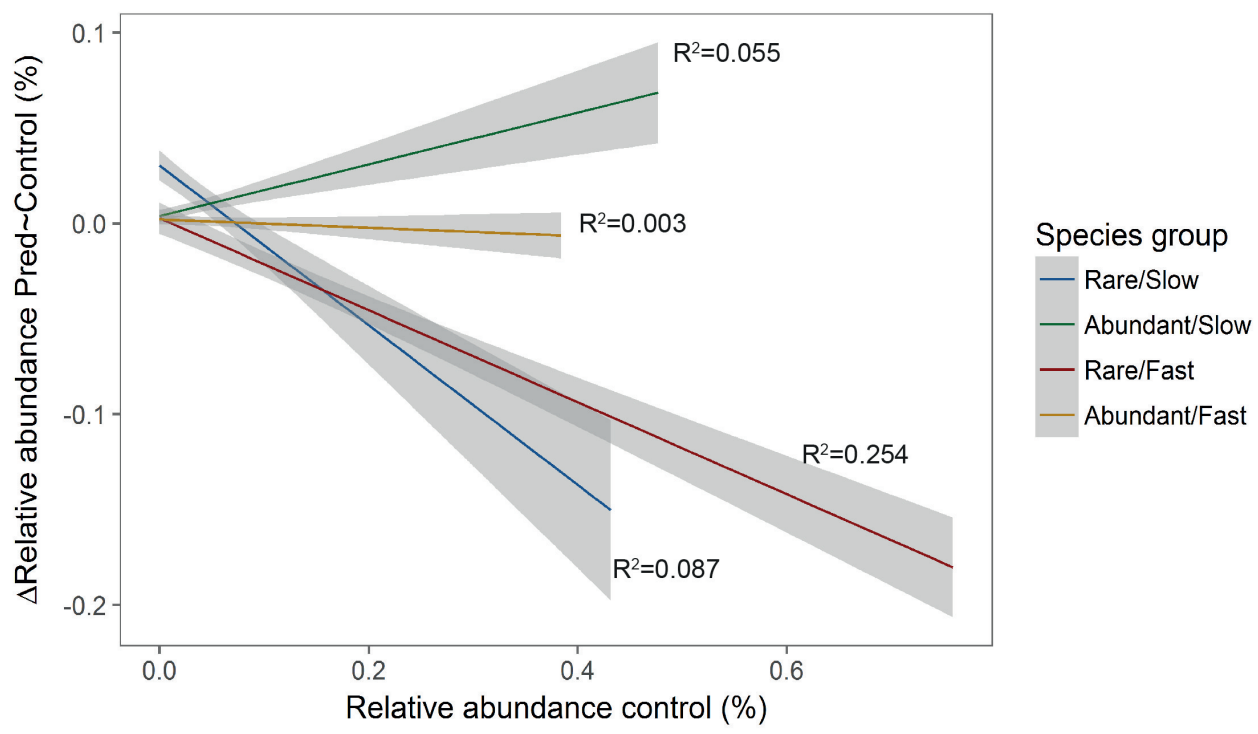

Fig. 3: Relationship between the relative abundance in the predator free control (X-axis) and the reduction of relative abundance with the addition of predators ( $\mathrm{Y}$ axis) for bacterial species belonging to the four different bacterial species groups. This relationship can be used as an indication of a trade-off between competitiveness and resistance to predation; shown is a linear model fit with standard error.

\section{Effect of nutrient concentration on predation}

Nutrient concentration and predation did not interactively influence the abundance of species that were rare or abundant in the field $\left(\mathrm{F}_{3,3732}=0.1, \mathrm{p}=0.95\right.$, Fig. S5).

However, the RarSlo group showed a significant interaction between the effects of nutrient concentration and predation treatment. Its relative abundance was significantly increased with predators at the highest nutrient concentration compared to the other three nutrient concentrations (Fig. 4, Table S9).

High coefficients of variation indicate variability within the four groups in their response to the different treatments (CV, RarSlo: 1.5, AbunSlo: 2.0, RarFas: 1.2, AbunFas: 1.5; for single species responses and statistics see Supplementary Methods; Table S10, Fig. S6). However, the differences between groups were still significant.

Effect of nutrients on the relationship between competitive success and predation resistance Nutrient concentration had a significant effect on the relationship between relative abundance in the control and loss from predation for the groups RarSlo, AbunSlo and AbunFas. For RarSlo and AbunSlo the relationship became more negative with increase in nutrient concentration, whereas it became more positive for the AbunFas group at a concentration of 
0.01 (Figure 5, Table S9). Consequentially, the difference between the RarSlo and AbunFas group was most pronounced at a nutrient concentration of 0.01 . Also the difference between the AbunSlo and AbunFas species was only significant at high nutrient levels (Table S11).

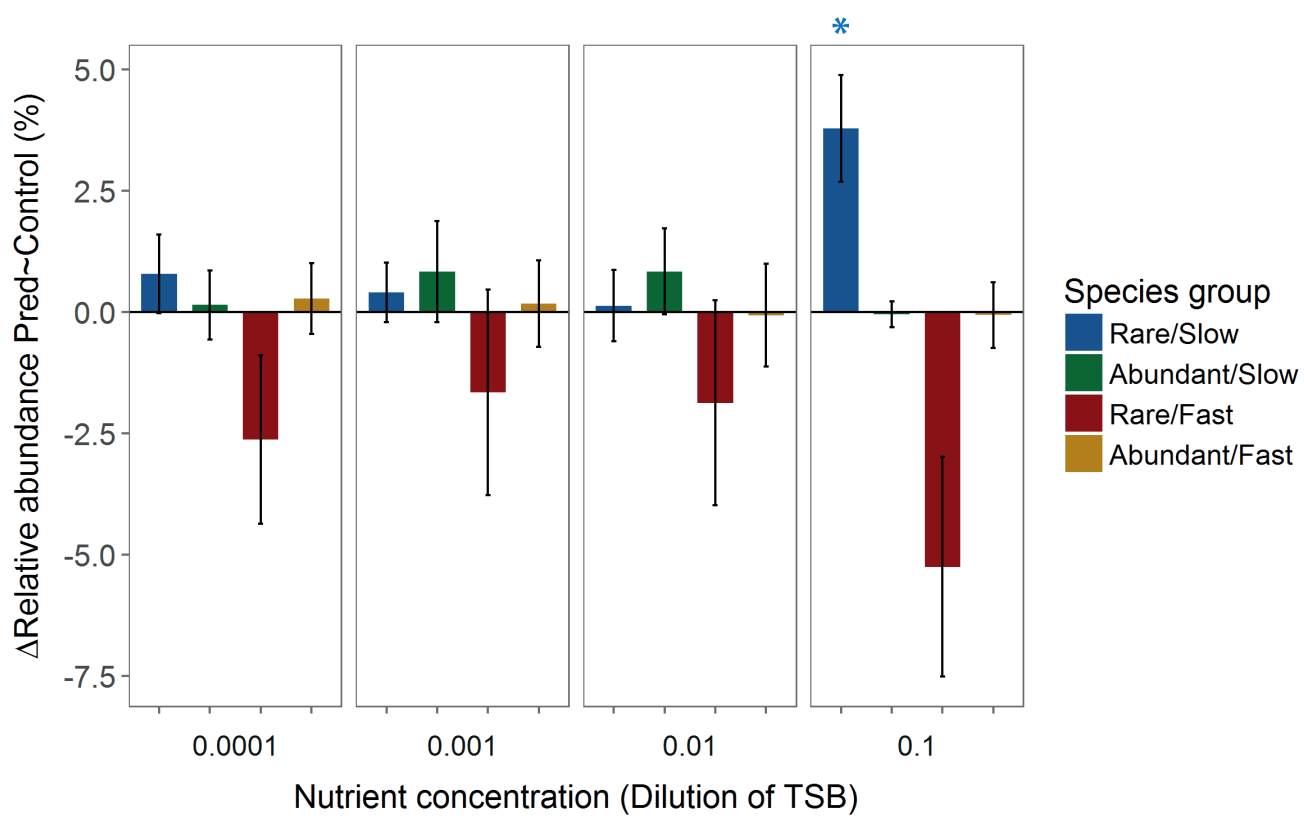

Fig. 4: Average difference in relative abundance between the control and the predation treatment of the four bacterial species groups at the different nutrient concentrations; results are averaged over communities; error bars represent the standard error; significant changes in relative abundance by predation are indicated by *. 

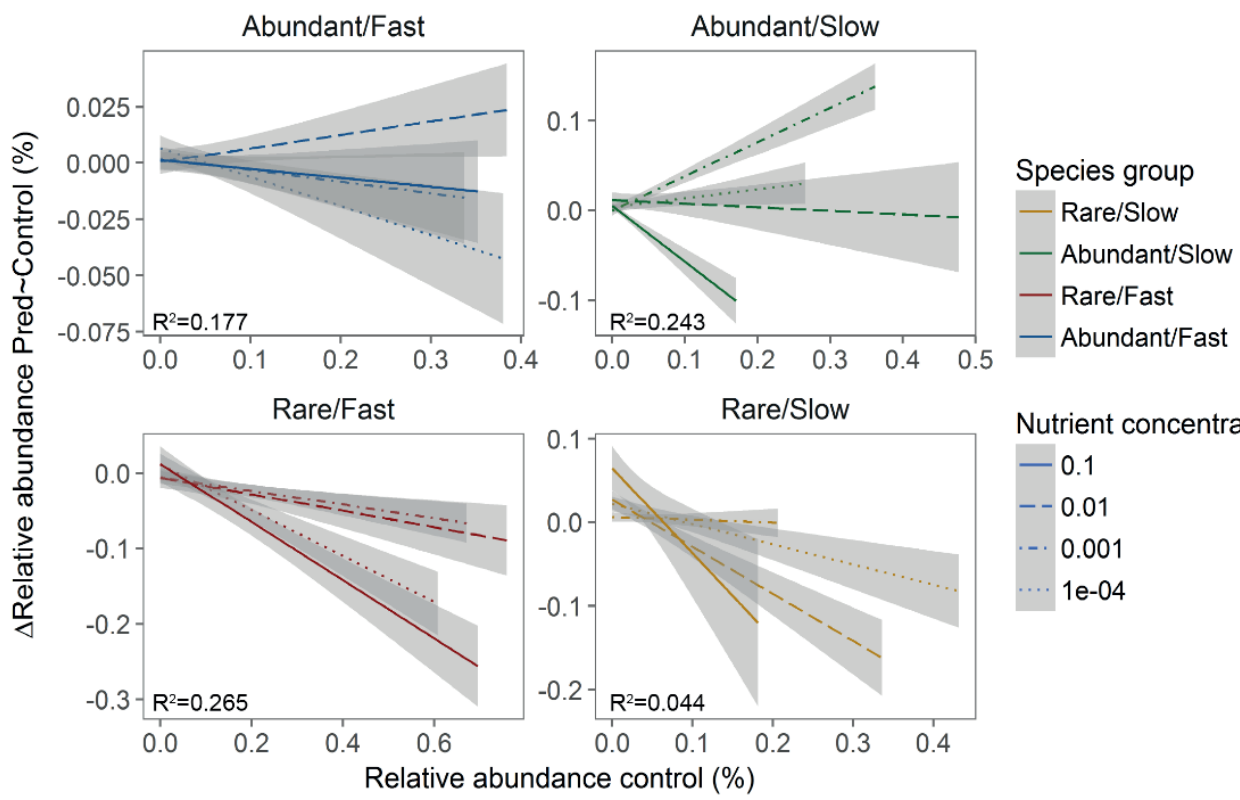

Nutrient concentration

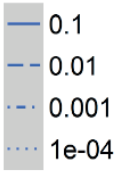

Figure 5: Relationship between the relative abundance in the predator free control and the reduction of relative abundance with the addition of predators at four different nutrient concentrations (indicated by different line types) and for the four species groups in the four panels as indication of a trade-off between competitiveness and resistance to predation; shown is a linear model fit with standard error. $\mathrm{R}^{2}$ values are given for each species group.

\section{Discussion}

We hypothesized that competitive success depends on potential species growth rates and nutrient availability. In accordance with our first hypothesis abundant slow growing bacteria (AbunSlo) decreased in abundance. However, this effect was not seen for rare slow growing bacteria (RareSlo). Our results are consistent with the theory of a trade-off between the ability for fast growth at high nutrient concentrations (i.e. copiotrophy) and the ability to grow at low nutrient concentrations (i.e. oligotrophy) (Fierer et al. 2007). This proposed trade-off has been suggested to be the cause of observed shifts in competitive ability of oligotrophic bacteria with nutrient availability in former studies (Gottschal 1985). In contrast to our hypothesis that abundance in the community depends on species growth rate and nutrient availability, however, the abundance of slow growing species did not exceed that of fast growing species at low nutrient levels. Although we used diluted media, soil might contain even more nutrient-poor patches due to extreme nutrient-heterogeneity (Paul 2014). In addition, carbon-compounds in soil are often more complex than glucose (Schmidt et al. 2011), which was the main carbon source in our study. Thus the concentration of readily available substrates in soil might at some sites be lower than in the used media. This could 
mean that the nutrient concentrations were not low enough to give slow growing species the advantage.

As was expected in our first hypothesis, several species that were previously characterized as fast growing increased in abundance with nutrient concentrations. However, most species that were characterized as abundant in the field and fast growing in vitro declined in abundance with increasing nutrient concentration similar to the slow growing species. This is in contrast to studies showing a positive relationship between growth rate and competitive ability in nutrient-rich environments (Gottschal 1985, Fierer et al. 2007). Since the abundant species have previously shown the ability for rapid growth under high nutrient concentrations (Kurm et al. 2017), our finding suggests that these bacteria are inferior competitors in spite of their fast growth. A possible explanation might be that bacteria do not only compete by rapid growth and nutrient uptake (i.e. exploitative competition), but also through other mechanisms, such as the production of antimicrobial compounds (i.e. interference competition) (Hibbing et al. 2010). Especially bacteria of the genus Pseudomonas often show the capability for producing several inhibiting compounds (Haas and Defago 2005). However, secondary metabolite production can vary substantially between different species and strains (Gross and Loper 2009) and there are no reports on the production of antibacterial substances by the other dominant species in this study.

In our results on the outcome of competition between fast and slow growing and rare and abundant bacterial species it was especially surprising that bacterial strains belonging to the RarFas group dominated the communities, in spite of being low abundant in the field. Although fast growth rates and high activity in itself have frequently been reported for rare bacteria in vitro (Kurm et al. 2017), as well as in the natural environment (Campbell et al. 2011, Baldrian et al. 2012), we expected them to become low abundant in the constructed communities, especially in comparison to the AbunFas group, as a result of competition. However, our results suggest that other factors might contribute to species rarity. For example, for macroorganisms disturbances and herbivory or predation were suggested to drive species abundances in the field (Rabinowitz et al. 1984).

In addition, we tested the hypothesis that bacteria that are rare in the field would be less resistant to protist predation in the constructed communities. While overall the most dominant taxa were reduced, this effect was most pronounced for the RarFas group. Although this did not change the rank order of the four species groups, a higher predator density than used in the present study might lead to a low abundance of these species. In soil, predation pressure on bacteria is likely to be stronger since this environment is known to harbour a huge taxonomic and functional diversity of protist predators and nematodes (Ekelund and Rønn 1994). Protist species are known to differ in their feeding specificity (Schulz-Bohm et al. 2016) and it has been shown that a higher predator diversity reduces the 
strength of competition and increases bacterial diversity (Saleem et al. 2012). Moreover, we found a negative correlation between abundance in the absence of predation and abundance reduction in the presence of predators for both rare species groups, but not for the abundant groups. This correlation suggests a trade-off between competitiveness and predation resistance for these groups. Such a trade-off has been observed before for both micro- and macroorganisms (Bohannan et al. 2002, Hanley and Sykes 2009, Våge et al. 2014). The results from the present study add evidence for such a trade-off for soil bacteria and indicate that it does not affect all species equally, potentially leading to rarity or dominance in the environment.

Our results are partly supporting our third hypothesis that predation would have a stronger negative effect on rare species and that there would be a more negative relationship between competitiveness and predation resistance at high nutrient concentrations. Both groups of slow growing species showed indications of a stronger trade-off between competitiveness and predation resistance at higher nutrient levels. This is in accordance with studies finding predation to be more important than competition at nutrient-rich conditions compared to nutrient-poor conditions (Bohannan and Lenski 2000b, Corno and Jürgens 2008). In contrast to our hypothesis, the AbunFas group was only weakly affected by predation at all nutrient concentrations. Toxin and volatile production by species belonging to the genera Pseudomonas, Paenibacillus and Bacillus might have enhanced their resistance to predation (Jousset et al. 2009, Schulz-Bohm et al. 2016). However, these interactions are highly species- and compound-specific (Schulz-Bohm et al. 2016) and are therefore beyond the scope of this study. Also for the RarFas group there was no change in predation effect over all nutrient levels indicating that the consistent negative relationship between competitiveness and predation resistance was unaffected by nutrient availability.

Some bacterial species clearly deviated from the main group response to the treatments resulting in a high variation. On the one hand, this shows that species were differentially affected by the treatments. On the other hand, the variation indicates that other factors might influence their abundance in the field, which we did not include in our experimental set-up, as for instance abiotic factors such as $\mathrm{pH}$ and moisture (Fierer and Jackson 2006, Bell et al. 2009). Although the species richness used here is large compared to most microbial competition studies (Bohannan and Lenski 2000b, Jiang and Adams Krumins 2006), our experimental communities were much less diverse than natural bacterial communities with respect to both prey and predators. Another difference between the experimental system and the soil environment is a reduced heterogeneity, both structural and with respect to resource availability. Heterogeneity is supposed to enable the coexistence of a high number of species, which differ in their niche requirements (Torsvik et al. 1996, Zhou et al. 2002). Batch cultures, as used in this experiment are rather homogeneous and the growth medium contained a single main carbon source. Nevertheless, our experimental set-up provides first 
insights about the potential impact of competition, predation and species traits on relative abundance. In addition, our constructed communities contained unequal numbers of species due to cross-contamination. Nevertheless, all isolates were characterized as rare or abundant and fast or slow growing respectively, which allowed us to relate these traits to the performance of the species in the constructed communities.

We conclude that the in vitro growth rate of bacterial species is not a good predictor of their competitive ability. Neither could we find evidence that growth rate or competitive ability might explain bacterial abundance in the field soil. However, we show that competitiveness may be negatively related to predation resistance in soil bacteria. Moreover, we show that this relationship is on average stronger for rare species than for abundant species. This inverse relationship suggests a trade-off, which might explain species rarity under natural conditions. Future work should test if the correlation we observed is based on a mechanistic trade-off in resource investment.

\section{Acknowledgements}

We thank Suzanne Naus-Wiezer and Peter Veenhuizen for their help in the experimental setup. Furthermore, we thank Tanja Bakx for help with the molecular work of this study. 


\section{Supplementary Information}

This supplementary includes methods detailing cultivation of the microbial organisms used in this study and results of an analysis after omitting a part of the dataset. Tables give details on the microbial isolates and the construction of communities as well as statistical results. Figures illustrate results from the main text.

Supplementary methods

\section{Cultivation of bacterial isolates}

We chose 24 bacterial species from a collection of species isolated from a soil of a long-term biodiversity experiment on ex-arable land near Ede (Gelderland, The Netherlands) (for details on the isolation procedure see Kurm et al. (2017)). In brief, we used both flow cell sorting and a streak plating method in combination with a range of different oligotrophic growth media for bacterial cultivation. In the flow cell sorting approach, individual bacterial cells with a size of $\sim 0.5 \mu \mathrm{m}$ were sorted from a soil sam ple into single wells of 96well plates containing 6 different media (tryptone soil agar at a 1/10 and 1/100 dilution, water yeast agar, dilute nutrient broth agar and soil agar with and without the addition of nutrients). For the streak plating approach $200 \mu \mathrm{l}$ of a $10^{-7}$ diluted soil solution were spread over petri-dishes containing two different media (soil extract medium with salts and VL55 medium + xylan). All plates were checked for visible bacterial growth every other day. The partial 16S rRNA genes of the isolated bacterial species were sequenced by Sanger sequencing to determine taxonomic placements of the bacterial strains. For determination of their abundance in field soil the sequences were compared to a 454-sequencing database of the v4-region of a microbial community from the same soil and matched to the closest related OTU. The relative abundance of sequences clustered into the respective OTU were subsequently taken as the relative abundance of the species in soil. We measured growth rate of the isolated species in tryptone soy broth (TSB; 3 g.1 $1^{-1}$ tryptone soy broth; Table S1) (Kurm et al. 2017).

Prior to community construction all bacterial species were pre-cultured separately for 5 days in liquid TSB at $25^{\circ} \mathrm{C}$ and $180 \mathrm{rpm}$ agitation on a flatbed shaker. One day prior to the set-up

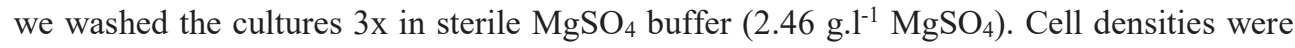
determined by staining subsamples of each bacterial solution with SYBR green at a final concentration of 1:10 000 (Sigma-Aldrich, St. Louis, Missouri, USA) for minimally 15 min counting by flow cytometry in an Accuri C6 Sampler (BD Biosciences, Franklin Lakes, New

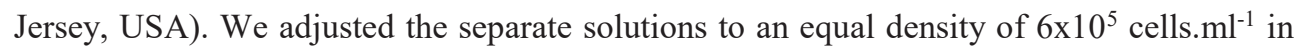
$\mathrm{MgSO}_{4}$-buffer and stored them at $4^{\circ} \mathrm{C}$ for maximally $24 \mathrm{~h}$ until community construction.

\section{Protist cultivation}

We prepared precultures in WG-medium (Geisen et al. 2014) with E. coli as a food source. Two days prior to community construction, we treated the cultures with three different antibiotic solutions to supress growth of E. coli using $25 \mu 1100 \mathrm{~m} \mathrm{g.m-1}$ am picillin, $10 \mu \mathrm{l} 20$ 
mg. $\mathrm{ml}^{-1}$ rifam picin and $5 \mu 150 \mathrm{mg} \cdot \mathrm{ml}^{-1}$ kanam ycin per $500 \mu \mathrm{l}$ of protist culture. One day prior to community construction, we washed protist cultures $3 \mathrm{x}$ in sterile $\mathrm{MgSO}_{4}$ buffer,

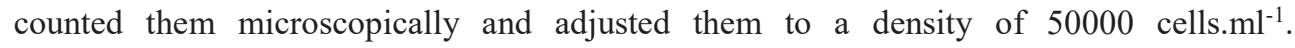
Subsequently, we stored the protist cultures at $4{ }^{\circ} \mathrm{C}$ for maximally $24 \mathrm{~h}$ until community construction.

Supplementary results

Relationship between competitive success and predation resistance

To explore whether he results for the RarSlo group were mainly driven by the strongly responding species $\mathrm{S} 4$ we conducted an additional analysis after omitting S4 from the dataset. Here the RarSlo group still differed significantly from both the AbunSlo and AbunFas group, but no longer from the RarFas group (Fig. S7, Table S12).

Effect of nutrients on the relationship between competitive success and predation resistance When omitting S4 from the dataset the relationship between relative abundance in the control and reduction in the predation treatment did not change anymore with nutrient level for the RarSlo group (Fig. S8, Table S13). 
Table S1: Description of the bacterial isolates used in this study; relative abundance in soil and growth rate as determined in Kurm et al. (2017).

\begin{tabular}{|c|c|c|c|c|c|}
\hline Species & Family & $\begin{array}{l}\text { Relative } \\
\text { abundance } \\
\text { in soil \% }\end{array}$ & $\begin{array}{l}\text { Growth rate } \\
\text { TSB }\left(h^{-1}\right)\end{array}$ & $\begin{array}{l}\text { Abundance } \\
\text { group }\end{array}$ & $\begin{array}{l}\text { Growth } \\
\text { group }\end{array}$ \\
\hline S1 & Methylobacteriaceae & 0.000272 & 0.0069 & rare & slow \\
\hline$S 2$ & Carnobacteriaceae & 0.000470 & 0.0344 & rare & slow \\
\hline$S 3$ & Sphingomonadaceae & 0.000000 & 0.0371 & rare & slow \\
\hline$S 4$ & Comamonadaceae & 0.000000 & 0.0383 & rare & slow \\
\hline S5 & Phyllobacteriaceae & 0.000000 & 0.0306 & rare & slow \\
\hline S6 & Microbacteriaceae & 0.000000 & 0.0834 & rare & slow \\
\hline$S 7$ & Caulobacteraceae & 0.089863 & 0.0102 & abundant & slow \\
\hline$S 8$ & Kineosporiaceae & 0.109113 & 0.0856 & abundant & slow \\
\hline S9 & Nocardioidaceae & 0.001160 & 0.0592 & abundant & slow \\
\hline$S 10$ & Xanthobacteraceae & 0.001970 & 0.0106 & abundant & slow \\
\hline$S 11$ & Bradyrhizobiaceae & 0.019739 & 0.0273 & abundant & slow \\
\hline S12 & Phyllobacteriaceae & 0.012511 & 0.0628 & abundant & slow \\
\hline$S 13$ & Staphylococcaceae & 0.000272 & 0.2120 & rare & fast \\
\hline S14 & Oxalobacteraceae & 0.000000 & 0.1778 & rare & fast \\
\hline$S 15$ & Enterobacteriaceae & 0.000340 & 0.1577 & rare & fast \\
\hline$S 16$ & Pseudomonadaceae & 0.000000 & 0.1625 & rare & fast \\
\hline S17 & Propionibacteriaceae & 0.000000 & 0.1245 & rare & fast \\
\hline$S 18$ & Xanthomonadaceae & 0.000000 & 0.1253 & rare & fast \\
\hline$S 19$ & Staphylococcaceae & 0.004340 & 0.1834 & abundant & fast \\
\hline$S 20$ & Nocardioidaceae & 0.002830 & 0.1614 & abundant & fast \\
\hline$S 21$ & Bacillaceae & 0.011025 & 0.1438 & abundant & fast \\
\hline$S 22$ & Intrasporangiaceae & 0.069526 & 0.1277 & abundant & fast \\
\hline$S 23$ & Pseudomonadaceae & 0.087731 & 0.1860 & abundant & fast \\
\hline$S 24$ & Paenibacillaceae & 0.015587 & 0.1144 & abundant & fast \\
\hline
\end{tabular}

Table S2: Composition of the 24 artificial communities. 0 designates absence and 1 designates presence of a species in the respective community. Different colours indicate the four different species groups (Rare/Slow, Abundant/Slow, Rare/Fast, and Abundant/Fast). 


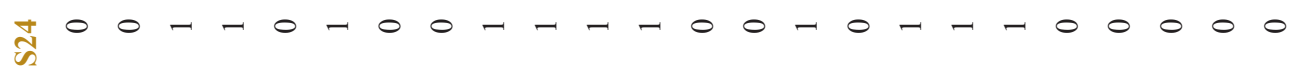

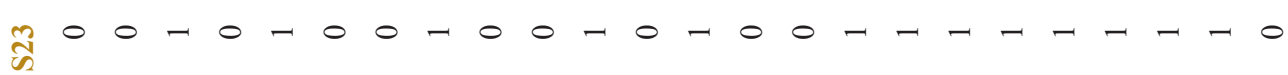

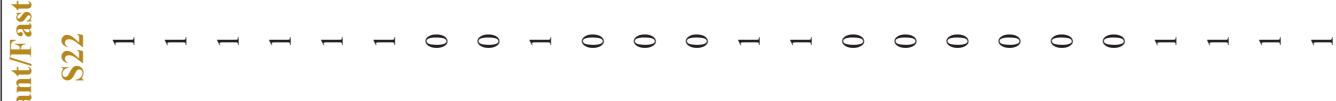

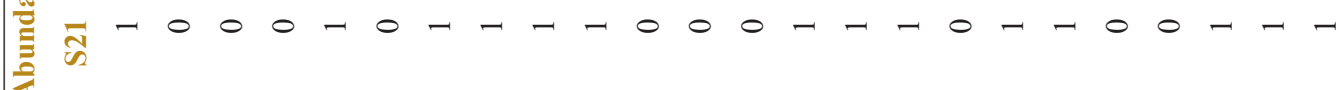
㫕 $0-0-0-1000-0-0-0-000-000-$

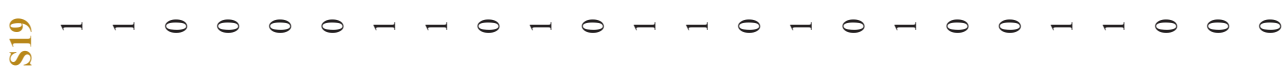
$\frac{\infty}{\infty}-1000--1-00-0-1-0-000-1-0$ $\frac{n}{n}-00-7-0000-000-1-7-00-70$

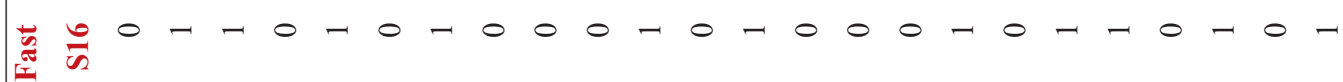
党

$\frac{\pi}{n} 0---1-0-0-000-0-00-1-0-0$ $\frac{m}{n}-00--0-1-1-0-10-0-1-0,0-0-$ $\frac{\pi}{2}-1-000-1-000-00-00-0-0-10$ $\vec{\nabla}-0-10-0-0-00-1-0-00-0000-$ 党

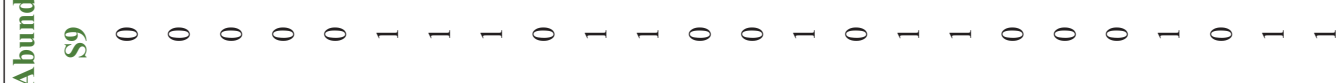
$\infty 0-0--1-0-1-0-10000-0-1-00$ in $000-1000-0-1-00-1-0-1-0-0$ బ $00-000-1-0-1000-1-1-00-1-0$ n $0-0-t-r-0000-1-0-00-1-000$

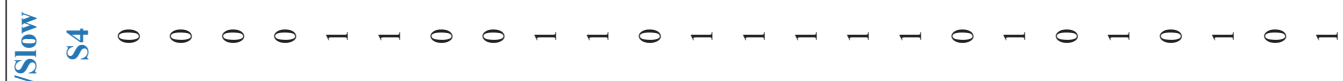
nू $\tilde{W}-0--100000-1-0-10-0-000--$ $\bar{D}-0-0-00-1-1-0000-1-00-0-0$ 
Table S3: Custom primers used for 16S-rRNA library generation; the 12-bp barcode is marked in bold letters.

\begin{tabular}{ll} 
Primer & Sequence $\left.\mathbf{( 5}^{\prime} \mathbf{- 3}{ }^{\prime}\right)$ \\
\hline 515f & AATGATACGGCGACCACCGAGATCTACACTATGGTAATTGTGTGCCAGCM \\
& GCCGCGGTAA \\
806r & CAAGCAGAAGACGGCATACGAGATTCCCTTGTCTCCAGTCAGTCAGCCGG \\
& ACTACHVGGGTWTCTAAT
\end{tabular}

Table S4: statistical results from linear mixed model with relative abundance as the dependent variable.

\begin{tabular}{lll} 
Factor & F & p \\
\hline Nutrients & $0.01_{3,3718}$ & 1.0 \\
Predator & $0.1_{1,3718}$ & 0.75 \\
Species group & $2.1_{3,19}$ & 0.13 \\
Nutrient:Species group & $7.9_{9,3718}$ & $<0.01^{*}$ \\
Predator:Species group & $11.3_{3.3718}$ & $<0.01^{*}$ \\
Predator:Nutrient & $0.02_{3,3718}$ & 1.0 \\
Predator:Nutrient:Species group & $2.09,3718$ & $0.04^{*}$
\end{tabular}

Table S5: statistical results from linear-mixed effect models for the change in relative abundance with nutrient concentration and predation for species group pairs (for the effect of predation on the group pair AbunFas:AbunSlo a $\mathrm{X}^{2}$-test was conducted).

\begin{tabular}{lllll} 
& \multicolumn{2}{l}{$\begin{array}{l}\text { Effect of nutrient } \\
\text { concentration }\end{array}$} & & \multicolumn{2}{l}{ Effect of predation } \\
Groups & F & p & F & p \\
\hline AbunFas:AbunSlo & $1.0_{1,1806}$ & 0.32 & & 0.37 \\
AbunFas:RarFas & $17.2_{1,1870}$ & $<0.01^{*}$ & $9.8_{1,1871}$ & $<0.01^{*}$ \\
AbunFas:RarSlo & $0.7_{1,2066}$ & 0.41 & $6.5_{1,2064}$ & $0.01^{*}$ \\
AbunSlo:RarSlo & $2.9_{1,1870}$ & 0.09 & $3.0_{1,1868}$ & 0.08 \\
AbunSlo:RarFas & $18.7_{1,1675}$ & $<0.01^{*}$ & $10.9_{1,1675}$ & $<0.01^{*}$ \\
RarFas:RarSlo & $13.4_{1,1936}$ & $<0.01^{*}$ & $20.5_{1,1933}$ & $<0.01^{*}$
\end{tabular}


Table S6: statistical results of Spearman correlations between relative abundance in the control and relative abundance reduction in the predation treatment for each species; significant $\mathrm{p}$-values are marked in bold $(\mathrm{n}=45-93)$.

\begin{tabular}{llll} 
Species & S & rho & p \\
\hline S1 & 23116 & 0.21 & 0.12 \\
S2 & 222682 & -0.66 & $\mathbf{0 . 0 0}$ \\
S3 & 196490 & -0.51 & $\mathbf{0 . 0 0}$ \\
S4 & 180480 & -0.35 & $\mathbf{0 . 0 0}$ \\
S5 & 86451 & 0.12 & 0.26 \\
S6 & 187652 & -0.40 & $\mathbf{0 . 0 0}$ \\
S7 & 28073 & -0.73 & $\mathbf{0 . 0 0}$ \\
S8 & 28811 & -0.67 & $\mathbf{0 . 0 0}$ \\
S9 & 19803 & -0.30 & $\mathbf{0 . 0 4}$ \\
S10 & 138197 & -0.82 & $\mathbf{0 . 0 0}$ \\
S11 & 60856 & -0.61 & $\mathbf{0 . 0 0}$ \\
S12 & 94656 & 0.29 & $\mathbf{0 . 0 0}$ \\
S13 & 170376 & -0.31 & $\mathbf{0 . 0 0}$ \\
S14 & 33569 & -0.52 & $\mathbf{0 . 0 0}$ \\
S15 & 222778 & -0.66 & $\mathbf{0 . 0 0}$ \\
S16 & 149394 & -0.11 & 0.27 \\
S18 & 193488 & -0.44 & $\mathbf{0 . 0 0}$ \\
S19 & 65739 & -0.44 & $\mathbf{0 . 0 0}$ \\
S20 & 145412 & -0.33 & $\mathbf{0 . 0 0}$ \\
S21 & 41974 & -0.51 & $\mathbf{0 . 0 0}$ \\
S22 & 147850 & -0.22 & $\mathbf{0 . 0 4}$ \\
S23 & 166182 & -0.24 & $\mathbf{0 . 0 2}$ \\
S24 & 184830 & -0.47 & $\mathbf{0 . 0 0}$
\end{tabular}

Table 7: Statistical results of a linear model and Anova testing differences in the relationship between relative abundance in the control and reduction in relative abundance by predation.

\begin{tabular}{lll} 
Factor & F & p \\
\hline Reduction & $235.0_{1}$ & $<0.01^{*}$ \\
Species group & $72.3_{3}$ & $<0.01^{*}$ \\
Reduction:Species group & $62.8_{3}$ & $<0.01^{*}$
\end{tabular}


Table 8: statistical results of pairwise linear models testing differences in the relationship between relative abundance in the control and reduction in relative abundance by predation between the four species groups.

\begin{tabular}{lll} 
Groups & $\mathbf{t}$ & $\mathbf{p}$ \\
\hline AbunFas:AbunSlo & $3.7_{3,846}$ & $<0.01^{*}$ \\
AbunFas:RarFas & $-4.3_{3,899}$ & $<0.01^{*}$ \\
AbunFas:RarSlo & $-0.5_{3,988}$ & 0.64 \\
AbunSlo:RarSlo & $-6.5_{3,876}$ & $<0.01^{*}$ \\
AbunSlo:RarFas & $7.2_{3,787}$ & $<0.01$ \\
RarFas:RarSlo & $9.8_{3,929}$ & $<0.01^{*}$
\end{tabular}

Table 9: Statistical results of pairwise contrasts from a linear model testing differences in the relationship between relative abundance in the control and reduction in relative abundance by predation for different nutrient concentrations within each species group.

\begin{tabular}{|c|c|c|c|c|c|c|c|c|c|c|c|c|}
\hline \multicolumn{2}{|c|}{$\begin{array}{l}\text { Nutrient } \\
\text { concentratio } \\
\text { n }\end{array}$} & $\begin{array}{l}0.0001- \\
0.001\end{array}$ & \multicolumn{2}{|c|}{$\begin{array}{l}0.0001- \\
0.01\end{array}$} & \multicolumn{2}{|c|}{$\begin{array}{l}0.0001- \\
0.1\end{array}$} & \multicolumn{2}{|c|}{$\begin{array}{l}\text { 0.001- } \\
0.01\end{array}$} & \multicolumn{2}{|c|}{$\begin{array}{l}0.001- \\
0.1\end{array}$} & \multicolumn{2}{|c|}{$\begin{array}{l}0.01- \\
0.1\end{array}$} \\
\hline Group & $\mathbf{t}$ & p & t- & $\mathbf{p}$ & $\mathrm{t}$ & p & $\mathbf{t}$ & $\mathbf{p}$ & $t$ & $\mathbf{p}$ & $\mathrm{t}$ & $\mathbf{p}$ \\
\hline \multirow[t]{3}{*}{ RarSlo } & - & 0.16 & $0.0_{50}$ & 1 & - & $<0.0$ & $2.3_{50}$ & 0.11 & - & 1 & - & $<0.0$ \\
\hline & $2.1_{50}$ & & 3 & & $4.3_{50}$ & $1^{*}$ & 3 & & $0.2_{50}$ & & $5.8_{50}$ & $1^{*}$ \\
\hline & 3 & & & & 3 & & & & 3 & & 3 & \\
\hline \multirow[t]{3}{*}{ RarFas } & $1.0_{41}$ & 0.77 & - & 0.66 & - & 0.83 & - & 0.31 & - & 0.31 & $0.6_{41}$ & 0.93 \\
\hline & 4 & & $1.1_{41}$ & & $0.9_{41}$ & & $1.7_{41}$ & & $1.5_{41}$ & & 4 & \\
\hline & & & 4 & & 4 & & 4 & & 4 & & & \\
\hline \multirow[t]{3}{*}{ AbunSlo } & - & $<0.0$ & $2.4_{36}$ & 0.08 & $3.6_{36}$ & $<0.0$ & $7.8_{36}$ & $<0.0$ & $7.3_{36}$ & $<0.0$ & $2.2_{36}$ & 0.14 \\
\hline & $3.5_{36}$ & $1^{*}$ & 1 & & 1 & $1^{*}$ & 1 & $1 *$ & 1 & $1^{*}$ & & \\
\hline & 1 & & & & & & & & & & & \\
\hline \multirow[t]{3}{*}{ AbunFas } & - & 0.91 & - & $<0.0$ & - & 0.85 & - & 0.02 & - & 0.99 & $2.5_{47}$ & 0.11 \\
\hline & $0.7_{47}$ & & $3.7_{47}$ & $1^{*}$ & $0.8_{47}$ & & $2.9_{47}$ & $*$ & $0.2_{47}$ & & 3 & \\
\hline & 3 & & 3 & & 3 & & 3 & & 3 & & & \\
\hline
\end{tabular}


Table S10: Statistical results of a linear mixed effect model testing the effect of predation and nutrient concentration on relative abundance for each species; significant p-values are marked in bold.

\begin{tabular}{|c|c|c|c|c|c|c|c|c|c|c|}
\hline $\begin{array}{l}\text { Spec } \\
\text { ies }\end{array}$ & Treatment & $\begin{array}{l}\text { D } \\
\text { f }\end{array}$ & $\begin{array}{l}\text { Sum. } \\
\text { Sq }\end{array}$ & $\begin{array}{l}\text { Mean } \\
\text {.Sq }\end{array}$ & $\begin{array}{l}\text { F.val } \\
\text { ue }\end{array}$ & $\begin{array}{l}\text { upper.d } \\
\text { en.df }\end{array}$ & $\begin{array}{l}\text { upper. } \\
\text { p.val }\end{array}$ & $\begin{array}{l}\text { lower.de } \\
\text { n.df }\end{array}$ & $\begin{array}{l}\text { lower.p } \\
\text {.val }\end{array}$ & $\begin{array}{l}\text { expl. } \\
\text { dev. }\end{array}$ \\
\hline S1 & Predator & 1 & $\begin{array}{l}0.000 \\
0 \\
\end{array}$ & $\begin{array}{l}0.000 \\
0 \\
\end{array}$ & 0.3 & 134 & 0.57 & 110 & 0.57 & 0.17 \\
\hline S1 & Nutrient & 1 & $\begin{array}{l}0.000 \\
1\end{array}$ & $\begin{array}{l}0.000 \\
1 \\
\end{array}$ & 30.2 & 134 & 0.00 & 110 & 0.00 & 15.98 \\
\hline S1 & $\begin{array}{l}\text { Predator:N } \\
\text { utrient }\end{array}$ & 1 & $\begin{array}{l}0.000 \\
0 \\
\end{array}$ & $\begin{array}{l}0.000 \\
0\end{array}$ & 0.1 & 134 & 0.81 & 110 & 0.81 & 0.03 \\
\hline S2 & Predator & 1 & $\begin{array}{l}0.011 \\
0\end{array}$ & $\begin{array}{l}0.011 \\
0\end{array}$ & 4.6 & 185 & 0.03 & 161 & 0.03 & 1.33 \\
\hline S2 & Nutrient & 1 & $\begin{array}{l}0.053 \\
1\end{array}$ & $\begin{array}{l}0.053 \\
1\end{array}$ & 22.1 & 185 & 0.00 & 161 & 0.00 & 6.41 \\
\hline S2 & $\begin{array}{l}\text { Predator:N } \\
\text { utrient }\end{array}$ & 1 & $\begin{array}{l}0.000 \\
4\end{array}$ & $\begin{array}{l}0.000 \\
4\end{array}$ & 0.2 & 185 & 0.68 & 161 & 0.68 & 0.05 \\
\hline $\mathbf{S 3}$ & Predator & 1 & $\begin{array}{l}0.001 \\
4\end{array}$ & $\begin{array}{l}0.001 \\
4\end{array}$ & 0.8 & 184 & 0.37 & 160 & 0.37 & 0.25 \\
\hline S3 & Nutrient & 1 & $\begin{array}{l}0.000 \\
3 \\
\end{array}$ & $\begin{array}{l}0.000 \\
3 \\
\end{array}$ & 0.2 & 184 & 0.67 & 160 & 0.67 & 0.06 \\
\hline $\mathbf{S 3}$ & $\begin{array}{l}\text { Predator:N } \\
\text { utrient }\end{array}$ & 1 & $\begin{array}{l}0.004 \\
5 \\
\end{array}$ & $\begin{array}{l}0.004 \\
5 \\
\end{array}$ & 2.5 & 184 & 0.11 & 160 & 0.11 & 0.79 \\
\hline S4 & Predator & 1 & $\begin{array}{l}0.630 \\
2\end{array}$ & $\begin{array}{l}0.630 \\
2\end{array}$ & $\begin{array}{l}154 . \\
3\end{array}$ & 185 & 0.00 & 161 & 0.00 & 27.01 \\
\hline S4 & Nutrient & 1 & $\begin{array}{l}0.173 \\
1\end{array}$ & $\begin{array}{l}0.173 \\
1\end{array}$ & 42.4 & 185 & 0.00 & 161 & 0.00 & 7.42 \\
\hline S4 & $\begin{array}{l}\text { Predator:N } \\
\text { utrient }\end{array}$ & 1 & $\begin{array}{l}0.477 \\
9\end{array}$ & $\begin{array}{l}0.477 \\
9\end{array}$ & $\begin{array}{l}117 . \\
0\end{array}$ & 185 & 0.00 & 161 & 0.00 & 20.49 \\
\hline S5 & Predator & 1 & $\begin{array}{l}0.000 \\
0\end{array}$ & $\begin{array}{l}0.000 \\
0\end{array}$ & 0.8 & 176 & 0.37 & 152 & 0.37 & 0.25 \\
\hline S5 & Nutrient & 1 & $\begin{array}{l}0.001 \\
3\end{array}$ & $\begin{array}{l}0.001 \\
3\end{array}$ & 36.7 & 176 & 0.00 & 152 & 0.00 & 11.28 \\
\hline S5 & $\begin{array}{l}\text { Predator:N } \\
\text { utrient }\end{array}$ & 1 & $\begin{array}{l}0.000 \\
0 \\
\end{array}$ & $\begin{array}{l}0.000 \\
0 \\
\end{array}$ & 0.1 & 176 & 0.80 & 152 & 0.80 & 0.02 \\
\hline S6 & Predator & 1 & $\begin{array}{l}0.006 \\
0 \\
\end{array}$ & $\begin{array}{l}0.006 \\
0 \\
\end{array}$ & 5.6 & 185 & 0.02 & 161 & 0.02 & 1.44 \\
\hline S6 & Nutrient & 1 & $\begin{array}{l}0.037 \\
6 \\
\end{array}$ & $\begin{array}{l}0.037 \\
6 \\
\end{array}$ & 35.0 & 185 & 0.00 & 161 & 0.00 & 9.02 \\
\hline S6 & $\begin{array}{l}\text { Predator:N } \\
\text { utrient }\end{array}$ & 1 & $\begin{array}{l}0.001 \\
1\end{array}$ & $\begin{array}{l}0.001 \\
1\end{array}$ & 1.0 & 185 & 0.32 & 161 & 0.32 & 0.26 \\
\hline S7 & Predator & 1 & $\begin{array}{l}0.000 \\
0\end{array}$ & $\begin{array}{l}0.000 \\
0\end{array}$ & 0.0 & 100 & 1.00 & 80 & 1.00 & 0.00 \\
\hline S7 & Nutrient & 1 & $\begin{array}{l}0.000 \\
0\end{array}$ & $\begin{array}{l}0.000 \\
0\end{array}$ & 2.2 & 100 & 0.14 & 80 & 0.14 & 0.22 \\
\hline S7 & $\begin{array}{l}\text { Predator:N } \\
\text { utrient }\end{array}$ & 1 & $\begin{array}{l}0.000 \\
0\end{array}$ & $\begin{array}{l}0.000 \\
0\end{array}$ & 0.4 & 100 & 0.55 & 80 & 0.55 & 0.03 \\
\hline S8 & Predator & 1 & $\begin{array}{l}0.000 \\
0 \\
\end{array}$ & $\begin{array}{l}0.000 \\
0 \\
\end{array}$ & 2.7 & 101 & 0.10 & 81 & 0.11 & 1.71 \\
\hline S8 & Nutrient & 1 & $\begin{array}{l}0.000 \\
0 \\
\end{array}$ & $\begin{array}{l}0.000 \\
0 \\
\end{array}$ & 25.4 & 101 & 0.00 & 81 & 0.00 & 16.25 \\
\hline S8 & $\begin{array}{l}\text { Predator:N } \\
\text { utrient }\end{array}$ & 1 & $\begin{array}{l}0.000 \\
0\end{array}$ & $\begin{array}{l}0.000 \\
0 \\
\end{array}$ & 1.1 & 101 & 0.29 & 81 & 0.29 & 0.73 \\
\hline S9 & Predator & 1 & $\begin{array}{l}0.000 \\
0\end{array}$ & $\begin{array}{l}0.000 \\
0\end{array}$ & 0.3 & 100 & 0.57 & 79 & 0.57 & 0.27 \\
\hline
\end{tabular}




\begin{tabular}{|c|c|c|c|c|c|c|c|c|c|c|}
\hline S9 & Nutrient & 1 & $\begin{array}{l}0.000 \\
1\end{array}$ & $\begin{array}{l}0.000 \\
1\end{array}$ & 18.4 & 100 & 0.00 & 79 & 0.00 & 15.45 \\
\hline S9 & $\begin{array}{l}\text { Predator:N } \\
\text { utrient }\end{array}$ & 1 & $\begin{array}{l}0.000 \\
0 \\
\end{array}$ & $\begin{array}{l}0.000 \\
0 \\
\end{array}$ & 0.4 & 100 & 0.52 & 79 & 0.52 & 0.36 \\
\hline S10 & Predator & 1 & $\begin{array}{l}0.000 \\
1\end{array}$ & $\begin{array}{l}0.000 \\
1 \\
\end{array}$ & 16.1 & 161 & 0.00 & 137 & 0.00 & 7.99 \\
\hline S10 & Nutrient & 1 & $\begin{array}{l}0.000 \\
1 \\
\end{array}$ & $\begin{array}{l}0.000 \\
1 \\
\end{array}$ & 13.1 & 161 & 0.00 & 137 & 0.00 & 6.50 \\
\hline S10 & $\begin{array}{l}\text { Predator:N } \\
\text { utrient }\end{array}$ & 1 & $\begin{array}{l}0.000 \\
0 \\
\end{array}$ & $\begin{array}{l}.000 \\
0 \\
\end{array}$ & 5.9 & 161 & 0.02 & 137 & 0.02 & 2.95 \\
\hline S11 & Predator & 1 & $\begin{array}{l}0.000 \\
0 \\
\end{array}$ & $\begin{array}{l}0.000 \\
0 \\
\end{array}$ & 0.8 & 141 & 0.37 & 117 & 0.37 & 0.48 \\
\hline S11 & Nutrient & 1 & $\begin{array}{l}0.000 \\
0\end{array}$ & $\begin{array}{l}0.000 \\
0 \\
\end{array}$ & 8.4 & 141 & 0.00 & 117 & 0.00 & 5.03 \\
\hline S11 & $\begin{array}{l}\text { Predator:N } \\
\text { utrient }\end{array}$ & 1 & $\begin{array}{l}0.000 \\
0 \\
\end{array}$ & $\begin{array}{l}0.000 \\
0\end{array}$ & 1.8 & 141 & 0.19 & 117 & 0.19 & 1.05 \\
\hline S12 & Predator & 1 & $\begin{array}{l}0.035 \\
3\end{array}$ & $\begin{array}{l}0.035 \\
3\end{array}$ & 12.2 & 185 & 0.00 & 161 & 0.00 & 2.19 \\
\hline S12 & Nutrient & 1 & $\begin{array}{l}0.251 \\
6 \\
\end{array}$ & $\begin{array}{l}0.251 \\
6 \\
\end{array}$ & 87.0 & 185 & 0.00 & 161 & 0.00 & 15.62 \\
\hline S12 & $\begin{array}{l}\text { Predator:N } \\
\text { utrient }\end{array}$ & 1 & $\begin{array}{l}0.009 \\
6 \\
\end{array}$ & $\begin{array}{l}0.009 \\
6\end{array}$ & 3.3 & 185 & 0.07 & 161 & 0.07 & 0.60 \\
\hline S13 & Predator & 1 & $\begin{array}{l}0.000 \\
0 \\
\end{array}$ & $\begin{array}{l}0.000 \\
0\end{array}$ & 0.0 & 184 & 0.89 & 160 & 0.89 & 0.01 \\
\hline S13 & Nutrient & 1 & $\begin{array}{l}0.040 \\
1\end{array}$ & $\begin{array}{l}0.040 \\
1\end{array}$ & 16.4 & 184 & 0.00 & 160 & 0.00 & 6.30 \\
\hline $\begin{array}{l}\text { S13 } \\
\end{array}$ & $\begin{array}{l}\text { Predator:N } \\
\text { utrient }\end{array}$ & 1 & $\begin{array}{l}0.003 \\
3 \\
\end{array}$ & $\begin{array}{l}0.003 \\
3 \\
\end{array}$ & 1.3 & 184 & 0.25 & 160 & 0.25 & 0.51 \\
\hline S14 & Predator & 1 & $\begin{array}{l}0.000 \\
0 \\
\end{array}$ & $\begin{array}{l}0.000 \\
0 \\
\end{array}$ & 0.0 & 117 & 0.88 & 95 & 0.89 & 0.02 \\
\hline S14 & Nutrient & 1 & $\begin{array}{l}0.000 \\
0\end{array}$ & $\begin{array}{l}0.000 \\
0\end{array}$ & 18.6 & 117 & 0.00 & 95 & 0.00 & 13.65 \\
\hline S14 & $\begin{array}{l}\text { Predator:N } \\
\text { utrient }\end{array}$ & 1 & $\begin{array}{l}0.000 \\
0\end{array}$ & $\begin{array}{l}0.000 \\
0\end{array}$ & 0.1 & 117 & 0.81 & 95 & 0.81 & 0.04 \\
\hline S15 & Predator & 1 & $\begin{array}{l}0.042 \\
8 \\
\end{array}$ & $\begin{array}{l}0.042 \\
8 \\
\end{array}$ & 24.0 & 185 & 0.00 & 161 & 0.00 & 4.94 \\
\hline S15 & Nutrient & 1 & $\begin{array}{l}0.026 \\
2 \\
\end{array}$ & $\begin{array}{l}0.026 \\
2 \\
\end{array}$ & 14.7 & 185 & 0.00 & 161 & 0.00 & 3.03 \\
\hline S15 & $\begin{array}{l}\text { Predator:N } \\
\text { utrient }\end{array}$ & 1 & $\begin{array}{l}0.007 \\
0 \\
\end{array}$ & $\begin{array}{l}0.007 \\
0 \\
\end{array}$ & 3.9 & 185 & 0.05 & 161 & 0.05 & 0.81 \\
\hline S16 & Predator & 1 & $\begin{array}{l}0.000 \\
1 \\
\end{array}$ & $\begin{array}{l}0.000 \\
1 \\
\end{array}$ & 0.0 & 185 & 0.91 & 161 & 0.91 & 0.00 \\
\hline S16 & Nutrient & 1 & $\begin{array}{l}2.076 \\
8\end{array}$ & $\begin{array}{l}2.076 \\
8\end{array}$ & $\begin{array}{l}360 . \\
0\end{array}$ & 185 & 0.00 & 161 & 0.00 & 44.80 \\
\hline S16 & $\begin{array}{l}\text { Predator:N } \\
\text { utrient }\end{array}$ & 1 & $\begin{array}{l}0.000 \\
3 \\
\end{array}$ & $\begin{array}{l}0.000 \\
3 \\
\end{array}$ & 0.1 & 185 & 0.81 & 161 & 0.81 & 0.01 \\
\hline S18 & Predator & 1 & $\begin{array}{l}0.374 \\
8 \\
\end{array}$ & $\begin{array}{l}0.374 \\
8\end{array}$ & 40.2 & 185 & 0.00 & 161 & 0.00 & 4.11 \\
\hline S18 & Nutrient & 1 & $\begin{array}{l}0.066 \\
4\end{array}$ & $\begin{array}{l}0.066 \\
4\end{array}$ & 7.1 & 185 & 0.01 & 161 & 0.01 & 0.73 \\
\hline S18 & $\begin{array}{l}\text { Predator:N } \\
\text { utrient }\end{array}$ & 1 & $\begin{array}{l}0.110 \\
3\end{array}$ & $\begin{array}{l}0.110 \\
3\end{array}$ & 11.8 & 185 & 0.00 & 161 & 0.00 & 1.21 \\
\hline S19 & Predator & 1 & $\begin{array}{l}0.000 \\
0\end{array}$ & $\begin{array}{l}0.000 \\
0\end{array}$ & 3.0 & 144 & 0.09 & 120 & 0.09 & 1.40 \\
\hline S19 & Nutrient & 1 & $\begin{array}{l}0.000 \\
0\end{array}$ & $\begin{array}{l}0.000 \\
0\end{array}$ & 22.2 & 144 & 0.00 & 120 & 0.00 & 10.31 \\
\hline S19 & $\begin{array}{l}\text { Predator:N } \\
\text { utrient }\end{array}$ & 1 & $\begin{array}{l}0.000 \\
0 \\
\end{array}$ & $\begin{array}{l}0.000 \\
0 \\
\end{array}$ & 1.6 & 144 & 0.21 & 120 & 0.21 & 0.73 \\
\hline
\end{tabular}




\begin{tabular}{|c|c|c|c|c|c|c|c|c|c|c|}
\hline S20 & Predator & 1 & $\begin{array}{l}0.000 \\
0\end{array}$ & $\begin{array}{l}0.000 \\
0\end{array}$ & 0.8 & 178 & 0.36 & 154 & 0.36 & 0.20 \\
\hline S20 & Nutrient & 1 & $\begin{array}{l}0.002 \\
1\end{array}$ & $\begin{array}{l}0.002 \\
1 \\
\end{array}$ & 56.9 & 178 & 0.00 & 154 & 0.00 & 13.52 \\
\hline $\mathbf{S 2 0}$ & $\begin{array}{l}\text { Predator:N } \\
\text { utrient }\end{array}$ & 1 & $\begin{array}{l}0.000 \\
0\end{array}$ & $\begin{array}{l}0.000 \\
0\end{array}$ & 0.2 & 178 & 0.66 & 154 & 0.66 & 0.05 \\
\hline S21 & Predator & 1 & $\begin{array}{l}0.000 \\
0\end{array}$ & $\begin{array}{l}0.000 \\
0\end{array}$ & 2.4 & 112 & 0.13 & 93 & 0.13 & 2.06 \\
\hline S21 & Nutrient & 1 & $\begin{array}{l}0.000 \\
0\end{array}$ & $\begin{array}{l}0.000 \\
0\end{array}$ & 0.6 & 112 & 0.43 & 93 & 0.43 & 0.55 \\
\hline S21 & $\begin{array}{l}\text { Predator:N } \\
\text { utrient }\end{array}$ & 1 & $\begin{array}{l}0.000 \\
0\end{array}$ & $\begin{array}{l}0.000 \\
0\end{array}$ & 0.4 & 112 & 0.55 & 93 & 0.55 & 0.32 \\
\hline S22 & Predator & 1 & $\begin{array}{l}0.001 \\
0\end{array}$ & $\begin{array}{l}0.001 \\
0\end{array}$ & 0.3 & 182 & 0.57 & 158 & 0.57 & 0.09 \\
\hline S22 & Nutrient & 1 & $\begin{array}{l}0.127 \\
5\end{array}$ & $\begin{array}{l}0.127 \\
5\end{array}$ & 41.5 & 182 & 0.00 & 158 & 0.00 & 11.37 \\
\hline S22 & $\begin{array}{l}\text { Predator:N } \\
\text { utrient }\end{array}$ & 1 & $\begin{array}{l}0.000 \\
6\end{array}$ & $\begin{array}{l}0.000 \\
6\end{array}$ & 0.2 & 182 & 0.65 & 158 & 0.65 & 0.06 \\
\hline $\mathbf{S 2 3}$ & Predator & 1 & $\begin{array}{l}0.001 \\
6 \\
\end{array}$ & $\begin{array}{l}0.001 \\
6 \\
\end{array}$ & 0.4 & 185 & 0.53 & 161 & 0.53 & 0.10 \\
\hline $\mathbf{S 2 3}$ & Nutrient & 1 & $\begin{array}{l}0.007 \\
6\end{array}$ & $\begin{array}{l}0.007 \\
6\end{array}$ & 1.9 & 185 & 0.17 & 161 & 0.17 & 0.49 \\
\hline $\mathbf{S 2 3}$ & $\begin{array}{l}\text { Predator:N } \\
\text { utrient }\end{array}$ & 1 & $\begin{array}{l}0.000 \\
3 \\
\end{array}$ & $\begin{array}{l}0.000 \\
3 \\
\end{array}$ & 0.1 & 185 & 0.79 & 161 & 0.79 & 0.02 \\
\hline S24 & Predator & 1 & $\begin{array}{l}0.000 \\
1\end{array}$ & $\begin{array}{l}0.000 \\
1\end{array}$ & 0.2 & 183 & 0.64 & 159 & 0.64 & 0.09 \\
\hline S24 & Nutrient & 1 & $\begin{array}{l}0.003 \\
7\end{array}$ & $\begin{array}{l}0.003 \\
7\end{array}$ & 9.0 & 183 & 0.00 & 159 & 0.00 & 3.95 \\
\hline S24 & $\begin{array}{l}\text { Predator:N } \\
\text { utrient }\end{array}$ & 1 & $\begin{array}{l}0.000 \\
0\end{array}$ & $\begin{array}{l}0.000 \\
0\end{array}$ & 0.1 & 183 & 0.82 & 159 & 0.82 & 0.02 \\
\hline
\end{tabular}


Table S11: Statistical results of pairwise non-parametric linear mixed models testing differences in the relationship between relative abundance in the control and reduction in relative abundance by predation for different nutrient concentrations between the groups with 0.0001 as the reference nutrient concentration.

\begin{tabular}{lllllll} 
& \multicolumn{2}{l}{$\mathbf{0 . 0 0 0 1 - 0 . 0 0 1}$} & \multicolumn{2}{l}{$\mathbf{0 . 0 0 0 1 - 0 . 0 1}$} & \multicolumn{2}{l}{$\mathbf{0 . 0 0 0 1 - 0 . 1}$} \\
Groups & $\mathbf{t}$ & $\mathbf{p}$ & $\mathbf{t}$ & $\mathbf{p}$ & $\mathbf{t}$ & $\mathbf{p}$ \\
\hline AbunFas:AbunSlo & 1.6 & 0.11 & -4.2 & $<0.01^{*}$ & -2.8 & $<0.01^{*}$ \\
AbunFas:RarFas & $-1,0$ & 0.32 & -1.4 & 0.16 & -0.2 & 0.86 \\
AbunFas:RarSlo & 0.4 & 0.57 & -3.6 & $<0.01^{*}$ & 0.4 & 0.67 \\
AbunSlo:RarSlo & -1.4 & 0.16 & 2.1 & $0.04^{*}$ & 4.6 & $<0.01^{*}$ \\
AbunSlo:RarFas & -1.9 & 0.06 & 1.5 & 0.13 & 1.7 & 0.08 \\
RarFas:RarSlo & 1.6 & 0.11 & -1.1 & 0.29 & 1.0 & 0.33
\end{tabular}

Table S12: statistical results of pairwise linear models testing differences in the relationship between relative abundance in the control and reduction in relative abundance by predation between groups over all nutrient levels; data analysis after exclusion of species $\mathrm{S} 4$, therefore only group RarSlo is shown; for all results see Table 4.

\begin{tabular}{lll} 
Group & t & p \\
\hline RarSlo:AbunFas & -5.9 & $<0.01^{*}$ \\
RarSlo:AbunSlo & -12.8 & $<0.01^{*}$ \\
RarSlo:RarFas & 0.9 & 0.35 \\
RarSlo & -15.7 & $<0.01^{*}$
\end{tabular}

Table S13: Statistical results of pairwise linear models resting differences in the relationship between relative abundance in the control and reduction in relative abundance by predation for different nutrient concentrations between the groups with 0.0001 as the reference nutrient concentration; data analysis after exclusion of species S4

\begin{tabular}{lllllll} 
& \multicolumn{2}{l}{$\mathbf{0 . 0 0 0 1 - 0 . 0 0 1}$} & \multicolumn{2}{c}{$\mathbf{0 . 0 0 0 1 - 0 . 0 1}$} & \multicolumn{2}{c}{$\mathbf{0 . 0 0 0 1 - 0 . 0 1}$} \\
Groups & $\mathbf{t}$ & $\mathbf{p}$ & $\mathbf{t}$ & $\mathbf{p}$ & $\mathbf{t}$ & $\mathbf{p}$ \\
\hline RarSlo:AbunFas & 1.5 & 0.13 & 4.0 & $<0.01^{*}$ & 0.7 & 0.49 \\
RarSlo:AbunSlo & 3.8 & $<0.01^{*}$ & -1.6 & 0.11 & -3.5 & $<0.01^{*}$ \\
RarSlo:RarFas & 0.1 & 0.95 & 1.2 & 0.24 & 0.4 & 0.72
\end{tabular}




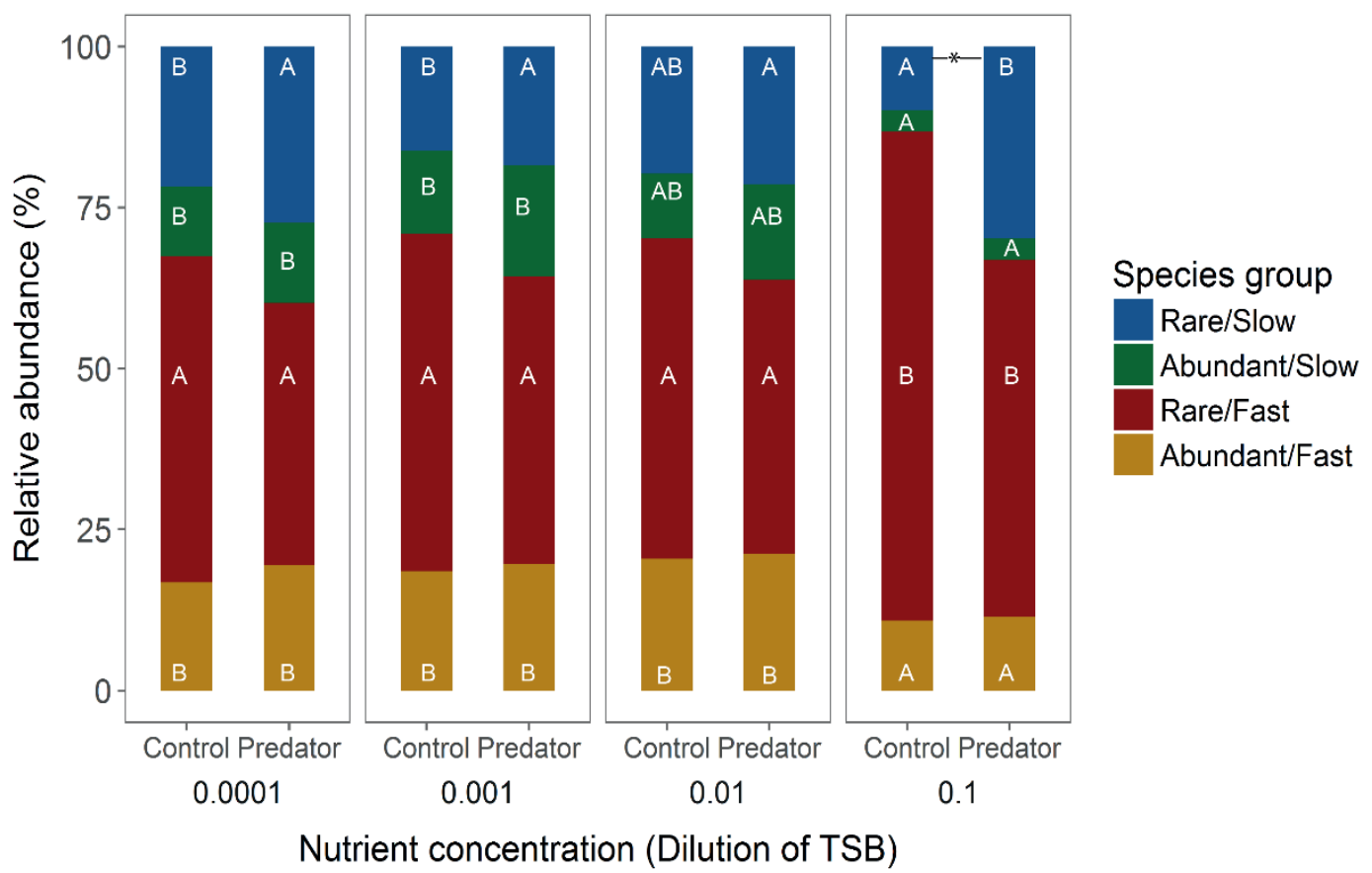

Fig. S1: Average relative abundance of the four bacterial species groups at the different nutrient concentrations in the predator free control and the predation treatment; different letters indicate significant differences between nutrient concentrations within one species group; significant differences are marked with *. 


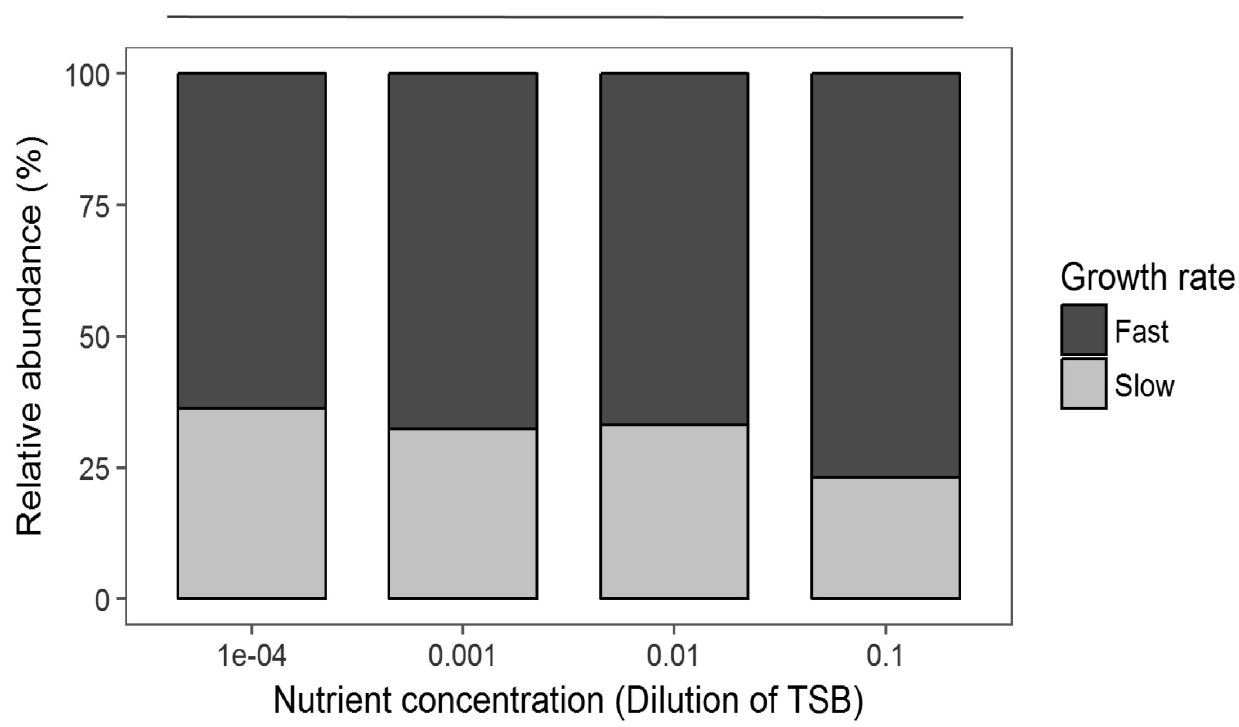

Figure S2: Average relative abundance of bacterial species with potential fast and slow growth rates at the four different nutrient concentrations; relative abundances are averaged over predation treatment, community and abundance groups; significant changes in abundance with nutrient concentration are indicated with *.

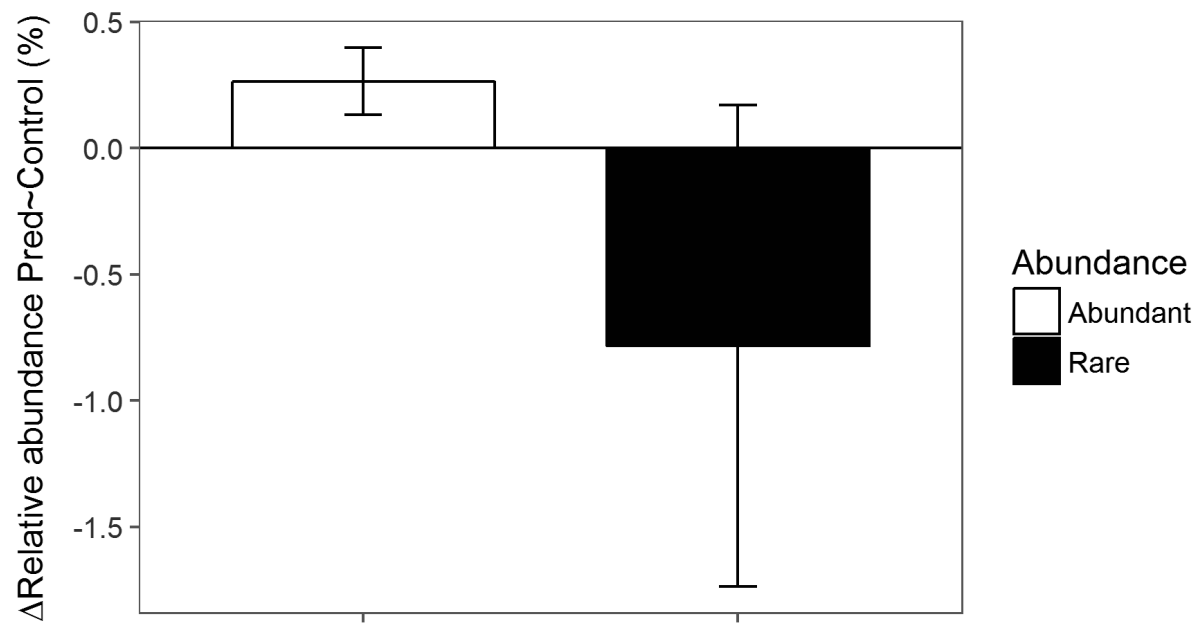

Fig. S3: Average difference in bacterial relative abundance between the control and the predation treatment concentrations for species that were characterized as abundant or rare in the field; results are averaged over nutrient concentration, community and potential growth rate; error bars represent the standard error. 

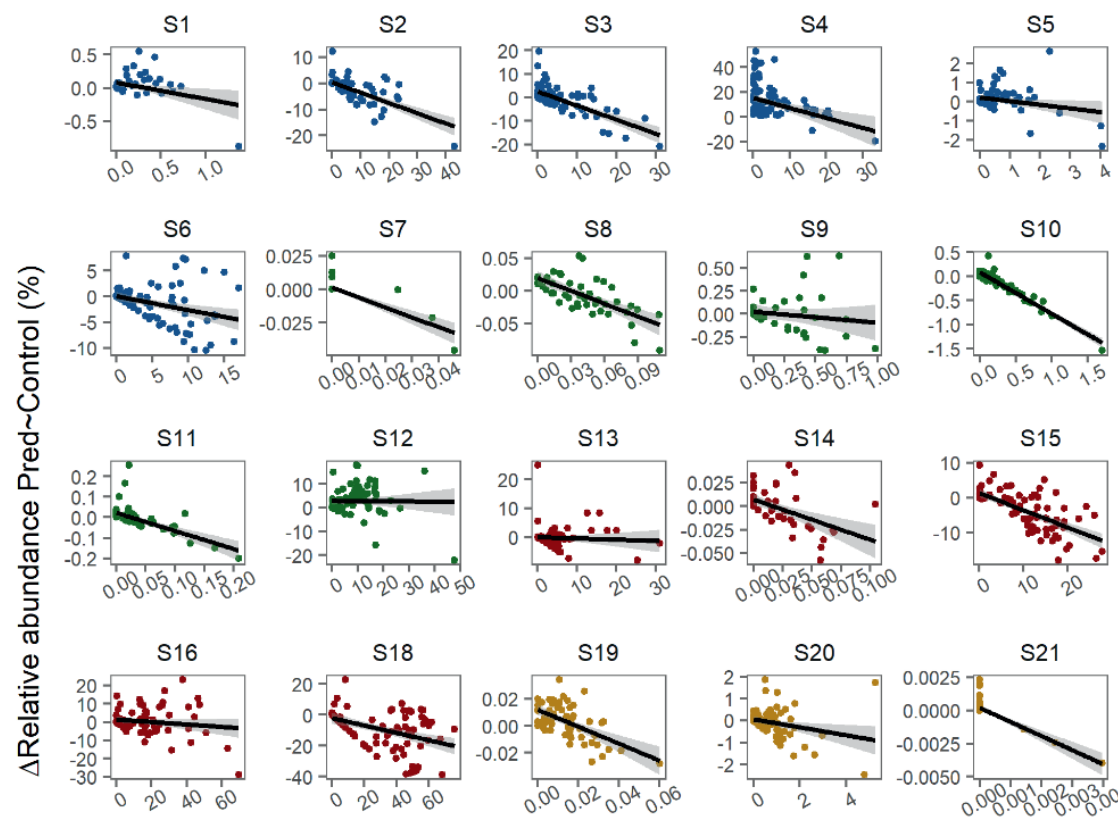

Species group

- Rare/Slow

- Abundant/Slow

- Rare/Fast

- Abundant/Fast
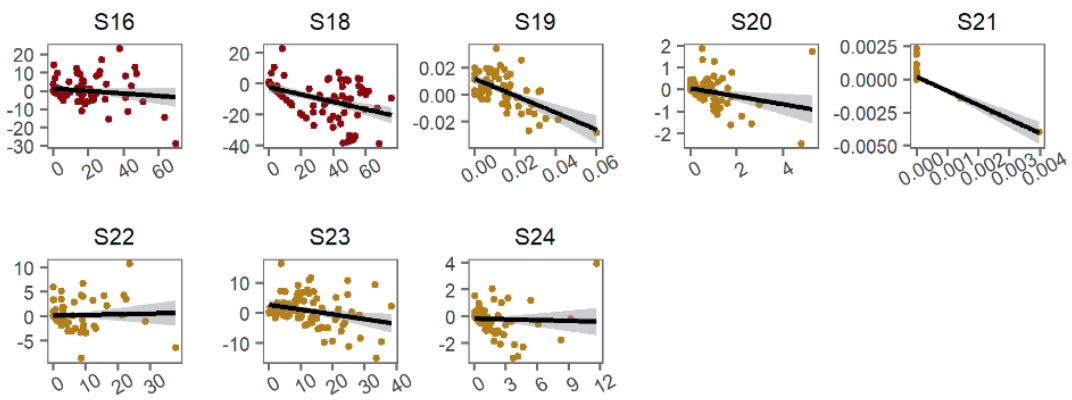

Relative abundance CTRL (\%)

Figure S4: Abundance loss by predation plotted against relative abundance in the control for each species; each dot represents one community at the 4 nutrient levels; different colours represent the four species groups; lines represent a linear model fit for each species. 


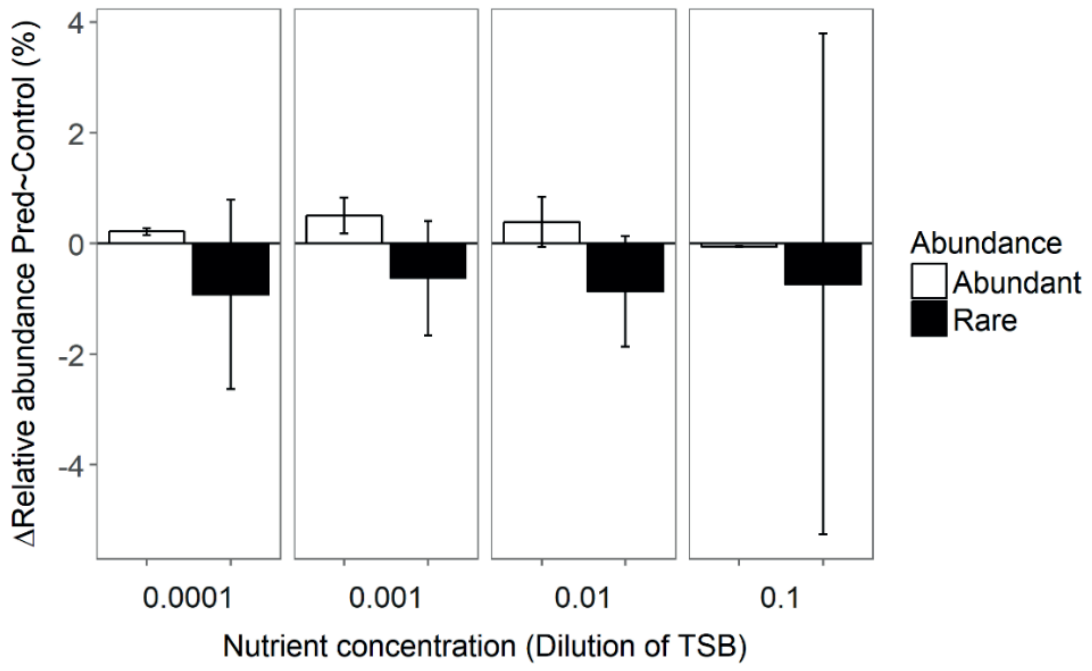

Figure S5: Average difference in relative abundance between the control and the predation treatment at the four different nutrient concentrations for species that were characterized as abundant or rare in the field; results are averaged over community and potential growth rate; error bars represent the standard error.
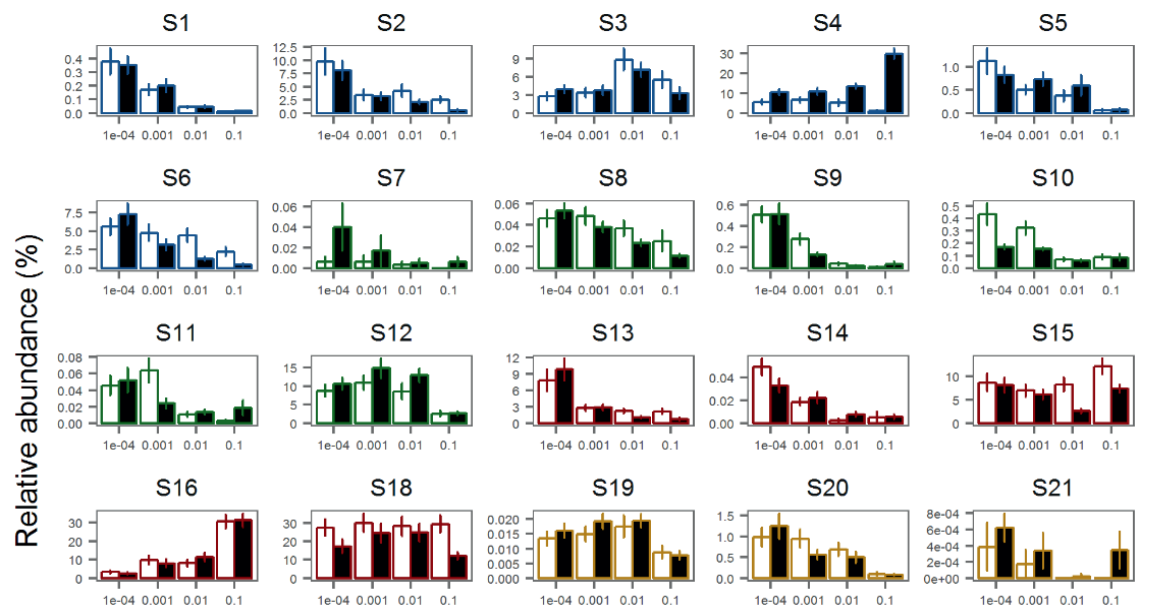

Predation
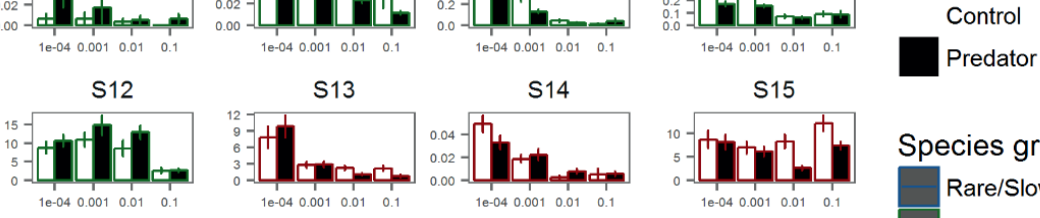

Predator
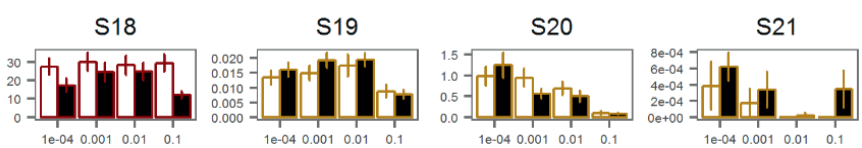

Species group
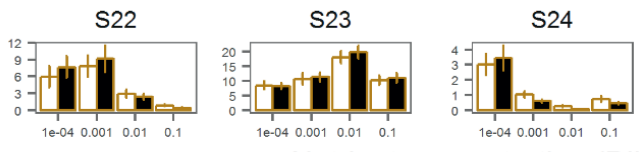

Nutrient concentration (Dilution of TSB)

Figure S6: Average relative abundance of each species at the different nutrient concentrations and with and without predation; relative abundances were averaged over communities; error bars indicate the standard error; different colours indicate the four species groups. 


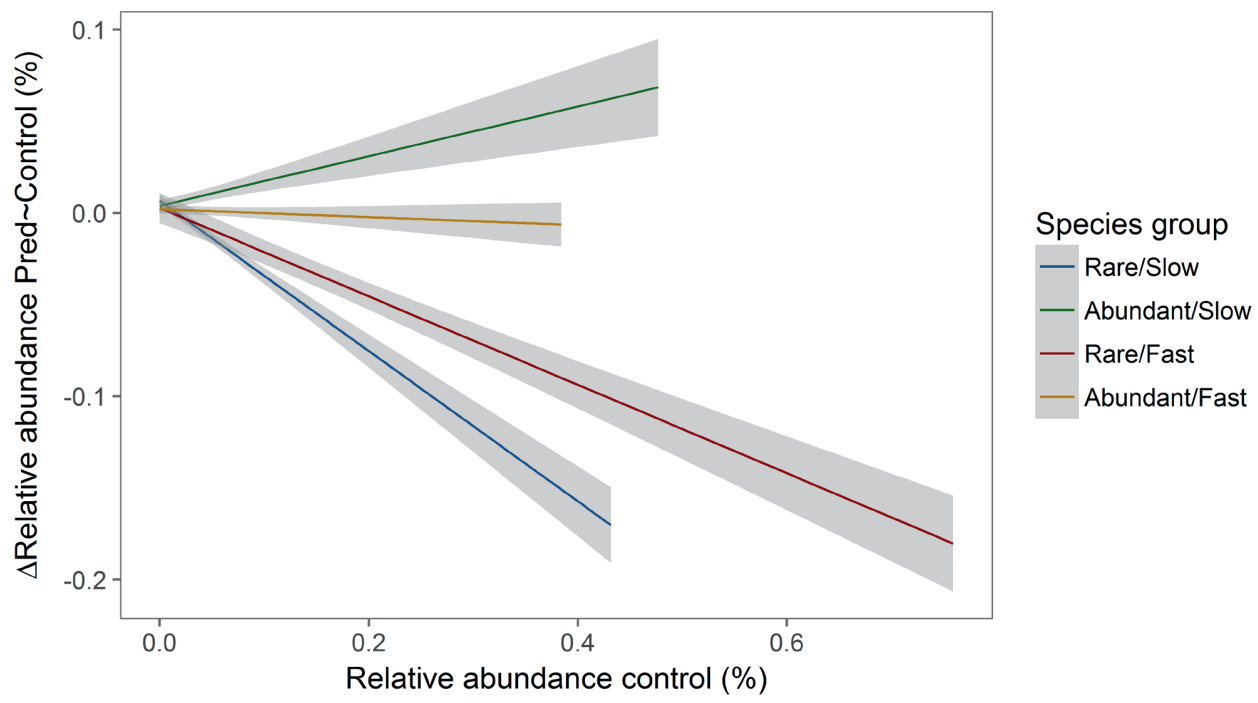

Figure S7: Linear model fit with standard error of the relationship between relative abundance in the control and relative abundance reduction in the predation treatment after omitting species S4; different colours represent the four species groups.

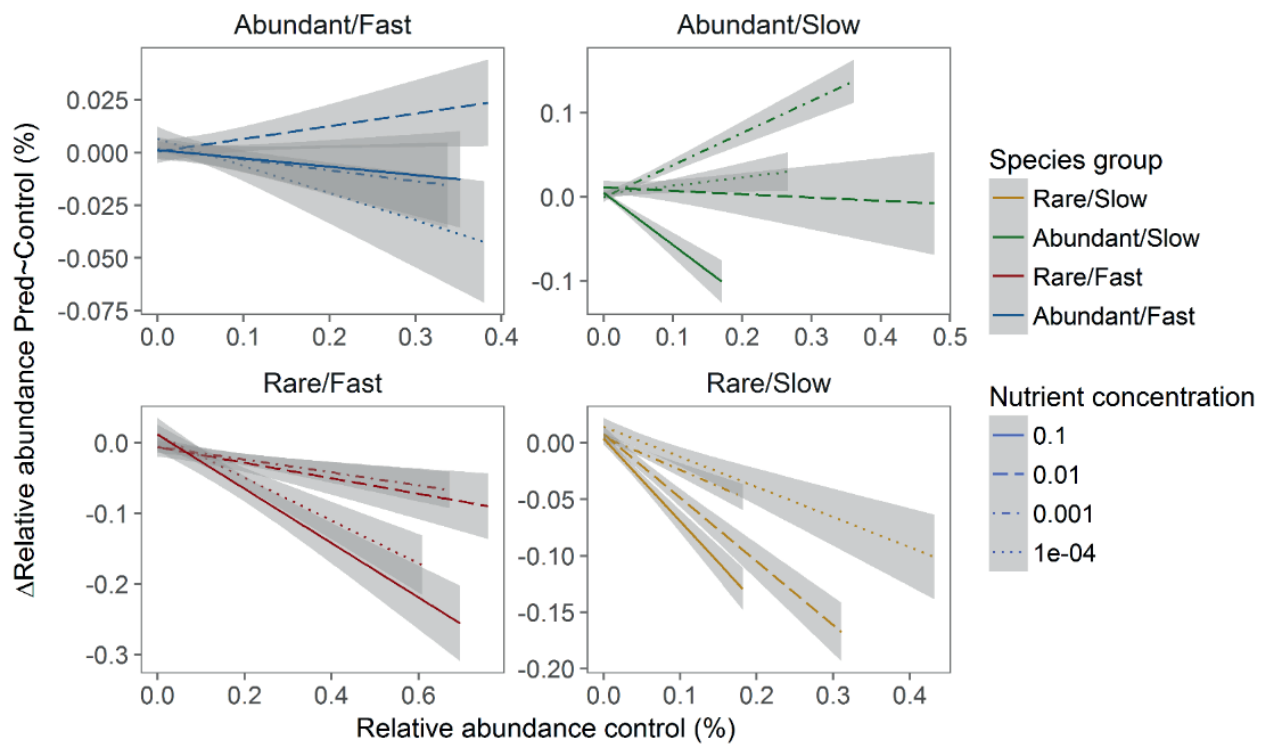

Figure S8: Linear model fit with standard error of the relationship between relative abundance in the control and relative abundance reduction in the predation treatment at the four different nutrient concentrations after omitting species S4; different colours represent the four species groups and different linetypes represent the different nutrient concentrations. 


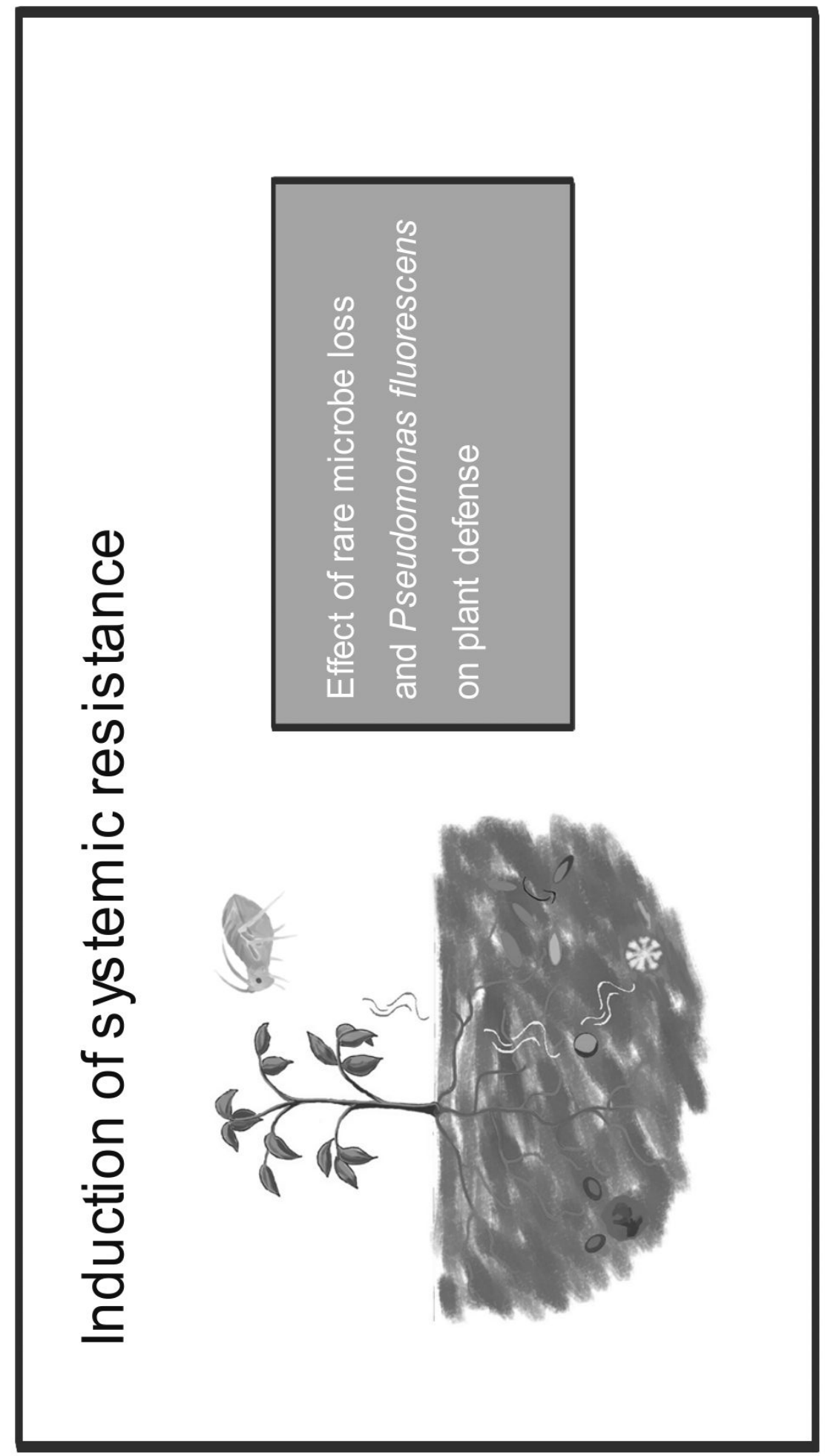




\section{Chapter 5}

Soil microbial species loss affects plant biomass and survival of an introduced bacterial strain, but not inducible plant defences

Viola Kurm, Wim H. van der Putten, Ana Pineda \& W.H. Gera Hol

Annals of Botany (2018) 


\begin{abstract}
Plant growth-promoting rhizobacteria (PGPR) strains can influence plant-insect interactions. However, little is known about the effect of changes in the soil bacterial community in general and especially the loss of rare soil microbes on these interactions. Here, the influence of rare soil microbe-reduction on induced systemic resistance (ISR) in a wild ecotype of Arabidopsis thaliana against the aphid Myzus persicae was investigated. To create a gradient of microbial abundances, soil was inoculated with a serial dilution of a microbial community and responses of Arabidopsis plants that originated from the same site as the soil microbes were tested. Plant biomass, transcription of genes involved in plant defences, and insect performance were measured. In addition, the effects of the PGPR strain Pseudomonas fluorescens SS101 on plant and insect performance were tested under influence of the various soil dilution treatments. Plant biomass showed a hump-shaped relationship with soil microbial community dilution, independent of aphid or Pseudomonas treatments. Both aphid infestation and inoculation with Pseudomonas reduced plant biomass, and led to downregulation of PR1 (salicylic acid-responsive gene) and CYP79B3 (involved in synthesis of glucosinolates). Aphid performance and gene transcription were unaffected by soil dilution. Neither the loss of rare microbial species, as caused by soil dilution, nor Pseudomonas, affect the resistance of A. thaliana against M. persicae. However, both Pseudomonas survival and plant biomass respond to rare species loss. Thus, loss of rare soil microbial species can have a significant impact on both above- and belowground organisms.
\end{abstract}

\title{
Introduction
}

There is increasing awareness that some soil bacterial strains may have beneficial effects on plants (Compant et al. 2010). Most intensively studied and applied are the so-called plant growth-promoting rhizobacteria (PGPR). PGPR can directly promote plant growth, and also systemically enhance plant defences against above- and belowground pathogens and herbivores (Lugtenberg and Kamilova 2009, Pieterse et al. 2014). A widely known mechanism through which beneficial soil microorganisms can affect plant defence is designated induced systemic resistance (ISR) (Van der Ent et al. 2009). ISR is dependent on jasmonic acid (JA) and ethylene (ET), but can also be mediated via salicylic acid (SA) signalling and is triggered by interaction with non-pathogenic microbes. Colonization of plant roots by certain PGPR may prime plant defences, resulting in a faster and stronger defence response upon pathogen or insect attack (Van Wees et al. 2008). ISR is most effective against necrotrophic pathogens and insect herbivores (Pieterse and Dicke 2007). However, little is known about how the induction of resistance by single PGPR strains compares to effect of a natural soil microbial community on plant resistance.

Many PGPR have been recognized to be able to induce systemic resistance in the plant. Especially fluorescent pseudomonads have a high effectiveness in the protection of plant health. Different bacterial species or strains have been found to induce resistance via different 
pathways. Some interact with only particular plant hosts (Pieterse et al. 2002, Pieterse et al. 2003). For example, Pseudomonas fluorescens WCS417 protects Arabidopsis thaliana against a variety of pathogens via priming of the jasmonic acid (JA)- signalling pathway, whereas $P$. fluorescens SS101 has been found to increase plant resistance by inducing SAdependent defences (Pieterse et al. 2002, Van de Mortel et al. 2012, Pangesti et al. 2017). Also other bacterial species, such as Bacillus amyloliquefaciens, Bacillus subtilis or Serratia marcescens, have shown protective ability (Mauch-Mani and Métraux 1998, Van Loon and Bakker 2006). In order to acquire effective induced resistance in plants, high densities of $10^{5}$ colony-forming units (CFU) per gram root of a previously cultured PGPR strain in soil are required (Raaijmakers et al. 1995). However, the bacterial numbers often rapidly decline once inoculated into soil, as a result of competition with the microbial community that already exists in the soil (Mallon et al. 2015, Adam et al. 2016). Reduced species richness could be expected to reduce competition and lead to increased survival of PGPR.

Besides well-studied PGPR strains, soil is also inhabited by numerous other bacteria and other microbial species carrying out many different functions (Bent and Forney 2008). Whereas soil bacterial diversity may relate positively to specific ecosystem functions (Griffiths et al. 2004, Cook et al. 2006), there is increasing evidence that the presence and absence of certain species, as well as their relative abundances, might be even more important than species diversity (Strickland et al. 2009). Especially low-abundant bacterial species, also termed the 'rare biosphere' (Sogin et al. 2006) can have a greater impact on certain ecosystem processes than predicted based on their abundance (Jousset et al. 2017). Rare taxa may contribute disproportionally to microbial community dynamics and activity (Jones and Lennon 2010, Shade et al. 2014, Wilhelm et al. 2014). Rare microbes that are specialized on recalcitrant substrates may play a crucial role in decomposition of soil organic matter. In addition, the presence of a high diversity of rare species may increase the community resistance to pathogen invasion, thereby enhancing soil disease suppressiveness (Van Elsas et al. 2012, Baumann et al. 2013). However, a high diversity might also reduce the survival of introduced beneficial microbes. Rare soil microbes have also been shown to influence plant defences (Hol et al. 2010). In that study, the loss of rare microbes from soil was correlated with a decrease in plant defensive compounds and an increase in aphid performance. However, the molecular mechanisms behind this decrease still remain unresolved.

The effect of specific plant growth-promoting bacterial strains on ISR in plants has been intensively studied. In contrast, the effect of soil microbial community composition, especially the low-abundant members of the community, are poorly studied. Recent reports on the possible roles of the rare biosphere in ecosystem functioning raise questions about their contribution to plant defence induction relative to introduced PGPR (Van Elsas et al. 2012, Delgado-Baquerizo et al. 2016). Therefore, the aim of the present study was to test 
how (loss of) rare soil microbial species influences plant performance and induction of plant defences against aboveground insect herbivores. Furthermore, we investigated how loss of rare soil microbes affects defence induction by a known PGPR strain.

Our first hypothesis was that plants growing in soils containing a complete assemblage of low-abundant microbes will be more resistant to insect herbivores than plants growing in soils that lack a large fraction of these low-abundant microbes, based on our previous research (Hol et al. 2010). We expected that this resistance would be based on induced systemic resistance, which is known to be effective against aphid herbivores (De Vos et al. 2007). We also expected that soil with a full microbial community compared to soil with a community reduced in rare microbes would lead to: (1) a less negative effect of aboveground aphids on biomass of Arabidopsis thaliana, (2) priming of enhanced expression of defencemarker genes in A. thaliana via the ISR pathway and consequently a higher expression of JA- and ET-dependent genes in the presence of herbivores, and (3) decreased insect fecundity. Our second hypothesis was that the addition of the PGPR strain Pseudomonas fluorescens SS101 would prime plant defences against insect herbivory, and that this effect would be reduced in microbial communities containing low abundance species (Mallon et al. 2015).

\section{Material and Methods}

To test these hypotheses, we performed a soil dilution experiment [using a similar approach to that described by Hol et al. (2010)], in which plants of a wild ecotype of Arabidopsis thaliana originating from a grassland were grown in soil with six subsequent dilutions of a microbial community from the same grassland. Pseudomonas bacteria and the aphid herbivore Myzus persicae were added in a full factorial design. Myzus persicae is a common herbivore of Arabidopsis in the field and Pseudomonas has been shown to induce systemic resistance in this plant species (Harvey et al. 2007, Van de Mortel et al. 2012). After $24 \mathrm{~h}$ of aphid feeding the expression of several genes involved in induced plant defences was measured. After 2 weeks of aphid feeding, plant biomass and aphid reproductive success were assessed.

\section{Soil collection and treatment}

Ten soil samples (referred to as soil origins in the following) were collected from a biodiversity field experiment near Ede (the Netherlands). (For more details see Supplementary Information, Soil collection). Soil inocula were made by suspending $30 \mathrm{~g}$ of

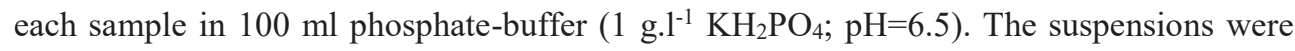
shaken for $1.5 \mathrm{~h}$ at $120 \mathrm{rpm}$, sonicated twice for $1 \mathrm{~min}$, followed by another $0.5 \mathrm{~h}$ of shaking. Subsequently they were sieved through a $45 \mu \mathrm{m}$ sieve. Thus, the mesofauna was excluded, but microorganisms, such as bacteria, archaea, fungi and protozoa were kept. The resulting suspension represents the undiluted inoculum (or $10^{\circ}$-dilution). Four subsequent 1:100 
dilutions were prepared from all ten suspensions and used as inocula. Consequently the five dilutions are $10^{0}, 10^{2}, 10^{4}, 10^{6}$ and $10^{8}$.

Three kilograms of sterilized bulk soil in autoclavable polypropylene plastic bags was inoculated with $100 \mathrm{ml}$ of each dilution from each of the ten soil origins. Ten bags, serving as the sterile control, received $100 \mathrm{ml}$ of sterile phosphate buffer similar to the dilution treatments resulting in 60 bags of $3 \mathrm{~kg}$ each (five dilution treatments + control $\times$ ten soil origins). The bags were closed with a cotton wool plug to allow gas exchange. Then, the bags were stored at room temperature for a period of 25 weeks during which the soil was homogenized every week by turning over the bags several times. This incubation was done in order to enable the microbial communities to reach similar cell densities independent of the dilution treatment (Griffiths et al. 2004, Hol et al. 2010). It was expected that in all soil origins dilution treatment would reduce the rare species as has been found in numerous previous dilution studies (Van Elsas et al. 2012, Yan et al. 2015, Roger et al. 2016).

\section{Pseudomonas fluorescens SS101 cultivation}

A rifampicin-resistant natural mutant of Pseudomonas fluorescens SS101 was cultured in liquid lysogeny broth (LB) medium for $24 \mathrm{~h}$ at $25^{\circ} \mathrm{C}$ with continuous shaking, washed three times in sterile $\mathrm{MgSO}_{4}$ buffer $\left(2.64 \mathrm{gl}^{-1} \mathrm{MgSO}_{4}\right)$ and adjusted to a final concentration of $10^{9}$ CFU per $\mathrm{ml}\left(\mathrm{OD}_{600}=1.0\right)$. One day prior to planting, all bags with $3 \mathrm{~kg}$ soil from all dilution treatments including the sterile control were split into two bags of $1.5 \mathrm{~kg}$ each. One bag of $1.5 \mathrm{~kg}$ for each treatment was inoculated with $15 \mathrm{ml}$ of Pseudomonas suspension resulting in a final concentration of $10^{7} \mathrm{CFU} \mathrm{g}^{-1}$ soil (+Pseudomonas). Soil receiving no Pseudomonas inoculum was mock-treated with $15 \mathrm{ml}$ sterile $\mathrm{MgSO}_{4}$ buffer (-Pseudomonas).

\section{Plant and insect material}

The ecotype of $A$. thaliana (Msl) used in this study was obtained from the Laboratory of Molecular Biology of Wageningen University (Wageningen, The Netherlands) and originally obtained from the site where the soil had been collected. All seeds used in this study originated from an inbred line and represented the third generation since collection from the field. The seeds were surface vapour-sterilized (van de Mortel et al., 2012). Five seeds per plate were sown on half-strength Murashige-Skoog agar (4.3 g. l $^{-1}$ Murashige-Skoog salts with vitamins, 10 g..$^{-1}$ sucrose, 8 g. $l^{-1}$ plant agar) and germinated for $7 \mathrm{~d}$ in a climate chamber at a day/night cycle of $8 / 16 \mathrm{~h}, 21 / 21^{\circ} \mathrm{C}, 200 \mu \mathrm{mol} \mathrm{m} \mathrm{m}^{-2} \mathrm{~s}^{-1}$ light intensity at plant level and $70 \%$ relative humidity.

The generalist aphid species Myzus persicae (Sulzer) was reared in a growth cabinet under a day/night cycle of $16 / 8 \mathrm{~h}, 22 / 22^{\circ} \mathrm{C}$ and $50-70 \%$ relative humidity. Aphids were reared on $A$. thaliana plants of the same ecotype as used in the experiment. One day prior to plant infestation adult aphids were isolated in a separate net cage to enable the collection of neonates. 


\section{Experimental setup and maintenance}

Each bag of soil was used to fill three pots of $500 \mathrm{~g}$ soil each, resulting in 360 pots [ten soil origins $\times$ six dilution treatments $\times$ two Pseudomonas treatments ( + Pseudomonas/Pseudomonas $) \times$ three pots]. The soil was saturated with autoclaved demineralized water (Demi) and one 7 d-old Arabidopsis seedling was planted in each pot. The plants were grown in a growth chamber in a randomized block design under the same conditions as during germination. Each block consisted of three trays each with 12 pots of a single soil origin with every dilution treatment present in duplicate (with and without Pseudomonas) and distributed randomly across the tray. This resulted in 27 trays with nine soil origins (Supplementary Information Fig. S2). Plants in soil from origin CA5 were randomly distributed over the 27 trays. Once a week, trays moved position in the growth chamber while keeping the trays for soil origins adjacent to each other. The plants were watered three times a week with a total volume of $50 \mathrm{ml}$ demineralized water per pot.

Five weeks after transfer of the seedlings to the soil, plants on two trays of each soil origin (two out of three pots with the same treatment) were infested with aphids resulting in a full factorial experiment with all 10 soil origins, all five dilution treatments and the sterile control, the Pseudomonas treatment ( + Pseudomonas/- Pseudomonas) and the aphid treatment (+Aphids/-Aphids). This resulted in a pot number of $n=10$ for treatments without aphids, whereas treatments with aphids had a pot number of $n=20$ (for all treatments see overview in Supplementary Information Fig. S1).

One-half of the plants that were chosen for the aphid treatment were infested with six aphids of mixed ages from the general rearing. The other half of these plants were infested with five aphids from the mixed rearing and one neonate aphid $(<24 \mathrm{~h})$, which was placed in a clipcage so that time until first reproduction and number of offspring could be measured (Supplementary Information Fig. S3). Clipcages are round cages of $2.3 \mathrm{~cm}$ diameter that are attached to a leaf and allow an insect to feed on this leave, but prevent it from moving freely on the plant. This setup resulted in six aphids for each plant in total. After aphid infestation, all trays were placed individually in insect cages to prevent movement of aphids between infested and uninfested plants. One fully expanded leaf was harvested from each plant $24 \mathrm{~h}$ after aphid infestation to analyse gene expression. For aphid-treated plants, leaves containing at least one aphid were selected, and harvested after removal of the insect from the leaf. Leaves were shock frozen in liquid nitrogen after clipping and stored at $-80^{\circ} \mathrm{C}$ until RNA isolation. The expression of five genes was assessed by real time quantitative PCR (RTqPCR): $C Y B 79 B 3, H E L, P D F 1.2$ and VSP2, involved in JA- and ET-dependent plant defence pathways, and $P R 1$, involved in SA-dependent defences (for more details see Supplementary Information: RNA extraction and quantitative RT-PCR analysis). 
The reproduction of the aphids in the clipcages was observed continuously and aphids reproduced latest at an age of $10 \mathrm{~d}$. Two weeks after aphid infestation the aphids in the clipcages were counted and all aphids were removed from the plants by careful brushing. On the same day plant shoots and roots were harvested. Subsequently, they were oven-dried for assessment of dry weight. Prior to root washing, rhizosphere soil was collected for +Pseudomonas treatments and several-Pseudomonas soils to control for contamination. The roots were carefully removed from the bulk soil and shaken gently. The remaining attached soil was designated as rhizosphere soil, transferred into a $1.5 \mathrm{ml}$ Eppendorf-tube and stored at $4^{\circ} \mathrm{C}$ for a maximum of 2 weeks for Pseudomonas quantification (see Supplementary Information: Pseudomonas quantification).

\section{Statistical analysis}

All statistical analyses were carried out in R (R Core Team 2016).

The effects of dilution treatment (specified as a discrete factor), Pseudomonas inoculation and aphid infestation on the response variables shoot and root biomass, the number of Pseudomonas, the number of aphid offspring, the time until first aphid reproduction and the expression of all five genes were analysed using linear mixed effect models. The fixed factors were nested in the random factor soil origin. For plant shoot biomass, time until first aphid reproduction and the expression of the genes $C Y B 79 B 3$ and $P R 1$ the function lmer() from the lme4 package was used together with the step function from the lmerTest package (Bates et al. 2015). Due to non-normal distribution of residuals glmmPQL() function from the package MASS was used to fit mixed models for plant root biomass, Pseudomonas numbers and the expression of the genes HEL, PDF1.2 and VSP2 (Venables and Ripley 2002). For the number of aphid offspring the glmer() function from the lme4 package was used. For the number of Pseudomonas a quasipoisson-error distribution was specified, for the gene expression and root biomass a Gaussian-distribution with a log link, and for the number of aphid offspring a Gamma-distribution with a log link.

In addition, the relationship between the number of Pseudomonas and gene-expression, as well as plant biomass and the relationship between the number of aphid offspring and plant biomass were analysed with the lmer() function with soil origin as a random factor.

\section{Results}

Plant biomass response to dilution, Pseudomonas inoculation and aphid infestation

Shoot and root biomass were significantly affected by dilution treatment (for statistical results see Table 1). Both shoot and root biomass showed a hump-shaped relationship with dilution treatment, increasing from the $10^{0}$ - to the $10^{6}$-dilution by $23 \%$ and $18 \%$, respectively (Fig. 1). Biomass then decreased from the $10^{6}$-dilution to the sterilized control by $15 \%$ in shoots and $8 \%$ in roots; however, this decrease was not significant. Aphids overall decreased shoot and root biomass by $46 \%$ and $25 \%$, respectively, but this reduction was independent of the 
dilution treatment (Fig. 1). There was considerable variation in biomass response to dilution and aphid treatment due to large differences among the soil origins (e.g. shoot biomass; Supplementary Information Fig. S4). The largest plant had on average twice as much biomass as the smallest plant (from soil origin LD2 and $\mathrm{NC} 2$ respectively).

At the end of the experiment, 7 weeks after Pseudomonas inoculation, this strain could still be recovered from soil. The number of Pseudomonas CFUs had decreased in all soils compared with the density that was inoculated $\left(10^{7} \mathrm{CFU} \cdot \mathrm{g}^{-1}\right.$ soil). The number of recovered Pseudomonas was positively associated with increasing soil dilution (Fig. 2). Pseudomonas decreased least in the sterilized control soil, to $37000 \mathrm{CFU} . \mathrm{g}^{-1}$ soil $(0.37 \%$ of the original inoculum) and most in the 100 -dilution, to $2700 \mathrm{CFU} \cdot \mathrm{g}^{-1}$ soil $(0.027 \%$ of the original inoculum). In spite of the substantial effect of dilution treatment on CFU.g ${ }^{-1}$ soil, the inoculation effect on shoot biomass did not depend on dilution treatment: Pseudomonas reduced shoot biomass by an average of $7.8 \%$ regardless of soil community dilution. Root biomass was unaffected by Pseudomonas inoculation (Supplementary Information Fig. S5). Pseudomonas numbers also differed between soil origins with an $\sim 19$-fold higher number in LD5 soil than in CA4 soil. 
Table 1: Statistical results of linear mixed models in this study assessed with ${ }^{1}$ the 1 mer function, ${ }^{2}$ the glmmPQL function with a gaussian error distribution, ${ }^{3}$ the glmmPQL function with a quasipoisson error distribution, ${ }^{4}$ the glmmPQL function with a Gamma error distribution and log link; below the results for the main effects the standard deviation of the random effect soil origin and the residual standard deviation are given. Stat represents the F or $\mathrm{X}^{2}$ value for analyses carried out using the lmer or the glmmPQL function respectively.

\begin{tabular}{|c|c|c|c|c|c|c|c|c|c|c|}
\hline & $\begin{array}{l}\text { Shoot } \\
\text { biom } \\
\text { ass }^{1}\end{array}$ & $\begin{array}{l}\text { Root } \\
\text { biomass }^{2}\end{array}$ & $\begin{array}{l}C Y B 79 \\
B 3^{I}\end{array}$ & $\underset{2}{H E L}$ & $P D F 1.2^{2}$ & $P R 1^{1}$ & $V S P 2^{2}$ & $\begin{array}{l}\text { Pseudom } \\
\text { onas } \\
\text { count }^{3}\end{array}$ & $\begin{array}{l}\text { Aphid } \\
\text { reproduc } \\
\text { tion } \\
\text { time }^{1} \\
\end{array}$ & $\begin{array}{l}\text { No. } \\
\text { Aphid } \\
\text { offspring } \\
4\end{array}$ \\
\hline Dilution df & 5 & 5 & 5 & 5 & 5 & 5 & 5 & 5 & 5 & 5 \\
\hline stat & 2.5 & 19.2 & 0.6 & 4.1 & 5.1 & 0.4 & 6.9 & 34.7 & 2.5 & 3.6 \\
\hline $\mathbf{p}$ & 0.04 & $<0.01$ & 0.74 & 0.53 & 0.4 & 0.81 & 0.23 & $<0.01$ & 0.78 & 0.61 \\
\hline Aphid df & 1 & 1 & 1 & 1 & 1 & 1 & 1 & 1 & & \\
\hline stat & 176.3 & 58.4 & 8.1 & 0.9 & 0.1 & 5.3 & 2.3 & 0.7 & & \\
\hline $\mathbf{p}$ & $<0.01$ & $<0.01$ & $<0.01$ & 0.34 & 0.75 & 0.02 & 0.25 & 0.4 & & \\
\hline $\begin{array}{l}\text { Pseudomonas } \\
\text { df }\end{array}$ & 1 & 1 & 1 & 1 & 1 & 1 & 1 & & 1 & 1 \\
\hline stat & 59.1 & 1.3 & 12.3 & 0.9 & 1 & 5.7 & 1 & & 0.002 & 0.4 \\
\hline $\mathbf{p}$ & 0.05 & 0.025 & $<0.01$ & 0.34 & 0.31 & 0.02 & 0.31 & & 0.96 & 0.52 \\
\hline $\begin{array}{l}\text { Dilution:Aphi } \\
\text { d df }\end{array}$ & 5 & 5 & 5 & 5 & 5 & 5 & 5 & 5 & & \\
\hline stat & $\begin{array}{l}0.4 \\
0.82\end{array}$ & $\begin{array}{l}6.8 \\
0.23\end{array}$ & $\begin{array}{l}0.7 \\
0.64\end{array}$ & $\begin{array}{l}5.2 \\
0.39\end{array}$ & $\begin{array}{l}7.8 \\
0.17\end{array}$ & $\begin{array}{l}1.5 \\
0.2\end{array}$ & $\begin{array}{l}7.4 \\
0.19\end{array}$ & $\begin{array}{l}19.9 \\
<0.01^{*}\end{array}$ & & \\
\hline $\begin{array}{l}\text { Dilution:Pseu } \\
\text { domonas } \mathrm{df} \\
\text { stat }\end{array}$ & $\begin{array}{l}5 \\
0.2\end{array}$ & 2.6 & 1.1 & 9.9 & 5 & 1.5 & 5.1 & & 1.7 & 2.77 \\
\hline p & 0.97 & 0.77 & 0.36 & 0.08 & 0.54 & 0.21 & 0.4 & & 0.88 & 0.74 \\
\hline $\begin{array}{l}\text { Aphid: } \\
\text { Pseudomonas } \\
\text { df } \\
\text { stat }\end{array}$ & 1 & 0.6 & 0.4 & 0.2 & 0.5 & 1.1 & 0.9 & & & \\
\hline $\mathbf{p}$ & 0.97 & 0.45 & 0.51 & 0.68 & 0.48 & 0.29 & 0.34 & & & \\
\hline $\begin{array}{l}\text { Dilution:Aphi } \\
\text { d:Pseudomona } \\
\text { s df } \\
\text { stat }\end{array}$ & 5 & 3.4 & 0.7 & 3.7 & 8.8 & 0.8 & 6.1 & & & \\
\hline $\mathbf{p}$ & 0.07 & 0.64 & 0.64 & 0.59 & 0.12 & 0.54 & 0.29 & & & \\
\hline $\begin{array}{l}\text { Random } \\
\text { effects stdev } \\
\text { Soil origin }\end{array}$ & 0.02 & 0.02 & ${ }_{9}^{4.0 \cdot 10^{-}}$ & 0.13 & $8.6 \cdot 10^{-5}$ & $\begin{array}{l}2.9 \cdot 1 \\
0^{-7}\end{array}$ & 8.15 & 0.36 & 0.14 & 0.12 \\
\hline Residual & 0.03 & 0.03 & 0.59 & 1.01 & 3.22 & 1.59 & 664.92 & 105.12 & 0.62 & 0.29 \\
\hline
\end{tabular}

* For only one dilution treatment there was a significant interaction effect, therefore effect of dilution treatment on Pseudomonas count was subsequently assessed after averaging over aphid treatments. 
Dilution Treatment

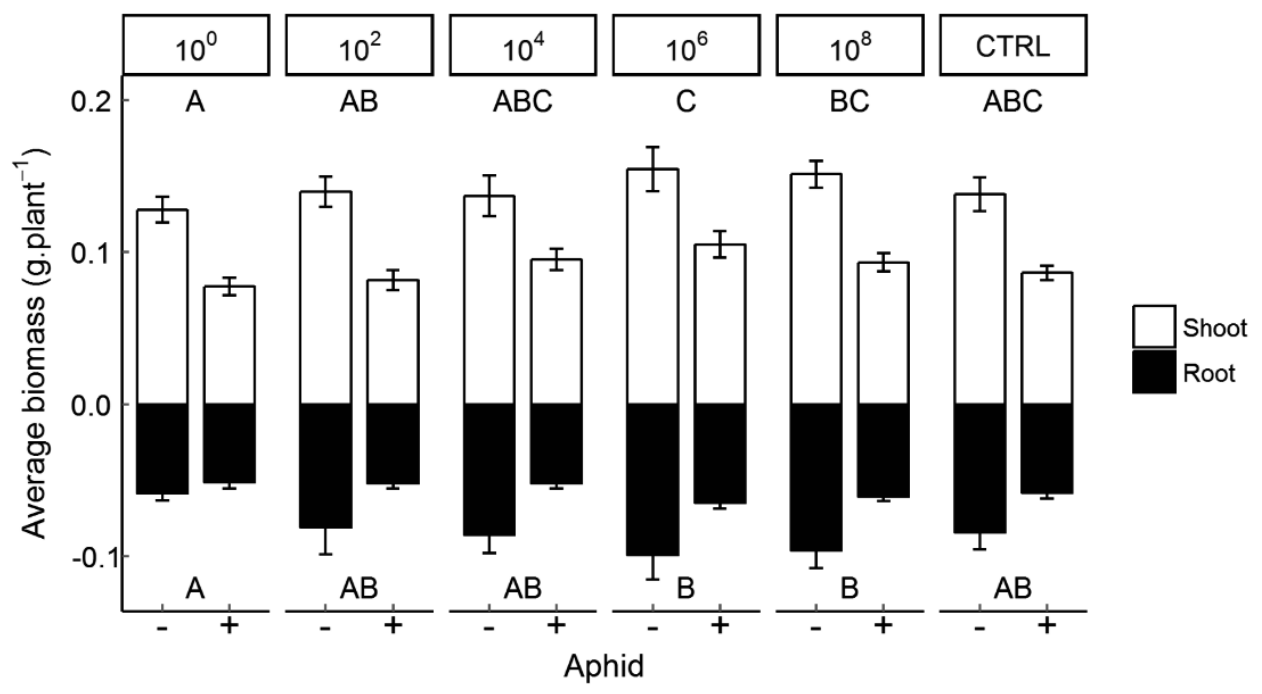

Fig. 1: Shoot and root biomass (g.plant ${ }^{-1}$ ) of plants grown in soil with different dilution treatments with and without aphid infestation averaged over Pseudomonas treatments because there were no significant interactions between the treatments $\left(10^{0}, 10^{2}, 10^{4}, 10^{6}\right.$ and $10^{8}$ represent the different dilutions; CTRL, control soil). White bars represent shoot biomass, black bars represent root biomass and error bars the standard error $(n=20$ for - Aphid treatment, $\mathrm{n}=40$ for + Aphid treatment); different letters represent significant differences $(\mathrm{p}<0.05)$. 


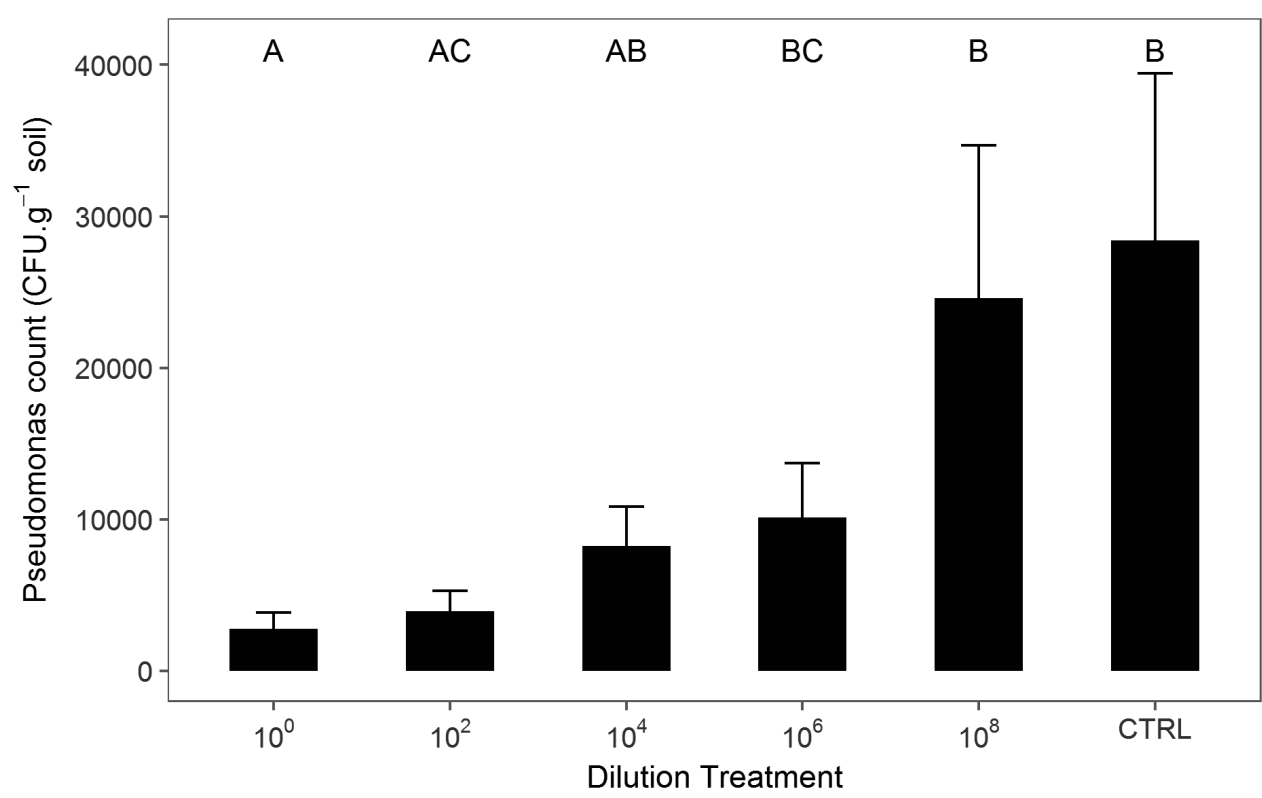

Fig. 2: Pseudomonas CFU counts. $\mathrm{g}^{-1}$ in soil subjected to different dilution treatments. Values represent averages of two technical replicates and aphid treatments and error bars indicate the standard error $(n=10)$; different letters represent significant differences $(\mathrm{p}<0.05)$. Control, control soil.

Plant gene expression in response to dilution, Pseudomonas inoculation and aphid infestation

Infestation by aphids led to significant downregulation of the expression of CYP79B3 by a factor of 0.6. The expression of $P R 1$ was significantly but slightly repressed $24 \mathrm{~h}$ after infestation (Fig. 3A). Similarly, the addition of Pseudomonas significantly repressed the genes CYP79B3 and PR1 (Fig. 3B). HEL, VSP2 and PDF1.2 expressions were not significantly affected by aphid or Pseudomonas treatment. Although both aphid infestation and Pseudomonas inoculation showed the same effect on gene expression, there was no interaction between the two treatments (for statistical results see Table 1). The number of Pseudomonas CFU recovered from soil was not correlated to gene expression. There was no effect of dilution treatment on plant gene expression (Supplementary Information Fig. S6). There was no interaction between dilution and Pseudomonas or aphid infestation effects. 


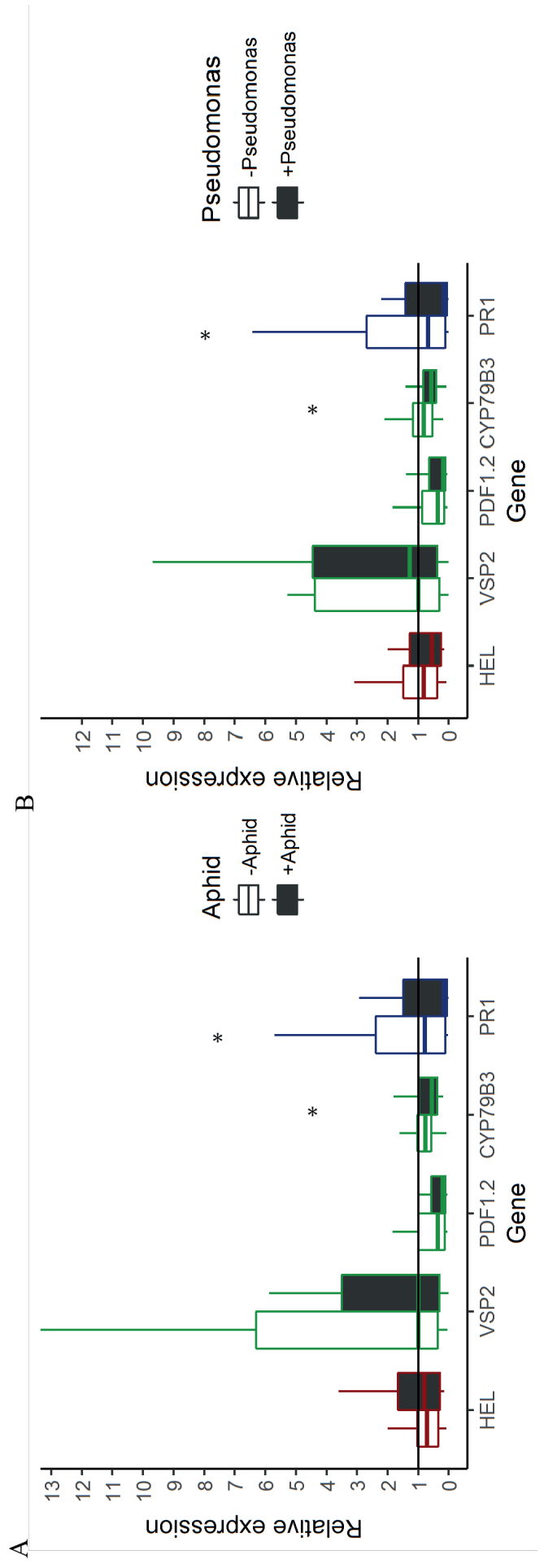

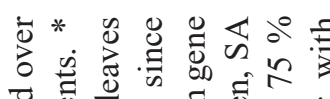
ठ্ৰ

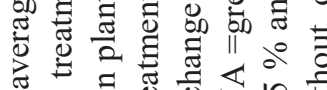
สิ

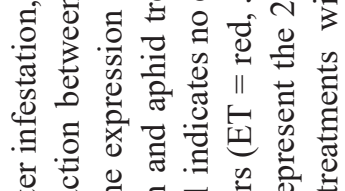

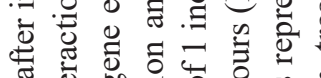

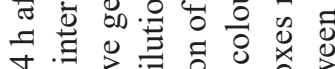

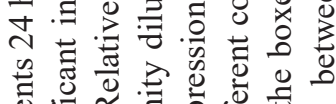

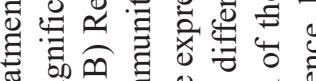

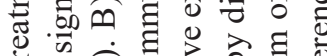

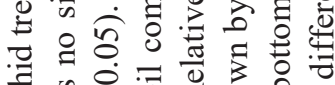

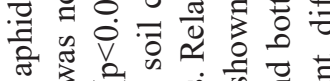

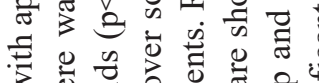

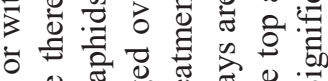

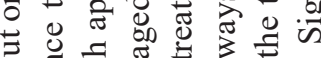

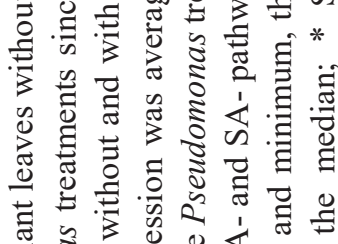

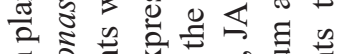

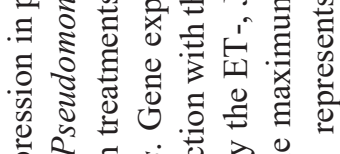

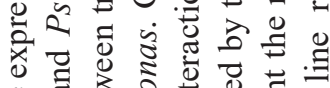
0

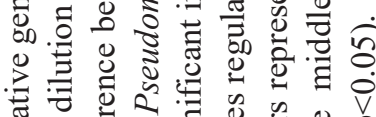

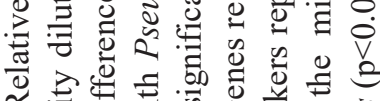

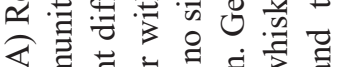
¿

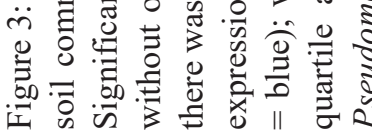




\section{Aphid reproductive success}

Although plant biomass varied between dilutions and Pseudomonas treatments, aphid reproduction (time until first reproduction and total number of offspring) did not differ between dilution treatments (Supplementary Information Fig. S7) or Pseudomonas treatments (Table 1). The pre-reproductive period was on average 7.1 days (minimum 6, maximum 10). The number of offspring per neonate aphid after 2 weeks varied between 1 and 26 with an average of 15 new-borne aphids. The number of aphid offspring was significantly positively associated with plant shoot biomass $\left(t_{1,56}=3.1, p<0.01\right)$ (Supplementary Information Fig. S8), but showed no relation with root biomass or with the number of Pseudomonas CFU recovered from soil (root biomass: $\mathrm{t}_{1,76}=1.3, \mathrm{p}=0.19$; Pseudomonas $\left.\mathrm{CFU}: \mathrm{t}_{1,33}=1.2, \mathrm{p}=0.24\right)$. Furthermore, the number of neonate aphids showed a maximum difference of $63 \%$ between the soil origins (LD2 having the highest average number of offspring and CA5 the lowest number).

\section{Discussion}

In spite of the many studies on the effects of single PGPR strains on plant growth and resistance to pathogens and insect herbivores, little is known about such effects when considering their effects in the presence of the entire soil microbiome, or subsets of it. Low abundance soil microbes are known to contain species with a high potential impact on various ecosystem functions (Delgado-Baquerizo et al. 2016). Therefore, we examined whether the absence of some of the rare microbes may play a role in priming plant defences against insect herbivores. We examined the effects of soil dilution on plant defence against aphids and show that there was no consistent effect of loss of rare microbes, indicating that species that are rare in the soil microbiome had no effect on plant resistance against herbivory by aphids. Interestingly, random removal of low abundance soil microbial species by dilution generally led to an initial increase in plant biomass. This was unexpected given that bacterial diversity and the presence of rare species have been found to be positively associated with several functions such as decomposition and the suppression of plant pathogens (Salonius 1981, Van Elsas et al. 2012). However, a previous study also showed that high microbial diversity negatively influenced plant biomass compared with a community with fewer rare species (Hol et al. 2010). The authors of that study suggested that more inter-bacterial interactions at a higher diversity might have led to increased production of phytotoxic compounds.

We used an Arabidopsis ecotype originating from the same site as the microbial community. Many other studies on Arabidopsis have confronted plant ecotypes with non-co-evolved soil microbes, which may help to understand interaction mechanisms, but not their ecological roles. We observed substantial differences between the dilutions that were prepared from soil samples collected from ten different plots in the field. This contributed to the high variation in biomass in the dilution treatments. Although we expected that the loss of rare species would have similar effects on plant growth and defence irrespective of the site of collection, 
our results indicate that the effect of dilution will depend on the initial soil community composition. Thus, this composition might have differed between the plots. This conclusion is supported by Hol et al. (2015a), who found the effect of changes in community composition by dilution on plant biomass to be dependent on soil origin and consequently initial microbiome community composition. Our results suggest that the absence or presence of certain species in the soil microbiome will be of importance for both plant performance and resistance.

Effects of our dilution treatment might not solely be due to the loss of rare species. While dilution has been shown to reliably reduce the number of low abundance species, it can also lead to an overall change in composition of the remaining species, for example because dominant species are released from (interference) competition. In addition, random sampling processes during dilution and cell regrowth could have led to differences among the dilutions of the different soil origins (Yan et al. 2015). Moreover, this study is focused on the effect of soil bacteria since low abundance bacterial species have frequently been demonstrated to affect other community members and ecosystem functioning. However, our experimental design did include other soil microorganisms, such as fungi, archaea and protozoa. Little is known about rare microbial species other than bacteria. Therefore, we cannot speculate on how they might have affected the present results.

In accordance with the overall lack of effect on plant biomass loss by aphid feeding, dilution treatments had no effect on plant defence-related gene expression. However, aphid infestation did affect the expression of several defence-related genes. In contrast to our expectation that aphid feeding would induce JA-dependent defence, they downregulated the expression of CYP79B3 involved in indole glucosinolate synthesis (Mikkelsen et al. 2003) and had no effect on the two other JA-responsive genes $V S P 2$ and $P D F 1$.2. In addition, aphids repressed $P R 1$, a marker gene of the SA pathway. Several studies have reported highly variable effects of aphids and other phloem feeders on different plant defence pathways (Thompson and Goggin 2006). It has been suggested that phloem feeding insects may use specific saliva components, such as glucose oxidase, to repress or redirect defence signalling in the plant (Giordanengo et al. 2010). Especially JA-dependent defences, which are supposed to be most effective against aphids, may be suppressed by phloem feeding insects through the induction of SA-dependent defences (Zhu-Salzman et al. 2004, Walling 2008, Kant et al. 2015). Kim and Jander (2007) also reported that M. persicae feeding decreased total indole glucosinolates, which are dependent on the enzyme encoded by CYP79B3. Nevertheless, our findings strongly indicate a reduction in plant defences following aphid infestation independent of microbial interactions.

We did not detect an effect of soil dilution treatment on induction of systemic resistance by aphids. Nevertheless, we cannot exclude that rare microbial species loss had an effect on 
resistance induction. On the one hand, induction of defences might have been restricted to the site of aphid feeding (De Vos et al. 2007). Variation in the number of aphids feeding on the leaves that were sampled for RNA expression might have led to high variation in gene expression. On the other hand, the pooling of leaves might have obscured potential differences in the measured gene expression.

Upon inoculation of Pseudomonas, we found repression of genes involved in SA- dependent defences and in the glucosinolate biosynthesis gene $C Y P 79 B 3$, and no effect on aphid performance. These results suggest that Pseudomonas did not induce systemic resistance in A. thaliana against aphid herbivores. Moreover, the presence of Pseudomonas decreased shoot biomass in all soil dilution and aphid treatments. Our results are unexpected for several reasons. First, the PGPR strain of Pseudomonas is known to act via both SA-dependent and SA-independent defences in plants and to lead to an increase in both aliphatic and indolyl glucosinolate levels (Tran et al. 2007, Van de Mortel et al. 2012). Second, Pseudomonas was previously found to induce resistance against leaf chewing herbivores and to promote plant growth (Van de Mortel et al. 2012, Park et al. 2015, Pangesti et al. 2017). Third, survival of the strain decreased dramatically with increasing dilution treatment, which is in accordance with previous studies finding decreasing success of invading strains in more diverse communities (Mallon et al. 2015), but this has never been shown for plant growth promoting rhizobacteria. Although there are several possible explanations, our results demonstrate that low abundance soil microbes may be a key component in the establishment of inoculated biocontrol strains in the soil. Whether the growth-reducing effects of Pseudomonas are caused by the strain itself or by its interaction with other members of the microbiome cannot be determined without more detailed studies on microbiome composition. Interactions of Pseudomonas with other microbial species might explain the negative effect of the PGPR strain even if it is reduced to low cell densities.

Plant interactions with PGPR may vary between species and even between bacterial strains and plant genotypes (Liu et al. 1995, Smith et al. 1999, Van Loon 2007, Wintermans et al. 2016). It has also been shown that different plant ecotypes select for specific rhizosphere microbial communities by secreting a particular blend of root exudates (Hartmann et al. 2009). This mechanism enables plants to recruit specific beneficial bacterial taxa upon attack by herbivores, which in turn induce plant resistance against insects (Yi et al. 2011). Speciesspecific interactions might also have played a role in the lack of growth promotion of Pseudomonas as observed here. Previous studies on this bacterial strain report largely positive effects on plant biomass and defence. However, these studies used the $A$. thaliana Col-0 accession, whereas in our study an accession (Msl)was used that was growing at the same site where the soil for the dilution experiment had been collected. The discrepancy between our findings and the results of studies using the Col- 0 accession indicate that the plant response to PGPR strains may depend on the plant genotype (Wintermans et al. 2016). 
Hence, matching plant accessions, bacterial communities and insect species should be used to create an ecologically relevant experimental system.

We conclude that the loss of rare microbial species from soil may affect plant performance, as well as the abundance of a single microbial strain of PGPR, but not the resistance of $A$. thaliana to leaf-sucking herbivores. However, different types of herbivores (e.g. phloem sucking versus chewing, generalists versus specialists) have been found to differentially trigger plant defence responses (Ali and Agrawal 2012, Erb et al. 2012). It is very possible that generalist chewers will cause stronger responses. Moreover, the high variation in biomass between plants grown in soil with inocula from the different soil origins indicates that differences in microbial communities, for example as a result of different plant community compositions, could be more important for plant performance than previously thought. Therefore, we suggest that variation in microbial community composition should be taken into account in studies on plant-insect interactions.

\section{Acknowledgements}

We thank Sebastian Yanore and employees of the NIOO-KNAW for their help with the setup, maintenance and harvest of the plant experiment. In addition, we are grateful to Julie Ferreira de Carvalho and Koen Verhoeven for help with the optimization and interpretation of the RT-qPCR assay. We also thank Léon Westerd for providing us with aphids and Xu Cheng and Ton Bisseling from Wageningen University for the provision of Arabidopsis Ms1 seeds and their kind advice. This is publication 6377 of NIOO-KNAW. 


\section{Supplementary Information}

Supplementary methods

\section{Soil collection}

Soil was collected in 2015 from a field at Mossel near Ede (Gelderland, the Netherlands, $52^{\circ} 04^{\prime} \mathrm{N} 05^{\circ} 45^{\prime} \mathrm{E}$ ) where a long-term plant biodiversity experiment is running since 1996 . Soil was collected from ten different plots of the biodiversity experiment that have originally been sown with different diversities of plant species with a minimal distance of $10 \mathrm{~m}$ between the collection sites. The soil samples of minimally $30 \mathrm{~g}$ each were collected from a depth of 0-10 $\mathrm{cm}$ and served as inoculum (see Supplementary Information Table S1). In addition to the inoculum soil, $180 \mathrm{~kg}$ of bulk-soil was collected just outside the fenced experimental field at a depth of $30 \mathrm{~cm}$, sieved and $\gamma$-sterilized ( $\geq 25 \mathrm{kGray}$, STERIS AST, Ede, The Netherlands).

\section{Pseudomonas quantification}

To assess colonization of soil by Pseudomonas, $0.5 \mathrm{~g}$ of soil was suspended in $5 \mathrm{ml} \mathrm{MgSO}_{4}$ buffer and shaken for $0.5 \mathrm{~h}$. Subsequently, $10^{-2}$ dilutions of these suspensions were plated on LB-agar supplemented with $100 \mu \mathrm{g} \mathrm{ml}^{-1}$ rifampicin, $25 \mu \mathrm{g} \mathrm{ml}^{-1}$ chloramphenicol, $50 \mu \mathrm{g}$ $\mathrm{ml}^{-1}$ ampicillin, $100 \mu \mathrm{g} \mathrm{ml}^{-1}$ cycloheximide and $50 \mu \mathrm{g} \mathrm{ml}^{-1}$ thiabendazole, which is selective for rifampicin-resistant Pseudomonas fluorescens SS101 (Mazzola et al. 2007). After $48 \mathrm{~h}$ of incubation at $25^{\circ} \mathrm{C}$ colonies were counted and the number CFU per gram of soil dry weight was determined.

\section{RNA extraction and quantitative RT-PCR analysis}

RNA was extracted using the Isolate II RNA Plant Kit (Bioline, London, United Kingdom) according to manufacturer's instructions. To reach the required amounts of plant material for extraction, two leaves from the same treatment of different soil origins were pooled. Leaves of two of the soil origins (CA4 and CA5) were not analysed due to limitations in time and material resulting in 4 replicates per treatment. RNA concentration and purity were measured by Nanodrop (NanoDrop 2000, Thermo Fisher, Waltham, MA, USA) and RNA integrity was confirmed by gel electrophoresis. An equal amount of each RNA sample was used for cDNA synthesis using the iScript cDNA synthesis Kit (Biorad, Hercules, CA, USA). Subsequently cDNA was diluted by a factor of 1:20 with RNase free water.

For RT-qPCR analysis specific primers were used for 5 genes involved in the 3 main plant defence pathways regulated by ET, JA or SA respectively: VSP2 (At5g24770; JA-dependent) (Anderson et al. 2004), PDF1.2 (At5g44420; JA-and ET-dependent), PR1 (At2g14610; SAdependent) (Pineda et al. 2012), HEL (At3g04720; ET-dependent) (Pangesti et al. 2015) and CYP79B3, involved in glucosinolate synthesis and inducible by jasmonic acid treatment (At2g22330; JA-dependent) (Lemarié et al. 2015) (for all primer sequences see Supplementary Information Table S2). In addition, the expression of the reference genes FBOX (At5g15710) (Remans et al. 2008) and GAPDH (At3g04120) (Pineda et al. 2012) was 
assessed for normalization. All qPCR reactions were performed in a Biorad CFX Thermocycler (Biorad, Hercules, CA, USA). The amplification mix with a volume of $25 \mu 1$, contained $10 \mu \mathrm{l}$ SensiFAST SYBR No-ROX mix (Bioline, London, United Kingdom), $1 \mu \mathrm{l}$ forward and reverse primer (concentration see Supplementary Information Table S2), $8 \mu 1$ RNase free water and $5 \mu \mathrm{cDNA}$. The following PCR protocol was used for all PCR analyses with exception of reactions containing the primer for $P D F 1.2: 95^{\circ} \mathrm{C}$ for $3 \mathrm{~min}$, followed by 40 cycles of $95^{\circ} \mathrm{C}$ for $5 \mathrm{~s}$ and $63^{\circ} \mathrm{C}$ for $30 \mathrm{~s}$. For reaction mixes containing $P D F 1.2$ primers the same protocol was used with 40 cycles of $95^{\circ} \mathrm{C}$ for $15 \mathrm{~s}$ and $63^{\circ} \mathrm{C}$ for $45 \mathrm{~s}$. All reactions were performed in duplicate with 4 biological replicates. Reaction efficiencies and $\mathrm{Ct}$ values were calculated using the LinRegPCR software (version 2014.7). The most stable reference was calculated from the two reference genes by repeated pair-wise correlation analysis using the Excel-based tool BestKeeper (Pfaffl et al. 2004). Duplicate samples were averaged and expression was normalized by substracting the BestKeeper reference. The gene expression was further normalized against the control treatment of the respective pool of soil replicated using the comparative Ct-method (also known as $2^{-\Delta \Delta C t}$ method) (Livak and Schmittgen 2001).

\begin{tabular}{|c|c|c|c|c|c|c|c|c|}
\hline \multicolumn{3}{|c|}{ Soil origin } & \multicolumn{2}{|l|}{ Dilution } & \multicolumn{2}{|l|}{ Pseudomonas } & \multicolumn{2}{|l|}{ Aphids } \\
\hline & HD2 & \multirow{10}{*}{$\mathrm{x}$} & & \multirow{10}{*}{$x$} & \multirow{10}{*}{$\begin{array}{l}\text { - Pseudomonas } \\
+ \text { Pseudomonas }\end{array}$} & \multirow{10}{*}{$x$} & \multirow{10}{*}{$\begin{array}{l}1 x-\text { M.persicae } \\
2 x+M . p e r s i c a e\end{array}$} & \\
\hline & HD3 & & & & & & & \\
\hline & HD5 & & $10^{\circ}$-dilution & & & & & \\
\hline & LD2 & & $10^{2}$-dilution & & & & & \\
\hline & LD3 & & $10^{4}$-dilution & & & & & \\
\hline & LD5 & & $10^{6}$-dilution & & & & & \\
\hline & NC2 & & \multirow{4}{*}{ Sterile control } & & & & & \\
\hline & NC3 & & & & & & & \\
\hline & CA4 & & & & & & & \\
\hline & CA5 & & & & & & & \\
\hline$n=$ & 10 & $\mathrm{x}$ & 6 & $\mathrm{x}$ & 2 & $\mathrm{x}$ & 2 & $=360$ \\
\hline Tim & \multicolumn{3}{|c|}{25 weeks incubation } & \multicolumn{2}{|c|}{ planting +5 weeks growth } & \multicolumn{3}{|c|}{2 weeks infestation } \\
\hline
\end{tabular}

Fig. S1: Overview of applied treatments; subsequently applied treatments, number of treatments $(n)$ and duration of treatment application. 


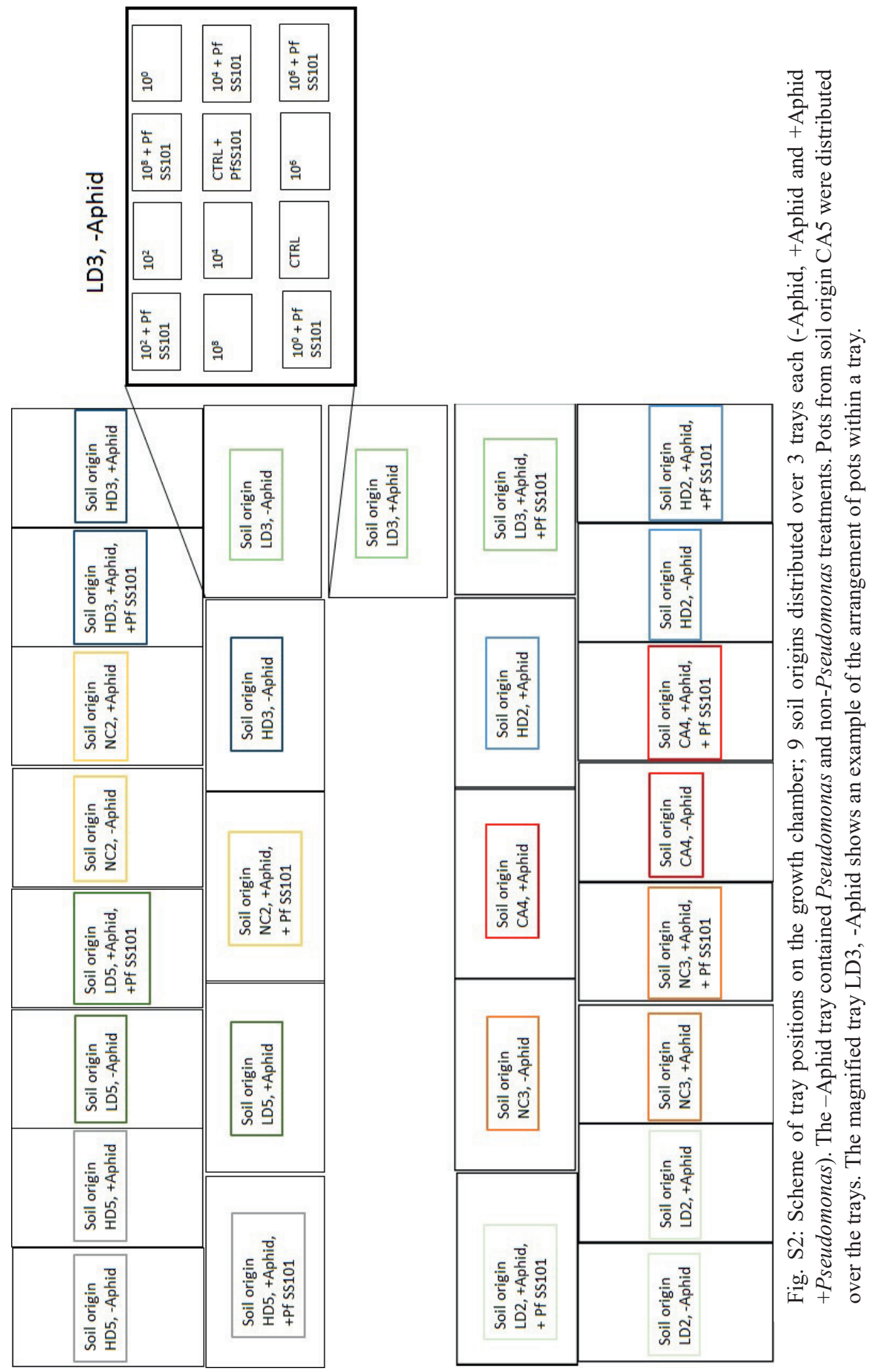




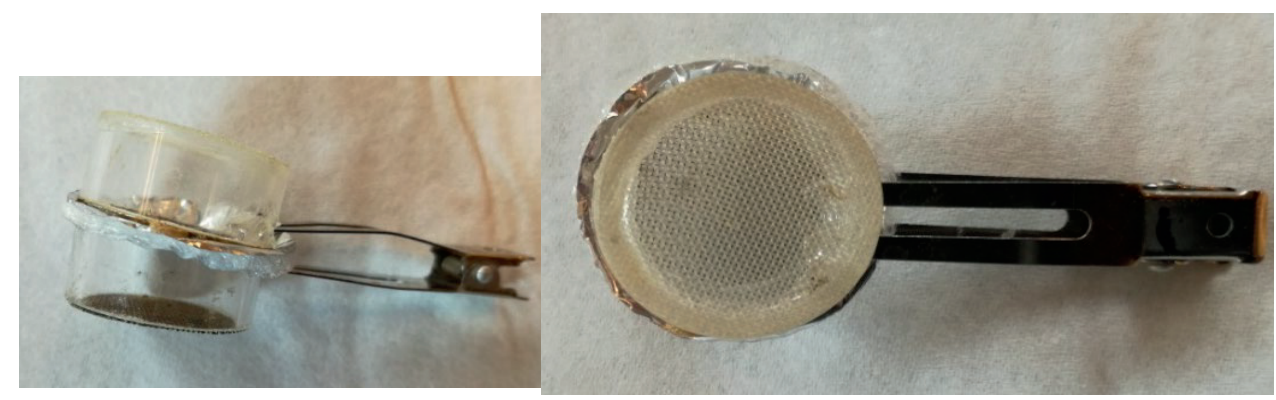

Fig. S3: Picture of a clipcage; lateral view and top view; diameter of the cage $=2.3 \mathrm{~cm}$ 


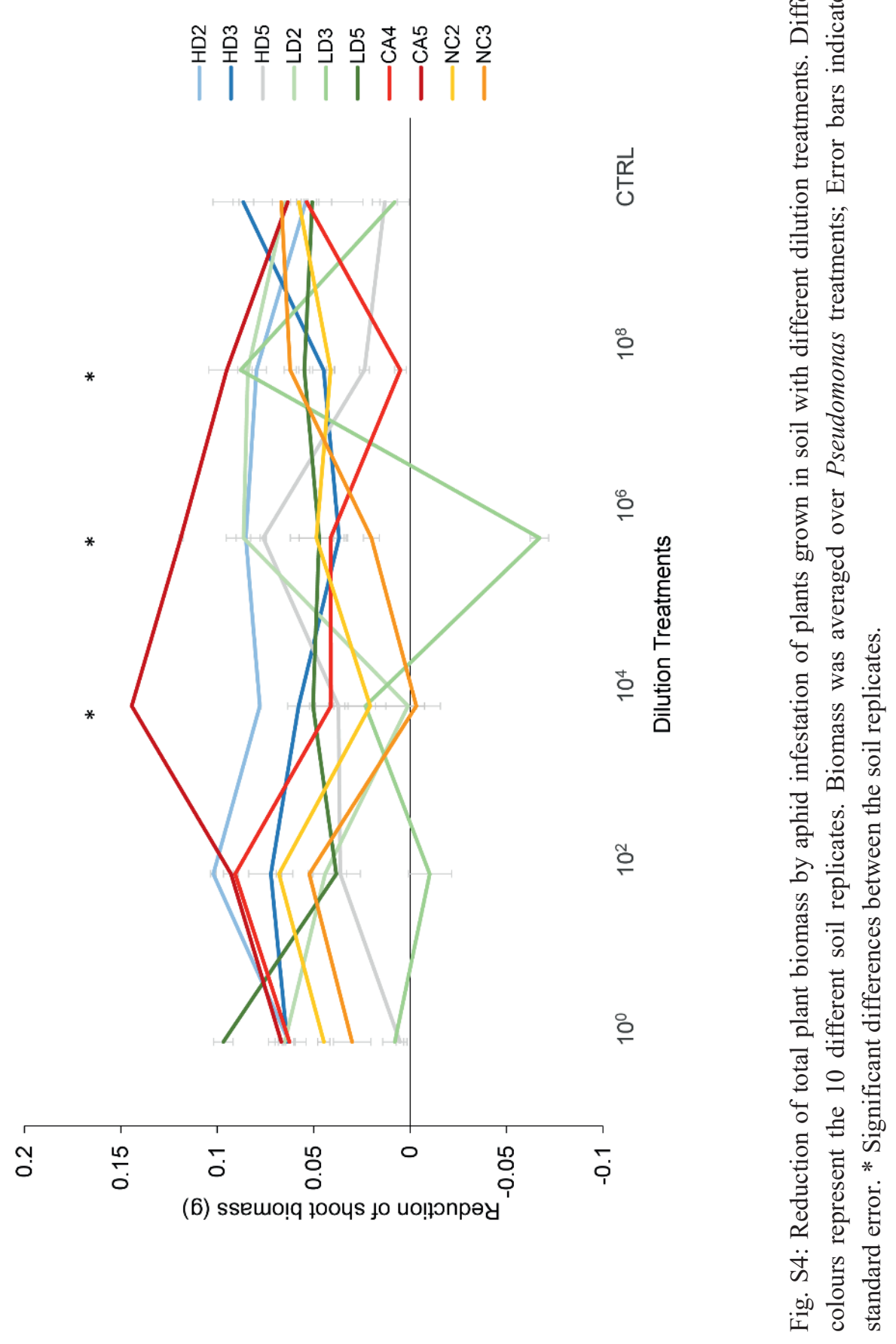




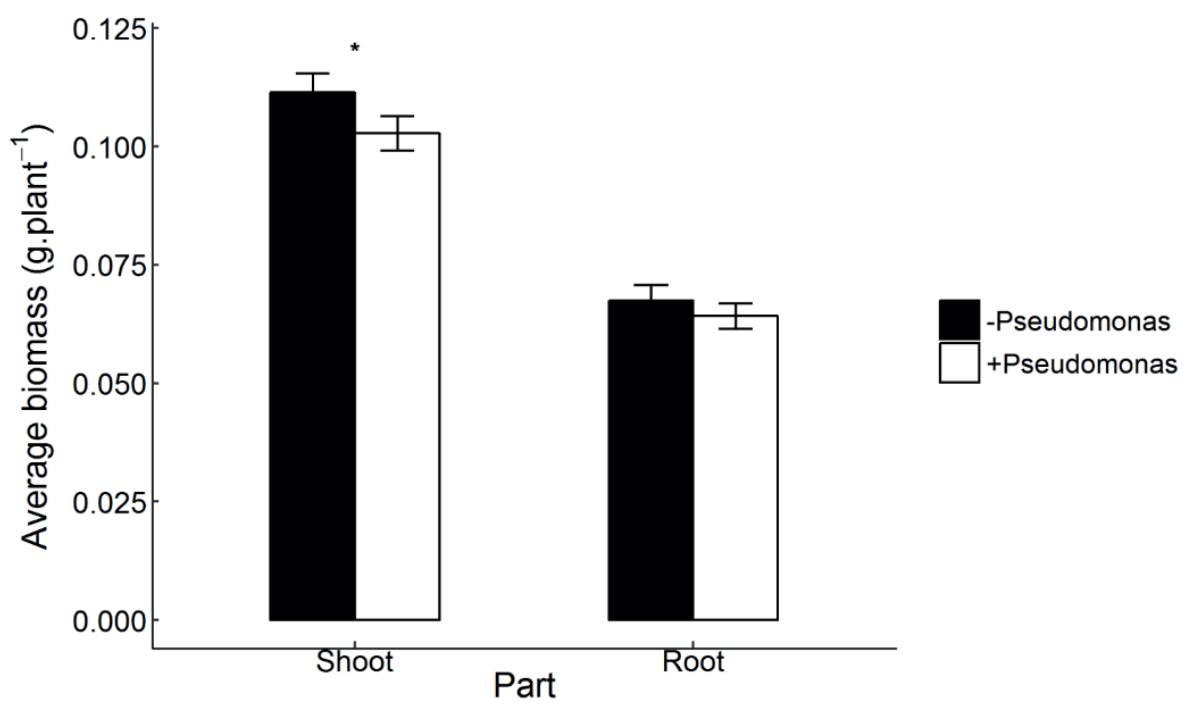

Fig. S5: Arabidopsis shoot and root biomass in -Pseudomonas and +Pseudomonas treatments; error bars indicate the standard error $(n=180)$. There was a significant effect of Pseudomonas on shoot biomass $\left(\mathrm{F}_{1,339}=4.9, \mathrm{p}=0.03\right)$, but not on root biomass $\left(\mathrm{F}_{1,336}=1.09\right.$, $\mathrm{p}=0.30$ ). Shoot and root biomass are averaged over dilution treatment because there was no significant interaction (shoot: $\mathrm{F}_{5,329}=0.21, \mathrm{p}=0.96$, root: $\mathrm{F}_{5,330}=0.56, \mathrm{p}=0.73$ ).

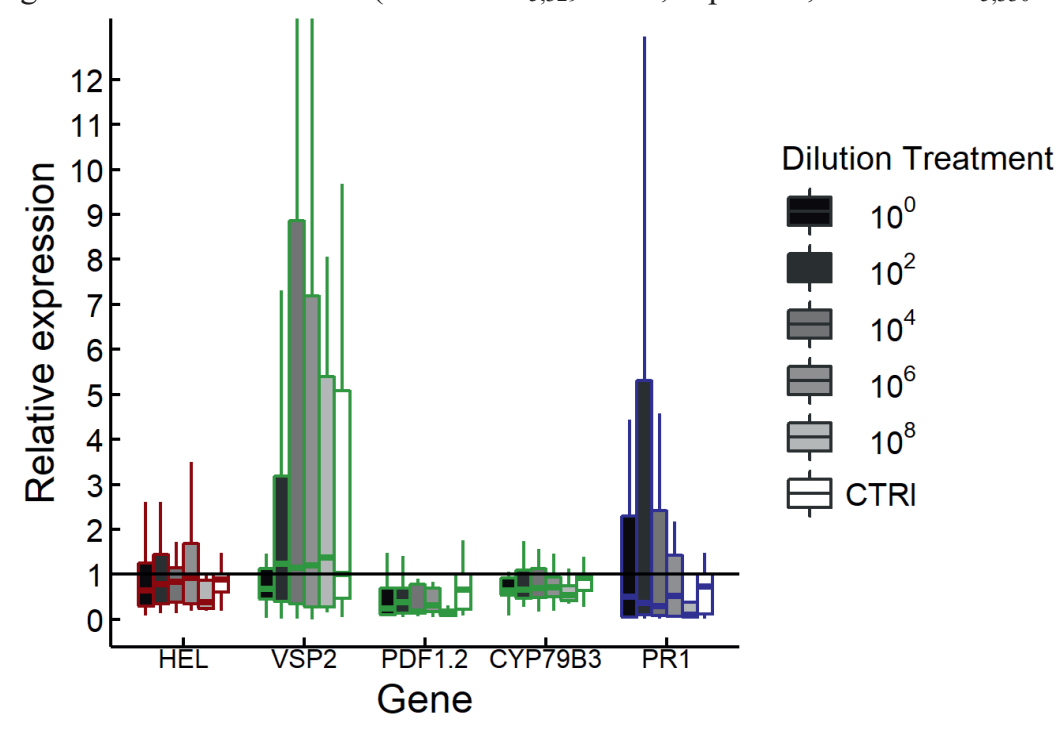

Fig. S6: Relative gene expression in plant leaves grown in soil with different dilution treatments, gene expression is averaged over aphid and Pseudomonas treatment; genes regulated by the ET-, JA- and SA- pathway respectively are marked by different colours (ET $=$ red, $\mathrm{JA}=$ green, $\mathrm{SA}=$ blue). 
$\mathbf{A}$

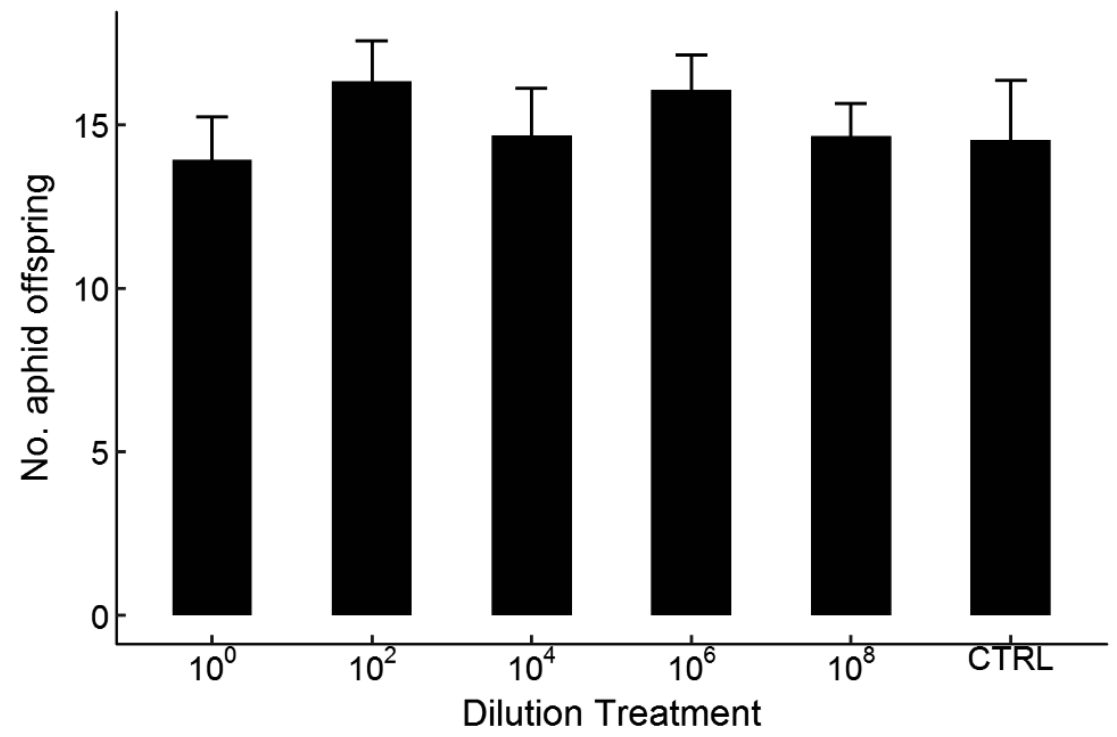

B

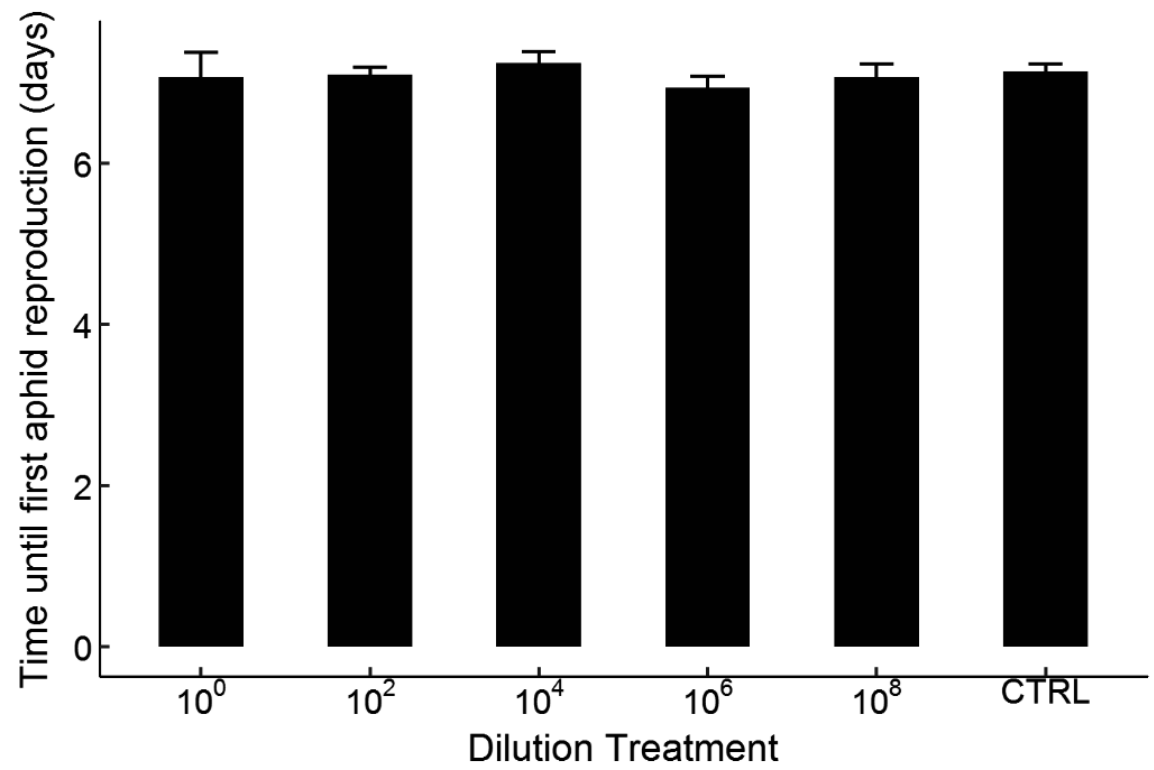

Fig. S7: Aphid fecundity on plants grown in soil with different dilution treatments; A) Number of newly born aphids after 2 weeks, B) time until first reproduction of neonate aphids $(<24 \mathrm{~h})$ placed in clipcages; on plants grown in soil with different dilution treatments averaged over Pseudomonas treatments; error bars indicate the standard error. 


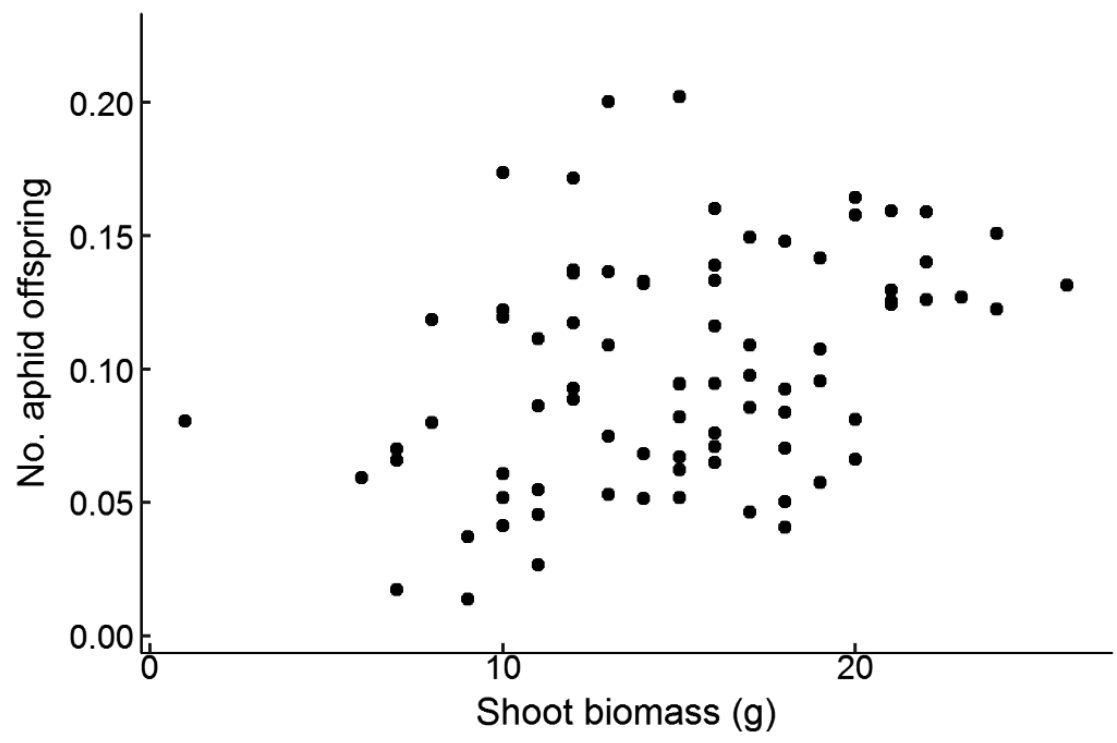

Fig. S8: No. of aphid offspring related to plant shoot biomass; shoot biomass (g) plotted against number of new-born aphids in 2 weeks 
Table S1: Description of site of soil origin; plots of the long term biodiversity experiment at the field site of soil collection at Mossel near Ede (Gelderland, the Netherlands, $52^{\circ} 04^{\prime} \mathrm{N}$ $05^{\circ} 45^{\prime} \mathrm{E}$ ); for a m ore detailed description of the treatm ents seeVan der Putten et al. (2000); plots for soil collection are marked in bold.

\begin{tabular}{|c|c|c|}
\hline Plot name & Treatment & Description \\
\hline HD1 & high diversity & $\begin{array}{l}15 \text { species sown in 1996; } 5 \text { grasses, } 5 \\
\text { forbs, } 5 \text { legumes }\end{array}$ \\
\hline HD2 & high diversity & $\begin{array}{l}15 \text { species sown in } 1996 ; 5 \text { grasses, } 5 \\
\text { forbs, } 5 \text { legumes }\end{array}$ \\
\hline HD3 & high divesity & $\begin{array}{l}15 \text { species sown in 1996; } 5 \text { grasses, } 5 \\
\text { forbs, } 5 \text { legumes }\end{array}$ \\
\hline HD4 & high divesity & $\begin{array}{l}15 \text { species sown in 1996; } 5 \text { grasses, } 5 \\
\text { forbs, } 5 \text { legumes }\end{array}$ \\
\hline HD5 & high divesity & $\begin{array}{l}15 \text { species sown in 1996; } 5 \text { grasses, } 5 \\
\text { forbs, } 5 \text { legumes }\end{array}$ \\
\hline LD1 & low diversity & $\begin{array}{l}4 \text { species sown in } 1996 ; 2 \text { grasses, } 1 \text { forb, } \\
1 \text { legume }\end{array}$ \\
\hline LD2 & low diversity & $\begin{array}{l}4 \text { species sown in } 1996 ; 2 \text { grasses, } 1 \text { forb, } \\
1 \text { legume }\end{array}$ \\
\hline LD3 & low diversity & $\begin{array}{l}4 \text { species sown in } 1996 ; 2 \text { grasses, } 1 \text { forb, } \\
1 \text { legume }\end{array}$ \\
\hline LD4 & low diversity & $\begin{array}{l}4 \text { species sown in } 1996 ; 2 \text { grasses, } 1 \text { forb, } \\
1 \text { legume }\end{array}$ \\
\hline LD5 & low diversity & $\begin{array}{l}4 \text { species sown in } 1996 ; 2 \text { grasses, } 1 \text { forb, } \\
1 \text { legume }\end{array}$ \\
\hline CA1 & continued agriculture & \\
\hline CA2 & continued agriculture & \\
\hline CA3 & continued agriculture & \\
\hline CA4 & continued agriculture & \\
\hline CA5 & continued agriculture & \\
\hline $\mathrm{NC} 1$ & natural colonisation & no treatment \\
\hline $\mathrm{NC2}$ & natural colonisation & no treatment \\
\hline NC3 & natural colonisation & no treatment \\
\hline $\mathrm{NC} 4$ & natural colonisation & no treatment \\
\hline NC5 & natural colonisation & no treatment \\
\hline
\end{tabular}


Table S2: Sequences of all primers used in RT-qPCR analysis

Gene AGI-codes Forward primer (5'-3') Reverse primer (5'-3') Conc.

\begin{tabular}{|c|c|c|c|c|}
\hline CYP79B3 & At2g22330 & $\begin{array}{l}\text { CTCTTCGGATCTCAC } \\
\text { GACCA }\end{array}$ & $\begin{array}{l}\text { CATCAAGAAGCAA } \\
\text { AGGGCCG }\end{array}$ & $\frac{(\mu \mathrm{N}}{7.5}$ \\
\hline$G A P D H$ & At3g04120 & $\begin{array}{l}\text { AATGAAGGACTGGA } \\
\text { GAGGTGGAAG }\end{array}$ & $\begin{array}{l}\text { ACGGTTGGGACAC } \\
\text { GGAAAGAC }\end{array}$ & 7.5 \\
\hline$F B O X$ & At5g15710 & $\begin{array}{l}\text { TTTCGGCTGAGAGGT } \\
\text { TCGAGT }\end{array}$ & $\begin{array}{l}\text { GATTCCAAGACGT } \\
\text { AAAGCAGATCAA }\end{array}$ & 7.5 \\
\hline$H E L$ & At3g04720 & $\begin{array}{l}\text { GAGAATAGTGGACC } \\
\text { AATGCAG }\end{array}$ & $\begin{array}{l}\text { GTAGACCGATCGA } \\
\text { TATTGACCT }\end{array}$ & 10 \\
\hline PDF1.2 & At5g44420 & $\begin{array}{l}\text { CACCCTTATCTTCGC } \\
\text { TGCTC }\end{array}$ & $\begin{array}{l}\text { GTTGCATGATCCAT } \\
\text { GTTTGG }\end{array}$ & 7.5 \\
\hline PR1 & At2g14610 & $\begin{array}{l}\text { CACTACACTCAAGTT } \\
\text { GTTTGGA }\end{array}$ & $\begin{array}{l}\text { TAGTATGGCTTCTC } \\
\text { GTTCACAT }\end{array}$ & 10 \\
\hline VSP2 & At5g24770 & $\begin{array}{l}\text { TCAGTGACCGTTGGA } \\
\text { AGTTGTG }\end{array}$ & $\begin{array}{l}\text { GTTCGAACCATTAG } \\
\text { GCTTCAATATG }\end{array}$ & 7.5 \\
\hline
\end{tabular}


Chapter 6

\section{Discussion}


The main motivation for my project and the aim of this thesis is to advance the field of research on rare species. Therefore, I commence most chapters of the thesis with this or similar wording: "Rare species are essential for many different ecosystem functions and yet we still lack essential knowledge about them. This is particularly worrisome because rare species are vulnerable to extinction and we run the risk of unwittingly loosing species that fulfil keystone functions in our ecosystems". I approached the field of rare species by studying soil bacterial communities for three reasons. First, bacterial communities are highly diverse and contain a high proportion of rare species with many of them still virtually uncharacterized. Second, many important ecosystem functions, such as decomposition, rely on soil bacteria. Third, bacteria can be studied using high-throughput experimental set-ups testing many factors at the same time under highly controlled conditions, which is laborious for other organisms. Here I will discuss how the main findings of my thesis add to current knowledge about rare bacteria and point out future directions of research. In addition I will address how my findings on rare bacterial species can be adopted in the research on other organisms.

\section{The cultivation of rare microorganisms- it is in the name}

In order to study rare species we have to be able to find and observe them. This is especially challenging for microorganisms due to their small size. In spite of intriguing and ongoing developments of molecular tools to detect microorganisms it is still a challenge to apply them to rare microbial species and to test their functional traits and abundance dynamics. Therefore, the cultivation of bacteria in the laboratory is still essential. However, the majority of bacterial species remains recalcitrant to cultivation with the methods employed today and it might be tempting to think that rare species would be especially difficult to culture assuming that they are slow growing and highly specialized in their niche. Still, the cultivability of rare bacterial species has seldom been tested as only few studies assessed the abundance of their isolates in situ with differing results (Shade et al. 2012a, VanInsberghe et al. 2013).

In Chapter 2 of this thesis, I isolated both rare and abundant bacterial species from soil for subsequent use in follow-up studies on species traits and factors that may cause rarity. In this cultivation study I also tested if the abundance distribution of the isolated species was representative of the abundance distribution of the field community and if the choice of cultivation medium and a prolonged incubation time could increase the proportion of rare species in the collection of isolates. I used flow cell sorting to select for small cells and prevent interspecific competition. Interestingly, in this cultivation study I could not capture a proportion of rare species equal to the proportion found in soil. Moreover, neither the choice of medium nor a prolonged incubation time led to a better representation of rare species. Although my cultivation approach is only one of many techniques that are commonly employed for bacterial cultivation, this study indicates that other approaches, such the streak- 
plate or spread-plate method, as well may inadvertently select against rare species. Consequently, studies that utilize isolates retrieved from these common approaches are likely to be biased towards the more abundant species. Hence, they might neglect rare species, which could differ in their response and effect traits from abundant species.

The bias of bacterial cultivation techniques towards abundant species calls attention to the necessity to test for the abundance distribution of bacterial isolates in the field. Not only will this measure enable researchers to deliberately study rare as well as abundant species, it will also facilitate the comparison of different cultivation techniques with respect to how well they capture the full range of species abundances. This comparison can subsequently help to develop techniques for the enrichment of rare species. Such techniques might include novel cultivation media. As some low abundant species have been proposed to be adapted to narrow niches and scarce nutrients (Östman et al. 2010), media with a lower substrate concentration or a wider range of more recalcitrant compounds could allow their cultivation. In addition, some rare species might require compounds produced by neighbouring species (Kaeberlein et al. 2002). Co-inoculation techniques could lead to successful cultivation of these particular species. Moreover, studies that mimic soil conditions, for example through the use of diffusion chambers placed directly in soil, succeeded in culturing many novel species that require soil specific compounds for growth (Nichols et al. 2010). It would be of high interest to test if these methods capture a higher amount of rare species than the approach of this thesis or other traditional cultivation techniques. However, a test of these methods was beyond the scope of this thesis.

With the approach outlined in Chapter 2 I did not only select for more abundant species, but also for species that are saprotrophic and able to grow on media that are still relatively nutrient-rich compared to most soils, i.e. copiotrophic species. It has not been experimentally tested yet if copiotrophy and oligotrophy are correlated with bacterial species abundance. However, other studies suggest that many rare species might be copiotrophs (Shade et al. 2012a). My collection of soil bacterial isolates allowed me to study rare as well as more abundant species that are comparable with each other with respect to their nutrient requirements. Therefore, growth related traits, competitiveness and predation resistance could be assessed under the same conditions. Moreover, the isolate collection still contained a gradient in growth rates and substrate utilization patterns as I showed in Chapter 3, which could be used for studying the interactive effect of species traits, competitor and predators on species abundance in Chapter 4. Thus, the isolation approach of Chapter $\mathbf{2}$ provided me with a set of isolates, which have been characterized for their abundance in the field to use for follow-up studies on rare species traits and abundance dynamics. At the same time it showed that further developments in cultivation techniques are needed to capture a more diverse set of species. 


\section{Implications for the research on non-microbial organisms}

I showed that isolation studies likely select for more abundant species. Furthermore, the utilization of a limited and specific set of bacterial isolates poses restrictions on our understanding of bacterial communities and the same is true for research on other organisms. In experimental studies on bacteria, model species, such as Escherichia coli or Pseudomonas fluorescens, are widely used to test concepts and mechanisms that are subsequently transferred to other species. Similarly, research on macroorganisms is often based on a few model species, such as Arabidopsis thaliana for plants or zebrafish and mice for vertebrates. In contrast, species that are low abundant in the environment are often disregarded in experimental set-ups. Both for microorganisms and macroorganisms the selective use of mostly common species that readily grow under laboratory conditions might not allow us to draw general conclusions (Alfred and Baldwin 2015, Yu et al. 2016). For microorganisms there is increasing awareness that yet uncultivated species could carry out highly relevant functions in the environment and should therefore be brought into culture and tested experimentally (Salcher and Simek 2016). Also for research on macroorganisms it should be encouraged to extend the scope of species.

\section{Causes for species rarity- many ways to one rarity}

Recently, the function of rare bacterial species has attracted considerable attention. However, the questions why is one species rare, whereas another is abundant and are there certain traits that can be used to predict species abundance have not yet been addressed. For communities ranging from plants to marine macrofauna and beetles, slow growth and a strong adaptation to specific conditions have frequently been proposed as causes for species rarity (Davies et al. 2004, Ellingsen et al. 2007, van Kleunen and Richardson 2007). However, these theories often stem from observational studies, whereas species traits have rarely been studied experimentally.

While for other organisms it has often been suggested that rare species might be slow growing, also the opposite has been found to occur frequently in bacteria. However, these studies were based on observances of community shifts or molecular methods assessing rDNA/rRNA ratios, which are prone to biases as mentioned earlier (Wilhelm et al. 2014, Aanderud et al. 2015). In contrast, cultivation-based tests of bacterial traits in concert with species abundance are scarce. In addition, species rarity has often been explained by a narrow niche breadth, but this has not been tested for microorganisms. Therefore, in Chapter 3 I used the bacterial isolates retrieved in Chapter $\mathbf{2}$ to test potential species growth rates and their ability to use a range of substrates. These life-history traits have been used to place species in the oligotrophic-copiotrophic continuum (Fierer et al. 2007). 
Even when using a relatively small collection of bacterial isolates I found striking differences in species traits and unexpected relationships between traits. For instance, copiotrophic and oligotrophic species so far have been assumed to differ in their reaction to the addition of nutrients (Morrissey et al. 2016). However, I showed for the first time that growth rate was also correlated with the number of substrates soil bacterial species could use. In addition, bacterial classes differed significantly with respect to growth rate and substrate use, suggesting that these traits can be highly phylogenetically conserved. Although these findings were unexpected and highly interesting, the results of that study could not help answering the question why in the field some species were rare and others abundant. Whereas for some species that were rare in the field, their slow growth and narrow niche breadth might have accounted for their low abundance, other rare species showed high growth rates and a broad niche breadth. Similarly, there were slow as well as fast growing species among the isolates that were both abundant in the field. Thus, from this study I could conclude that for saprotrophic soil bacteria, factors other than growth rate and substrate use are likely to influence abundance in field soil.

In Chapter 4, I decided to test the effects of competitors and predators on species abundance in addition to the species traits measured in Chapter 3. For this purpose, I chose 24 species from my isolate collection that were rare or abundant in the field community as well as fast or slow growing in the laboratory, and combined them in constructed communities at four different nutrient levels. I expected that the competitive success and therefore abundance of fast and slow growing species would change with nutrient availability. Fast growing species were expected to be competitively superior at high nutrient concentrations whereas slow growing species were expected to have an advantage at low nutrient concentrations, according to the oligotrophic-copiotrophic concept (Fierer et al. 2007). However, the results of my experiment defied this expectation. Slow growing species were subordinate under all nutrient concentrations indicating that slow growing species can be competitively inferior. While some slow growing species were clearly abundant in the field, some might be permanently rare. Most surprisingly, the rare fast growing species dominated the artificial communities over the whole nutrient range. Since the species abundances in the constructed communities differed essentially from the abundances in the field soil, this part of my study indicated that competition for nutrients alone might not shape species abundances. Moreover, my results showed that rare species with high potential growth rates might have the ability to become abundant under favourable conditions.

Up to this point, I demonstrated that some bacterial species are fast growing, metabolically versatile and highly competitive, but that they nevertheless are rare in the field. To determine why they are rare in spite of their high competitiveness, I performed a competition experiment simultaneously with the addition of protistan grazers as another layer of complexity in the system. It has been suggested that there is a trade-off between 
competitiveness and susceptibility to predation among bacteria (Bohannan et al. 2002), but so far this has not been investigated in the context of species abundance. In Chapter 4, I found indications for such a trade-off between competitiveness and susceptibility to predation for soil bacterial species Moreover, I found differences in the strength of the trade-off between rare and abundant species under the tested conditions. Especially rare fast growing species were highly competitive in the constructed communities, but more negatively affected by predation, which is in accordance with the "Kill the Winner" hypothesis (Winter et al. 2010). Hence, my study suggests that rarity in soil bacterial communities might be due partly to predation by protists.

In addition, I investigated the influence of nutrient availability on the effects of predation and competition on bacterial community composition. In nutrient-rich systems predation (topdown effects) is supposed to be of greater importance for community composition than competition (bottom-up effects) as outlined in the general introduction of this thesis (see also Fig. 3 of the introduction). The expectations raised in the introduction could only partially be supported by my results from Chapter 4. In the predator-free communities a low nutrient concentration decreased the abundance of rare fast growing species, but the abundance of abundant fast growing species was slightly increased. (Fig. 1 A, B). Neither did a lower nutrient concentration lead to a change in rank between fast and slow growers, as predicted in the introduction. Similarly, in the presence of predators the group of rare fast growing species was constantly decreased, but again did not become low abundant (Fig. 1 C, D). Except for the group of rare and slow growing species there was no interaction between the effect of nutrient availability and the effect of predation on abundance. However, I did observe a stronger negative relationship between abundance without predation and predation resistance at higher nutrient concentrations for several species. This indicates that the tradeoff between competitiveness and predation became more important for species abundance with increase in nutrient concentration. If I apply the theory of fitness cost, outlined above, to my results, I can speculate that relatively high nutrient concentrations enabled the abundant species to invest resources in anti-predator defences, which rendered them resistant to predation, while they were not limited by competition for nutrients. In contrast, the rare species might not have been able to develop effective defences.

However, even within the relatively small collection of rare isolates there was a considerable variation between species. As already established in Chapter 3, in Chapter 4 some species were slow growing and also showed a low competitive ability under most nutrient regimes. These species might be adapted to a life style of permanent rarity. Other species were growing fast, but were outcompeted in the artificial communities. Finally, several fast growing species were superior competitors, but at the same time vulnerable to predation. Still, not for all species rarity could be explained sufficiently in the constructed communities; in the soil other (abiotic) factors might affect their abundance, such as $\mathrm{pH}$ or moisture. I conclude that for soil 
bacteria there might be no overarching cause, but rather different causes for rarity for different species. However, predation had the most distinct effect on species abundance in my study.
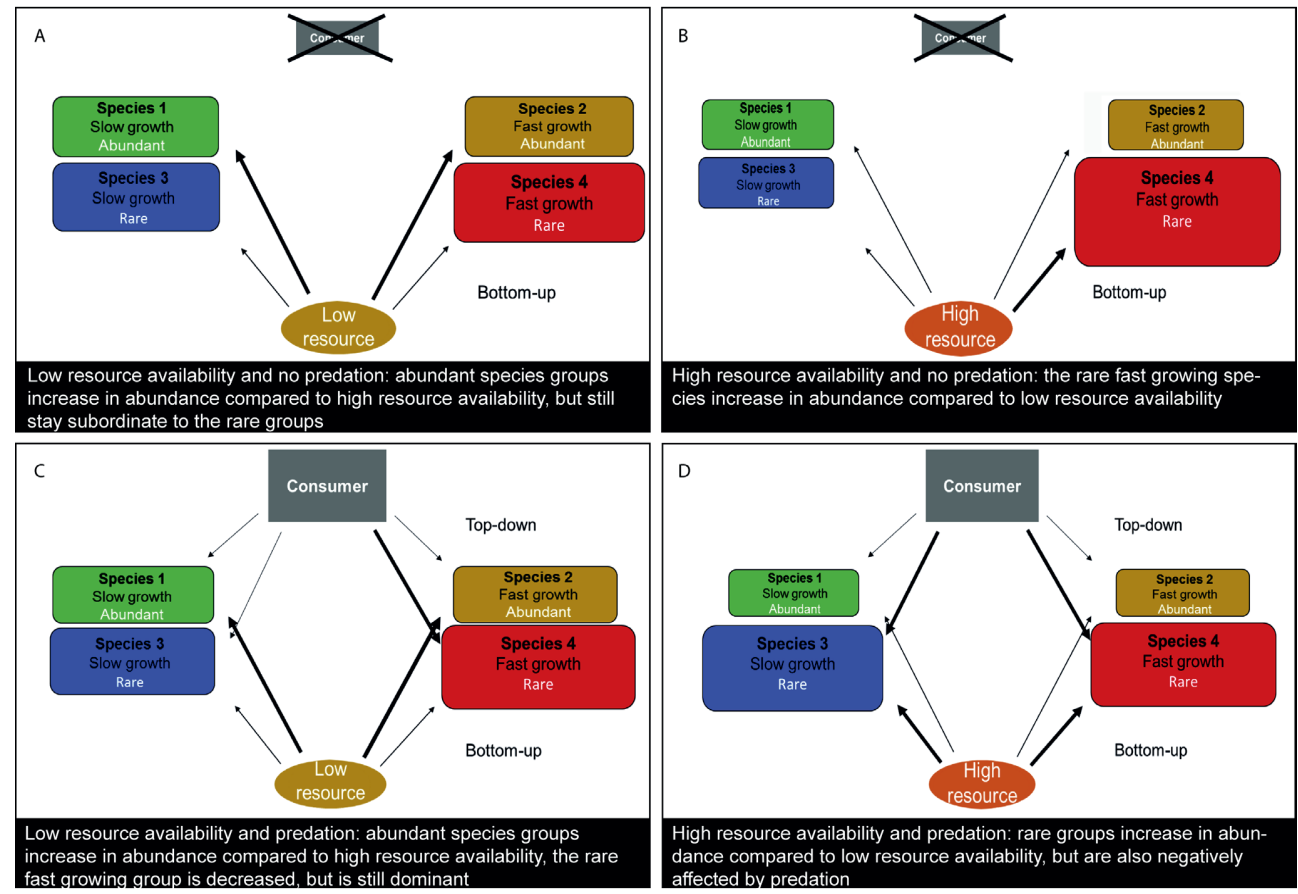

Fig. 1: Effects of resource availability (bottom-up) and consumption (top-down) on the abundances of the four species groups as found in the study of Chapter 4. The size of species boxes represent species abundances as found in the constructed communities; thick arrows ( $\longrightarrow$ ) indicate a strong effect, thin arrows ( $\longrightarrow$ ) indicate a weak effect.

\section{Mechanisms of defence and competition}

Competition between bacterial species and predation shifted species abundance in my microcosm study compared to the initial equal densities. There are many possible mechanisms that can explain my observations as bacteria compete in a variety of ways and can escape predation by several means. Mechanisms of competition, for instance, are usually divided into exploitative and interference competition (Hibbing et al. 2010). Exploitative competition often can be linked simply to life-history traits. Fast growing species may more quickly exploit a source of nutrients, while slow growing, oligotrophic species are able to reduce nutrients to the lowest level. Thereby they can gain a competitive advantage at extremely low concentrations. However, these mechanisms alone could not explain my findings. In particular, the dominance of one group of fast growing bacteria throughout the experiment could not be due to growth rate alone, because other species with similar potential 
growth rate were outcompeted. This indicates that other mechanisms of competition have been involved in generating the abundance pattern in my constructed communities.

One such mechanism could have been exploitative competition by other means than fast growth. For example the production of secondary metabolites can enhance the ability of a bacterial species to monopolize a nutrient source (Stubbendieck and Straight 2016). One example is the production of siderophores, which facilitates the scavenging of iron from the environment (Compant et al. 2005). However, the production of extracellular siderophores can also benefit neighbouring strains, which reduces the benefit of siderophore production in homogenous conditions, such as microcosms (Traxler et al. 2012). Furthermore, bacteria can engage in multiple ways of interference competition. Probably best known is the production of inhibitory secondary compounds such as antibiotics, but also disruption of cell-to-cell signalling of competitor species can result in a distinct competitive advantage for the inhibitory species (Hibbing et al. 2010). In addition to secondary compounds, the production of certain enzymes can give bacterial species an advantage in competition (Stubbendieck and Straight 2016). Nevertheless, bacterial competition in multispecies communities is even more complex, as bacteria cannot only produce inhibitory compounds, but also evolve resistance to the antibiotics produced by their competitors. Both production and resistance involve a fitness cost, which can enable sensitive non-producer species to outcompete resistant strains resulting in what is called a non-transitive competition network (Kerr et al. 2002).

In the experiment described in Chapter $4 \mathrm{I}$ did not assess the mechanisms by which species competed. However, the significant differences in final abundance in the artificial communities between species with similar growth rates suggest that other mechanisms than rapid growth were involved in a species' competitive success in the constructed communities. Follow-up studies should test for interference competition by secondary metabolite production of bacteria. For instance, the ability of bacterial strains to produce antimicrobial compounds or inhibitors of cell signalling can be tested by full-genome sequencing of cultivated strains or transcriptome analysis (see e.g. Juhas et al. (2005), Paulsen et al. (2005)). However, in order to prove that the respective compounds are also produced during the actual species interaction, in situ detection methods have to be applied. For example, high performance liquid chromatography (HPLC) linked to mass spectrometry is effective for the detection of antibiotics, even directly in the soil environment (Raaijmakers et al. 2002). In addition, the expression of genes involved in secondary metabolite production tagged with fluorescent proteins can be followed using reporter strains (Baehler et al. 2005). Assessing the mechanisms of bacterial competition in addition to changes in species abundance could enable determining their relative importance for the outcome of species interactions and improve our understanding of species abundance dynamics. 
In addition to competitive traits, bacteria have evolved many ways to escape predation by protists. Anti-predator defences include morphological adaptations, such as oversized or filamentous cells, but also very small cell sizes, or increased motility (Matz and Kjelleberg 2005). Moreover, the production of antimicrobial compounds has proven to be also effective against protists, especially against non-size-selective grazers, such as amoebae (Matz and Kjelleberg 2005). However, anti-predator defences are subject to similar or even greater costs as traits increasing competitive ability, and it has been shown that nutrient limitation can change the expression of defence traits or even prevent it (Matz and Kjelleberg 2005). This fitness cost is also supposed to cause a trade-off between fast growth and predation resistance (Corno and Jürgens 2008). Indeed, in Chapter 4 I could observe a negative relationship between abundance without predators and predation resistance. This relationship was on average strongest for species that were rare in field. This difference in trade-off between competitiveness through fast growth and predation resistance indicates that many of my rare bacterial isolates possessed traits aiding them in competition, but were not able to develop predator-resistance traits as effectively as some of the more abundant isolates. To gain further insights into the role of predator resistance in determining bacterial community composition, bacterial defence traits could be assessed for example by measuring secondary compound production as well as testing for morphological changes.

\section{Long-term community dynamics}

A question following from my studies is how the constructed communities would develop over time. Former studies using simple artificial communities can give some indications about the community dynamics in the long-term. A study initiated by Lenski (2017) in 1987 and running ever since, showed ongoing evolutionary adaptation of E. coli in simple batch cultures (see also Wiser et al. (2013)). In addition to changes in competitiveness, studies using E. coli and T-phages demonstrated that very small genetic changes can have large effects on the trade-off between competitiveness and predation resistance in 3-species communities. These small changes subsequently led to widely different outcomes of community dynamics, from competitive exclusion, to stable coexistence and even oscillations (Bohannan and Lenski 2000a). As these studies used only 2- and 3-species interactions, it seems likely that communities of 12 bacterial species and a predator will show even more variable dynamics if allowed to develop over longer periods of time. While it can be expected that the communities will change, it seems impossible to anticipate how these changes will look like. Moreover, the studies by Lenski (2017) indicate that different replicates of the same community will develop differently based on small random mutations of the various species. However, it would be of high interest to test if some species show lifestyles of permanent rarity or fluctuating abundance and if this can be correlated with their abundance in the environment. 


\section{The advantages of cultivation-dependent approaches for studying rare bacteria}

It can be argued that the use of simple artificial communities, as in this thesis, is in no way representative of natural systems. Especially soil is much more complex than the bacterial microcosms used here or, indeed, any laboratory system today. Soil structure provides spatial separation, which can regulate competition and facilitate the co-existence of a high diversity of species (Torsvik et al. 2002). In addition, substrate supply is heterogeneous both with respect to the variety in compounds and fluctuations in time, and also other abiotic factors, such as $\mathrm{pH}$ and moisture, are subject to dynamic changes (De Deyn and Van der Putten 2005, Pereira e Silva et al. 2012). To account for this natural heterogeneity, study systems could be used that more closely mimic natural conditions, such as synthetic ecosystems created by nanofabrication and microfluidics and -droplets (Hol and Dekker 2014, Boitard et al. 2015). As an alternative, natural communities could directly been studied in soil. For instance, the effects of predation could be assessed by excluding or adding protistan predators to soil. Similar studies as proposed here have been conducted in aquatic systems (Corno et al. 2008), but not yet in soil.

Most of these nature-mimiking techniques, however, jeopardize the advantages that simple laboratory model communities provide. Environmental variables can be easily manipulated and controlled. This enables to accurately define and replicate experimental conditions, while, in the field and more complex set-ups, confounding factors cannot be excluded. Moreover, by using a small set of well-defined bacterial species, we can disentangle different mechanisms behind the community shifts we observe. Thus, only a reduction of complexity enables us to test general principles in community ecology (Bohannan and Lenski 2000a). My study confirms that cultivation-based approaches in combination with diverse artificial communities can be used to study the dynamics of individual species and of larger subsets of the community. Therefore, I propose that simplified systems are indispensable to answer general questions in microbial ecology. Still we have to keep in mind that these simplified systems cannot reproduce natural ones (Jessup et al. 2004). Instead they can be used as a complementary approach, and relatively species rich artificial communities can bridge between the study of single model organisms and complex natural systems.

\section{Causes of rarity for macroorganisms- what can we learn?}

Soil bacteria are without doubt a fascinating study system, not in the least because they are crucial for life on earth. Nevertheless, understanding the causes of species rarity is also an important but poorly discussed topic on other scales of life. It would be of advantage to apply theories on the causes of rarity in microorganisms to causes of rarity of macroorganisms since bacterial communities can be tested in high-throughput assays. However, there are limitations in the comparability between macro- and microorganisms. In Chapter 3 I tested if the bacterial life-history traits growth rate and substrate utilization are associated with species abundance. However, what are the equivalents of those traits in other organisms? For 
plants the rate of vegetative growth, but also seed production might be considered as being similar to bacterial growth rates. Moreover, seed production involves several traits, such as seed size and seed number. For animals, the growth rate is commonly defined as the number of offspring, but this is modified by parameters, such as reproductive effort and many others (see also review by Stearns (1976)). And while the oligotrophic-copiotrophic concept has originally been derived from the K- and r-strategist concept in macroorganisms, today their definitions are fundamentally different (Parry 1981). Many studies, which attempted to relate species traits to their abundance, whether studying plant species, lizards or other organisms did not find any clear associations (Luiselli et al. 2012, Godefroid et al. 2014, Pianka 2014). Hence, neither for bacteria nor for macroorganisms traits have been identified that can be used as reliable predictors for species rarity, wherein lies their similarity.

In contrast to species traits, general concepts such as the roles of competition and predation might be more comparable between micro- and macroorganisms. For example, for plants, a trade-off between the ability for rapid growth in nutrient rich environments and the ability to tolerate low nutrient concentrations has also been predicted (Tilman 1982, Grace 1990). These concepts are very similar to what has been found for microbial communities (see e.g. $\mathrm{Hu}$ et al. (1999)) and also the results from Chapter 4 indicate that changes in competitive ability might occur with differences in nutrient concentration. However, for macroorganisms (as well as for microorganisms) little is known about how competitiveness affects species abundances in the field. Whereas Candeias and Warren (2016) conclude that rare grassland species are on average weak competitors, several other studies did not find a connection between competitiveness and abundance (Rabinowitz et al. 1984, Müller et al. 2016). This, too, is in accordance with my findings for bacterial competition because several bacterial isolates that were rare in soil proved to be highly competitive in artificial microcosms. Hence, current studies suggest that competition might not be a primary cause for rarity for many species.

The failure to explain species abundance by competitiveness could indicate that predation might play a role not only for micro-, but also for macroorganisms. A negative relationship between competition through fast growth and predation resistance or tolerance seems to be common across kingdoms (Kneitel and Chase 2004b). The similarities in the concepts of competitiveness and predation resistance between micro- and macroorganisms indicate that also causes of rarity might be similar to a certain degree. My findings in Chapter 4 suggest that the rare fast growing bacterial species were more strongly affected by predation than abundant species. Moreover, resource availability has been shown to change the influence of predators on community composition for bacterial as well as non-bacterial organisms as predation can be expected to be most important at a high nutrient availability (Bohannan and Lenski 2000b, Kneitel and Chase 2004a). The results of Chapter 4 suggest that the negative impact of predation by protists on highly competitive bacterial species was stronger at higher 
nutrient concentrations. However, little is known about how predation in interaction with resource availability influence species abundances of macroorganisms. Therefore, I propose that predation should also be more closely investigated as a cause of species rarity in communities other than microorganisms.

While causes of rarity are likely to differ tremendously importantly between species, the results in this thesis also demonstrate that it is possible to discern factors with particularly strong effects. Eventually, investigating the causes of rarity might enable us to predict community composition, as well prevent the extinction of threatened species.

\section{Functions of rare soil bacterial species- beneficial or harmful?}

In Chapter 5 of my thesis I shifted attention from what causes rarity of species to the functions of rare soil bacterial species. Since in a former study a beneficial effect of rare bacteria on plant resistance has been found (Hol et al. 2010), I investigated the mechanisms that may have enabled rare bacteria to induce plant resistance. To this end I tested the effect of soil bacterial dilution on the resistance of Arabidopsis thaliana against an aphid herbivore. Surprisingly, I did not find any effect of the reduction of bacterial diversity, and at the same time rare soil bacteria, on plant resistance or aphid reproduction. Instead, plant growth was reduced in the presence of rare bacteria and the survival of the introduced plant-growth promoting strain Pseudomonas fluorescens SS101 was also reduced. Thus, in contrast to the frequently reported positive effects of rare soil bacteria, in my study they appeared to be detrimental to plant health, posing the question if we should consider rare species as harmful instead of beneficial.

Unfortunately, as so often is the case in ecology, the relationship between soil microbial diversity and ecosystem functions is not simple or constant. While many studies show a positive relationship, using soil dilution as a means to decrease diversity, there are at the same time studies reporting no or even negative effects (Salonius 1981, Wertz et al. 2007, Juarez et al. 2013). There are indications that rather than rare species or species diversity per se, community composition can have strong influence on certain functions. A study by Hol et al. (2015a) found that soils from different origins had different effects on plant productivity. In addition, they observed that serial dilution of the microbial community of different soils resulted in positive, negative or neutral effects on plant growth depending on soil origin. They concluded that the effect of rare species loss is dependent on the initial community composition. Also in my experiment the effect of different soil origins and their dilutions on plant performance varied strongly, even though the soil sampling sites were only a few meters apart. While communities can be expected to differ between sites, these findings still raise the question how this does affect community dynamics following dilution. 
Several processes could have caused this difference between microbial community dilutions from different sampling sites. On the one hand, the dependence on soil origin could indicate that the identity of rare and abundant species in the initial community played a role, determining which species were first eliminated by dilution. This is in accordance with the selection effect stating that the positive effect of species diversity on certain ecosystem functions is dependent on the higher probability to include species with large effects (Loreau et al. 2001). On the other hand, the dilution and subsequent regrowth to equal cell densities could have led to changes in the overall community composition. The latter is a general shortcoming of the dilution approach implicating that the effects we observed are not necessarily due to a reduction in rare species per se. Rather, the presence of particularly important species by chance might determine the outcome of dilution studies. The assessment of community composition before and after dilution might show the magnitude of those changes. However, neither does it allow us to disentangle the relative effects of community shifts vs. rare species loss, nor to control community response to dilution. Therefore, it must be kept in mind that by using dilution approaches we might measure effects of community change in addition to effects of biodiversity- and rare species-reduction.

While effects of dilution on plant performance and resistance were highly dependent on soil origin, in Chapter 5 I also observed that communities containing rare species in comparison to communities reduced in rare species by dilution, reduced the survival of an added PGPR strain. The resistance to invasion of pathogens of more diverse communities has been shown several times (Matos et al. 2005, Van Elsas et al. 2007), but it has not yet been tested for plant beneficial bacteria, although the high invasion resistance of natural communities has been suggested to be a cause for the low colonization success of PGPRs in the field (Bashan et al. 2014). Mallon et al. (2015) demonstrated that this increased resistance can be attributed to a more complete resource use of a diverse community, also called complementarity effect. As the reduction of $P$. fluorescens survival in my study was significant over all soil origins, it can be assumed that this effect could be more dependent on rare species reduction that on community composition. These findings, too, indicate that for the purpose of improving plant health by introducing beneficial bacterial strains, a reduction of the rare species could be advantageous. Yet, at the same time this reduction can make soil more susceptible to invading pathogens as has been shown for biodiversity reductions by radiation or anaerobic disinfestation (van Agtmaal et al. 2015). Moreover, I could show that even at low concentrations in the most diverse communities $P$. fluorescens still elicited changes in plant gene expression. Although this particular strain was not able to induce an effective resistance response in the used ecotype of $A$. thaliana, this indicates that PGPRs could still be effective even when survival was reduced. Therefore, a reduction of soil bacterial diversity might not be necessary for the successful use of PGPR strains. 
The ineffectiveness of a known PGPR strain in my study, whether successfully colonizing or not, suggests that a fundamentally different approach is needed in order to enhance plant resistance than the introduction of one general PGPR. For example, the interaction between PGPRs and plant has been demonstrated to be often species- or even strain-specific (Wintermans et al. 2016). This specificity might have been the reason for a lack of growth and resistance promotion by the Pseudomonas strain used in Chapter 5. Therefore, speciesand strain-specificity should be taken into account in the development of novel PGPR strains. Furthermore, the effect of the composition of the soil community on both plant performance and resistance is increasingly recognized. As a consequence, it has been suggested to improve the indigenous community in order to enhance its plant-beneficial properties (Adam et al. 2016). As a first step towards this goal, Lemanceau et al. (2015) proposed to identify both plant genotype and compatible bacterial strains in the soil that together show the best performance. Second, practices could be tested to promote these strains within the community. In addition, investigating the mechanisms behind beneficial interactions, such as induction of systemic resistance, can facilitate finding and engineering of successful plantbacterial combinations. In summary, there appears to be no solution for enhancing plant resistance that fits all, just as there does not seem to be an effect of rare species or species diversity per se. In order to enhance plant health, individual plant-bacterial interactions in the context of the whole soil microbial community should be taken into account.

\section{Functions of rare species- beyond bacteria}

Although rare species can be involved in many different ecosystem functions, here I focused on the effect of rare species on ecosystems through their interactions with other species. Rare species other than bacteria can be involved in similar interactions. For instance, rare species loss can have cascading effects on higher trophic levels. Bracken and Low (2012) removed rare sessile species from rocky shore communities and found a strong negative impact on consumer biomass. However, a disproportionate impact of rare predator species on lower trophic levels has also been observed. These particular species with large effects on their community, in spite of their low abundance, have often been called keystone species (Paine 1969). In addition, several studies report evidence for invasion resistance in more diverse communities. For example, grassland communities reduced in rare species were more susceptible to the invasion of an exotic plant species than the non-reduced communities (Lyons and Schwartz 2001). The authors propose that the removal of species might have left open niches allowing for the invader to establish, which is in accordance with the complementarity effect as has been found for bacteria (Mallon et al. 2015). However, for both in the microbial and in the macrobial world the effect of rare species and diversity on ecosystems is variable and far from straightforward (Balvanera et al. 2006).

My study on the effects of rare soil bacteria on plant herbivore resistance is only a small glimpse in the wide world of research on the functions of rare species and species diversity 
in general. Still, it can certainly stand as an example for the high variability in results among studies. Several meta-analyses including a wide range of different organisms show positive, but also negative and neutral relationships between diversity an ecosystem functioning. Some functions, such as ecosystem stability and invasion resistance are more frequently positively associated with diversity, which could be due to a niche complementarity effect (Balvanera et al. 2006). In contrast, the response of other functions, such as biomass and decomposition, to diversity is more inconsistent, indicating the prevalence of the selection effect (Hooper et al. 2005, Cardinale et al. 2006). In the light of this variability, we will have to accept that there might be no general beneficial effect of rare species or of species diversity.

In fact, the lack of a general effect of rare species presence or absence is not surprising. For example, not all rare species are permanently rare, as many rare species have been found to cycle between periods or sites of low and high abundance (Brown et al. 1995). Furthermore, not all species are likely to be of similar importance in all contexts. Rather, some species might contribute more to a particular function than others and this will vary with changes in environmental conditions. In this line, it has been proposed to use functional diversity instead of species richness in order to determine diversity effects on ecosystem functioning (Díaz et al. 2007). Functional diversity has been found to be better related to ecosystem functioning and stability than species diversity per se and species richness was not always a good predictor of functional richness (Tilman et al. 1997, Cadotte et al. 2011). However, for many species, both macro- and especially for microorganisms, their functional traits are still poorly understood. Instead of focusing on diversity only or on "the rare species", I propose that future studies should assess species functional traits and their influence on ecosystem functioning under differing conditions. Given our incomplete knowledge on how species diversity is associated with ecosystem functioning I agree with Balvanera et al. (2006) who suggested that we should preserve species diversity as we cannot anticipate the consequences of their loss.

\section{Endangerment and conservation of rare species}

Species diversity is currently under threat and habitat loss and climate change, among other factors, have been identified as the major cause of species endangerment and extinction in macroorganisms (Thuiller et al. 2005, Pimm et al. 2014). However, for bacteria and other microbial species only little is known about patterns and consequences of species loss. On the one hand, there is still no clear consensus about the definition of a bacterial species. Furthermore, only a small part of the huge bacterial diversity that is assumed to inhabit this planet, is currently characterized (Achtman and Wagner 2008). Nevertheless, species extinction can be considered a real threat for microbial species. For example, microbial symbionts and pathogens that are specific to endangered plant or animal species are likely to share the fate of their hosts and also free-living microbial species can suffer from habitat loss (Staley 1997). Anthropogenic disturbances, such as chemical contaminations, have been 
shown to compromise bacterial species diversity, at least locally (Moffett et al. 2003, Sun et al. 2015). Rare species, both among macroorganisms and microorganisms are particularly threatened by extinction (Pimm et al. 1988, Martiny et al. 2006). However, while conservation measures currently focus on the protection of rare macroorganisms, hardly any attention is being paid to rare microbial species. Protection of individual species, as it is practised for macroorganisms, is unfeasible for most microbial species, especially for those that are yet undiscovered (Colwell 1997). Instead, protection of areas should be considered as an approach to preserve habitats and thus at the same time both plant- and animal species and the microorganisms associated with those species and with the environment. Moreover, enhancing knowledge on the global microbial diversity and individual species is still called for in order to direct more targeted conservation approaches.

\section{Conclusions}

The results of my thesis allow me to draw several conclusions. From the cultivation approach in Chapter 2 I conclude that rare soil bacterial species can be underrepresented in isolate collections. Therefore, more studies should attempt to determine the abundance of their isolates in the field.

Based on Chapter 3 and 4, I conclude that there is no general cause that may explain rarity of bacterial species in soil. Some species can be rare due to slow growth rates, while others are poor competitors or sensitive to predation. Still, predation by protists had a stronger effect on rare species than a 1000-fold decrease in nutrient supply in my study. Future studies should further investigate the role of predation for species abundance.

From the results of Chapter 5 I conclude that reduction of rare soil microbial species does not affect induced systemic resistance in plants against insect herbivores. However, rare species loss facilitates the invasion by an added PGPR strain. More research is needed to determine how the soil microbial community affects plant resistance.

\section{Outlook}

\section{Causes of species rarity and community composition}

By investigating the causes of bacterial rarity we are at the same time looking at what makes a species abundant. Investigating species abundances will also give important insights into microbial community assembly. Understanding these processes is not merely a quirk of curious scientists. Imbalances in the microbial community composition are known to be a major cause of disease and dysfunction in the soil and rhizosphere as well as in other host environments (Adam et al. 2016). Adam et al. (2016) suggest that host-health can be 
improved by changing the indigenous community composition and enhancing beneficial species while reducing detrimental ones. Knowledge on the causes of species rarity and abundance may, therefore, be essential in this endeavour.

In this thesis and other studies it has been shown that predation by protists has the potential to alter microbial community composition (Bonkowski et al. 2000, Rønn et al. 2002). Moreover, it has been demonstrated that the presence of soil protists can benefit plant growth (Bonkowski 2004). Recently this experimental knowledge has even been started to be used in products containing protists that are applied in horticulture, which demonstrates the huge potential of protists to be used for the improvement of plant health and crop yield. However, little is known about the main mechanism through which protists affect plants. On the one hand, they are supposed to free up nutrients by grazing on bacteria that can subsequently be taken up by plants, which is also known as the microbial loop in soil (Clarholm 1985). On the other hand, they have been supposed to favour the growth of plant beneficial bacteria by grazing on their competitors or by directly producing hormones that stimulate plant growth (Bonkowski 2004). Given current successes in using soil protists, continued research on how different protists affect bacterial communities and benefit plant growth has the potential to lead to an increased quality and working consistency of protist applications.

While I could show that predation by protists can change bacterial abundances, other factors are likely to influence abundances as well. For example, the order of species arrival during the colonisation of a new habitat can strongly affect the outcome of species interactions, community composition and even the relationship between diversity and community productivity (Fukami and Morin 2003). In addition, abiotic factors, such as $\mathrm{pH}$, temperature or chemical and mechanical disturbances are known to change bacterial communities (Fuhrman et al. 2006, Shade et al. 2012b). By measuring changes in community composition in response to experimental alterations of these abiotic factors, researchers could determine under which conditions a bacterial species becomes rare. At the same time, this type of experiment can show which species increase in abundance in response to abiotic changes and disturbances. These increasing species might contribute to community resistance and resilience. Changing climatic conditions and disturbances of soils through human actions are becoming more and more prevalent. Knowledge on how the soil microbiome will be affected by these changes will be essential to predict the consequences of climatic change and disturbances for soil health.

\section{Functions of rare species}

Given the high variability in the relationship between the presence of rare microbial species and many ecosystem functions it can be assumed that rare microbial species per se might not be essential for the support of these functions. Rather the functions could be dependent on specific species with particularly unique functional traits or large effects. Some rare species 
have been demonstrated to have such large effects, as for example a sulphate reducing bacterial species in peatland (Pester et al. 2010). However, even if rare species are demonstrated to have a large influence on ecosystem functions, it is often not clear whether the rare species themselves are involved in supporting this function or if they do so by affecting more abundant species. One way to test the functional potential of a bacterial species is whole genome sequencing, which is becoming increasingly affordable and builds on an increasing database of reference genomes (Land et al. 2015, Bhattacharyya et al. 2017). Still, actual functional traits have to be tested experimentally by isolating the respective species. In addition, the roles of rare species in affecting abundant community members could be tested by constructing communities with or without the respective species. Ideally whole soil communities should be used in which individual species are selectively removed or added and shifts in community composition and functioning are monitored. Such tests could enable us to identify species with large effects on ecosystem functioning under certain sets of conditions.

With my work on soil bacteria I zoomed in on only one part of the world's ecosystems. However, as I mentioned throughout different parts of this discussion chapter, the study of rare bacteria can have implications for a much broader group of organisms. Although most macroorganisms are more thoroughly studied than microorganisms, causes and consequences of species rarity vs. abundance are still poorly understood. Furthermore, also for macroorganisms simple community properties, such as an overall high species diversity, are not generally related to ecosystem functioning. Therefore, I propose that also for macroorganisms a connection should be drawn between the mechanisms that govern species abundance and their changes in space and time, and the individual functions of species. 


\section{References}

Aanderud, Z. T., S. E. Jones, N. Fierer, and J. T. Lennon. 2015. Resuscitation of the rare biosphere contributes to pulses of ecosystem activity. Frontiers in Microbiology 6:24.

Achtman, M., and M. Wagner. 2008. Microbial diversity and the genetic nature of microbial species. Nature Reviews Microbiology 6:431-440.

Adam, E., A. E. Groenenboom, V. Kurm, M. Rajewska, R. Schmidt, O. Tyc, S. Weidner, G. Berg, W. De Boer, and J. Falcão Salles. 2016. Controlling the microbiome: microhabitat adjustments for successful biocontrol strategies in soil and human gut. Frontiers in Microbiology 7.

Aerts, R. 1999. Interspecific competition in natural plant communities: mechanisms, tradeoffs and plant-soil feedbacks. Journal of Experimental Botany 50:29-37.

Ai, D., C. Chu, M. D. F. Ellwood, R. Hou, and G. Wang. 2013. Migration and niche partitioning simultaneously increase species richness and rarity. Ecological Modelling 258:33-39.

Alain, K., and J. Querellou. 2009. Cultivating the uncultured: limits, advances and future challenges. Extremophiles 13:583-594.

Alfred, J., and I. T. Baldwin. 2015. New opportunities at the wild frontier. eLife 4:e06956.

Ali, J. G., and A. A. Agrawal. 2012. Specialist versus generalist insect herbivores and plant defense. Trends in Plant Science 17:293-302.

Altieri, M. A. 1999. The ecological role of biodiversity in agroecosystems. Agriculture, Ecosystems \& Environment 74:19-31.

Amarasekare, P. 2003. Competitive coexistence in spatially structured environments: a synthesis. Ecology Letters 6:1109-1122.

Anderson, J. P., E. Badruzsaufari, P. M. Schenk, J. M. Manners, O. J. Desmond, C. Ehlert, D. J. Maclean, P. R. Ebert, and K. Kazan. 2004. Antagonistic interaction between abscisic acid and jasmonate-ethylene signaling pathways modulates defense gene expression and disease resistance in Arabidopsis. The Plant Cell 16:3460-3479.

Apprill, A., S. McNally, R. Parsons, and L. Weber. 2015. Minor revision to V4 region SSU rRNA 806R gene primer greatly increases detection of SAR11 bacterioplankton. Aquatic Microbial Ecology 75:129-137.

Baehler, E., M. Bottiglieri, M. Péchy-Tarr, M. Maurhofer, and C. Keel. 2005. Use of green fluorescent protein-based reporters to monitor balanced production of antifungal compounds in the biocontrol agent Pseudomonas fluorescens CHA0. Journal of Applied Microbiology 99:24-38.

Bakker, P. A. H. M., R. L. Berendsen, R. F. Doornbos, P. C. A. Wintermans, and C. M. J. Pieterse. 2013. The rhizosphere revisited: root microbiomics. Frontiers in Plant Science 4:165. 
Baldrian, P., M. Kolarik, M. Stursova, J. Kopecky, V. Valaskova, T. Vetrovsky, L. Zifcakova, J. Snajdr, J. Ridl, C. Vlcek, and J. Voriskova. 2012. Active and total microbial communities in forest soil are largely different and highly stratified during decomposition. The ISME Journal 6:248-258.

Balvanera, P., A. B. Pfisterer, N. Buchmann, J.-S. He, T. Nakashizuka, D. Raffaelli, and B. Schmid. 2006. Quantifying the evidence for biodiversity effects on ecosystem functioning and services. Ecology Letters 9:1146-1156.

Barberán, A., E. O. Casamayor, and N. Fierer. 2014. The microbial contribution to macroecology. Frontiers in Microbiology 5:203.

Bartram, A. K., M. D. Lynch, J. C. Stearns, G. Moreno-Hagelsieb, and J. D. Neufeld. 2011. Generation of multimillion-sequence $16 \mathrm{~S}$ rRNA gene libraries from complex microbial communities by assembling paired-end illumina reads. Applied and Environmental Microbiology 77:3846-3852.

Bashan, Y., L. de-Bashan, S. R. Prabhu, and J.-P. Hernandez. 2014. Advances in plant growth-promoting bacterial inoculant technology: formulations and practical perspectives (1998-2013). Plant and Soil 378:1-33.

Bates, D., M. Maechler, B. Bolker, and S. Walker. 2015. Fitting linear mixed-effects models using lme4. Journal of Statistical Software 67:1-48.

Baumann, K., M.-F. Dignac, C. Rumpel, G. Bardoux, A. Sarr, M. Steffens, and P.-A. Maron. 2013. Soil microbial diversity affects soil organic matter decomposition in a silty grassland soil. Biogeochemistry 114:201-212.

Bell, C. W., V. Acosta-Martinez, N. E. McIntyre, S. Cox, D. T. Tissue, and J. C. Zak. 2009. Linking microbial community structure and function to seasonal differences in soil moisture and temperature in a Chihuahuan desert grassland. Microbial Ecology 58:827-842.

Bent, S. J., and L. J. Forney. 2008. The tragedy of the uncommon: understanding limitations in the analysis of microbial diversity. The ISME Journal 2:689-695.

Berendsen, R. L., C. M. J. Pieterse, and P. A. H. M. Bakker. 2012. The rhizosphere microbiome and plant health. Trends in Plant Science 17:478-486.

Bergmann, G. T., S. T. Bates, K. G. Eilers, C. L. Lauber, J. G. Caporaso, W. A. Walters, R. Knight, and N. Fierer. 2011. The under-recognized dominance of Verrucomicrobia in soil bacterial communities. Soil Biology and Biochemistry 43:1450-1455.

Berns, A. E., H. Philipp, H. D. Narres, P. Burauel, H. Vereecken, and W. Tappe. 2008. Effect of gamma-sterilization and autoclaving on soil organic matter structure as studied by solid state NMR, UV and fluorescence spectroscopy. European Journal of Soil Science 59:540-550.

Bhattacharyya, C., U. Bakshi, I. Mallick, S. Mukherji, B. Bera, and A. Ghosh. 2017. Genomeguided insights into the plant growth promotion capabilities of the physiologically versatile Bacillus aryabhattai strain AB211. Frontiers in Microbiology 8. 
Bloemberg, G. V., and B. J. J. Lugtenberg. 2001. Molecular basis of plant growth promotion and biocontrol by rhizobacteria. Current Opinion in Plant Biology 4:343-350.

Bohannan, B. J. M., B. Kerr, C. M. Jessup, J. B. Hughes, and G. Sandvik. 2002. Trade-offs and coexistence in microbial microcosms. Antonie Van Leeuwenhoek 81:107-115.

Bohannan, B. J. M., and R. E. Lenski. 2000a. Linking genetic change to community evolution: insights from studies of bacteria and bacteriophage. Ecology Letters 3:362-377.

Bohannan, B. J. M., and R. E. Lenski. 2000b. The relative importance of competition and predation varies with productivity in a model community. The American Naturalist 156:329-340.

Boitard, L., D. Cottinet, N. Bremond, J. Baudry, and J. Bibette. 2015. Growing microbes in millifluidic droplets. Engineering in Life Sciences 15:318-326.

Bonkowski, M. 2004. Protozoa and plant growth: the microbial loop in soil revisited. New Phytologist 162:617-631.

Bonkowski, M., W. Cheng, B. S. Griffiths, J. Alphei, and S. Scheu. 2000. Microbial-faunal interactions in the rhizosphere and effects on plant growth. European Journal of Soil Biology 36:135-147.

Bouvier, T., and P. A. Del Giorgio. 2007. Key role of selective viral-induced mortality in determining marine bacterial community composition. Environmental Microbiology 9:287-297.

Bracken, M. E. S., and N. H. N. Low. 2012. Realistic losses of rare species disproportionately impact higher trophic levels. Ecology Letters 15:461-467.

Brown, J. H., D. W. Mehlman, and G. C. Stevens. 1995. Spatial variation in abundance. Ecology 76:2028-2043.

Buckling, A., R. Kassen, G. Bell, and P. B. Rainey. 2000. Disturbance and diversity in experimental microcosms. Nature 408:961-964.

Buerger, S., A. Spoering, E. Gavrish, C. Leslin, L. Ling, and S. S. Epstein. 2012. Microbial scout hypothesis and microbial discovery. Applied and Environmental Microbiology 78:3229-3233.

Buermans, H. P. J., and J. T. den Dunnen. 2014. Next generation sequencing technology: Advances and applications. Biochimica et Biophysica Acta (BBA) - Molecular Basis of Disease 1842:1932-1941.

Cadotte, M. W., K. Carscadden, and N. Mirotchnick. 2011. Beyond species: functional diversity and the maintenance of ecological processes and services. Journal of Applied Ecology 48:1079-1087.

Campbell, B. J., L. Yu, J. F. Heidelberg, and D. L. Kirchman. 2011. Activity of abundant and rare bacteria in a coastal ocean. Proceedings of the National Academy of Sciences of the United States of America 108:12776-12781. 
Campbell, C. D., S. J. Grayston, and D. J. Hirst. 1997. Use of rhizosphere carbon sources in sole carbon source tests to discriminate soil microbial communities. Journal of Microbiological Methods 30:33-41.

Candeias, M., and R. J. Warren. 2016. Rareness starts early for disturbance-dependent grassland plant species. Biodiversity and Conservation 25:2771-2785.

Caporaso, J. G., C. L. Lauber, W. A. Walters, D. Berg-Lyons, C. A. Lozupone, P. J. Turnbaugh, N. Fierer, and R. Knight. 2011. Global patterns of 16S rRNA diversity at a depth of millions of sequences per sample. Proceedings of the National Academy of Sciences 108:4516-4522.

Caporaso, J. G., K. Paszkiewicz, D. Field, R. Knight, and J. A. Gilbert. 2012. The Western English Channel contains a persistent microbial seed bank. The ISME Journal 6:1089-1093.

Cardillo, M., G. M. Mace, J. L. Gittleman, K. E. Jones, J. Bielby, and A. Purvis. 2008. The predictability of extinction: biological and external correlates of decline in mammals. Proceedings of the Royal Society B: Biological Sciences 275:1441-1448.

Cardinale, B. J., D. S. Srivastava, J. Emmett Duffy, J. P. Wright, A. L. Downing, M. Sankaran, and C. Jouseau. 2006. Effects of biodiversity on the functioning of trophic groups and ecosystems. Nature 443:989-992.

Carini, P., P. J. Marsden, J. W. Leff, E. E. Morgan, M. S. Strickland, and N. Fierer. 2016. Relic DNA is abundant in soil and obscures estimates of soil microbial diversity. Nature Microbiology 2:16242.

Chase, J. 2013. An inordiate fondness of rarity. PLoS Biology 11: e1001573.

Chesson, P. 2000. Mechanisms of maintenance of species diversity. Annual Review of Ecology and Systematics 31:343-366.

Chesson, P., and J. J. Kuang. 2008. The interaction between predation and competition. Nature 456:235.

Chisholm, R. A. 2007. Sampling species abundance distributions: resolving the veil-line debate. Journal of Theoretical Biology 247:600-607.

Christie-Oleza, J. A., B. Fernandez, B. Nogales, R. Bosch, and J. Armengaud. 2012. Proteomic insights into the lifestyle of an environmentally relevant marine bacterium. The ISME Journal 6:124-135.

Clarholm, M. 1985. Interactions of bacteria, protozoa and plants leading to mineralization of soil nitrogen. Soil Biology and Biochemistry 17:181-187.

Colwell, R. R. 1997. Microbial diversity: the importance of exploration and conservation. Journal of Industrial Microbiology and Biotechnology 18:302-307.

Compant, S., C. Clément, and A. Sessitsch. 2010. Plant growth-promoting bacteria in the rhizo- and endosphere of plants: Their role, colonization, mechanisms involved and prospects for utilization. Soil Biology and Biochemistry 42:669-678.

Compant, S., B. Duffy, J. Nowak, C. Clément, and E. A. Barka. 2005. Use of plant growthpromoting bacteria for biocontrol of plant diseases: principles, mechanisms of 
action, and future prospects. Applied and Environmental Microbiology 71:49514959.

Cook, K. L., J. L. Garland, A. C. Layton, H. M. Dionisi, L. H. Levine, and G. S. Sayler. 2006. Effect of microbial species richness on community stability and community function in a model plant-based wastewater system processing system. Microbial Ecology 52:725-737.

Corno, G., E. Caravati, C. Callieri, and R. Bertoni. 2008. Effects of predation pressure on bacterial abundance, diversity, and size-structure distribution in an oligotrophic system. Journal of limnology 67:107-119.

Corno, G., and K. Jürgens. 2006. Direct and indirect effects of protist predation on population size structure of a bacterial strain with high phenotypic plasticity. Applied and Environmental Microbiology 72:78-86.

Corno, G., and K. Jürgens. 2008. Structural and functional patterns of bacterial communities in response to protist predation along an experimental productivity gradient. Environmental Microbiology 10:2857-2871.

Costello, M. J., R. M. May, and N. E. Stork. 2013. Can we name earth's species before they go extinct? Science 339:413-416.

Davies, K. F., C. R. Margules, and J. F. Lawrence. 2004. A synergistic effect puts rare, specialized species at greater risk of extinction Ecology 85:265-271.

Davis, K. E., S. J. Joseph, and P. H. Janssen. 2005. Effects of growth medium, inoculum size, and incubation time on culturability and isolation of soil bacteria. Applied and Environmental Microbiology 71:826-834.

De Deyn, G. B., and W. H. Van der Putten. 2005. Linking aboveground and belowground diversity. Trends in Ecology \& Evolution 20:625-633.

De Vos, M., J. H. Kim, and G. Jander. 2007. Biochemistry and molecular biology of Arabidopsis-aphid interactions. BioEssays 29:871-883.

DeAngelis, K. M., and M. K. Firestone. 2012. Phylogenetic clustering of soil microbial communities by $16 \mathrm{~S}$ rRNA but not $16 \mathrm{~S}$ rRNA genes. Applied and Environmental Microbiology 78:2459-2461.

DeBruyn, J. M., L. T. Nixon, M. N. Fawaz, A. M. Johnson, and M. Radosevich. 2011. Global biogeography and quantitative seasonal dynamics of Gemmatimonadetes in soil. Applied and Environmental Microbiology 77:6295-6300.

Delgado-Baquerizo, M., L. Giaramida, P. B. Reich, A. N. Khachane, K. Hamonts, C. Edwards, L. A. Lawton, and B. K. Singh. 2016. Lack of functional redundancy in the relationship between microbial diversity and ecosystem functioning. Journal of Ecology 104:936-946.

Díaz, S., S. Lavorel, F. de Bello, F. Quétier, K. Grigulis, and T. M. Robson. 2007. Incorporating plant functional diversity effects in ecosystem service assessments. Proceedings of the National Academy of Sciences 104:20684-20689. 
Duffy, J. E. 2009. Why biodiversity is important to the functioning of real-world ecosystems. Frontiers in Ecology and the Environment 7:437-444.

Dunbar, J., S. Takala, S. M. Barns, J. A. Davis, and C. R. Kuske. 1999. Levels of bacterial community diversity in four arid soils compared by cultivation and 16S rRNA gene cloning. Applied and Environmental Microbiology 65:1662-1669.

Dunn, A. K., and J. Handelsman. 2002. Toward an understanding of microbial communities through analysis of communication networks. Antonie Van Leeuwenhoek 81:565574.

Edgar, R. C. 2010. Search and clustering orders of magnitude faster than BLAST. Bioinformatics 26:2460-2461.

Edgar, R. C., B. J. Haas, J. C. Clemente, C. Quince, and R. Knight. 2011. UCHIME improves sensitivity and speed of chimera detection. Bioinformatics 27:2194-2200.

Edwards, J., C. Johnson, C. Santos-Medellín, E. Lurie, N. K. Podishetty, S. Bhatnagar, J. A. Eisen, and V. Sundaresan. 2015. Structure, variation, and assembly of the rootassociated microbiomes of rice. Proceedings of the National Academy of Sciences 112:E911-E920.

Ekelund, F., and R. Rønn. 1994. Notes on protozoa in agricultural soil with emphasis on heterotrophic flagellates and naked amoebae and their ecology. FEMS Microbiology Reviews 15:321-353.

Ellingsen, K. E., J. E. Hewitt, and S. F. Thrush. 2007. Rare species, habitat diversity and functional redundancy in marine benthos. Journal of Sea Research 58:291-301.

Ellis, R. J., P. Morgan, A. J. Weightman, and J. C. Fry. 2003. Cultivation-dependent and independent approaches for determining bacterial diversity in heavy-metalcontaminated soil. Applied and Environmental Microbiology 69:3223-3230.

Endara, M.-J., and P. D. Coley. 2011. The resource availability hypothesis revisited: a metaanalysis. Functional Ecology 25:389-398.

Erb, M., S. Meldau, and G. A. Howe. 2012. Role of phytohormones in insect-specific plant reactions. Trends in Plant Science 17:250-259.

Estes, J. A., and J. F. Palmisano. 1974. Sea otters: their role in structuring nearshore communities. Science 185:1058-1060.

Feys, B. J., and J. E. Parker. 2000. Interplay of signaling pathways in plant disease resistance. Trends in Genetics 16:449-455.

Fierer, N., M. A. Bradford, and R. B. Jackson. 2007. Toward an ecological classification of soil bacteria. Ecology 88:1354-1364.

Fierer, N., and R. B. Jackson. 2006. The diversity and biogeography of soil bacterial communities. Proceedings of the National Academy of Sciences of the United States of America 103:626-631.

Flather, C. H., and C. H. Sieg. 2007. Species rarity: definition, causes and classification. Pages 40-66 in M. G. Raphael and R. Molina, editors. Conservation of rare or little- 
known species: biological, social, and economic considerations. Island Press, Washington DC.

Foladori, P., B. Laura, A. Gianni, and Z. Giuliano. 2007. Effects of sonication on bacteria viability in wastewater treatment plants evaluated by flow cytometry-Fecal indicators, wastewater and activated sludge. Water Research 41:235-243.

Fox, J., and S. Weisberg. 2011. An $\{\mathrm{R}\}$ companion to applied regression, Second Edition. Sage, Thousand Oaks CA.

Franklin, R. B., and A. L. Mills. 2006. Structural and functional responses of a sewage microbial community to dilution-induced reductions in diversity. Microbial Ecology 52:280-288.

Fuhrman, J. A. 2009. Microbial community structure and its functional implications. Nature 459:193-199.

Fuhrman, J. A., I. Hewson, M. S. Schwalbach, J. A. Steele, M. V. Brown, and S. Naeem. 2006. Annually reoccurring bacterial communities are predictable from ocean conditions. Proceedings of the National Academy of Sciences 103:13104-13109.

Fuhrman, J. A., and R. T. Noble. 1995. Viruses and protists cause similar bacterial mortality in coastal seawater. Limnology and Oceanography 40:1236-1242.

Fukami, T., and P. J. Morin. 2003. Productivity-biodiversity relationships depend on the history of community assembly. Nature 424:423-426.

Galand, P. E., E. O. Casamayor, D. L. Kirchman, and C. Lovejoy. 2009. Ecology of the rare microbial biosphere of the Arctic Ocean. Proceedings of the National Academy of Sciences of the United States of America 106:22427-22432.

Gaston, K. J., T. M. Blackburn, J. J. D. Greenwood, R. D. Gregory, R. M. Quinn, and J. H. Lawton. 2000. Abundance-occupancy relationships. Journal of Applied Ecology 37:39-59.

Geisen, S., J. Weinert, A. Kudryavtsev, A. Glotova, M. Bonkowksi, and A. Smirnov. 2014. Two new species of the genus Stenamoeba (Discosea, Longamoebia):Cytoplasmic MTOC is present in one more amoebae lineage. European Journal of Protistology 50: $153-165$.

Giordanengo, P., L. Brunissen, C. Rusterucci, C. Vincent, A. Van Bel, S. Dinant, C. Girousse, M. Faucher, and J.-L. Bonnemain. 2010. Compatible plant-aphid interactions: How aphids manipulate plant responses. Comptes Rendus Biologies 333:516-523.

Godefroid, S., S. Janssens, and T. Vanderborght. 2014. Do plant reproductive traits influence species susceptibility to decline? Plant Ecology and Evolution 147:154-164.

Goldfarb, K., U. Karaoz, C. Hanson, C. Santee, M. Bradford, K. Treseder, M. Wallenstein, and E. Brodie. 2011. Differential growth responses of soil bacterial taxa to carbon substrates of varying chemical recalcitrance. Frontiers in Microbiology 2:94.

Gonzalez, J. M., M. C. Portillo, P. Belda-Ferre, and A. Mira. 2012. Amplification by PCR artificially reduces the proportion of the rare biosphere in microbial communities. PlosOne 7:e29773. 
Gottschal, J. 1985. Some reflections on microbial competitiveness among heterotrophic bacteria. Antonie Van Leeuwenhoek 51:473-494.

Grace, J. B. 1990. On the relationship between plant traits and competitive ability. Pages 5165. Academic Press, Inc., San Diego, CA.

Green, P., and B. Ewing. 2002. Phred. Version 0.020425 c. Computer program and documentation available at www. phrap. org.

Griffiths, B., K. Ritz, R. Wheatley, H. Kuan, B. Boag, S. Christensen, F. Ekelund, S. J. Sørensen, S. Muller, and J. Bloem. 2001a. An examination of the biodiversityecosystem function relationship in arable soil microbial communities. Soil Biology and Biochemistry 33:1713-1722.

Griffiths, B. S., M. Bonkowski, J. Roy, and K. Ritz. 2001b. Functional stability, substrate utilisation and biological indicators of soils following environmental impacts. Applied Soil Ecology 16:49-61.

Griffiths, B. S., H. L. Kuan, K. Ritz, L. A. Glover, A. E. McCaig, and C. Fenwick. 2004. The relationship between microbial community structure and functional stability, tested experimentally in an upland pasture soil. Microbial Ecology 47:104-113.

Grime, J. P. 1977. Evidence for the existence of three primary strategies in plants and its relevance to ecological and evolutionary theory. The American Naturalist 111:1169-1194.

Grime, J. P. 1998. Benefits of plant diversity to ecosystems: immediate, filter and founder effects. Journal of Ecology 86:902-910.

Gross, H., and J. E. Loper. 2009. Genomics of secondary metabolite production by Pseudomonas spp. Natural Product Reports 26:1408-1446.

Grover, J. P. 1991. Resource competition in a variable environment: phytoplankton growing according to the variable-internal-stores model. The American Naturalist 138:811835.

Haas, D., and G. Defago. 2005. Biological control of soil-borne pathogens by fluorescent pseudomonads. Nature Reviews Microbiology 3:307-319.

Hamaki, T., M. Suzuki, R. Fudou, Y. Jojima, T. Kajiura, A. Tabuchi, K. Sen, and H. Shibai. 2005. Isolation of novel bacteria and actinomycetes using soil-extract agar medium. Journal of Bioscience and Bioengineering 99:485-492.

Hamasaki, K., A. Taniguchi, Y. Tada, R. A. Long, and F. Azam. 2007. Actively growing bacteria in the inland sea of Japan, identified by combined bromodeoxyuridine immunocapture and denaturing gradient gel electrophoresis. Applied and Environmental Microbiology 73:2787-2798.

Hanley, M. E., and R. J. Sykes. 2009. Impacts of seedling herbivory on plant competition and implications for species coexistence. Annals of Botany 103:1347-1353.

Hanski, I., and M. Gyllenberg. 1993. Two general metapopulation models and the coresatellite species hypothesis. The American Naturalist 142:17-41. 
Hanski, I., and M. Gyllenberg. 1997. Uniting two general patterns in the distribution of species. Science 275:397-400.

Harpole, W. S., and D. Tilman. 2006. Non-neutral patterns of species abundance in grassland communities. Ecology Letters 9:15-23.

Hartmann, A., M. Schmid, D. v. Tuinen, and G. Berg. 2009. Plant-driven selection of microbes. Plant and Soil 321:235-257.

Harvey, J. A., L. M. A. Witjes, M. Benkirane, H. Duyts, and R. Wagenaar. 2007. Nutritional suitability and ecological relevance of Arabidopsis thaliana and Brassica oleracea as foodplants for the cabbage butterfly, Pieris rapae. Plant Ecology 189:117-126.

Hausmann, B., K.-H. Knorr, K. Schreck, S. G. Tringe, T. Glavina del Rio, A. Loy, and M. Pester. 2016. Consortia of low-abundance bacteria drive sulfate reductiondependent degradation of fermentation products in peat soil microcosms. The ISME Journal 10:2365-2375.

Hector, A., B. Schmid, C. Beierkuhnlein, M. C. Caldeira, M. Diemer, P. G. Dimitrakopoulos, J. A. Finn, H. Freitas, P. S. Giller, J. Good, R. Harris, P. Högberg, K. Huss-Danell, J. Joshi, A. Jumpponen, C. Körner, P. W. Leadley, M. Loreau, A. Minns, C. P. H. Mulder, G. O'Donovan, S. J. Otway, J. S. Pereira, A. Prinz, D. J. Read, M. SchererLorenzen, E.-D. Schulze, A.-S. D. Siamantziouras, E. M. Spehn, A. C. Terry, A. Y. Troumbis, F. I. Woodward, S. Yachi, and J. H. Lawton. 1999. Plant diversity and productivity experiments in European grasslands. Science 286:1123-1127.

Herms, D. A., and W. J. Mattson. 1992. The dilemma of plants: to grow or defend. The Quarterly Review of Biology 67:283-335.

Hibbing, M. E., C. Fuqua, M. R. Parsek, and S. B. Peterson. 2010. Bacterial competition: surviving and thriving in the microbial jungle. Nature Reviews Microbiology 8:1525.

Hill, G. T., N. A. Mitkowski, L. Aldrich-Wolfe, L. R. Emele, D. D. Jurkonie, A. Ficke, S. Maldonado-Ramirez, S. T. Lynch, and E. B. Nelson. 2000. Methods for assessing the composition and diversity of soil microbial communities. Applied Soil Ecology 15:25-36.

Hiltunen, T., and J. Laakso. 2013. The relative importance of competition and predation in environment characterized by resource pulses - an experimental test with a microbial community. BMC Ecology 13:1-8.

Hirsch, P. R., T. H. Mauchline, and I. M. Clark. 2010. Culture-independent molecular techniques for soil microbial ecology. Soil Biology and Biochemistry 42:878-887.

Hol, F. J. H., and C. Dekker. 2014. Zooming in to see the bigger picture: Microfluidic and nanofabrication tools to study bacteria. Science 346.

Hol, W. H. G., W. De Boer, M. De Hollander, E. E. Kuramae, A. Meisner, and W. H. Van der Putten. 2015a. Context dependency and saturating effects of loss of rare soil microbes on plant productivity. Frontiers in Plant Science 6:485. 
Hol, W. H. G., W. De Boer, A. Termorshuizen, K. M. Meyer, J. H. M. Schneider, N. M. Van Dam, J. A. Van Veen, and W. H. Van der Putten 2010. Reduction of rare soil microbes modifies plant-herbivores interactions. Ecology Letters 13:292-301.

Hol, W. H. G., P. Garbeva, C. Hordijk, P. J. Hundscheid, P. J. Gunnewiek, M. Van Agtmaal, E. E. Kuramae, and W. De Boer. 2015b. Non-random species loss in bacterial communities reduces antifungal volatile production. Ecology 96:2042-2048.

Hooper, D. U., F. S. Chapin, J. J. Ewel, A. Hector, P. Inchausti, S. Lavorel, J. H. Lawton, D. M. Lodge, M. Loreau, S. Naeem, B. Schmid, H. Setala, A. J. Symstad, J. Vandermeer, and D. A. Wardle. 2005. Effects of biodiversity on ecosystem functioning: A consensus of current knowledge. Ecological monographs 75:3-35.

Hu, S. J., A. H. C. van Bruggen, and N. J. Grünwald. 1999. Dynamics of bacterial populations in relation to carbon availability in a residue-amended soil. Applied Soil Ecology 13:21-30.

Hugoni, M., N. Taib, D. Debroas, I. Domaizon, I. Jouan Dufournel, G. Bronner, I. Salter, H. Agogue, I. Mary, and P. E. Galand. 2013. Structure of the rare archaeal biosphere and seasonal dynamics of active ecotypes in surface coastal waters. Proceedings of the National Academy of Sciences of the United States of America 110:6004-6009.

Janssen, P. H. 2006. Identifying the dominant soil bacterial taxa in libraries of 16S rRNA and 16S rRNA genes. Applied and Environmental Microbiology 72:1719-1728.

Janssen, P. H., P. S. Yates, B. E. Grinton, P. M. Taylor, and M. Sait. 2002. Improved culturability of soil bacteria and isolation in pure culture of novel members of the divisions Acidobacteria, Actinobacteria, Proteobacteria, and Verrucomicrobia. Applied and Environmental Microbiology 68:2391-2396.

Jaspers, E., and J. Overmann. 2004. Ecological significance of microdiversity: identical 16S rRNA gene sequences can be found in bacteria with highly divergent genomes and ecophysiologies. Applied and Environmental Microbiology 70:4831-4839.

Jeraldo, P., M. Sipos, N. Chia, J. M. Brulc, A. S. Dhillon, M. E. Konkel, C. L. Larson, K. E. Nelson, A. Qu, L. B. Schook, F. Yang, B. A. White, and N. Goldenfeld. 2012. Quantification of the relative roles of niche and neutral processes in structuring gastrointestinal microbiomes. Proceedings of the National Academy of Sciences 109:9692-9698.

Jessup, C. M., R. Kassen, S. E. Forde, B. Kerr, A. Buckling, P. B. Rainey, and B. J. M. Bohannan. 2004. Big questions, small worlds: microbial model systems in ecology. Trends in Ecology \& Evolution 19:189-197.

Jiang, L., and J. Adams Krumins. 2006. Consumer vs environmental productivity control of bacterial diversity and bacteria-mediated organic matter decomposition. Oikos 114:441-450.

Jones, S. E., and J. T. Lennon. 2010. Dormancy contributes to the maintenance of microbial diversity. Proceedings of the National Academy of Sciences of the United States of America 107:5881-5886. 
Joseph, S. J., P. Hugenholtz, P. Sangwan, C. A. Osborne, and P. H. Janssen. 2003. Laboratory cultivation of widespread and previously uncultured soil bacteria. Applied and Environmental Microbiology 69:7210-7215.

Jousset, A. 2012. Ecological and evolutive implications of bacterial defences against predators. Environmental Microbiology 14:1830-1843.

Jousset, A., C. Bienhold, A. Chatzinotas, L. Gallien, A. Gobet, V. Kurm, K. Kusel, M. C. Rillig, D. W. Rivett, J. F. Salles, M. G. Van der Heijden, N. H. Youssef, X. Zhang, Z. Wei, and W. H. Hol. 2017. Where less may be more: how the rare biosphere pulls ecosystems strings. The ISME Journal 11:853-862.

Jousset, A., L. Rochat, M. Pechy-Tarr, C. Keel, S. Scheu, and M. Bonkowski. 2009. Predators promote defence of rhizosphere bacterial populations by selective feeding on nontoxic cheaters. The ISME Journal 3:666-674.

Juarez, S., N. Nunan, A. C. Duday, V. Pouteau, and C. Chenu. 2013. Soil carbon mineralisation responses to alterations of microbial diversity and soil structure. Biology and Fertility of Soils 49:939-948.

Juhas, M., L. Eberl, and B. Tümmler. 2005. Quorum sensing: the power of cooperation in the world of Pseudomonas. Environmental Microbiology 7:459-471.

Jürgens, K., and C. Matz. 2002. Predation as a shaping force for the phenotypic and genotypic composition of planktonic bacteria. Antonie Van Leeuwenhoek 81:413-434.

Kaeberlein, T., K. Lewis, and S. Epstein. 2002. Isolating "uncultivable" microorganisms in pure culture in a simulated natural environment. Science 296:1127 - 1129.

Kahm, M., G. Hasenbrink, H. Lichtenberg-Frat'e, J. Ludwig, and M. Kischischo. 2010. grofit: fitting biological growth curves with R. Journal of Statistical Software 33:1-21.

Kant, M. R., W. Jonckheere, B. Knegt, F. Lemos, J. Liu, B. C. J. Schimmel, C. A. Villarroel, L. M. S. Ataide, W. Dermauw, J. J. Glas, M. Egas, A. Janssen, T. Van Leeuwen, R. C. Schuurink, M. W. Sabelis, and J. M. Alba. 2015. Mechanisms and ecological consequences of plant defence induction and suppression in herbivore communities. Annals of Botany 115:1015-1051.

Kembel, S. W., M. Wu, J. A. Eisen, and J. L. Green. 2012. Incorporating 16S gene copy number information improves estimates of microbial diversity and abundance. PLOS Computational Biology 8:e1002743.

Kerr, B., M. A. Riley, M. W. Feldman, and B. J. M. Bohannan. 2002. Local dispersal promotes biodiversity in a real-life game of rock-paper-scissors. Nature 418:171174.

Kim, J. H., and G. Jander. 2007. Myzus persicae (green peach aphid) feeding on Arabidopsis induces the formation of a deterrent indole glucosinolate. The Plant Journal 49:1008-1019.

Kim, M., H.-S. Oh, S.-C. Park, and J. Chun. 2014. Towards a taxonomic coherence between average nucleotide identity and 16S rRNA gene sequence similarity for species 
demarcation of prokaryotes. International Journal of Systematic and Evolutionary Microbiology 64:346-351.

Kirchman, D. L. 2016. Growth rates of microbes in the oceans. Annual Review of Marine Science 8:285-309.

Kneitel, J. M., and J. M. Chase. 2004a. Disturbance, predator, and resource interactions alter container community composition. Ecology 85:2088-2093.

Kneitel, J. M., and J. M. Chase. 2004b. Trade-offs in community ecology: linking spatial scales and species coexistence. Ecology Letters 7:69-80.

Koch, A. L. 2001. Oligotrophs versus copiotrophs. BioEssays 23:657-661.

Koeppel, A. F., and M. Wu. 2013. Surprisingly extensive mixed phylogenetic and ecological signals among bacterial Operational Taxonomic Units. Nucleic Acids Research 41:5175-5188.

Kunin, V., A. Engelbrektson, H. Ochman, and P. Hugenholtz. 2010. Wrinkles in the rare biospere: pyrosequencing errors can lead to artificial inflation of diversity estimates. Environmental Microbiology 12:118-123.

Kunin, W. E., and K. Gaston. 2012. The biology of rarity: causes and consequences of rarecommon differences. Springer Science \& Business Media.

Kurm, V., 2016. Low abundant soil bacteria can be metabolically versatile and fast growing.DOI: https://doi.org/10.5061/dryad.80724

Kurm, V., W. H. van der Putten, W. de Boer, S. Naus-Wiezer, and W. H. G. Hol. 2017. Low abundant soil bacteria can be metabolically versatile and fast growing. Ecology 98:555-564.

Land, M., L. Hauser, S.-R. Jun, I. Nookaew, M. R. Leuze, T.-H. Ahn, T. Karpinets, O. Lund, G. Kora, T. Wassenaar, S. Poudel, and D. W. Ussery. 2015. Insights from 20 years of bacterial genome sequencing. Functional \& Integrative Genomics 15:141-161.

Lee, Z. M.-P., C. Bussema, and T. M. Schmidt. 2009. rrnDB: documenting the number of rRNA and tRNA genes in bacteria and archaea. Nucleic Acids Research 37:D489D493.

Leitão, R. P., J. Zuanon, S. Villéger, S. E. Williams, C. Baraloto, C. Fortunel, F. P. Mendonça, and D. Mouillot. 2016. Rare species contribute disproportionately to the functional structure of species assemblages. Proceedings of the Royal Society of London B: Biological Sciences 283.

Lemanceau, P., P.-A. Maron, S. Mazurier, C. Mougel, B. Pivato, P. Plassart, L. Ranjard, C. Revellin, V. Tardy, and D. Wipf. 2015. Understanding and managing soil biodiversity: a major challenge in agroecology. Agronomy for Sustainable Development 35:67-81.

Lemarié, S., A. Robert-Seilaniantz, C. Lariagon, J. Lemoine, N. Marnet, A. Levrel, M. Jubault, M. J. Manzanares-Dauleux, and A. Gravot. 2015. Camalexin contributes to the partial resistance of Arabidopsis thaliana to the biotrophic soilborne protist Plasmodiophora brassicae. Frontiers in Plant Science 6:539. 
Lenski, R. E. 2017. Experimental evolution and the dynamics of adaptation and genome evolution in microbial populations. The ISME Journal 11:2181-2194.

Lenth, R. V. 2016. Least-squares means: The R package lsmeans. Journal of Statistical Software 69:1-33.

Liao, J., X. Cao, J. Wang, L. Zhao, J. Sun, D. Jiang, and Y. Huang. 2017. Similar community assembly mechanisms underlie similar biogeography of rare and abundant bacteria in lakes on Yungui Plateau, China. Limnology and Oceanography 62:723-735.

Liu, L., J. W. Kloepper, and S. Tuzun. 1995. Induction of systemic resistance in cucumber by plant growth-promoting rhizobacteria - duration of protection and effect of hostresistance on protection and root colonization. Phytopathology 85:1064-1068.

Livak, K. J., and T. D. Schmittgen. 2001. Analysis of relative gene expression data using real-tim e quantitative PCR and the 2- $\Delta \Delta$ CTmethod. Methods 25:402-408.

Loreau, M., S. Naeem, P. Inchausti, J. Bengtsson, J. P. Grime, A. Hector, D. U. Hooper, M. A. Huston, D. Raffaelli, B. Schmid, D. Tilman, and D. A. Wardle. 2001. Biodiversity and ecosystem functioning: current knowledge and future challenges. Science 294:804-808.

Low-Décarie, E., M. Kolber, P. Homme, A. Lofano, A. Dumbrell, A. Gonzalez, and G. Bell. 2015. Community rescue in experimental metacommunities. Proceedings of the National Academy of Sciences of the United States of America 112:14307-14312.

Lugtenberg, B., and F. Kamilova. 2009. Plant-growth-promoting rhizobacteria. Annual Review Microbiology 63:541-556.

Luiselli, L., M. Capula, L. Rugiero, D. Salvi, and G. C. Akani. 2012. Does interspecific competition with a stronger competitor explain the rarity of an endangered snake on a Mediterranean island? Ecological Research 27:649-655.

Lynch, M. D., A. K. Bartram, and J. D. Neufeld. 2012. Targeted recovery of novel phylogenetic diversity from next-generation sequence data. The ISME Journal 6:2067-2077.

Lynch, M. D. J., and J. D. Neufeld. 2015. Ecology and exploration of the rare biosphere. Nature Reviews Microbiology 13:217-229.

Lyons, K. G., and M. W. Schwartz. 2001. Rare species loss alters ecosystem function invasion resistance. Ecology Letters 4:358-365.

Magurran, A. E., and P. A. Henderson. 2003. Explaining the excess of rare species in natural species abundance distributions. Nature 422:714-716.

Mallon, C. A., F. Poly, X. Le Roux, I. Marring, J. D. Van Elsas, and J. F. Salles. 2015. Resource pulses can alleviate the biodiversity-invasion relationship in soil microbial communities. Ecology 96:915-926.

Martiny, J. B., B. J. Bohannan, J. H. Brown, R. K. Colwell, J. A. Fuhrman, J. L. Green, M. C. Horner-Devine, M. Kane, J. A. Krumins, C. R. Kuske, P. J. Morin, S. Naeem, L. Ovreas, A. L. Reysenbach, V. H. Smith, and J. T. Staley. 2006. Microbial 
biogeography: putting microorganisms on the map. Nature Reviews Microbiology 4:102-112.

Matos, A., L. Kerkhof, and J. L. Garland. 2005. Effects of microbial community diversity on the survival of Pseudomonas aeruginosa in the wheat rhizosphere. Microbial Ecology 49:257-264.

Matz, C., and S. Kjelleberg. 2005. Off the hook - how bacteria survive protozoan grazing. Trends in Microbiology 13:302-307.

Mauch-Mani, B., and J.-P. Métraux. 1998. Salicylic acid and systemic acquired resistance to pathogen attack. Annals of Botany 82:535-540.

Mazzola, M., X. Zhao, M. F. Cohen, and J. M. Raaijmakers. 2007. Cyclic lipopeptide surfactant production by Pseudomonas fluorescens SS101 is not required for suppression of complex Pythium spp. populations. Phytopathology 97:1348-1355.

McCaig, A. E., S. J. Grayston, J. I. Prosser, and L. A. Glover. 2001. Impact of cultivation on characterisation of species composition of soil bacterial communities. FEMS Microbiology Ecology 35:37-48.

McCarthy, A., E. Chiang, M. L. Schmidt, and V. J. Denef. 2015. RNA preservation agents and nucleic acid extraction method bias perceived bacterial community composition. Plos One 10:e121659.

McGill, B. J., R. S. Etienne, J. S. Gray, D. Alonso, M. J. Anderson, H. K. Benecha, M. Dornelas, B. J. Enquist, J. L. Green, F. He, A. H. Hurlbert, A. E. Magurran, P. A. Marquet, B. A. Maurer, A. Ostling, C. U. Soykan, K. I. Ugland, and E. P. White. 2007. Species abundance distributions: moving beyond single prediction theories to integration within an ecological framework. Ecology Letters 10:995-1015.

Mi, Z., N. G. Swenson, R. Valencia, W. J. Kress, D. L. Erickson, A. J. Pérez, H. Ren, S. H. Su, N. Gunatilleke, S. Gunatilleke, Z. Hao, W. Ye, M. Cao, H. S. Suresh, H. S. Dattaraja, R. Sukumar, and K. Ma. 2012. The contribution of rare species to community phylogenetic diversity across a global network of forest plots. The American Naturalist 180:E17-E30.

Mikkelsen, M. D., B. L. Petersen, E. Glawischnig, A. B. Jensen, E. Andreasson, and B. A. Halkier. 2003. Modulation of CYP79 genes and glucosinolate profiles in Arabidopsis by defense signaling pathways. Plant Physiology 131:298-308.

Mitsui, H., K. Gorlach, H.-j. Lee, R. Hattori, and T. Hattori. 1997. Incubation time and media requirements of culturable bacteria from different phylogenetic groups. Journal of Microbiological Methods 30:103-110.

Moffett, B. F., F. A. Nicholson, N. C. Uwakwe, B. J. Chambers, J. A. Harris, and T. C. J. Hill. 2003. Zinc contamination decreases the bacterial diversity of agricultural soil. FEMS Microbiology Ecology 43:13-19.

Morrissey, E. M., R. L. Mau, E. Schwartz, J. G. Caporaso, P. Dijkstra, N. van Gestel, B. J. Koch, C. M. Liu, M. Hayer, T. A. McHugh, J. C. Marks, L. B. Price, and B. A. 
Hungate. 2016. Phylogenetic organization of bacterial activity. The ISME Journal 10:2336-2340.

Mouillot, D., D. R. Bellwood, C. Baraloto, J. Chave, R. Galzin, M. Harmelin-Vivien, M. Kulbicki, S. Lavergne, S. Lavorel, N. Mouquet, C. E. Paine, J. Renaud, and W. Thuiller. 2013. Rare species support vulnerable functions in high-diversity ecosystems. PLoS Biol 11:e1001569.

Müller, G., M. van Kleunen, and W. Dawson. 2016. Commonness and rarity of alien and native plant species - the relative roles of intraspecific competition and plant-soil feedback. Oikos 125:1458-1466.

Murray, B. R., P. H. Thrall, A. M. Gill, and A. B. Nicotra. 2002. How plant life-history and ecological traits relate to species rarity and commonness at varying spatial scales. Australian Ecology 27:291-310.

Nacke, H., A. Thürmer, A. Wollherr, C. Will, L. Hodac, N. Herold, I. Schöning, M. Schrumpf, and R. Daniel. 2011. Pyrosequencing-based assessment of bacterial community structure along different management types in German forest and grassland soils. Plos One 6:1-12.

Neuenschwander, S. M., J. Pernthaler, T. Posch, and M. M. Salcher. 2015. Seasonal growth potential of rare lake water bacteria suggest their disproportional contribution to carbon fluxes. Environmental Microbiology 17:781-795.

Nichols, D., N. Cahoon, E. M. Trakhtenberg, L. Pham, A. Mehta, A. Belanger, T. Kanigan, K. Lewis, and S. S. Epstein. 2010. Use of Ichip for high-throughput in situ cultivation of "uncultivable" microbial species. Applied and Environmental Microbiology 76:2445-2450.

Nuccio, E. E., J. Anderson-Furgeson, K. Y. Estera, J. Pett-Ridge, P. de Valpine, E. L. Brodie, and M. K. Firestone. 2016. Climate and edaphic controllers influence rhizosphere community assembly for a wild annual grass. Ecology 97:1307-1318.

Nunes da Rocha, U., L. Van Overbeek, and J. D. Van Elsas. 2009. Exploration of hithertouncultured bacteria from the rhizosphere. FEMS Microbiology Ecology 69:313328.

Oksanen, J., F. G. Blanchet, R. Kindt, P. Legendre, P. R. Minchin, R. B. O'Hara, G. L. Simpson, P. Solymos, M. H. H. Stevens, and H. Wagner. 2016. vegan: Community Ecology Package.

Östman, Ö., S. Drakare, E. S. Kritzberg, S. Langenheder, J. B. Logue, and E. S. Lindström. 2010. Regional invariance among microbial communities. Ecology Letters 13:118127.

Paine, R. T. 1969. The Pisaster-Tegula interaction: prey patches, predator food preference, and intertidal community structure. Ecology 50:950-961.

Pangesti, N., A. Pineda, M. Dicke, and J. J. A. van Loon. 2015. Variation in plant-mediated interactions between rhizobacteria and caterpillars: potential role of soil composition. Plant Biology 17:474-483. 
Pangesti, N., S. Vandenbrande, A. Pineda, M. Dicke, J. M. Raaijmakers, and J. J. A. Van Loon. 2017. Antagonism between two root-associated beneficial Pseudomonas strains does not affect plant growth promotion and induced resistance against a leafchewing herbivore. FEMS Microbiology Ecology 93.

Park, Y.-S., S. Dutta, M. Ann, J. M. Raaijmakers, and K. Park. 2015. Promotion of plant growth by Pseudomonas fluorescens strain SS101 via novel volatile organic compounds. Biochemical and Biophysical Research Communications 461:361-365.

Parry, G. D. 1981. The Meanings of r- and K-Selection. Oecologia 48:260-264.

Paul, E. A. 2014. Soil microbiology, ecology and biochemistry. Academic press, London.

Paulsen, I. T., C. M. Press, J. Ravel, D. Y. Kobayashi, G. S. A. Myers, D. V. Mavrodi, R. T. DeBoy, R. Seshadri, Q. Ren, R. Madupu, R. J. Dodson, A. S. Durkin, L. M. Brinkac, S. C. Daugherty, S. A. Sullivan, M. J. Rosovitz, M. L. Gwinn, L. Zhou, D. J. Schneider, S. W. Cartinhour, W. C. Nelson, J. Weidman, K. Watkins, K. Tran, H. Khouri, E. A. Pierson, L. S. Pierson, L. S. Thomashow, and J. E. Loper. 2005. Complete genome sequence of the plant commensal Pseudomonas fluorescens Pf5. Nature Biotechnology 23:873-878.

Pedrós-Alió, C. 2006. Marine microbial diversity: can it be determined? Trends in Microbiology 14:257-263.

Pereira e Silva, M. C., F. Poly, N. Guillaumaud, J. D. van Elsas, and J. F. Salles. 2012. Fluctuations in Ammonia Oxidizing Communities Across Agricultural Soils are Driven by Soil Structure and $\mathrm{pH}$. Frontiers in Microbiology 3:77.

Pester, M., N. Bittner, P. Deevong, M. Wagner, and A. Loy. 2010. A 'rare biosphere' microorganism contributes to sulfate reduction in a peatland. The ISME Journal 4:1591-1602.

Peter, H., S. Beier, S. Bertilsson, E. S. Lindstrom, S. Langenheder, and L. J. Tranvik. 2011. Function-specific response to depletion of microbial diversity. The ISME Journal 5:351-361.

Pfaffl, M. W., A. Tichopad, C. Prgomet, and T. P. Neuvians. 2004. Determination of stable housekeeping genes, differentially regulated target genes and sample integrity: BestKeeper - Excel-based tool using pair-wise correlations. Biotechnology Letters 26:509-515.

Philippot, L., J. M. Raaijmakers, P. Lemanceau, and W. H. van der Putten. 2013a. Going back to the roots: the microbial ecology of the rhizosphere. Nature Reviews Microbiology 11:789-799.

Philippot, L., A. Spor, C. Henault, D. Bru, F. Bizouard, C. M. Jones, A. Sarr, and P. A. Maron. 2013b. Loss in microbial diversity affects nitrogen cycling in soil. The ISME Journal 7:1609-1619.

Pianka, E. R. 2014. Rarity in Australian desert lizards. Austral Ecology 39:214-224. 
Pieterse, C. M., J. A. Van Pelt, B. W. Verhagen, J. Ton, A. Van Wees, K. M. LéonKloosterziel, and L. C. Van Loon. 2003. Induced systemic resistance by plant growth-promoting rhizobacteria. Symbiosis 35:39-54.

Pieterse, C. M. J., and M. Dicke. 2007. Plant interactions with microbes and insects: from molecular mechanisms to ecology. Trends in Plant Science 12:564-569.

Pieterse, C. M. J., S. C. M. Van Wees, J. Ton, J. A. Van Pelt, and L. C. Van Loon. 2002. Signalling in rhizobacteria-induced systemic resistance in Arabidopsis thaliana. Plant Biology 4:535-544.

Pieterse, C. M. J., C. Zamioudis, R. L. Berendsen, D. M. Weller, S. C. M. Van Wees, and P. A. H. M. Bakker. 2014. Induced systemic resistance by beneficial microbes. Annual Review of Phytopathology 52:347-375.

Pilloni, G., M. S. Granitsiotis, M. Engel, and T. Lueders. 2012. Testing the limits of 454 pyrotag sequencing: reproducibility, quantitative assessment and comparison to TRFLP fingerprinting of aquifer microbes. Plos One 7:e40467.

Pimm, S. L., C. N. Jenkins, R. Abell, T. M. Brooks, J. L. Gittleman, L. N. Joppa, P. H. Raven, C. M. Roberts, and J. O. Sexton. 2014. The biodiversity of species and their rates of extinction, distribution, and protection. Science 344:1246752.

Pimm, S. L., H. L. Jones, and J. Diamond. 1988. On the risk of extinction. The American Naturalist 132:757-785.

Pineda, A., S. J. Zheng, J. J. A. van Loon, and M. Dicke. 2012. Rhizobacteria modify plantaphid interactions: a case of induced systemic susceptibility. Plant Biology 14:8390.

Portillo, M. C., J. W. Leff, C. L. Lauber, and N. Fierer. 2013. Cell size distributions of soil bacterial and archaeal taxa. Applied and Environmental Microbiology 79:76107617.

Powell, J. R., S. Karunaratne, C. D. Campbell, H. Yao, L. Robinson, and B. K. Singh. 2015. Deterministic processes vary during community assembly for ecologically dissimilar taxa. Nature Communications 6:8444.

Power, M. E., D. Tilman, J. A. Estes, B. A. Menge, W. J. Bond, L. S. Mills, G. Daily, J. C. Castilla, J. Lubchenco, and R. T. Paine. 1996. Challenges in the quest for keystones. BioScience 46:609-620.

Preston, F. W. 1948. The commonness, and rarity, of species. Ecology 29:254-283.

Prosser, J. I., B. J. M. Bohannan, T. P. Curtis, R. J. Ellis, M. K. Firestone, R. P. Freckleton, J. L. Green, L. E. Green, K. Killham, J. J. Lennon, A. M. Osborn, M. Solan, C. J. van der Gast, and J. P. W. Young. 2007. The role of ecological theory in microbial ecology. Nature Reviews Microbiology 5:384-392.

Proulx, M., and A. Mazumder. 1998. Reversal of grazing impact on plant species richness under nutrient-poor vs. nutrient-rich ecosystems. Ecology 79:2581-2592.

Pruesse, E., J. Peplies, and F. O. Glöckner. 2012. SINA: Accurate high-throughput multiple sequence alignment of ribosomal RNA genes. Bioinformatics 28:1823-1829. 
Puspita, I. D., Y. Kamagata, M. Tanaka, K. Asano, and C. H. Nakatsu. 2012. Are uncultivated bacteria really uncultivable? Microbes and Environments 27:356-366.

R Core Team. 2016. R: A language and environment for statistical computing.

Raaijmakers, J. M., M. Leeman, M. M. P. Vanoorschot, I. Vandersluis, B. Schippers, and P. A. H. M. Bakker. 1995. Dose-response relationships in biological-control of Fusarium-wilt of radish by Pseudomonas spp. Phytopathology 85:1075-1081.

Raaijmakers, J. M., M. Vlami, and J. T. de Souza. 2002. Antibiotic production by bacterial biocontrol agents. Antonie Van Leeuwenhoek 81:537.

Rabinowitz, D. 1981. Seven forms of rarity.in H. Synge, editor. The biological aspects of rare plant conservation. John Wiley \& Sons Ltd., Hoboken, New Jersey, USA.

Rabinowitz, D., J. K. Rapp, and P. M. Dixon. 1984. Competitive abilities of sparse grass species: means of persistence or cause of abundance. Ecology 65:1144-1154.

Rafrafi, Y., E. Trably, J. Hamelin, E. Latrille, I. Meynial-Salles, S. Benomar, M.-T. GiudiciOrticoni, and J.-P. Steyer. 2013. Sub-dominant bacteria as keystone species in microbial communities producing bio-hydrogen. International Journal of Hydrogen Energy 38:4975-4985.

Rajkumar, M., N. Ae, M. N. V. Prasad, and H. Freitas. 2010. Potential of siderophoreproducing bacteria for improving heavy metal phytoextraction. Trends in Biotechnology 28:142-149.

Remans, T., K. Smeets, K. Opdenakker, D. Mathijsen, J. Vangronsveld, and A. Cuypers. 2008. Normalisation of real-time RT-PCR gene expression measurements in Arabidopsis thaliana exposed to increased metal concentrations. Planta 227:13431349.

Rodríguez, H., and R. Fraga. 1999. Phosphate solubilizing bacteria and their role in plant growth promotion. Biotechnology Advances 17:319-339.

Roger, F., S. Bertilsson, S. Langenheder, O. A. Osman, and L. Gamfeldt. 2016. Effects of multiple dimensions of bacterial diversity on functioning, stability and multifunctionality. Ecology 97:2716-2728.

Rognes, T., T. Flouri, B. Nichols, C. Quince, and F. Mahé. 2016. VSEARCH: a versatile open source tool for metagenomics. PeerJ 4.

Roller, B. R. K., S. F. Stoddard, and T. M. Schmidt. 2016. Exploiting rRNA operon copy number to investigate bacterial reproductive strategies. Nature Microbiology 1:16160.

Rønn, R., A. E. McCaig, B. S. Griffiths, and J. I. Prosser. 2002. Impact of protozoan grazing on bacterial community structure in soil microcosms. Applied and Environmental Microbiology 68:6094-6105.

Ryu, C.-M., M. A. Farag, C.-H. Hu, M. S. Reddy, H.-X. Wei, P. W. Paré, and J. W. Kloepper. 2003. Bacterial volatiles promote growth in Arabidopsis. Proceedings of the National Academy of Sciences of the United States of America 100:4927-4932. 
Sait, M., P. Hugenholtz, and P. H. Janssen. 2002. Cultivation of globally distributed soil bacteria from phylogenetic lineages previously only detected in cultivationindependent surveys. Environmental Microbiology 4:654-666.

Salcher, M. M., and K. Simek. 2016. Isolation and cultivation of planktonic freshwater microbes is essential for a comprehensive understanding of their ecology. Aquatic Microbial Ecology 77:183-196.

Saleem, M., I. Fetzer, C. F. Dormann, H. Harms, and A. Chatzinotas. 2012. Predator richness increases the effect of prey diversity on prey yield. Nature Communications 3:1305.

Salonius, P. 1981. Metabolic capabilities of forest soil microbial populations with reduced species diversity. Soil Biology and Biochemistry 13:1-10.

Schloss, P. D., D. Gevers, and S. L. Westcott. 2011. Reducing the Effects of PCR Amplification and Sequencing Artifacts on 16S rRNA-Based Studies. Plos One 6:e27310.

Schmidt, M. W. I., M. S. Torn, S. Abiven, T. Dittmar, G. Guggenberger, I. A. Janssens, M. Kleber, I. Kögel-Knabner, J. Lehmann, D. A. C. Manning, P. Nannipieri, D. P. Rasse, S. Weiner, and S. E. Trumbore. 2011. Persistence of soil organic matter as an ecosystem property. Nature 478:49.

Schmidt, R., V. Cordovez, W. de Boer, J. Raaijmakers, and P. Garbeva. 2015. Volatile affairs in microbial interactions. The ISME Journal 9:2329-2335.

Schnider-Keel, U., A. Seematter, M. Maurhofer, C. Blumer, B. Duffy, C. Gigot-Bonnefoy, C. Reimmann, R. Notz, G. Défago, D. Haas, and C. Keel. 2000. Autoinduction of 2,4-diacetylphloroglucinol biosynthesis in the biocontrol agent Pseudomonas fluorescensCHA0 and repression by the bacterial metabolites salicylate and pyoluteorin. Journal of Bacteriology 182:1215-1225.

Schulz-Bohm, K., S. Geisen, E. R. J. Wubs, C. Song, W. de Boer, and P. Garbeva. 2016. The prey's scent - Volatile organic compound mediated interactions between soil bacteria and their protist predators. The ISME Journal 11:817.

Semenov, A. M. 1991. Physiological bases of oligotrophy of microorganisms and the concept of microbial community. Microbial Ecology 22:239-247.

Shade, A., C. S. Hogan, A. K. Klimowicz, M. Linske, P. S. McManus, and J. Handelsman. 2012a. Culturing captures members of the soil rare biosphere. Environmental Microbiology 14:2247-2252.

Shade, A., S. E. Jones, J. G. Caporaso, J. Handelsman, R. Knight, N. Fierer, and J. A. Gilbert. 2014. Conditionally rare taxa disproportionately contribute to temporal changes in microbial diversity. MBio. American Society of Microbiology, 1752 N St., N.W., Washington, DC.

Shade, A., H. Peter, S. D. Allison, D. L. Baho, M. Berga, H. Bürgmann, D. H. Huber, S. Langenheder, J. T. Lennon, and J. B. Martiny. 2012b. Fundamentals of microbial community resistance and resilience. Frontiers in Microbiology 3. 
Simek, K., J. Vrba, J. Pernthaler, T. Posch, P. Hartman, J. Nedoma, and R. Psenner. 1997. Morphological and compositional shifts in an experimental bacterial community influenced by protists with contrasting feeding modes. Applied and Environmental Microbiology 63:587-595.

Skopina, M. Y., A. A. Vasileva, E. V. Pershina, and A. V. Pinevich. 2016. Diversity at low abundance: The phenomenon of the rare bacterial biosphere. Microbiology 85:272282.

Slatyer, R. A., M. Hirst, and J. P. Sexton. 2013. Niche breadth predicts geographical range size: a general ecological pattern. Ecology Letters 16:1104-1114.

Smirnov, A. V., and S. Brown. 2004. Guide to the methods of study and identification of soil gymnamoebae. Protistology 3:148-190.

Smith, K. P., J. Handelsman, and R. M. Goodman. 1999. Genetic basis in plants for interactions with disease-suppressive bacteria. Proceedings of the National Academy of Sciences of the United States of America 96:4786-4790.

Smith, M. D., and A. K. Knapp. 2003. Dominant species maintain ecosystem function with non-random species loss. Ecology Letters 6:509-517.

Sogin, M. L., H. G. Morrison, J. A. Huber, D. Mark Welch, S. M. Huse, P. R. Neal, J. M. Arrieta, and G. J. Herndl. 2006. Microbial diversity in the deep sea and the underexplored "rare biosphere". Proceedings of the National Academy of Sciences of the United States of America 103:12115-12120.

Solan, M., B. J. Cardinale, A. L. Downing, K. A. M. Engelhardt, J. L. Ruesink, and D. S. Srivastava. 2004. Extinction and ecosystem function in the marine benthos. Science 306:1177-1180.

Soliveres, S., P. Manning, D. Prati, M. M. Gossner, F. Alt, H. Arndt, V. Baumgartner, J. Binkenstein, K. Birkhofer, S. Blaser, N. Blüthgen, S. Boch, S. Böhm, C. Börschig, F. Buscot, T. Diekötter, J. Heinze, N. Hölzel, K. Jung, V. H. Klaus, A.-M. Klein, T. Kleinebecker, S. Klemmer, J. Krauss, M. Lange, E. K. Morris, J. Müller, Y. Oelm ann, J. Overm ann, E. Pašalić, S. C. Renner, M. C. Rillig, H. M. Schaefer, M. Schloter, B. Schmitt, I. Schöning, M. Schrumpf, J. Sikorski, S. A. Socher, E. F. Solly, I. Sonnemann, E. Sorkau, J. Steckel, I. Steffan-Dewenter, B. Stempfhuber, M. Tschapka, M. Türke, P. Venter, C. N. Weiner, W. W. Weisser, M. Werner, C. Westphal, W. Wilcke, V. Wolters, T. Wubet, S. Wurst, M. Fischer, and E. Allan. 2016. Locally rare species influence grassland ecosystem multifunctionality. Philosophical Transactions of the Royal Society B: Biological Sciences 371.

Spatharis, S., and G. Tsirtsis. 2013. Zipf-Mandelbrot model behavior in marine eutrophication: two way fitting on field and simulated phytoplankton assemblages. Hydrobiologia 714:191-199.

Srinivasan, M. C., R. S. Laxman, and M. V. Deshpande. 1991. Physiology and nutritional aspects of actinomycetes: an overview. World Journal of Microbiology \& Biotechnology 7:171-184. 
Stackebrandt, E., and B. M. Goebel. 1994. Taxonomic note: a place for DNA-DNA reassociation and $16 \mathrm{~S}$ rRNA sequence analysis in the present species definition in bacteriology. International Journal of Systematic and Evolutionary Microbiology 44:846-849.

Staley, J. T. 1997. Biodiversity: are microbial species threatened?: Commentary. Current Opinion in Biotechnology 8:340-345.

Staley, J. T. 2006. The bacterial species dilemma and the genomic-phylogenetic species concept. Philosophical Transactions of the Royal Society B: Biological Sciences 361:1899-1909.

Staley, J. T., and A. Konopka. 1985. Measurement of in situ activities of nonphotosynthetic microorganisms in aquatic and terrestrial habitats. Annual Review of Microbiology 39:321-346.

Stearns, S. C. 1976. Life-History Tactics: A Review of the Ideas. The Quarterly Review of Biology 51:3-47.

Stevenson, B. S., and T. M. Schmidt. 2004. Life history implications of rRNA gene copy number in Escherichia coli. Applied and Environmental Microbiology 70:66706677.

Strauss, S. Y., and A. A. Agrawal. 1999. The ecology and evolution of plant tolerance to herbivory. Trends in Ecology \& Evolution 14:179-185.

Strickland, M. S., C. Lauber, N. Fierer, and M. A. Bradford. 2009. Testing the functional significance of microbial community composition. Ecology 90:441-451.

Stubbendieck, R. M., and P. D. Straight. 2016. Multifaceted interfaces of bacterial competition. Journal of Bacteriology 198:2145-2155.

Sun, R., X.-X. Zhang, X. Guo, D. Wang, and H. Chu. 2015. Bacterial diversity in soils subjected to long-term chemical fertilization can be more stably maintained with the addition of livestock manure than wheat straw. Soil Biology and Biochemistry 88:918.

Suriya, J., M. Chandra Shekar, N. M. Nathani, T. Suganya, S. Bharathiraja, and M. Krishnan. 2017. Assessment of bacterial community composition in response to uranium levels in sediment samples of sacred Cauvery River. Applied Microbiology and Biotechnology 101:831-841.

Suwa, Y., and T. Hattori. 1984. Effects of nutrient concentration on the growth of soil bacteria. Soil Science and Plant Nutrition 30:397-403.

Thingstad, T., and R. Lignell. 1997. Theoretical models for the control of bacterial growth rate, abundance, diversity and carbon demand. Aquatic Microbial Ecology 13:1927.

Thompson, G. A., and F. L. Goggin. 2006. Transcriptomics and functional genomics of plant defence induction by phloem-feeding insects. Journal of Experimental Botany 57:755-766. 
Thuiller, W., S. Lavorel, M. B. Araújo, M. T. Sykes, and I. C. Prentice. 2005. Climate change threats to plant diversity in Europe. Proceedings of the National Academy of Sciences of the United States of America 102:8245-8250.

Tilman, D. 1982. Resource competition and community structure. Princeton University Press, Princeton, New Jersey.

Tilman, D. 2004. Niche tradeoffs, neutrality, and community structure: A stochastic theory of resource competition, invasion, and community assembly. Proceedings of the National Academy of Sciences of the United States of America 101:10854-10861.

Tilman, D., S. S. Kilham, and P. Kilham. 1982. Phytoplankton community ecology: the role of limiting nutrients. Annual Review of Ecology and Systematics 13:349-372.

Tilman, D., J. Knops, D. Wedin, P. Reich, M. Ritchie, and E. Siemann. 1997. The influence of functional diversity and composition on ecosystem processes. Science 277:13001302.

Tilman, D., D. Wedin, and J. Knops. 1996. Productivity and sustainability influenced by biodiversity in grassland ecosystems. Nature 379:718-720.

Tindall, B. J., R. Rosselló-Móra, H.-J. Busse, W. Ludwig, and P. Kämpfer. 2010. Notes on the characterization of prokaryote strains for taxonomic purposes. International Journal of Systematic and Evolutionary Microbiology 60:249-266.

Torsvik, V., L. Øvreås, and T. F. Thingstad. 2002. Prokaryotic diversity--magnitude, dynamics, and controlling factors. Science 296:1064-1066.

Torsvik, V., R. Sørheim, and J. Goksøyr. 1996. Total bacterial diversity in soil and sediment communities-A review. Journal of Industrial Microbiology 17:170-178.

Tran, H., A. Ficke, T. Asiimwe, M. Höfte, and J. M. Raaijmakers. 2007. Role of the cyclic lipopeptide massetolide A in biological control of Phytophthora infestans and in colonization of tomato plants by Pseudomonas fluorescens. New Phytologist 175:731-742.

Traxler, M. F., M. R. Seyedsayamdost, J. Clardy, and R. Kolter. 2012. Interspecies modulation of bacterial development through iron competition and siderophore piracy. Molecular Microbiology 86:628-644.

Tsementzi, D., R. Poretsky, L. M. Rodriguez-R, C. Luo, and K. T. Konstantinidis. 2014. Evaluation of metatranscriptomic protocols and application to the study of freshwater microbial communities. Environmental Microbiology Reports 6:640655.

Tyc, O., H. Zweers, W. de Boer, and P. Garbeva. 2015. Volatiles in inter-specific bacterial interactions. Frontiers in Microbiology 6:1412.

Urich, T., A. Lanzén, J. Qi, D. H. Huson, C. Schleper, and S. C. Schuster. 2008. Simultaneous assessment of soil microbial community structure and function through analysis of the meta-transcriptome. Plos One 3:e2527-e2527. 
Våge, S., J. E. Storesund, J. Giske, and T. F. Thingstad. 2014. Optimal defense strategies in an idealized microbial food web under trade-off between competition and defense. Plos One 9:e101415.

van Agtmaal, M., G. J. van Os, W. H. G. Hol, M. P. J. Hundscheid, W. T. Runia, C. A. Hordijk, and W. de Boer. 2015. Legacy effects of anaerobic soil disinfestation on soil bacterial community composition and production of pathogen-suppressing volatiles. Frontiers in Microbiology 6:701.

Van de Mortel, J. E., R. C. H. De Vos, E. Dekkers, A. Pineda, L. Guillod, K. Bouwmeester, J. J. A. Van Loon, M. Dicke, and J. M. Raaijmakers. 2012. Metabolic and transcriptomic changes induced in Arabidopsis by the rhizobacterium Pseudomonas fluorescens SS101. Plant Physiology 160:2173-2188.

van de Voorde, T. F. J., W. H. van der Putten, and T. M. Bezemer. 2012. The importance of plant-soil interactions, soil nutrients, and plant life history traits for the temporal dynamics of Jacobaea vulgaris in a chronosequence of old-fields. Oikos 121:12511262.

Van der Ent, S., S. C. M. Van Wees, and C. M. J. Pieterse. 2009. Jasmonate signaling in plant interactions with resistance-inducing beneficial microbes. Phytochemistry 70:15811588.

Van der Putten, W. H., M. Macel, and M. E. Visser. 2010. Predicting species distribution and abundance responses to climate change: why it is essential to include biotic interactions across trophic levels. Philosophical Transactions of the Royal Society of London B: Biological Sciences 365:2025-2034.

Van der Putten, W. H., S. R. Mortimer, K. Hedlund, C. Van Dijk, V. K. Brown, J. Lepä, C. Rodriguez-Barrueco, J. Roy, T. A. Diaz Len, and D. Gormsen. 2000. Plant species diversity as a driver of early succession in abandoned fields: a multi-site approach. Oecologia 124:91-99.

Van Elsas, J. D., M. Chiurazzi, C. A. Mallon, D. Elhottová, V. Kristufek, and J. Falcao Salles. 2012. Microbial diversity determines the invasion of soil by a bacterial pathogen. Proceedings of the National Academy of Sciences of the United States of America 109:1159-1164.

Van Elsas, J. D., P. Hill, A. Chronáková, M. Grekova, Y. Topalova, D. Elhottová, and V. Kristufek. 2007. Survival of genetically marked Escherichia coli O157:H7 in soil as affected by soil microbial community shifts. The ISME Journal 1:204-214.

van Kleunen, M., and D. M. Richardson. 2007. Invasion biology and conservation biology: time to join forces to explore the links between species traits and extinction risk and invasiveness. Progress in Physical Geography 31:447-450.

Van Loon, L., and P. Bakker. 2006. Root-associated bacteria inducing systemic resistance. Pages 269-316 in G. S.S., editor. Plant-associated bacteria. Springer, Dordrecht.

Van Loon, L. C. 2007. Plant responses to plant growth-promoting rhizobacteria. European Journal of Plant Pathology 119:243-254. 
Van Wees, S. C. M., S. Van der Ent, and C. M. J. Pieterse. 2008. Plant immune responses triggered by beneficial microbes. Current Opinion in Plant Biology 11:443-448.

VanInsberghe, D., M. Hartmann, G. R. Stewart, and W. W. Mohn. 2013. Isolation of a substantial proportion of forest soil bacterial communities detected via pyrotag sequencing. Applied and Environmental Microbiology 79:2096-2098.

Venables, W. N., and B. D. Ripley. 2002. Modern Applied Statistics with S. Fourth Edition. Fourth edition. Springer, New York.

Veresoglou, S. D., J. M. Halley, and M. C. Rillig. 2015. Extinction risk of soil biota. Nature Communications 6:8862.

Vergin, K. L., B. Done, C. A. Carlson, and S. J. Giovannoni. 2013. Spatiotemporal distributions of rare bacterioplankton populations indicate adaptive strategies in the oligotrophic ocean. Aquatic Microbial Ecology 71:1-13.

Větrovský, T., and P. Baldrian. 2013. The variability of the 16S rRNA gene in bacterial genomes and its consequences for bacterial community analyses. Plos One 8:e57923.

Walling, L. L. 2008. Avoiding effective defenses: strategies employed by phloem-feeding Insects. Plant Physiology 146:859-866.

Wamelink, G. W. W., P. W. Goedhart, and J. Y. Frissel. 2014. Why some plant species are rare. Plos One 9:e102674.

Wei, Z., T. Yang, V.-P. Friman, Y. Xu, Q. Shen, and A. Jousset. 2015. Trophic network architecture of root-associated bacterial communities determines pathogen invasion and plant health. Nature Communications 6:8413.

Wertz, S., V. Degrange, J. I. Prosser, F. Poly, C. Commeaux, T. Freitag, N. Guillaumaud, and X. L. Roux. 2006. Maintenance of soil functioning following erosion of microbial diversity. Environmental Microbiology 8:2162-2169.

Wertz, S., V. Degrange, J. I. Prosser, F. Poly, C. Commeaux, N. Guillaumaud, and X. Le Roux. 2007. Decline of soil microbial diversity does not influence the resistance and resilience of key soil microbial functional groups following a model disturbance. Environmental Microbiology 9:2211-2219.

Westcott, S. L., and P. D. Schloss. 2015. De novo clustering methods outperform referencebased methods for assigning 16S rRNA gene sequences to operational taxonomic units. PeerJ 3:e1487.

Whittaker, R. H. 1965. Dominance and diversity in land plant communities: numerical relations of species express the importance of competition in community function and evolution. Science 147:250-260.

Wilbur, H. M., D. W. Tinkle, and J. P. Collins. 1974. Environmental certainty, trophic level, and resource availability in life history evolution. The American Naturalist 108:805817. 
Wilhelm, L., K. Besemer, C. Fasching, T. Urich, G. A. Singer, C. Quince, and T. J. Battin. 2014. Rare but active taxa contribute to community dynamics of benthic biofilms in glacier-fed streams. Environmental Microbiology 16:2514-2524.

Wilson, J. B. 1991. Methods for fitting dominance/diversity curves. Journal of Vegetation Science 2:35-46.

Wilson, M., and S. E. Lindow. 1994. Coexistence among epiphytic bacterial populations mediated through nutritional resource partitioning. Applied and Environmental Microbiology 60:4468-4477.

Winter, C., T. Bouvier, M. G. Weinbauer, and T. F. Thingstad. 2010. Trade-offs between competition and defense specialists among unicellular planktonic organisms: the "Killing the Winner" hypothesis revisited. Microbiology and Molecular Biology Reviews 74:42-57.

Wintermans, P. C. A., P. A. H. M. Bakker, and C. M. J. Pieterse. 2016. Natural genetic variation in Arabidopsis for responsiveness to plant growth-promoting rhizobacteria. Plant Molecular Biology 90:623-634.

Wiser, M. J., N. Ribeck, and R. E. Lenski. 2013. Long-term dynamics of adaptation in asexual populations. Science 342:1364-1367.

Worm, B., H. K. Lotze, H. Hillebrand, and U. Sommer. 2002. Consumer versus resource control of species diversity and ecosystem functioning. Nature 417:848-851.

Yachi, S., and M. Loreau. 1999. Biodiversity and ecosystem productivity in a fluctuating environment: The insurance hypothesis. Proceedings of the National Academy of Sciences of the United States of America 96:1463-1468.

Yan, Y., E. E. Kuramae, P. G. L. Klinkhamer, and J. A. Van Veen. 2015. Revisiting the dilution procedure used to manipulate microbial biodiversity in terrestrial systems. Applied and Environmental Microbiology 81:4246-4252.

Yi, H.-S., J. W. Yang, S.-Y. Ghim, and C.-M. Ryu. 2011. A cry for help from leaf to root. Plant Signaling \& Behavior 6:1192-1194.

Yu, Z., S. M. B. Krause, D. A. C. Beck, and L. Chistoserdova. 2016. A synthetic ecology perspective: how well does behavior of model organisms in the laboratory predict microbial activities in natural habitats? Frontiers in Microbiology 7.

Zengler, K., G. Toledo, M. Rappe, J. Elkins, and E. Mathur. 2002. Cultivating the uncultured. Proceedings of the National Academy of Sciences of the United States of America 99:15681 - 15686.

Zhou, J., B. Xia, D. S. Treves, L.-Y. Wu, T. L. Marsh, R. V. O’Neill, A. V. Palumbo, and J. M. Tiedje. 2002. Spatial and resource factors influencing high microbial diversity in soil. Applied and Environmental Microbiology 68:326-334.

Zhu-Salzman, K., R. A. Salzman, J.-E. Ahn, and H. Koiwa. 2004. Transcriptional regulation of Sorghum defense determinants against a phloem-feeding aphid. Plant Physiology 134:420-431. 
Summary 


\section{Summary}

Since the advancing of sequencing technology and the wide spread of metagenome sequencing of environmental samples we are aware that a high proportion of most bacterial communities is low abundant. This proportion has also been termed the "rare biosphere" (Sogin et al. 2006). For a time, it has been believed that these rare species would not contribute to overall community functioning due to their low abundance. However, already decades ago it could be shown that the loss of rare bacterial species can be deleterious for the maintenance of ecosystem functions (Salonius 1981). Especially rare soil bacteria were found to be involved in important functions, such as decomposition, specific mineralization processes, resistance and resilience to disturbance and invasion resistance (see e.g. Salonius (1981), Pester et al. (2010), Van Elsas et al. (2007) and Low-Décarie et al. (2015)). Rare soil bacteria have even been shown to affect interactions between plants and insect herbivores (Hol et al. 2010). However, the mechanism behind this particular effect is still unclear. Furthermore, it is still poorly understood why some bacterial species are rare, whereas others are abundant and consequently knowledge about the mechanisms of microbial community assembly is incomplete. The aim of this thesis is to increase knowledge about rare bacteria with the focus on soil bacterial communities. For one, I asked which species traits or interactions with the biotic and abiotic environment can lead to species rarity. Second, I attempted to shed light on the mechanism behind the earlier observed plant protecting effect of the rare soil biosphere.

In the first part of this thesis (Chapter 2) I isolated bacteria from soil to retrieve rare species that could be used in subsequent studies. By flow cell sorting I selected bacteria with small cell sizes $(\sim 0.5 \mu \mathrm{m})$, which are supposed to be on average lower in abundance (Portillo et al. 2013) and separated single cells at the same time. Comparing the sequences of the isolated species to a 16S rRNA-sequencing database from the same soil allowed me to assess their relative abundance in the field. Although both rare and abundant species appeared on the various cultivation media, rare species were still underrepresented in my cultures compared to their high proportion in soil. This finding asserts the importance of testing the in situ abundance of bacterial isolates to avoid a bias towards abundant species in in vitro studies. Moreover, cultivation techniques should be improved with the aim to increase the proportion of rare cultivated species. These techniques could include novel cultivation media with specific growth substrates or co-cultivation methods. In contrast, a prolonged incubation time does not seem to lead to the cultivation of more rare species. In spite of the relatively low proportion of isolated rare bacterial species, this cultivation attempt yielded a phylogenetically diverse set of both high and low abundant bacterial species for comparison in my subsequent studies.

In the following (Chapter $3 \& 4$ ), I used these bacterial isolates from Chapter 2 to investigate potential causes of species rarity. First, I tested whether bacterial isolates that were rare or 
abundant in the field differ in their life-history traits. Rare species have often been assumed to be slow growing and highly specialized in their niche (Wilson and Lindow 1994, PedrosAlio 2007). Therefore, I measured bacterial growth rates and the ability of bacterial species to use a range of different substrates as a measure of niche breadth. Bacterial growth rate was positively correlated with the number of substrates they could use, which is in accordance with the concept of oligotrophy and copiotrophy (Fierer et al. 2007). However, in contrast to the expectations, there was no association between slow growth and species rarity because growth rates and substrate use of rare species was highly variable. This suggests that for some species slow growth and a narrow niche breadth might contribute to their low abundance in soil, but for many other species a low growth rate is unlikely to lead to rarity. This result is in accordance with former studies, which found indications for a high activity of low abundant bacterial species using cultivation-independent techniques (Baldrian et al. 2012, Wilhelm et al. 2014).

Since growth rate was not clearly related to species rarity among my soil bacterial isolates I subsequently tested if species interactions could explain abundance. Based on my former studies in Chapter 2 and 3, in Chapter 4 I chose bacterial isolates with low and high potential growth rates and differing abundances in the field. I combined them in constructed communities, which were grown at different nutrient concentrations and with and without predation by protists. Several rare bacterial species, especially those with fast growth rates, showed a high competitive ability and dominated most constructed communities. However, their decline in abundance at lower nutrient concentrations indicates that they might become subordinate in extremely nutrient-poor environments. Neither did the addition of predators change their dominance. Still, rare bacteria that were most competitive were also most negatively affected by predation. This finding suggests that these bacterial species did invest more in competitive traits, at the cost of traits contributing to anti-predator defences. Hence, an even stronger predation pressure might lead to species rarity in the environment. Studies in situ and on different communities will still have to show if a stronger trade-off between competitiveness and predation resistance in rare species is a general concept. Overall, species varied considerably in their competitiveness and sensitivity to predation, indicating that the importance of the different factors affecting abundance might differ between species. Given the dominance of several rare species in the artificial communities, they can be expected to become abundant under favourable conditions, which is in accordance to the fluctuations in abundance that have been found for a large proportion of the rare biosphere (Shade et al. 2014).

In the final part of my thesis (Chapter 5), I tested how the loss of rare soil microbial species would affect plant-aphid interactions as has been indicated earlier (Hol et al. 2010), and whether this would be due to a reduction in systemic plant defences. To this end I used serial dilutions of soil microbial communities from different soil samples in combination with the 
bacterium Pseudomonas fluorescens, which is known for its ability to induce systemic plant defences. Arabidopsis thaliana plants were grown in soil inoculated with the different dilutions and with or without Pseudomonas. Half of the plants were infested with the aphid species Myzus persicae. Subsequently I measured plant growth, defence-related gene expression and aphid performance. In contrast to the former study by Hol et al. (2010), the loss of rare species had no effect on aphid performance. Neither did Pseudomonas addition increase plant defences. This lack of a Pseudomonas-effect indicates that bacteria-plantinsect interactions might be highly species- and even strain-specific. This specificity might also have caused the high variability in plant defence response to the different soil microbial communities leading to overall non-significant effects. Communities from different samples might have contained different low abundant species or random species loss by dilution and regrowth might have led to differing communities and hence variable effects of dilution on plants. However, I did find increased survival of Pseudomonas and an initial increase in plant biomass in response to community dilution. Based on my findings I propose that some effects of rare species loss could be consistent, while plant defence might be more responsive to microbial community composition than to loss of rare species per se.

Overall, my project did not confirm many expectations that are held about rare bacterial species. In contrast, the variable results indicate that rare bacteria are no homogeneous group. For example, factors affecting species abundance, such as growth rate, niche breadth, competition, and predation likely differ between species. At the same time, many rare species show the potential to become abundant under some experimental conditions. This is in accordance with sequencing-based studies and suggests that the rare biosphere and bacterial communities in general are highly dynamic (Caporaso et al. 2012). Such dynamics in species abundances could also be responsible for inconsistent effects of rare species reductions between or within studies, as I also observed in my experiment on the induction of systemic plant defences. Thus, I conclude that there might be no beneficial effect of rare bacteria per se. Instead, I propose that community composition might determine functioning. My study shows that we yet need to learn more about species-specific functions and community dynamics if we wish to understand and influence their functioning. 


\section{Samenvatting}

Sinds vorderingen in sequentie-technologieën en sinds de verspreiding van metagenoomsequentie-analyse van milieu-monsters weet men dat een groot deel van de meeste bacteriële gemeenschappen laag abundant is. Dit aandeel wordt dan ook wel de "rare biosphere" genoemd (Sogin et al. 2006). Een tijd lang dacht men dat deze zeldzame soorten niet bijdragen aan de functionering van de gehele gemeenschap vanwege hun lage abundantie. Het werd echter al tientallen jaren geleden aangetoond dat het verlies van zeldzame bacteriële soorten schadelijk kan zijn voor het behoud van ecosysteem functies (Salonius 1981). Vooral zeldzame bodembacteriën zijn betrokken bij belangrijke functies, zoals decompositie, specifieke mineraliseerings-processen, resistentie en veerkracht tegen storingen, en weerstand tegen invasies (zie b.v. Salonius (1981), Pester et al. (2010), Van Elsas et al. (2007) en Low-Décarie et al. (2015)). Het werd zelfs aangetoond dat zeldzame bodembacteriën de interactie tussen planten en insecten kunnen beïnvloeden (Hol et al. 2010). Niettemin is het mechanisme achter dit effect nog steeds onduidelijk. Ook begrijpt men nog steeds niet goed, waarom sommige bacteriën zeldzaam en anderen abundant zijn en dus is onze kennis van gemeenschaps-vorming incompleet. Het is het doel van deze thesis de kennis over zeldzame bacteriën te vergroten met bijzonder oogmerk op gemeenschappen van bodembacteriën. Ten eerste stelde ik de vraag welke eigenschappen van soorten, of interacties met de biotische en abiotische omgeving naar zeldzaamheid kunnen leiden. Ten tweede deed ik onderzoek naar de mechanismes achter de plant-beschermende effecten van de zeldzame bodem biosfeer die al eerder werd aangetoond.

In het eerste deel van deze thesis (hoofdstuk 2) isoleerde ik bacteriën uit de bodem om zeldzame soorten te verzamelen voor gebruik in de volgende experimenten. Met behulp van flow cytometrie selecteerde ik bacteriën met een lage celgrootte $(\sim 0.5 \mu \mathrm{m})$ die worden geacht in het gemiddelde lager abundant te zijn (Portillo et al. 2013), en scheidde tegelijkertijd cellen van elkaar. Door de sequenties van de geïsoleerde soorten te vergelijken met en $16 \mathrm{~S}$ rRNAsequentie database afkomstig van dezelfde bodem, kon ik hun relatieve abundantie in het veld vaststellen. Alhoewel zowel zeldzame als abundante soorten op de verschillende cultivatie-media groeiden, waren zeldzame soorten nog steeds ondervertegenwoordigd in de culturen vergeleken met hun grote aandeel in de bodem. Deze ontdekking bevestigt het belang van het testen van de abundantie van bacteriële isolaten in situ om een bias naar abundante soorten in studies in vitro te voorkomen. Verder zouden cultivatie technieken moeten worden verbeterd met het doel om het aandeel van zeldzame soorten te verhogen. Adequate technieken zouden onder ander nieuwe cultivatie media met specifieke groeistoffen of co-cultivatie kunnen zijn. Lange incubatietijden lijken echter niet tot een cultivatie van meer zeldzame soorten te leiden. Ongeacht het relatief lage aandeel van geïsoleerde zeldzame bacteriële soorten, leverde dit cultivatie experiment een fylogenetisch divers set van zowel hoog als laag abundant soorten op voor vergelijkingen in mijn volgende studies. 
In het volgende deel van deze thesis (hoofdstukken 3 en 4) gebruikte ik de bacteriële isolaten van hoofdstuk 2 om de mogelijke redenen voor zeldzaamheid te onderzoeken. Eerst testte ik of bacteriële isolaten, die in het veld zeldzaam of abundant waren, verschilden in de kenmerken van hun levenscyclus. Zeldzame soorten werden vaak geacht langzaam te groeien en heel gespecialiseerd in hun niche te zijn (Wilson and Lindow 1994, Pedros-Alio 2007). Daarom mat ik bacteriële groeipercentages en hun vermogen een aantal verschillende substraten te gebruiken als een maat voor hun niche breedte. De bacteriële groeipercentage had een positief verband met het aantal substraten dat ze konden gebruiken wat overeenkomt met het concept van oligotrophie en copiotrophie (Fierer et al. 2007). Niettemin, in tegenstelling tot mijn verwachtingen, was er geen verband tussen langzame groei en zeldzaamheid, want groeipercentages en substraatgebruik van zeldzame bacteriën waren uitermate variabel. Dit duidt aan dat langzame groei en een beperkte niche breedte kunnen bijdragen aan de lage abundantie van sommige soorten. Maar bij veel andere soorten lijkt langzame groei niet tot zeldzaamheid te lijden. Dit resultaat komt overeen met eerdere studies die aanwijzingen voor een hoge activiteit van laag abundante soorten hebben gevonden met behulp van cultivatie-onafhankelijke technieken (Baldrian et al. 2012, Wilhelm et al. 2014).

Omdat groeipercentages bij mijn bacteriële isolaten geen duidelijk verband hield met zeldzaamheid testte ik verder of de interacties tussen soorten abundantie konden verklaren. Gebaseerd op mijn eerdere studies in hoofdstuk 2 en 3, koos ik in hoofdstuk 4 voor bacteriële isolaten met hoge en lage potentiele groeipercentages en verschillende abundantie in het veld. Ik combineerde ze in geconstrueerde gemeenschappen die ik met verschillende hoeveelheden aan voedingsstoffen en met of zonder predatie van protisten liet groeien. Meerdere bacteriële soorten, in het bijzonder soorten met hoge groeipercentages, toonden een sterk concurrentievermogen en domineerden de meeste geconstrueerde gemeenschappen. Hun afname in abundantie met lagere hoeveelheden aan voedingsstoffen duidde echter aan dat zij mogelijkerwijs onder extreem voedingsarme omstandigheden ondergeschikt zouden kunnen worden. Het toevoegen van protisten veranderde evenmin hun dominantie. Niettemin werden de zeldzame bacteriën met het hoogste concurrentievermogen tegelijkertijd het meest negatief beïnvloed door predatie. Deze vondst duidt aan dat deze bacteriële soorten meer in concurrentievermogen investeerden ten koste van verdediging tegen predatie. Als gevolg daarvan zou een nog hogere predatiedruk tot zeldzaamheid in het veld kunnen leiden. Studies in situ en van verschillende gemeenschappen zullen moeten tonen of een sterkere trade-off tussen concurrentievermogen en weerstand tegen predatie bij zeldzame soorten een algemeen concept zou kunnen zijn. In het algemeen, verschilden de soorten beduidend in hun concurrentievermogen en gevoeligheid voor predatie, wat aanduidt dat diverse factoren verschillen in hun belang voor de abundantie van soorten. Vanwege de dominantie van meerdere zeldzame soorten in de geconstrueerde gemeenschappen kunnen deze soorten worden verwacht onder gunstige omstandigheden abundant te kunnen worden. Dit komt 
overeen met fluctuaties in abundantie die werden gevonden voor een groot aandeel van de rare biosphere (Shade et al. 2014).

In het laatste deel van mijn thesis (hoofdstuk 5) heb ik onderzocht hoe het verlies van zeldzame bodem-microben, plant-bladluis interacties zou beïnvloeden, zoals eerder aangetoond (Hol et al. 2010), en of dit te wijten zou zijn aan een afname in systemische plantresistentie. Daarvoor gebruikte ik opeenvolgende verdunningen van microbiële gemeenschappen van verschillende bodemmonsters in combinatie met de bacterie Pseudomonas fluorescens die bekend staat om zijn vermogen systemische plant-resistentie te induceren. Arabidopsis thaliana planten werden gekweekt in bodem die werd geïnoculeerd met de verschillende verdunningen en met of zonder Pseudomonas. De helft van de planten werden met de bladluis Myzus persicae besmet. Vervolgens mat ik plantengroei, defensiegerelateerde genexpressie en bladluis-voortplanting. In tegenstelling tot de eerdere studie van (Hol et al. 2010) had het verlies van zeldzame soorten geen invloed op bladluizen. Pseudomonas toevoeging verhoogde evenmin plant-resistentie. Het ontbreken van een effect van Pseudomonas duidt aan dat bacterie-plant-insect interacties uitermate soort-specifiek of zelf ras-specifiek zouden kunnen zijn. Deze specifiteit zou ook tot de sterke variabiliteit in plant-resistentie in reactie op de verschillende bodem-gemeenschappen hebben kunnen geleid wat overal niet-significante zou kunnen verklaren. Gemeenschappen van verschillende monsters zouden verschillende laag abundante soorten hebben kunnen bevat of willekeurig verlies van soorten door verdunning en bijgroei zou tot verschillende gemeenschappen en dus variabele effecten op planten hebben kunnen geleid. Niettemin vond ik wel een verhoogd overleven van Pseudomonas in de bodem en een aanvankelijk verhoging in plant biomassa ten gevolge van verdunning. Naar aanleiding van mijn vondsten stel ik voor dat sommige effecten van het verlies van zeldzame soorten consistent zijn terwijl plant resistentie eerder afhankelijk is van de compositie van de microbiële gemeenschap dan van het verlies van zeldzame soorten op zich.

Overal kon mijn project vele verwachtingen over zeldzame bacteriële soorten niet bevestigen. Mijn resultaten duidden in het tegendeel aan dat zeldzame bacteriën geen uniforme groep zijn. Bijvoorbeeld verschillen de factoren, die abundantie beïnvloeden, zoals het groeipercentage, niche breedte, concurrentie en predatie, waarschijnlijk tussen soorten. Tegelijkertijd tonen vele zeldzame soorten het vermogen om onder een aantal experimentele omstandigheden abundant te worden. Dit komt overeen met studies gebaseerd op sequentieanalyses en duidt aan dat de rare biosphere en de bacteriële gemeenschappen in het algemeen heel dynamisch kunnen zijn (Caporaso et al. 2012). Deze dynamiek in de abundantie van soorten zou ook verantwoordelijk kunnen zijn voor de inconsistente effecten van het verlies van zeldzame soorten binnen of tussen studies zoals in mijn experiment over de inductie van systemische plant-resistentie. Dus concludeer ik, dat er geen gunstig effect van zeldzame bacteriën per se zou kunnen zijn. In plaats daarvan, stel ik voor dat de compositie van de 
gemeenschap functionering kan bepalen. Mijn studie toont aan dat we nog steeds meer moeten leren over soort-specifieke functies en gemeenschap-dynamieken als we hun werking willen begrijpen en beïnvloeden. 


\section{Zusammenfassung}

Seit Fortschritten in Sequenzier-Techologien und der Verbreitung der MetagenomSequenzierung von Umweltproben wissen wir, dass ein großer Teil der meisten bakteriellen Gemeinschaften niedrig abundant ist. Dieser Anteil wird auch „rare biosphere“ (seltene Biosphäre) genannt (Sogin et al. 2006). Eine Zeit lang glaubte man, dass diese seltenen Arten wegen ihrer niedrigen Abundanz nicht zum allgemeinen Funktionieren der Gemeinschaft beitragen würden. Jedoch wurde schon vor Jahrzehnten gezeigt, dass sich der Verlust seltener Bakterienarten nachteilig auf den Erhalt von Ekosystem-Funktionen auswirken kann (Salonius 1981). Vor allem für seltene Bodenbakterien wurde gezeigt, dass sie an vielen wichtigen Funktionen, wie Dekomposition, spezifischen Mineralisierungsprozessen, Resistenz und Resilienz gegen Störungen und Resistenz gegen Invasionen, beteiligt sind (siehe z.B. Salonius (1981), Pester et al. (2010), Van Elsas et al. (2007) und Low-Décarie et al. (2015)). Es wurde sogar gezeigt, dass seltene Bodenbakterien die Interaktionen zwischen Pflanzen und Insekten beeinflussen können (Hol et al. 2010). Der Mechanismus hinter diesem Effekt ist jedoch noch unbekannt. Des Weiteren weiß man noch immer wenig darüber, warum manche Bakterienarten selten, andere aber abundant sind und daher ist unser Wissen über die Zustammenstellung bakterieller Gemeinschaften noch immer unvollständig. Das Ziel meiner Thesis ist das Wissen über seltene Bakterien zu vergrößern, mit besonderem Augenmerk auf bakterielle Bodengemeinschaften. Zum einen stellte ich die Frage, welche Eigenschaften von Arten oder Interaktionen mit ihrer biotischen und abiotischen Umgebung zu Seltenheit führen können. Zum Zweiten habe ich versucht den Mechanismus hinter dem bereits beobachtetetn Pflanzen-schützenden Effekt der seltenen Boden-Biosphäre aufzuklären.

Im ersten Teil dieser Thesis (Kapitel 2) habe ich Bakterien aus dem Boden isoliert um seltene Arten zu erhalten, die in volgenden Experimenten verwendet werden konnten. Mithilfe von Durchflusszytometrie habe ich Bakterien mit geringer Zellgröße $(\sim 0.5 \mu \mathrm{m})$ selektiert, von welchen man annimmt, dass sie im Mittel geringere Abundanzen haben (Portillo et al. 2013), und habe sie gleichzeitig in einzelne Zellen aufgetrennt. Der Vergleich zwischen den Sequenzen der isolierten Arten und einer 16S rRNA-Sequenz Datenbank desselben Bodens, ermöglichte es mir ihre relatieve Abundanz im Feld zu bestimmen. Obwohl sowohl seltene als auch abundante Arten auf den verschiedenen Kultivierungs-Medien wuchsen, waren seltene Arten in meinen Kulturen immer noch unterrepräsentiert verglichen mit ihrem hohen Anteil im Boden. Dieser Fund zeigt, wie wichtig es ist, die Abundanz von bakteriellen Isolaten in situ zu testen, um eine Verzerrung hin zu abundanten Arten in in vitro Studien zu verhindern. Des Weiteren sollten Kultivierungs-Techniken verbessert werden, um den Anteil kultivierbarer, seltener Arten zu erhöhen. Solche Techniken könnten neuartige Medien mit speziellen Substraten oder Co-Kultivierungsmethoden einschließen. Eine lange Inkubationszeit jedoch, scheint nicht zur Kultivierung von mehr seltenen Arten zu führen. Trotz des relatief geringen Anteils seltener isolierter Arten, lieferte mein 
Kultivierungsversuch einen Satz phylogenetisch diverser niedrig- und hoch-abundanter Bakterienarten für Vergleiche in meinen folgenden Studien.

Im Folgenden (Kapitel $3 \& 4$ ) habe ich die bakteriellen Isolate aus Kapitel 2 verwendet um die möglichen Gründe für die Seltenheit von Arten zu untersuchen. Zunächst habe ich getestet ob bakterielle Isolate, die im Feld selten oder abundant waren, sich in ihrem Lebenszyklus unterscheiden. Von seltenen Arten wurde oft angenommen, dass sie langsam wachsen und eine sehr spezifische Nische haben (Wilson and Lindow 1994, Pedros-Alio 2007). Daher habe ich bakterielle Wachstumsraten und ihre Fähigkeit eine Reihe verschiedener Substrate zu konsumieren, als Maß für die Nischenbreite von Arten, gemessen. Die bakterielle Wachstumsrate stand in einem positiven Bezug zu der Anzahl Substrate, die sie konsumieren konnten, was mit dem Konzept von Oligotrophie und Kopiotrophie übereinstimmt (Fierer et al. 2007). Dennoch gab es, entgegen der Erwartungen, keine Verbindung zwischen langsamem Wachstum und der Seltenheit von Arten, da Wachstumsraten und Substrat-Gebrauch sehr variabel waren. Dies weist darauf hin, dass zwar bei manchen Arten langsames Wachstum und eine eingeschränkte Nischenbreite zu ihrer geringen Abundanz betragen könnten, aber bei vielen anderen Arten eine gerine Wachstumsrate wahrscheinlich nicht zu Seltenheit führt. Dieses Resultat entspricht früheren Studien, welche mit Kultivierungs-unabhängingen Methoden Hinweise auf eine hohe Aktivität gering abundanter bakterieller Arten gefunden haben (Baldrian et al. 2012, Wilhelm et al. 2014).

Da die Wachstumsrate in keiner deutlichen Beziehung zu der Seltenheit meiner bakteriellen Isolate stand, habe ich als nächstes getestet ob die Interaktionen zwischen Arten Abundanz erklären kann. Beruhend auf meinen vorherigen Studien in Kapitel 2 und 3, habe ich in Kapitel 4 bakterielle Isolate mit niedriger und hoher potenzieller Wachstumsrate und verschiedenen Abundanzen im Feld gewählt. Diese habe ich in konstruierten Gemeinschaften kombiniert, welche ich bei verschiedenen Nährstoffkonzentrationen und mit oder ohne Predation durch Protisten wachsen ließ. Mehrere seltene bakterielle Arten, besonders solche mit hohen Wachstumsraten, zeigten sich äußerst konkurrenzfähig und dominierten die meisten konstruierten Gemeinschaften. Trotzdem deutete ihre Abnahme bei geringeren Nährstoffkonzentrationen darauf hin, dass sie in extrem nährstoffarmen Umgebungen geringer abundant werden könnten. Auch das Hinzufügen von Protisten änderte nichts an der Dominanz dieser Arten. Dennoch waren die seltenen Bakterien mit der größten Konkurrenzfähigkeit auch am stärksten von Predation betroffen. Dieser Fund weist darauf hin, dass diese bakteriellen Arten mehr in Eigenschaften, welche die Konkurrenzfähigkeit erhöhen, investierten, auf Kosten von Eigenschaften, welche zur Resistenz gegen Predatoren beitragen. Daher könnte ein noch stärkerer Predationsdruck zur Seltenheit dieser Arten im Feld führen. Weitere Studien in situ und mit anderen Gemeischaften werden zeigen müssen, ob ein stärkerer trade-off zwischen Konkurrenzfähigkeit und Resistenz gegen Predation bei 
seltenen Arten ein allgemeines Phänomen ist. Insgesamt unterschieden sich die einzelnen Arten stark in ihrer Konkurrenzfähigkeit und Anfälligkeit gegenüber Predation, was darauf inweist, dass die Bedeutung verschiedener Faktoren, die Abundanz beeinflussen, sich zwischen den Arten unterscheidet. Aufgrund der Dominanz mehrerer seltener Arten in den konstruierten Gemeinschaften, kann man auch ewarten, dass diese unter günstigen Umständen in Abundanz zunehmen könnten, was übereinstimmt mit Fluktuationen in Abundanz, die bei einem großen Anteil der seltenen Biosphäre gefunden worden sind (Shade et al. 2014).

Im letzten Teil meiner Thesis (Kapitel 5) habe ich getestet, wie der Verlust von seltenen mikrobiellen Arten im Boden Pflanzen-Blattlaus Interaktionen beeinflussen kann, wie bereits in einer früheren Studie angedeutet (Hol et al. 2010), und ob dies in einer Reduktion systemischer Pflanzenresistenz begründet liegt. Dafür habe ich serielle Verdünnungen von mikrobiellen Gemeinschaften verschiedener Bodenproben verwendet, in Kombination mit dem Bakterium Pseudomonas fluorescens, welches bekannt ist für seine Eigenschaft systemische Pflanzenresistenz zu induzieren. Arabidopsis thaliana Pflanzen wurden in Bodem herangezogen, der mit den verschiedenen Verdünnungen und mit oder ohne Pseudomonas inokuliert wurde. Die Hälfte der Pflanzen wurde mit der Blattlaus Myzus persicae infiziert. Danach habe ich Pflanzenwachstum, resistenzabhängige Genexpression und Blattlausreproduktion gemessen. Im Gegensatz zu der vorherigen Studie von Hol et al. (2010) hatte der Verlust seltener Arten keinen Effekt auf die Blattläuse. Auch das Hinzufügen von Pseudomonas erhöhte die Pflanzenresistenz nicht. Dieser fehlende Effekt von Pseudomonas weist darauf hin, dass Bakterien-Pflanzen-Insekten Interaktionen äußerst Artoder sogar Sorten-spezifisch sein könnten. Diese Spezifität könnte auch für die große Variabilität in Pflanzenresistenz als Reaktion auf die verschiedenen mikrobiellen Gemeinschaften, verantwortlich gewesen sein, was ingesamt zu nicht-signifikanten Effekten geführt haben könnte. Gemeinschaften aus verschiedenen Proben könnten verschiedene niedrig abundant Arten beinhaltet haben oder zufälliger Artenverlust und Nachwachsen könnten zu unterschiedlichen Gemeinschaften geführt haben und daher zu variablen Effekten der Verdünnungen auf die Pflanzen. Dennoch habe ich ein erhöhtes Überleben von Pseudomonas und eine anfängliche Steigerung in Pflanzenbiomasse als Folge der Verdünnung gefunden. Aufgrund meiner Ergebnisse stelle ich die Hypothese auf, dass einige Effekte des Verlustes seltener Arten beständig sein könnten, während Pflanzenresistenz eher von der Zusammensetzung der bakteriellen Gemeinschaft als von einem Verlust seltener Arten an sich abhängig ist.

Insgesamt konnte mein Projekt einige Erwartungen über seltene bakterielle Arten nicht bestätigen. Meine variablen Ergebnisse weisen im Gegenteil darauf hin, dass seltene Bakterien keine einheitliche Gruppe sind. So können sich Faktoren, welche Artabundanz beeinflussen, wie Wachstumsrate, Nischenbreite, Konkurrenz und Predation zwischen Arten 
unterscheiden. Gleichzeitung zeigen viele seltene Arten das Potenzial unter einigen experimentellen Bedingungen abundant zu werden. Dies entspricht Sequenz-basierten Studien und deutet an, dass die seltene Biosphäre, und bakterielle Gemeinschaften im Allgemeinen, sehr dynamisch sind (Caporaso et al. 2012). Solche Dynamiken in Artabundanzen könnten auch für die uneinheitlichen Effekte von Reduktionen seltener Spezies innerhalb oder zwischen Studien verantwortlich sein, so wie ich es auch in meinem Experiment über die Induktion systemischer Pflanzenresistenz beobachten konnte. Daher komme ich zu dem Schluss, dass seltene Bakterien im Allgemeinen keinen günstigen Effekt haben könnten. Ich bin der Meinung, dass stattdessen die Zusammensetzung der Gemeinschaft ihr Funktionieren bestimmt. Meine Studie zeigt, dass wir noch immer mehr über artspezifische Eigenschaften und Dynamiken von Gemeinschaften lernen müssen, wenn wir ihr Funktionieren verstehen und beeinflussen wollen. 


\section{Acknowledgements}

Writing a $\mathrm{PhD}$ thesis is not entirely unlike above- belowground interactions. The thesis is the aboveground part that is the visible output of four years of work. However, belowground there is a vast unseen number of people that had their influence on this output, mediated through the writer of the thesis. Just as the belowground part of an ecosystem should be more recognized as an integral part of the system, all my colleagues, family and friends have to be credited. Writing this thesis was a period of growth and not only my scientific work, but also my personality have been shaped by those that were near to me and all those I met, however briefly. That said, it is impossible to thank all of these people adequately and whoever it concerns can hereby feel acknowledged. However, I do not want to miss the opportunity to thank several people by name.

My first and foremost thanks are, of course, to my supervisors. As in ladies first: Gera, you did not only create this wonderful project and took me on to work on it, you also guided me safely through all the steps of it. When I started 4 years ago I was a blank sheet of a researcher and you were certainly the one who wrote most on it. There is so much I learned from you, I will not even attempt to mention it all here. Most importantly, you always knew how to handle my moments of despair. You knew when to help and when to give me the freedom of helping myself. I also do not want to leave unmentioned entirely non-work related conversations on fantasy-books and the exchange thereof. Without Fitz and the Fool my life would have been less rich.

Wim, you too, will forever influence the way I think about and do science and I count myself lucky to have had your influence. Your keen eyes and directness were a major improvement to my writing style even (and foremost) when I got annoyed by your comments. Your patience and understanding when faced with my problems (sorry! Issues, challenges...) and your jokes should become legendary.

While my supervisors were most important in my growth as a scientist, my family, and especially my parents, can be held accountable for my growth as a person. Therefore, they also had an essential contribution to this thesis and I wish to thank them all.

Heike, obwohl du wahrscheinlich nicht immer glücklich darüber warst, dass ich für meine Doktorarbeit in die Niederlande gegangen bin, hast du mich immer darin unterstützt und bist nicht vor stundenlangen Telefongesprächen zurückgeschreckt, wenn es mal nicht so gut lief. Vielen, vielen Dank, dass du immer für mich da warst.

Frank, alle meine Umzüge hast du klaglos mitgemacht, inklusive Bücher schleppen und Wellenreiten auf der Autobahn. Unsere zwei-wöchentlichen Skype-Gespräche wurden des 
Öfteren von einem schwarzen Fusselteppich unterbrochen, was dich jedoch nicht hinderte. Von dir habe ich meinen Mut das Unbekannte anzugehen. Vielen Dank dafür.

Auch vielen lieben Dank an Steffen (und sorry nochmal, dass ich deine Kreditkarte gecrasht habe), Waltraud und Günter (auch für die Kuchenpakete und die bereitwillige Gastfreundschaft) und Ralf (für alle Musik-Inspirationen).

Of course, these four years would have been much less enjoyable without all my amazing colleagues. Therefore, many thanks to all people at the NIOO because every single one of you makes this place what it is.

Especially I want to mention my long-term office mates Marta and Rutger who never hesitated with help and advice. Also the VDPP association should be mentioned as the ultimate place and company to have a hot beverage, while relaxing on the godly inclination. In addition, I want to thank all the people involved in my projects: Stefan for the provision of both guidance and amoebae, Ana for her knowledge about plant-insect interactions, Wietse for willingly sharing his considerable expertise, Max for encouraging me to think for myself, Tanja for patiently working through hundreds of DNA-extractions and PCRs with me, Suzanne for her flow-cytometry magic, Basten and Sven for braving the depths of dataanalysis with me, Mattias and Fleur for letting me face one of my biggest fears (Unix command line), and all my co-authors.

My thanks also to all colleagues who regularly gather at coffee-time in the canteen. Here I learned not only the latest rumours, but also a considerable amount of Dutch. I am also grateful to the colleagues at Utrecht University that were always eager to help me navigate their chaotic labs. And thanks to the TE-department, although there is much too little space to mention you all by name. But each and every one of you is awesome. Never forget that!

Last, but not least I want to thank my friends, which - whether colleague or not - helped me to get through these four years that were not always peachy, but at times demanding and stressful. You always reminded me to take a break from thinking about statistics and aphids and that there is a life waiting outside the NIOO.

Ming-Hua, I have to state it black and white: you are a genius, but also a listener and potential reader of thoughts. A rare combination. Thank you for: mails at precisely 8 in the morning, pink unicorns, stories about pea plants on Mars, forgetting time, synchronicity, hugging emojis, Haikus, the most amazing conversations and a lot of weird stuff in general. There is much more I could add here, but I guess you understand if I say I would be a different person without you.

Simone, actually we did not know each other so well before we started our PhDs. I count myself lucky that we had the opportunity to do several projects together because it was 
always a pleasure to spend time with you. You have always been my partner in crime when it comes to complaining about students and supervisors. Moreover, you are a terrific scientist and one of the warmest and most cordial people I have ever met.

Mandy, without your encouragement and company there is so much I would have missed, including awesome festivals, board-games and relaxing holidays. Thank you so much for luring me out of my shell to have the time of my life. You are incredibly much fun to be around and I hope you will never be far.

Stijn, thank you so much for making me a more agreeable colleague and dissipating my negative thoughts whenever I asked you to. Although we do not see each other often, I know you will always be there when I need you.

Chrissie, you are a person with many interests and it is never boring to talk to you. I especially enjoyed our weekend walks in the floodplains. Thank you for making time for me in you busy travelling-schedule.

Jonas and Christoph, I always mention you in one breath, although of course, you are both amazing personalities in your own right. However, you are the ones that keep me anchored to where I come from and I will never forget that you stood by me in my most difficult times.

Jolande, I have a lot to thank you for. Let me just mention that there are many things I would not have done and many people I would not have met without you and all these deeds and people have profoundly changed me.

Lots of thanks also to the TPG team. I do not know you guys for long, but you immediately made me feel welcome and it is awesome to work and joke with you. You are all brilliant and I am certain that what we create will be incredible.

It is inevitable that I forgot to mention several people that deserve my gratitude as well. As a consolation: you are the rare and unrecognized ones belowground that can have huge impacts on what is visible above. Therefore, this existence of this thesis is also thanks to you. 


\section{About the author}

Viola Kurm was born on 01.06.1989 in Remscheid, Germany, and grew up in nearby Wuppertal, where she attended high school until graduation in 2008. With good intentions, but no clear idea as to which career she would like to follow, she started studying biology at the University of Cologne in 2008. During the brief flicking through all basic courses her interest quickly settled on the field of Ecology. However, at this point she could not imagine working with anything else than animals and plants and thus "real", visible organisms (which is to say: no microbes).

A project on earthworms brought her into the group of Soil Ecology. There she was offered to do a Bachelor thesis on (gasp!) bacteria-amoebae interactions. Ever since then she stayed in the field of microbial ecology as she discovered that the microbial world still held plenty of mysteries to uncover.

During her Master in Biological Sciences from 2011 to 2013 at the University of Cologne she gained a more diverse knowledge on aquatic and chemical ecology and plant genetics. Her Master thesis, however focused again on bacteria and plant-bacterial interactions. Thus, it finally reconciled her interest in the small and in the large. It happened that during this Master program she first heard of the NIOO-KNAW and she knew immediately that a whole institute for ecology was something she would like to see from the inside. Thus she embarked on an internship in 2012 within the department of microbial ecology. Although the science was just as exciting as she had imagined, it was the company of amazing colleagues and the Dutch friendliness that decided it: she would be back.

When she first saw the $\mathrm{PhD}$ position for research on rare soil bacteria at the terrestrial ecology department it was clear to her that this project suited her interests perfectly and fortunately her potential supervisors Gera Hol and Wim van der Putten thought the same. Hence, since 2014 she got to enjoy working in cutting-edge research, both with microorganisms and plants, and last but not least 4 more years with all the people at the NIOO. 


\section{List of publications}

Adam, E., Groenenboom, A. E., Kurm, V., Rajewska, M., Schmidt, R. L., Tyc, O., Weidner, S., Berg, G., De Boer, W. \& Salles, J. F (2016). Controlling the microbiome: microhabitat adjustments for successful biocontrol strategies in soil and human gut: Opinion article. Frontiers in Microbiology, 7(1079), doi:10.3389/fmicb.2016.01079

Jousset, A., Bienhold, C., Chatzinotas, A., Gallien, L., Gobet, A., Kurm, V., Küsel, K., Rillig, M. C., Rivett, D.W., Salles, J.F., van der Heijden, M. G. A., Youssef, N. H., Zhang, X., Wei, Z. \& Hol, W. H. G. (2017). Where less may be more: How the rare biosphere pulls ecosystems strings. ISME Journal,. doi:10.1038/ismej.2016.174

Kurm, V., van der Putten, W. H., De Boer, W., Naus-Wiezer, S. M. H., \& Hol, W. H. G. (2017). Low abundant soil bacteria can be metabolically versatile and fast growing.

Ecology, 98(2), 555-564. doi:10.1002/ecy.1670

Kurm, V., van der Putten, W. H., Pineda, A. \& Hol, W. H. G. (2018). Soil microbial species loss affects plant biomass and survival of an introduced bacterial strain, but not inducible plant defences. Annals of Botany. mcx162, https://doi.org/10.1093/aob/mcx162 


\section{PE\&RC Training and Education Statement}

With the training and education activities listed below the $\mathrm{PhD}$ candidate has complied with the requirements set by the C.T. de Wit Graduate School for Production Ecology and Resource Conservation (PE\&RC) which comprises of a minimum total of 32 ECTS (= 22 weeks of activities)

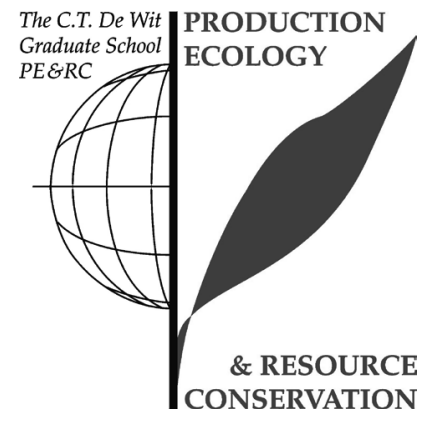

\section{Review of literature (5.5 ECTS)}

- The role of rare soil bacteria in biodiversity and ecosystem function (2014)

\section{Writing of project proposal (4 ECTS)}

- $\quad$ Rarity makes the heart grow fonder

\section{Post-graduate courses (6.1 ECTS)}

- Introduction to R for statistical analysis; PE\&RC (2014)

- $\quad$ Microbial ecology workshop; PE\&RC (2015)

- $\quad$ Soil ecology and planetary boundaries; PE\&RC (2016)

- Multivariate analysis; PE\&RC (2016)

\section{Laboratory training and working visits (4 ECTS)}

- Effects of rare bacteria on volatile production and impact on fungal and plant growth; UU (2017)

\section{Invited review of (unpublished) journal manuscript (3 ECTS)}

- Current science: bioformulation of a plant growth promoting rhizobacterium $P$. fluorescens (2016)

- New Phytologist: rare bacteria and plant soil feedback (2016)

- Insect Science: feeding patterns of monophagous, oligophagous, and polyphagous insect herbivores: the effect of resource abundance and plant chemistry (2017)

\section{Deficiency, refresh, brush-up courses (1.3 ECTS)}

- Next generation sequencing workshop; Mattias Hollander, NIOO (2014)

- Bioinformatics: introduction and methods; Peking University online (2014) 
Competence strengthening / skills courses (2.4 ECTS)

- Competence assessment; WGS (2014)

- $\quad$ PhD Peer consultation; PE\&RC (2015)

- $\quad$ PhD Carousel; WGS (2015)

- $\quad$ WUR Career day with workshops; WUR (2017)

PE\&RC Annual meetings, seminars and the PE\&RC weekend (0.6 ECTS)

- PE\&RC Day (2014)

- PE\&RC Day (2015)

Discussion groups / local seminars / other scientific meetings (5 ECTS)

- Host microbe interactions; Wageningen (2014)

- Ecological theory and application discussion group (2014-2017)

- Wageningen plant microbiome kick-off meeting (2016)

- $\quad$ IEB workshop; UU $(2016,2017)$

- $\quad$ KPNV symposium plant and soil microbiome (2017)

International symposia, workshops and conferences (10.2 ECTS)

- $\quad$ sRareBio; Leipzig (2014)

- GSBI; Dijon (2014)

- $\quad$ NAEM (2015)

- $\quad$ NAEM (2016)

- $\quad$ NAEM (2017)

- $\quad$ Ecology across borders; joint annual meeting (2017)

Supervision of MSc students (3 ECTS)

- $\quad$ Effects of rare soil bacteria on induced systemic resistance in plants 


\section{Colophon}

The research has been carried out at the Department of Terrestrial Ecology at the Netherlands Institute of Ecology (NIOO-KNAW) in Wageningen.

This is NIOO thesis number 150

Cover design by Viola Kurm

Printed by: DigiForce | Proefschriftmaken.nl 


\section{Propositions}

1. The effects of bottom-up and top-down processes on bacterial rarity are not general, but species specific.

(this thesis)

2. For resistance against bacterial invasion the number of rare species is crucial, while other functions, such as plant growth and resistance, depend on the community composition of the rare biosphere.

(this thesis)

3. The product of human creativity cannot be distinguished from the product of the creativity of artificial intelligence (AI).

4. Plants are capable of associative learning to improve their resource acquisition.

5. People should be made aware that the information they readily express on social media enables algorithms to accurately predict and express sensitive personal information they do not share.

6. We have no proof that reality is as we perceive it or that reality even exists outside our perception.

Propositions belonging to the thesis entitled

\section{"Causes and consequences of soil bacterial rarity"}

Viola Kurm,

Wageningen, 22. May 2018 



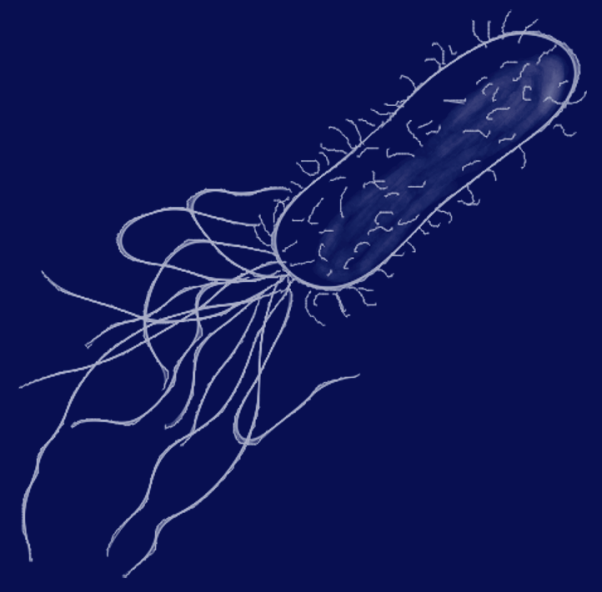

